\title{
Anterior chronic exertional compartment syndrome of the leg
}

Citation for published version (APA):

de Bruijn, J. A. (2020). Anterior chronic exertional compartment syndrome of the leg: improving recognition and surgical treatment . [Doctoral Thesis, Maastricht University]. Maastricht University. https://doi.org/10.26481/dis.20201209jb

Document status and date:

Published: 01/01/2020

DOI:

10.26481/dis.20201209jb

Document Version:

Publisher's PDF, also known as Version of record

\section{Please check the document version of this publication:}

- A submitted manuscript is the version of the article upon submission and before peer-review. There can be important differences between the submitted version and the official published version of record.

People interested in the research are advised to contact the author for the final version of the publication, or visit the DOI to the publisher's website.

- The final author version and the galley proof are versions of the publication after peer review.

- The final published version features the final layout of the paper including the volume, issue and page numbers.

Link to publication

\footnotetext{
General rights rights.

- You may freely distribute the URL identifying the publication in the public portal. please follow below link for the End User Agreement:

www.umlib.nl/taverne-license

Take down policy

If you believe that this document breaches copyright please contact us at:

repository@maastrichtuniversity.nl

providing details and we will investigate your claim.
}

Copyright and moral rights for the publications made accessible in the public portal are retained by the authors and/or other copyright owners and it is a condition of accessing publications that users recognise and abide by the legal requirements associated with these

- Users may download and print one copy of any publication from the public portal for the purpose of private study or research.

- You may not further distribute the material or use it for any profit-making activity or commercial gain

If the publication is distributed under the terms of Article $25 \mathrm{fa}$ of the Dutch Copyright Act, indicated by the "Taverne" license above, 


\title{
ANTERIOR CHRONIC EXERTIONAL COMPARTMENT SYNDROME OF THE LEG:
}

IMPROVING RECOGNITION AND SURGICAL TREATMENT

\author{
Johan A. de Bruijn
}

2020 


\section{SBCH}

voor artsen in opleiding

\section{¿í máxima mc}
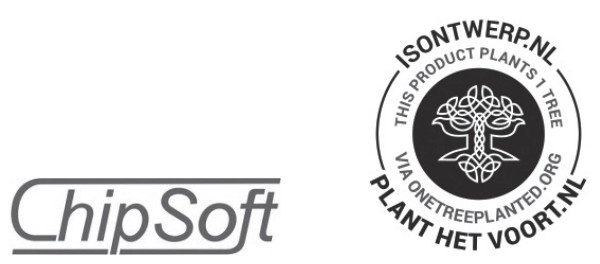

\section{COLOFON}

Anterior chronic exertional compartment syndrome of the leg: improving recognition and surgical treatment, Johan A. de Bruijn

ISBN: 9789492303325

Copyright ( 2020 Johan de Bruijn

All rights reserved. No part of this thesis may be reproduced, stored or transmitted in any way or by any means without the prior permission of the author, or when applicable, of the publishers of the scientific papers.

Cover illustration \& design: Ilse Schrauwers | isontwerp.nl Layout and design by Anna Bleeker | persoonlijkproefschrift.nl Printing: Ridderprint | www.ridderprint.nl

Publication of this thesis was financially supported by: Máxima MC; MMC academie; Maastricht University; SBOH, employer of GP trainees; chipsoft 


\title{
Anterior chronic exertional compartment syndrome of the leg: improving recognition and surgical treatment
}

\author{
PROEFSCHRIFT \\ ter verkrijging van de graad van doctor aan de Universiteit Maastricht, \\ op gezag van Rector Magnificus, prof. dr. Rianne M. Letschert \\ volgens het besluit van het College van Decanen, \\ in het openbaar te verdedigen \\ op woensdag 9 december 2020 om 14.00 uur \\ door \\ Johannes Anthonius de Bruijn
}

geboren te Maurik op 11 november 1985 


\section{Promotor}

Prof. dr. J.A.W. Teijink

\section{Copromotor}

Dr. M.R.M. Scheltinga (Máxima Medisch Centrum)

\section{Beoordelingscommissie}

Prof. dr. M. Poeze (voorzitter)

Prof. dr. F.J.G. Backx (UMC Utrecht)

Prof. dr. I.C. Heyligers

Dr. W.O. Zimmermann (Koninklijke Landmacht, Utrecht) 


\section{TABLE OF CONTENTS}

Chapter 1 Introduction and outline 8

Partly published in: Unfallchirurg, vol 22, 2019

Chapter 2 Factors predicting lower leg chronic exertional compartment syndrome in a large population International Journal of Sports Medicine, 2018 vol. 39, p58-66

Chapter 3 Lower leg chronic exertional compartment syndrome in patients 50 years of age and older Orthopaedic Journal of Sports Medicine, 2018 vol. 6, 2325967118757179

Chapter 4 Exercise induced leg pain in patients older than 50 years: Peripheral arterial disease or chronic exertional compartment syndrome?

Under review

Chapter 5 Feasibility and safety of an operative tool for anterior chronic exertional compartment syndrome treatment Foot \& Ankle International, 2015, vol. 36, p1475-82

Chapter 6 Superficial peroneal nerve injury risk during a semiblind 100 fasciotomy for anterior chronic exertional compartment syndrome of the leg: An anatomical and clinical study Foot \& Ankle international, 2019, vol. 40(3), p343-351

Chapter 7 Fasciotomy for leg anterior chronic exertional compartment syndrome: A comparison of two operative devices Under review

Chapter 8 Summary, discussion, and future perspectives

Chapter 10 Dutch summary, acknowledgements, list of publications, curriculum vitae 


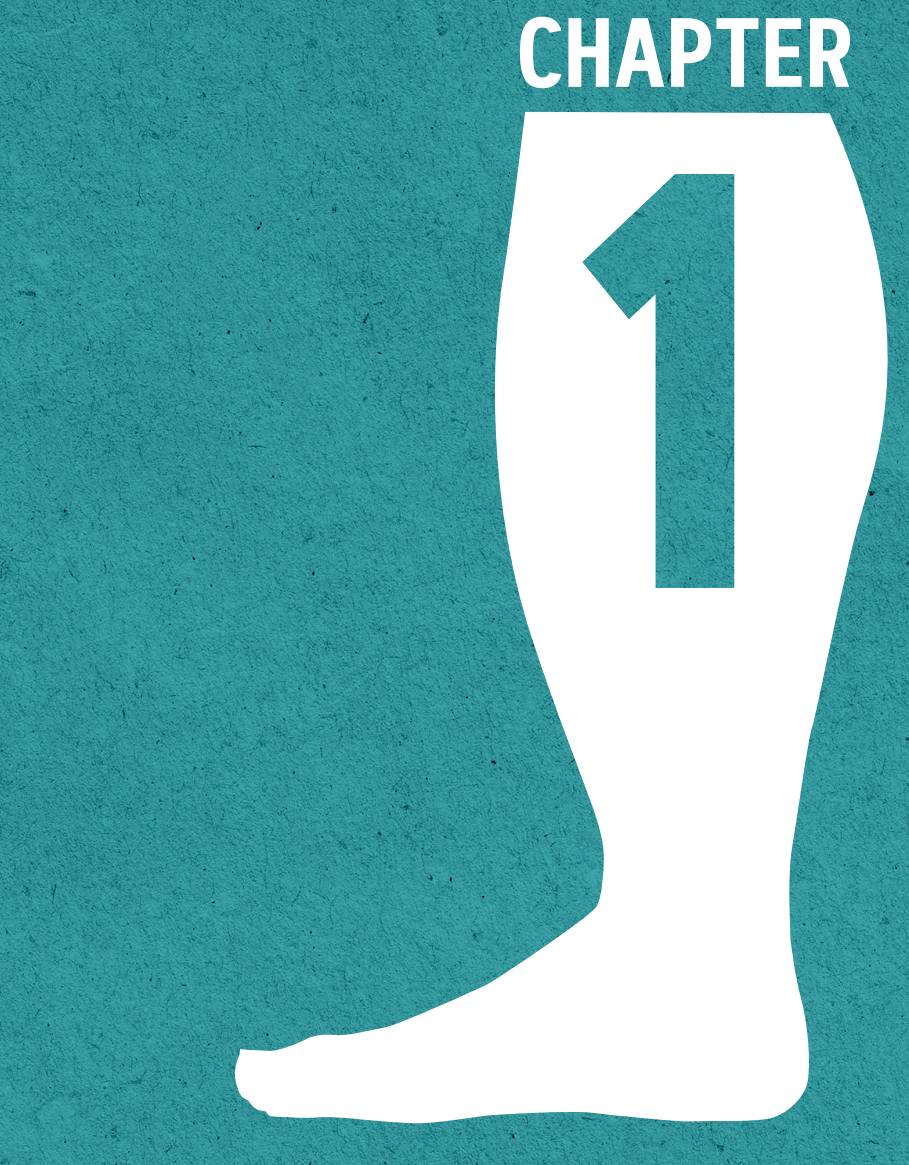




\section{CHAPTER 1}

\section{INTRODUCTION AND OUTLINE}

Partly published in:

Unfallchirurg, vol 22, 2019 


\section{INTRODUCTION}

\section{General introduction}

A compartment syndrome is defined as "a condition in which increased pressure within a space compromises the circulation to the contents of

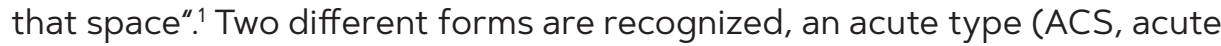
compartment syndrome) and a chronic type (CECS, chronic exertional compartment syndrome). In addition, transition from a chronic presentation to a (sub)acute compartment syndrome is described in some case reports. ${ }^{2}$ ACS in the leg is mostly seen after major trauma, crush injuries or as a complication after operative revascularization or thrombolysis as a reperfusion syndrome. It progresses swiftly and tissue damage within the affected compartment is irreversible unless pressure is released within hours. ${ }^{3,4}$ ACS is beyond the scope of this thesis and will not be further discussed.

CECS is a more benign and reversible type of compartment syndrome. Complaints are far less profound than in an ACS and are induced by repetitive intensive muscle use such as during sports. ${ }^{5}$ Prolonged rest alleviates complaints in most patients. In theory, a CECS may develop in any muscle compartment that is surrounded by fascia but in practice its occurrence is limited to the distal extremities.

This thesis will focus on leg CECS, therefore lower arm and/or hand CECS is beyond its scope. Three separate types of leg CECS are distinguished depending on the involved compartment(s), namely ant-CECS (anterior tibialis muscle), dp-CECS (deep posterior or flexor muscles) and lat-CECS (peroneal muscles). ${ }^{6}$ In daily practice, a substantial portion of individuals with CECS presents with a combination of the 3 types or develop different types over time.

\section{Historical milestones}

Dr. Edward Wilson, an English junior military surgeon, naturalist and zoologist, unwittingly documented the first possible case of a CECS in 1912. In his diaries, he reported severe pain and swelling in his own legs while skiing during an Antarctic expedition. Symptoms intensified with each consecutive trip but always disappeared after rest. Over time, rest pain also emerged suggesting a gradual transition from a chronic to a (sub)acute 
compartment syndrome. Unfortunately, as all expedition members died during their journey home, the presence of a CECS could not be confirmed. ${ }^{7}$

In 1945, Horn described a 26 -year old previously healthy soldier with acute pain in the right leg that started immediately after an evening's walk. In the preceding months, he had noted pain in both legs during marching. On examination, the anterior portion of the right leg was swollen and stony hard. Surgical exploration revealed a compartment syndrome and severe anterior tibial muscle ischemia necessitating a fasciotomy and an extensive necrotectomy. In retrospect, he was likely suffering from ant-CECS that had turned into an acute compartment syndrome. ${ }^{2}$

In 1956, Mavor described a phenomenon that he dubbed "anterior tibial syndrome" in a professional soccer player who was bothered with pain and tightness for over two years. He had several small muscle hernias in the anterior tibialis fascia that were considered spontaneous ruptures due to an elevated muscle compartment pressure. Mavor incised the muscle's fascia including the hernias and closed the defect with a piece of fascia lata leading to a full recovery. ${ }^{8}$ In the following years, multiple cases were reported as well as a case-series of 61 (mostly military) patients. ${ }^{9}$ This group also demonstrated that the intracompartmental pressure was elevated in CECS patients and could be normalized by diathermically cutting the anterior tibialis fascia with a thin metal wire. ${ }^{9}$

Terminology was initially somewhat confusing and non-uniform during the first decades. The term 'anterior tibial syndrome' was introduced early on, but as time and knowledge progressed other entities emerged. 'Chronic compartment syndrome', 'Shin splints', 'medial tibial syndrome', 'runners legs', 'march synovitis', and 'fresher's legs' were all terms used to describe exercise induced leg complaints. ${ }^{10-12}$ Nowadays, chronic exertional compartment syndrome (CECS) is deemed most appropriate to describe the condition.

\section{Anatomy of the leg and its compartments}

The walls of the concealed space where CECS may emerge are made of sturdy connective tissue termed the fascia. A fascia envelops all muscular compartments and provides a semi-rigid separation of a muscle group and adjacent structures. ${ }^{13}$ Typically, fascia is rather simply defined as "masses 
of connective tissue large enough to be visible to the unaided eye".14 It is thought that a fascia has several functions. Comparable to other connective tissues, it has an important role in the transmission of (epi)muscular and mechanical force. Furthermore, its interface facilitates frictionless sliding along adjacent structures such as other types of connective tissue, vessels and nerves. ${ }^{13}$ In addition, there is some evidence to support the contention that fascia contribute to propriocepsis. ${ }^{15}$

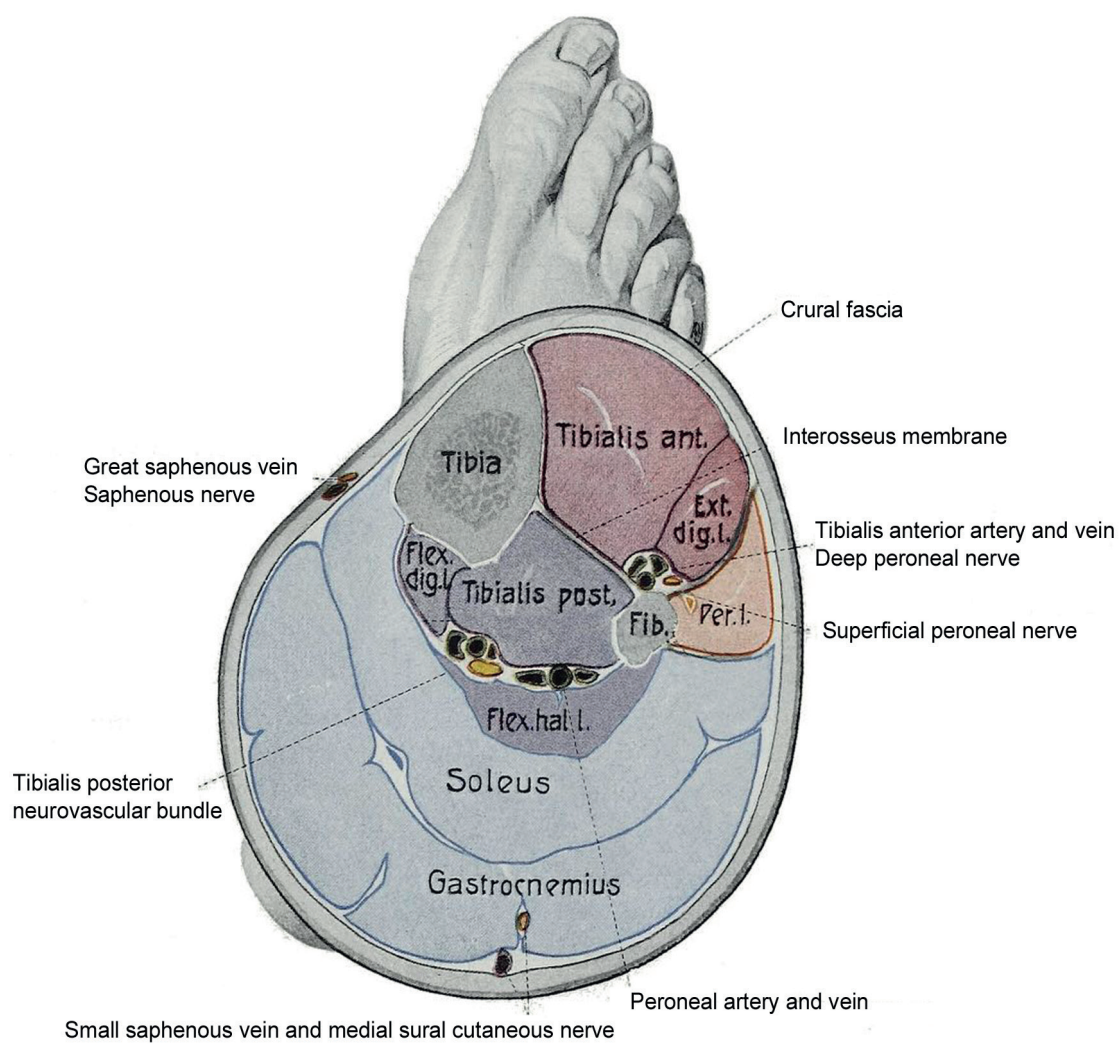

Figure 1.1: Cross section of the leg (adapted from "Anatomie des Menschen; ein lehrbuch für studierende und ärtze", 1921)

The leg consists of four distinct muscle compartments that are restricted by the fascia cruris, tibial bone, fibular bone, interosseous membrane, anterior intermuscular fascia, posterior intermuscular fascia, and transverse intermuscular fascia (Figure 1.1). Each compartment harbors one or more muscles, nerves and blood vessels. 
The anterior compartment contains the anterior tibial muscle, extensor digitorum longus muscle and extensor hallucis longus muscle, which induce dorsiflexion of the foot and contribute to inversion and eversion. They are vascularized by the anterior tibial artery and vein and innervated by the deep peroneal nerve.

The lateral compartment contains the fibularis longus and fibularis brevis muscles, is vascularized by both the posterior tibial artery and fibular artery and is innervated by the superficial peroneal nerve. The main function of its muscles is foot eversion while also weakly supporting plantar flexion. The superficial posterior compartment contains the gastrocnemius, soleus and plantaris muscles. They induce plantar flexion of the foot and assist in flexing the knee. Oxygen-rich blood is supplied by the posterior tibial artery and the tibial nerve provides innervation.

The deep posterior compartment contains the muscles that induce plantarflexion and help with inversion, namely the flexor hallucis longus muscle, flexor digitorum longus muscle, tibialis posterior muscle and popliteus muscle. These are vascularized by the posterior tibial artery and innervated by the tibial nerve. Recent Magnetic Resonance Imaging (MRI) and perioperative findings suggest the existence of a fifth compartment consisting of the tibialis posterior muscle that consistently has a separate fascia. ${ }^{16,17}$

\section{Pathophysiology of CECS}

Repetitive muscular contractions, such as during exercise, increase blood flow to the involved muscles and induce a physiological increase in intracompartmental pressure (ICP). ${ }^{18}$ In asymptomatic individuals, these elevated pressures will not cause complaints and will normalize quickly after cessation of the activity. ${ }^{19}$ In patients with CECS, however, persistent ICP elevation during exercise may possibly result in relative ischemia of these muscles. ${ }^{5,20,21}$ Several synergistic mechanisms may also contribute to the onset of CECS. Some believe that the compartment's circulation is impaired as muscle lactate levels are elevated immediately after exercise, ${ }^{22}$ muscle relaxation pressure is increased, ${ }^{23}$ the arteriovenous gradient is decreased ${ }^{24}$ and blood flow during muscle relaxation is decreased. ${ }^{25}$ Meanwhile, others question the role of ischemia and reduced blood flow in the development of CECS. ${ }^{26,27} \mathrm{~A}$ different theory implies that a less 
compliant fascia is responsible for increased ICP in patients with CECS ${ }^{28-}$ ${ }^{30}$ while others doubt that stiffness and thickness of the fascia have any influence. ${ }^{31}$ Pressure-induced stretching of the fascia and stimulation of intramuscular pressure receptors may also contribute to the experienced complaints. ${ }^{27,32}$ Therefore, consensus is lacking with regard to the interplay of all underlying pathophysiological mechanisms that eventually cause CECS.

\section{Clinical history and physical examination}

The exact incidence of leg CECS in the general population is not known. Most publications describe a somewhat or highly selected population resulting in heterogeneous incidence numbers that depends largely on patient selection. ${ }^{33,34}$ In a cohort of individuals with exercise-induced leg complaints that visited a sports physician, one in eight patients was diagnosed with CECS. ${ }^{22}$ In highly selected populations such as athletes or military service members, these numbers are even higher. ${ }^{35,36}$ Recently, a study demonstrated that roughly one in 2000 active military service members was diagnosed with leg CECS each year. ${ }^{37}$ These numbers suggests that CECS may also be common in the general population. The anterior compartment (40-60\%) and deep flexor compartment (32-60\%) are affected most often, although the lateral compartment may also develop CECS (12-35\%). ${ }^{34,38,39} \mathrm{~A}$ combination of multiple affected compartments is frequently observed.

Virtually all patients with leg CECS experience progressive pain and tightness during or shortly after exercise. Cramps, muscle weakness and altered foot skin sensation may also be reported. 5,40 In addition, some patients describe a sensation of 'filling up' during sports leading to a hard and tense muscle. Over time, symptoms tend to start earlier during the provocative exercise necessitating premature termination of the sportive activities. Both males and females are susceptible, any reported gender distribution therefor appears to be largely dependent on patient selection. ${ }^{34,37,41}$ CECS is mostly described in young and otherwise healthy individuals, although there are some reports focusing on older, less athletic and diabetic individuals. ${ }^{42,43}$ Variations in reported patient characteristics can again be attributed to patient selection but true predictive characteristics are largely unknown. 
Physical examination entails observation when standing, walking and running. Muscle herniation through fascial defects may occasionally be visible during active extension. Firm palpation of the affected muscle compartments usually causes tenderness, possibly different from the contralateral side in a one-sided CECS. Palpation, active and passive range of motion and resistance tests should be performed before and after a provocative exercise such as a treadmill run. Since these symptoms are mostly non-specific, physical examination is often normal in patients with leg CECS. Therefore, the role of a physical examination in the management of CECS is not to confirm the diagnosis but to exclude concomitant entities other than CECS. ${ }^{44,45}$ A painful palpation of the distal posteromedial tibial rim in an ant-CECS patient may indicate a simultaneous medial tibial stress syndrome (MTSS, formerly 'shin splints'. ${ }^{46}$ Hypoesthesia (occasionally hyperesthesia) of portions of the foot and/or distal portions of the leg indicate entrapment of branches of the common peroneal or tibial nerve. ${ }^{47}$ Blanching of foot sole or reduced arterial pulsations in prone position may indicate popliteal artery entrapment syndrome (PAES). ${ }^{48}$

\section{Supportive examinations}

In patients with a suggestive history and physical examination, CECS may be confirmed with a 'dynamic' ICP measurement. Based on results of the clinical history and physical examination, the suspected compartment(s) are selected and pressure is measured in rest and after a provocative exercise, usually following a treadmill run. Previously used 'static' ICP measurements are considered less accurate. ${ }^{49}$ A slit catheter technique connected to an arterial line transducer system is currently regarded as most accurate for timed pressure measurements. ${ }^{50,51}$ The diagnosis CECS is confirmed when ICP exceeds predefined cut-off values in rest or shortly after exercise. The most commonly used cut-off points are suggested by Pedowitz $(\geq 15$ $\mathrm{mm} \mathrm{Hg}$ in rest, $\geq 30 \mathrm{~mm} \mathrm{Hg} 1$ minute after, or $\geq 20 \mathrm{~mm} \mathrm{Hg} 5$ minutes after a provocative exercise). ${ }^{52}$ In recent years however, the technique itself as well as the used threshold values are under debate. ${ }^{53}$ Several reports indicate that an elevated pressure alone is not sufficient for the diagnosis CECS. ${ }^{54}$ Also, others proposed potentially improved methods and cut-off values. ${ }^{55}$

The role of imaging is limited in the diagnostic process of CECS. NIRS (near infrared spectroscopy) and MRI have a potential to confirm the diagnosis but are used only in an experimental setting. ${ }^{56,57}$ By detecting 
diffuse compartment edema, MRI successfully aided in diagnosing isolated lat-CECS in a patient with exercise-induced calf pain. ${ }^{58}$ Similar to the role of physical examination, imaging is predominantly indicated for exclusion of MTSS (bone scintigraphy, ultrasound), intermittent claudication (anklebrachial index), PAES (Duplex), nerve entrapments (MRI) or stress fractures (plain X-ray).

\section{Treatment of leg CECS}

Evidence supporting the efficacy of conservative treatments for ant-CECS is scarce. ${ }^{59}$ Frequently used non-operative treatments are rest, massage, stretching exercises, icing or extracorporeal shockwave therapy. ${ }^{11,60}$ Moreover, correction of foot overpronation and optimization of shoes may reduce complaints. Evidence suggest that adopting a forefoot strike resulted in fewer symptoms, improved running distance and a lower ICP in patients with ant-CECS. ${ }^{61,62}$ In an experimental setting, Botulinum Toxin A (Botox) injections were useful as both pain and ICP were significantly reduced. ${ }^{63,64}$

In most patients however, non-operative treatments do not result in longterm reduction of symptoms. ${ }^{65}$ However, as adverse effects are absent, a conservative regimen is advised as initial treatment for at least 3-6 months prior to considering surgery. During operative treatment the fascia of the affected compartment(s) is either cut (fasciotomy) or partly removed (fasciectomy). A fasciotomy is less invasive and thus the preferred technique as an initial procedure. A fasciectomy is reserved for recalcitrant CECS. ${ }^{66}$ Compared with non-operative treatment, surgery has markedly higher success rates. ${ }^{67}$

\section{Aims of the thesis}

This thesis has two general aims. The first is to improve recognition of CECS in patients with exercise induced lower leg complaints and thereby reducing the rate of under-diagnosis due to doctor's delay. The second aim is to evaluate a novel operative tool that may improve outcome in ant-CECS.

Specific aims of the thesis are

1. To identify factors associated with leg CECS thus facilitating the identification of CECS in patients with exercise-induced leg complaints. 
2. To describe symptomatology of CECS in older patients and to assess similarities and differences with their younger counterparts.

3. To compare symptoms and characteristics of older patients with exerciseinduced leg pain caused by CECS with patients suffering from peripheral artery disease.

4. To assess feasibility and safety of a novel operative tool (FascioMax) for treatment of patients with ant-CECS.

5. To study the potential risk on superficial peroneal nerve injury during a semiblind fasciotomy of the anterior compartment using the FascioMax fasciotome.

6. To compare safety and efficacy of the FascioMax fasciotome with a commonly used alternative fasciotome during a semiblind fasciotomy in patients with ant-CECS.

\section{OUTLINE}

Literature describing patients with CECS is very heterogeneous in terms of patient selection, cohort size and goals. Therefore, reported characteristics that are associated with CECS differ substantially between studies. As a consequence, true predictive factors are largely unknown. In chapter 2 we studied a large cohort of patients with exercise-induced leg symptoms and have identified factors predictive of leg CECS. The predictive nomogram may aid clinicians in selecting individuals who require invasive ICP measurements.

A typical CECS patient is described as a young and athletic individual. However, two reports have found CECS in older, less sportive and less healthy individuals. It is largely unknown if these older patients differ from their younger counterparts. If so, recognition of CECS in these older patients is even more difficult potentially increasing an already long doctor's delay. In chapter $\mathbf{3}$ we selected patients with CECS aged 50 years and older from a large retrospective cohort and compared their characteristic with CECS patients younger than 50 .

Exercise-induced leg pain (intermittent claudication) in older patients is mostly caused by peripheral artery disease (PAD). However, in some patients these complaints are actually caused by a CECS. As a CECS is often not recognized, complaints may cause the individual to cease physical activity thereby reducing health and quality of life. In order to differentiate 
CECS from PAD we compared patient characteristics and symptoms of older patients with CECS to patients with intermittent claudication due to PAD in chapter 4.

A minimally invasive fasciotomy is the preferred operative treatment in patients with ant-CECS. Most (orthopaedic) surgeons prefer a semiblind fasciotomy with the aid of a specialized instrument, namely a fasciotome. A semiblind fasciotomy is fast and requires only a small skin incision but the lack of visual contact with the fasciotome's tip may increase the risk of collateral tissue damage. In chapter $\mathbf{5}$ feasibility and safety of a novel fasciotome (FascioMax) are assessed in a small cohort of patients with ant-CECS.

Injury of the superficial peroneal nerve (SPN) is a feared complication of a fasciotomy of the anterior compartment. Some claim that a semiblind fasciotomy increases the risk on SPN trauma and therefore use an open approach or endoscope-assistance. In chapter 6 the risk of SPN injury during a semiblind fasciotomy with the FascioMax fasciotome is assessed in an anatomical and clinical study.

Chapter $\mathbf{7}$ describes the results of a randomized clinical trial that compares two operative techniques for the treatment of isolated bilateral ant-CECS. One leg was treated with the FascioMax fasciotome whereas the other was operated using a commonly used other fasciotome. Outcome parameters were surgical trauma, symptom reduction and complication rates.

In chapter $\mathbf{8}$ the results of this thesis are summarized and discussed and future perspectives are given. Valorization is provided in chapter 9, and chapter 10 includes a Dutch summary, acknowledgements, list of publications and curriculum vitae of the author. 


\section{REFERENCES}

1. Matsen FA. Compartmental syndrome. An unified concept. Clin Orthop Relat Res. 1975;(113):8-14.

2. Horn CE. Acute ischaemia of the anterior tibial muscle and the long extensor muscles of the toes. J Bone Joint Surg Am. 1945;27(4):615-622.

3. Vaillancourt C, Shrier I, Vandal A, et al. Acute compartment syndrome: how long before muscle necrosis occurs? CJEM. 2004;6(3):147-154.

4. Köstler W, Strohm PC, Südkamp NP. Acute compartment syndrome of the limb. Injury. 2005;36(8):992-998.

5. Blackman PG. A review of chronic exertional compartment syndrome in the lower leg. Medicine \& Science in Sports \& Exercise. 2000;32(3 Suppl):S4-S10.

6. Tucker AK. Chronic exertional compartment syndrome of the leg. Curr Rev Musculoskelet Med. 2010;3(1-4):32-37.

7. Freedman BJ. Dr. Edward Wilson of the Antarctic; a Biographical Sketch, Followed by an Inquiry Into the Nature of His Last Illness. Vol 47. Royal Society of Medicine Press; 1954:183-189.

8. Mavor GE. The anterior tibial syndrome. J Bone Joint Surg Br. 1956;38-B(2):513517.

9. Reneman RS. The anterior and the lateral compartmental syndrome of the leg due to intensive use of muscles. Clin Orthop Relat Res. 1975;(113):69-80.

10. Puranen J. The medial tibial syndrome: exercise ischaemia in the medial fascial compartment of the leg. J Bone Joint Surg Br. 1974;56-B(4):712-715.

11. Barnes M. Diagnosis and management of chronic compartment syndromes: a review of the literature. British Journal of Sports Medicine. 1997;31(1):21-27.

12. French EB, Price WH. Anterior tibial pain. Br Med J. 1962;2(5315):1290-1296.

13. Kwong EH, Findley TW. Fascia--Current knowledge and future directions in physiatry: narrative review. J Rehabil Res Dev. 2014;51(6):875-884.

14. Standring S, ed. Gray's Anatomy: the Anatomical Basis of Clinical Practice. 40 ed. Edinburgh (UK); 2008.

15. Stecco C, Macchi V, Porzionato A, et al. The ankle retinacula: morphological evidence of the proprioceptive role of the fascial system. Cells Tissues Organs (Print). 2010;192(3):200-210.

16. Winkes MB, Tseng CM, Pasmans HL, van der Cruijsen-Raaijmakers M, Hoogeveen AR, Scheltinga MR. Accuracy of Palpation-Guided Catheter Placement for Muscle Pressure Measurements in Suspected Deep Posterior Chronic Exertional Compartment Syndrome of the Lower Leg: A Magnetic Resonance Imaging Study. American Journal of Sports Medicine. 2016;44(10):2659-2666 
17. Winkes MB, van Zantvoort APM, de Bruijn JA, et al. Fasciotomy for Deep Posterior Compartment Syndrome in the Lower Leg: A Prospective Study. Am J Sports Med. 2016;44(5):1309-1316.

18. Arai M, Endoh $\mathrm{H}$. Blood flow through human skeletal muscle during and after contraction. Tohoku J Exp Med. 1974;114(4):379-384.

19. Veith RG, Matsen FA, Newell SG. Recurrent Anterior Compartmental Syndromes. Phys Sportsmed. 1980;8(11):80-88.

20.Puranen J, Alavaikko A. Intracompartmental pressure increase on exertion in patients with chronic compartment syndrome in the leg. J Bone Joint Surg Am. 1981;63(8):1304-1309.

21. Styf J. Chronic exercise-induced pain in the anterior aspect of the lower leg. An overview of diagnosis. Sports Med. 1989;7(5):331-339.

22. Qvarfordt P, Christenson JT, Eklöf B, Ohlin P, Saltin B. Intramuscular pressure, muscle blood flow, and skeletal muscle metabolism in chronic anterior tibial compartment syndrome. Clin Orthop Relat Res. 1983;(179):284-290.

23. Styf J, Körner L, Suurkula M. Intramuscular pressure and muscle blood flow during exercise in chronic compartment syndrome. J Bone Joint Surg Br. 1987;69(2):301-305.

24. Hutchinson MR, Ireland ML. Common compartment syndromes in athletes. Treatment and rehabilitation. Sports Med. 1994;17(3):200-208.

25.Zhang Q, Styf J. Abnormally elevated intramuscular pressure impairs muscle blood flow at rest after exercise. Scandinavian Journal of Medicine \& Science in Sports. 2004;14(4):215-220.

26. Balduini FC, Shenton DW, O'Connor KH, Heppenstall RB. Chronic exertional compartment syndrome: correlation of compartment pressure and muscle ischemia utilizing 31P-NMR spectroscopy. Clinics in Sports Medicine. 1993;12(1):151-165.

27. Amendola A, Rorabeck CH, Vellett D, Vezina W, Rutt B, Nott L. The use of magnetic resonance imaging in exertional compartment syndromes. American Journal of Sports Medicine. 1990;18(1):29-34.

28. Hurschler C, Vanderby R, Martinez DA, Vailas AC, Turnipseed WD. Mechanical and biochemical analyses of tibial compartment fascia in chronic compartment syndrome. Ann Biomed Eng. 1994;22(3):272-279.

29. Turnipseed WD, Hurschler C, Vanderby R. The effects of elevated compartment pressure on tibial arteriovenous flow and relationship of mechanical and biochemical characteristics of fascia to genesis of chronic anterior compartment syndrome. Journal of Vascular Surgery. 1995;21(5):810-6-discussion816-7.

30.Barbour TDA. Histology of the fascial-periosteal interface in lower limb chronic deep posterior compartment syndrome. British Journal of Sports Medicine. 2004;38(6):709-717. 
31. Dahl M, Hansen P, Stål P, Edmundsson D, Magnusson SP. Stiffness and thickness of fascia do not explain chronic exertional compartment syndrome. Clin Orthop Relat Res. 2011;469(12):3495-3500.

32. Rorabeck CH, Fowler PJ, Nott L. The results of fasciotomy in the management of chronic exertional compartment syndrome. American Journal of Sports Medicine. 1988;16(3):224-227.

33. Styf J. Diagnosis of exercise-induced pain in the anterior aspect of the lower leg. American Journal of Sports Medicine. 1988;16(2):165-169.

34. Detmer DE, Sharpe K, Sufit RL, Girdley FM. Chronic compartment syndrome: diagnosis, management, and outcomes. American Journal of Sports Medicine. 1985;13(3):162-170.

35. Clanton TO, Solcher BW. Chronic leg pain in the athlete. In: Foot and Ankle Injuries. Vol 13. Clinics in Sports Medicine; 1994:743-759.

36. Verleisdonk EJMM, Schmitz RF, van der Werken C. Long-term results of fasciotomy of the anterior compartment in patients with exercise-induced pain in the lower leg. Int J Sports Med. 2004;25(3):224-229.

37. Waterman BR, Liu J, Newcomb R, Schoenfeld AJ, Orr JD, Belmont PJ. Risk factors for chronic exertional compartment syndrome in a physically active military population. Am J Sports Med. 2013;41(11):2545-2549.

38. Martens MA, Backaert M, Vermaut G, Mulier JC. Chronic leg pain in athletes due to a recurrent compartment syndrome. American Journal of Sports Medicine. 1984;12(2):148-151.

39. Reinking MF. Exercise Related Leg Pain (ERLP): a Review of The Literature. $N$ Am J Sports Phys Ther. 2007;2(3):170-180.

40.George CA, Hutchinson MR. Chronic exertional compartment syndrome. Clinics in Sports Medicine. 2012;31(2):307-319.

41. Davis DE, Raikin S, Garras DN, Vitanzo P, Labrador H, Espandar R. Characteristics of patients with chronic exertional compartment syndrome. Foot Ankle Int. 2013;34(10):1349-1354.

42. Edmundsson D, Toolanen G, Sojka P. Chronic compartment syndrome also affects nonathletic subjects: a prospective study of 63 cases with exerciseinduced lower leg pain. SORT. 2007;78(1):136-142.

43. Edmundsson D, Toolanen G. Chronic exertional compartment syndrome in diabetes mellitus. Diabet Med. 2011;28(1):81-85.

44.Apigian AK, Landry GJ. Basic data underlying decision making in nonatherosclerotic causes of intermittent claudication. Annals of Vascular Surgery. 2015;29(1):138-153.

45. Touliopolous S, Hershman EB. Lower Leg Pain. Sports Med. 1999;27(3):193-204. 
46. Mubarak SJ, Gould RN, Lee YF, Schmidt DA, Hargens AR. The medial tibial stress syndrome. A cause of shin splints. American Journal of Sports Medicine. 1982;10(4):201-205.

47. van Zantvoort APM, Setz MJM, Hoogeveen AR, Scheltinga MRM. Common Peroneal Nerve Entrapment in the Differential Diagnosis of Chronic Exertional Compartment Syndrome of the Lateral Lower Leg: A Report of 5 Cases. Orthop J Sports Med. 2018;6(8):2325967118787761.

48. Turnipseed WD. Functional popliteal artery entrapment syndrome: A poorly understood and often missed diagnosis that is frequently mistreated. Journal of Vascular Surgery. 2009;49(5):1189-1195.

49. Hutchinson M. Chronic exertional compartment syndrome. British Journal of Sports Medicine. 2011;45(12):952-953.

50.Boody AR, Wongworawat MD. Accuracy in the measurement of compartment pressures: a comparison of three commonly used devices. J Bone Joint Surg Am. 2005;87(11):2415-2422.

51. Hammerberg EM, Whitesides TE, Seiler JG. The reliability of measurement of tissue pressure in compartment syndrome. J Orthop Trauma. 2012;26(9):e166

52. Pedowitz RA, Hargens AR, Mubarak SJ, Gershuni DH. Modified criteria for the objective diagnosis of chronic compartment syndrome of the leg. American Journal of Sports Medicine. 1990;18(1):35-40.

53. Aweid O, Del Buono A, Malliaras P, et al. Systematic review and recommendations for intracompartmental pressure monitoring in diagnosing chronic exertional compartment syndrome of the leg. Clin J Sport Med. 2012;22(4):356-370. d

54.Roberts A, Franklyn-Miller A. The validity of the diagnostic criteria used in chronic exertional compartment syndrome: a systematic review. Scandinavian Journal of Medicine \& Science in Sports. 2012;22(5):585-595.

55.Roscoe D, Roberts AJ, Hulse D. Intramuscular Compartment Pressure Measurement in Chronic Exertional Compartment Syndrome: New and Improved Diagnostic Criteria. Am J Sports Med. 2014;43(2):392-398.

56.van den Brand JGH, Verleisdonk EJMM, van der Werken C. Near Infrared Spectroscopy in the Diagnosis of Chronic Exertional Compartment Syndrome. American Journal of Sports Medicine. 2004;32(2):452-456.

57. van den Brand JGH, van der Werken C, Verleisdonk EJMM, T N. The Diagnostic Value of Intracompartmental Pressure Measurement, Magnetic Resonance Imaging, and Near-Infrared Spectroscopy in Chronic Exertional Compartment Syndrome: A Prospective Study in 50 Patients. American Journal of Sports Medicine. 2005;33(5):699-704.

58.Park S, Lee HS, Seo SG. Selective Fasciotomy for Chronic Exertional Compartment Syndrome Detected With Exercise Magnetic Resonance Imaging. Orthopedics. 2017;40(6):e1099-e1102. 
59. Rajasekaran S, Hall MM. Nonoperative Management of Chronic Exertional Compartment Syndrome: A Systematic Review. Curr Sports Med Rep. 2016;15(3):191-198.

60. Helmhout PH, Diebal-Lee MA, Poelsma LR, Harts CC, Zimmermann LWO. Modifying marching technique in military service members with chronic exertional compartment syndrome: a case series. Int J Sports Phys Ther. 2016;11(7):1106-1124.

61. Diebal AR, Gregory R, Alitz C, Gerber JP. Forefoot running improves pain and disability associated with chronic exertional compartment syndrome. Am J Sports Med. 2012;40(5):1060-1067.

62. Helmhout PH, Diebal AR, van der Kaaden L, Harts CC, Beutler A, Zimmermann WO. The Effectiveness of a 6-Week Intervention Program Aimed at Modifying Running Style in Patients With Chronic Exertional Compartment Syndrome: Results From a Series of Case Studies. Orthop J Sports Med. 2015;3(3):2325967115575691.

63. Isner-Horobeti M-E, Dufour SP, Blaes C, Lecocq J. Intramuscular pressure before and after botulinum toxin in chronic exertional compartment syndrome of the leg: a preliminary study. Am J Sports Med. 2013;41(11):2558-2566.

64.Baria MR, Sellon JL. Botulinum Toxin for Chronic Exertional Compartment Syndrome. Clinical Journal of Sport Medicine. 2016;26(6):e111-e113.

65. Van der Wal WA, Heesterbeek PJC, van den Brand JGH, Verleisdonk EJMM. The natural course of chronic exertional compartment syndrome of the lower leg. Knee Surg Sports Traumatol Arthrosc. January 2014:1-6.

66. Bell S. Repeat compartment decompression with partial fasciectomy. J Bone Joint Surg Br. 1986;68(5):815-817.

67. Packer JD, Day MS, Nguyen JT, Hobart SJ, Hannafin JA, MetzI JD. Functional outcomes and patient satisfaction after fasciotomy for chronic exertional compartment syndrome. Am J Sports Med. 2013;41(2):430-436. 


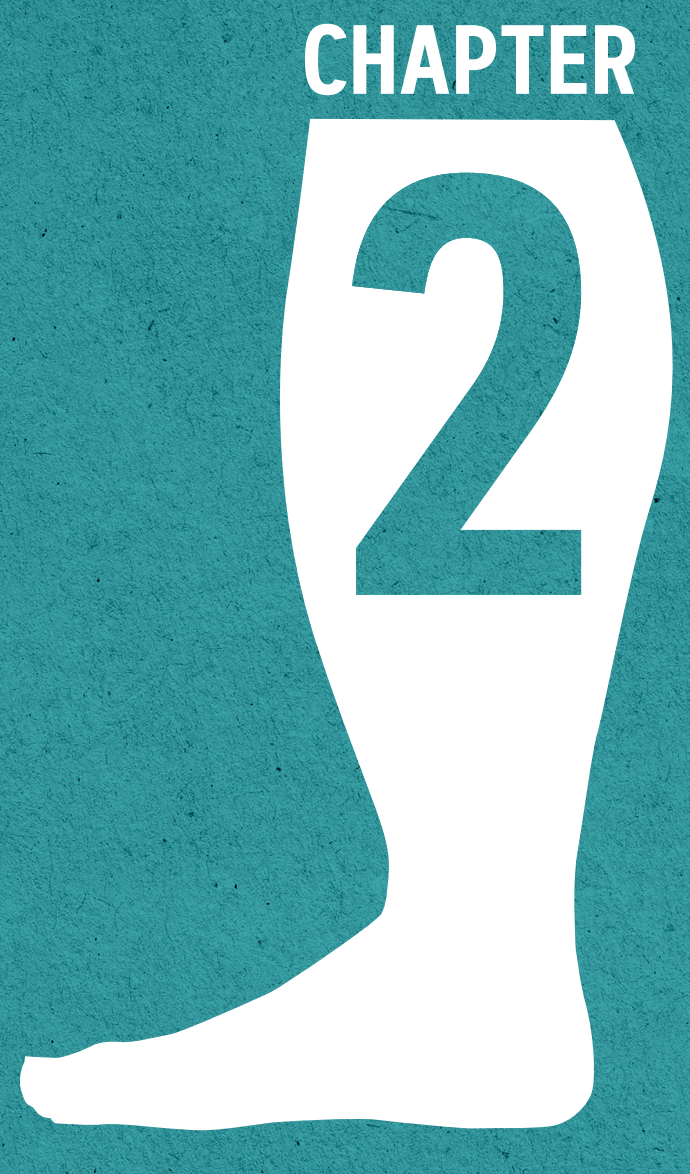




\section{CHAPTER 2}

\section{FACTORS PREDICTING LOWER}

\section{LEG CHRONIC EXERTIONAL}

\section{COMPARTMENT SYNDROME}

\section{IN A LARGE POPULATION}

\section{Published in}

International Journal of Sports Medicine, 2018 vol. 39, p58-66

J.A. de Bruijn ${ }^{*, 1}$, A.P.M. van Zantvoortt,1, D. van Klaveren², M.B. Winkes', M. van der Cruijsen-Raaijmakers' ${ }^{3}$, A.R. Hoogeveen ${ }^{3}$, J.A.W. Teijink ${ }^{4,5}$, M.R. Scheltinga ${ }^{1}$

* Both authors equally contributed

1 Department of Surgery, Maxima Medical Center, Veldhoven

2 Department of public Health, Erasmus MC - University Medical Center, Rotterdam

3 Department of Sports Medicine, Maxima Medical Center, Veldhoven

4 Department of Surgery, Catharina Hospital, Eindhoven

5 CAPHRI research school, department of epidemiology, Maastricht University 


\section{Chapter 2}

\section{ABSTRACT}

Introduction: Knowledge about lower leg chronic exertional compartment syndrome (CECS) is largely obtained from highly selected populations. Patient characteristics may therefore not be appropriate for the general population. Our purpose was to describe a heterogeneous population of individuals suspected of lower leg CECS and to identify predictors of CECS.

Methods: Charts of individuals who were analyzed for exercise induced lower leg pain in a referral center between 2001 and 2013 were retrospectively studied. Patients were included if history and physical examination were suggestive of CECS and if they had undergone a dynamic intracompartmental pressure measurement.

Results: 698/1411 individuals were diagnosed with CECS in one or more of three lower leg muscle compartments (anterior tibial, deep flexor, lateral). Prevalence of CECS peaked around the age of 20-25 years and decreased thereafter, although a plateau around 50 years was found. Age, gender, bilateral symptoms, previous lower leg pathology, sports (running and skating) and tender muscle compartments were identified as independent predictors of lower leg CECS. The proposed predictive model has moderate discriminative ability (AUC 0.66) and good calibration over the complete range of predicted probabilities.

Discussion: The predictive model, displayed as a nomogram, may aid in selecting individuals requiring an invasive dynamic intracompartmental muscle pressure measurement. 


\section{INTRODUCTION}

Chronic exertional compartment syndrome (CECS) may cause exerciseinduced extremity pain in young individuals. ${ }^{1-3}$ CECS is most commonly found in the anterior (ant-CECS), deep flexor (dp-flex-CECS), or lateral (lat-CECS) compartment of the lower leg. ${ }^{4-6}$ The etiology is a subject of ongoing discussion, but a pathologically elevated muscle compartment pressure is a key factor in the pathogenesis. ${ }^{7.8}$ The diagnosis is based on a suggestive clinical history and is supported by elevated intracompartmental pressure. The latter is mostly determined with a dynamic (rather than static) intracompartmental pressure (ICP) measurement. ${ }^{9}$

The stereotypical lower leg CECS patient is a young individual who reports a progressively painful and tense muscle compartment during and after exercise. ${ }^{2,4,10} \mathrm{Cramps}$, muscle weakness and altered skin sensation are also experienced. ${ }^{11}$ Symptoms usually subside within half an hour of rest. ${ }^{12}$ The current knowledge on CECS is largely based on small or highly selected cohorts such as athletes or military service members and may therefore be biased. ${ }^{13,14}$

The department of Sports Medicine of Máxima Medical Center serves as a referral center for a variety of exercise induced pain syndromes, exposing it to a large number of individuals who may have CECS. 15,16 This population is highly diverse with patients of all ages and levels of sports. The goal of the present study was to describe this heterogeneous population of individuals suspected of CECS who were referred for a dynamic ICP measurement. Furthermore, we aimed to identify predictors for lower leg CECS.

\section{METHODS}

\section{Patient selection}

All patients evaluated for lower leg CECS in our department of sports medicine between January 2001 and December 2013 were eligible for this retrospective cohort study. Patients were previously evaluated by a range of clinicians, both from within and from outside of our hospital. As a diagnosis was unclear by then, they were referred to our center for additional analysis. Patients were included for the present study if history and physical examination were suggestive of CECS and if they had undergone a dynamic ICP. A history was considered 'suggestive' if one or more lower leg compartments were reportedly painful or felt tense during 
training or thereafter. Patients who did not receive an ICP measurement were excluded, as were patients with recurrent CECS or with a CECS of the lower arms or upper legs. The local medical ethical committee judged that the rules laid down in the Medical Research Involving Human Subjects Act (WMO) did not apply to the study protocol. All procedures performed in this study are in accordance with the ethical standards of our institutional research committee, the ethical standards in sports and exercise science research and with the 1964 Helsinki declaration and its later amendments. ${ }^{17}$

\section{Consultation and ICP measurements}

At presentation, one of two highly experienced sport physicians reviewed the patient's history. Comorbidities such as intermittent claudication, earlier lower leg surgery, venous insufficiency or neurological deficits were tabulated. Significant previous traumatic events including fractures, extensive soft tissue damage, tendon rupture or major vessel damage were also documented. A physical examination was conducted on all individuals. Signs of arterial or venous insufficiency were identified and distal arterial pulses were palpated. Muscle compartments were tested for tenderness and, when indicated, a neurological examination or pedal pulse test was performed. If history and physical examination were suggestive of CECS, ICP measurements of the anterior tibial muscle compartment, the deep posterior compartment, the lateral compartment, or a combination thereof were performed. The choice and number of compartments that were measured was not standardized but dictated by location of symptoms and findings during physical examination. If a patient reported bilateral pain, an ICP measurement was performed in just one leg. Patients with bilateral symptoms and elevated muscle compartment pressure in one leg were considered as having a bilateral CECS. By doing so, the number of invasive ICP measurements was limited, thus minimizing the risk of potential complications such as pain, bleeding, and nerve damage. Details of the slitcatheter technique were described earlier. ${ }^{18,19}$

Patients were diagnosed with a CECS if they had a suggestive history and physical examination and at least one ICP value above the three cut-off points ( $\geq 15 \mathrm{~mm} \mathrm{Hg}$ at rest, $\geq 30 \mathrm{~mm} \mathrm{Hg} 1$ minute after provocative exercise or $\geq 20 \mathrm{~mm} \mathrm{Hg} 5$ minutes later). ${ }^{9}$ After the diagnosis, most patients were sent back to their referring physician for treatment. However, some patients underwent surgical treatment in our hospital. 


\section{Data collection}

Data were obtained from two electronic sources. Between January 2001 and March 2010, data were extracted from a custom made Microsoft Access database. We supplemented this database with recordings from paper patient files. Between April 2010 and December 2013, electronic patient files were used. Both databases were combined into one comprehensive data file.

\section{Statistics}

Analyses were performed using SPSS Statistics version 22.0.0.0 (IBM corp, Armonk, NY) and R version 3.1.3 (R foundation for Statistical computing, Vienna, Austria). Data are expressed as mean ( \pm SD) when normally distributed, or as median (with range) when nonparametric. A P $\leq 0.05$ was considered significant. The relation between previous history and unilateral complaints was assessed using chi-square testing. Graphs illustrating the relation between age and risk on CECS were smoothened to improve visual clarity (Graphpad prism 6). Associations of patient related variables and the diagnosis CECS were determined using univariable logistic regression. Only variables that were present in $>50 \%$ of the patients were included. Significant variables were included as covariates in a multivariable logistic regression model. Missing values were handled by means of multiple imputation. ${ }^{20}$

The strength of the association of each variable with the diagnosis CECS is displayed by its multivariate odds ratio (OR), together with its $95 \%$ confidence interval. Variables without a significant association with the outcome were excluded from the model in a backward approach. The discriminative ability of the final model was assessed with the area under the receiver operating characteristic curve (AUC). In a useless test, such as a coin flip, the AUC is 0.5; a model that discriminates perfectly has an AUC of $1 .{ }^{21}$ The validity of the model was tested with the Hosmer and Lemeshow test and agreement between predicted probabilities and observed frequencies was visualized with a calibration plot. We used bootstrapping to correct the final AUC for optimism. The final model is presented as a nomogram. 


\section{RESULTS}

\section{General}

We evaluated 1867 individuals suspected of having CECS between 2001 and 2013 in our facility. Based on an atypical clinical history and/or physical examination, CECS was considered highly unlikely in 153 patients. The remaining 1714 patients underwent an ICP measurement. After exclusion (previous CECS analysis, $\mathrm{n}=201$; symptoms in lower arms or upper legs, $n=102), 1411$ unique patients suspected of lower leg CECS were included in the present study (figure 2.1).

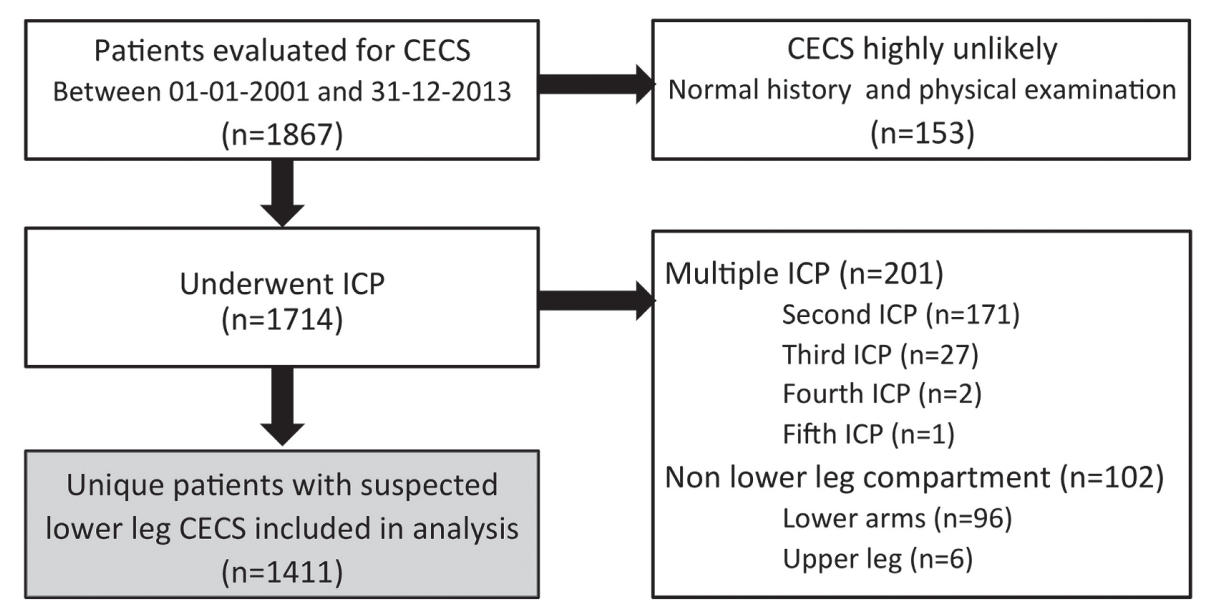

Figure 2.1: Study flow chart of unique patients undergoing dynamic intracompartmental pressure measurement (ICP) for suspected lower leg chronic exertional compartment syndrome (CECS). Multiple ICP: $\geq 1$ previous CECS evaluation including ICPs.

\section{Single or multiple ICP measurements}

We performed 1938 ICP measurements in these 1411 patients (figure 2.2). Measurement of just one compartment occurred in 70\% (983/1411, figure 2.2 , left panel) whereas the remaining $30 \%$ of the individuals underwent ICP measurements of multiple compartments (figure 2.2, right panel). Half of these patients $(698 / 1411,49 \%)$ had elevated intracompartmental pressure in at least one compartment. The number of patients with elevated ICP values depended on type of CECS (ant-CECS, 53\%(433/814); dp-CECS, $38 \%$ (344/904); lat-CECS, 35\% (78/220). 

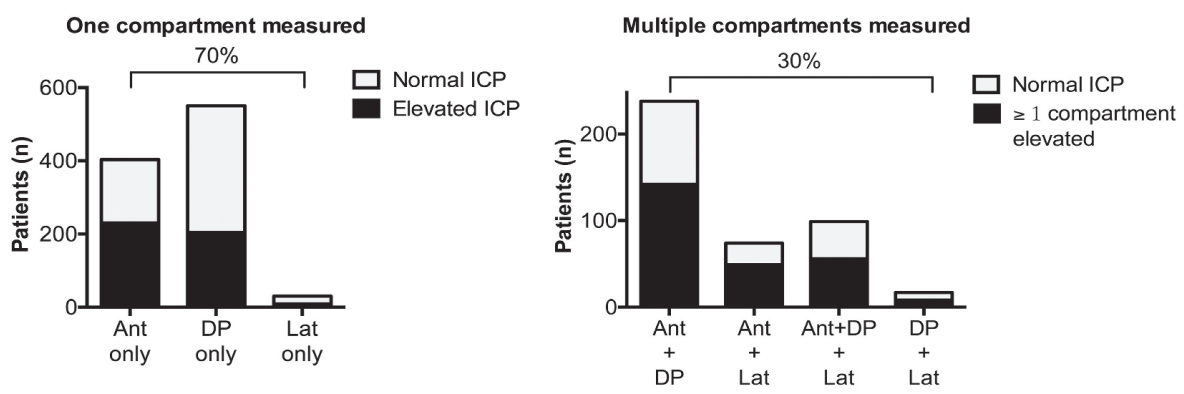

Figure 2.2: 1938 lower leg muscle compartments of 1411 patients were studied, $70 \%$ of the patients underwent an intracompartmental pressure measurement (ICP) of just one compartment (left), 30\% underwent ICP in $>1$ compartment. Ant = anterior tibial compartment, DP = deep flexor compartment, Lat = lateral compartment.

Table 2.1: Characteristics of patients ( $n=1411)$ who underwent ICP for suspected lower leg CECS

\begin{tabular}{|c|c|c|c|c|}
\hline & & CECS & hon-CECS & Total \\
\hline & $\mathrm{n}(\%)$ & $698(50)$ & $713(50)$ & $1411(100)$ \\
\hline $\operatorname{Sex}(n=1411)$ & Female n (\%) & $352(50)$ & $426(60)$ & $778(55)$ \\
\hline \multirow[t]{2}{*}{ Age $(n=1411)$} & Median (years) & 25 & 33 & 28 \\
\hline & Range (years) & $12-81$ & $14-90$ & $12-90$ \\
\hline \multirow[t]{2}{*}{ Duration symptoms $(n=1131)$} & Median (months) & 18 & 18 & 18 \\
\hline & Range (months) & $1-360$ & $1-300$ & $1-360$ \\
\hline \multirow[t]{8}{*}{ Clinical history } & Data available, n (\%) & $595(85)$ & $610(86)$ & $1205(85)$ \\
\hline & $\begin{array}{l}\text { No relevant clinical } \\
\text { history, } \mathrm{n}(\%)\end{array}$ & $429(72)$ & 362 (59) & $791(66)$ \\
\hline & $\begin{array}{l}\text { Relevant clinical } \\
\text { history, n (\%) }\end{array}$ & $166(28)$ & $248(41)$ & $414(34)$ \\
\hline & Surgery leg, n (\%) & $64(11)$ & $66(11)$ & $130(11)$ \\
\hline & Trauma leg, n (\%) & $33(6)$ & $56(9)$ & $89(7)$ \\
\hline & $\begin{array}{l}\text { Peripheral artery } \\
\text { disease, } \mathrm{n}(\%)\end{array}$ & $8(1)$ & $10(2)$ & $18(1)$ \\
\hline & $\begin{array}{l}\text { Peripheral venous } \\
\text { disease, } \mathrm{n}(\%)\end{array}$ & $15(3)$ & $25(4)$ & $40(3)$ \\
\hline & Other, n (\%) & $46(8)$ & $91(15)$ & $137(11)$ \\
\hline \multirow[t]{6}{*}{ Previous treatment } & Data available, n (\%) & $455(65)$ & $495(69)$ & $950(67)$ \\
\hline & $\begin{array}{l}\text { Conservative } \\
\text { treatment } \mathrm{n}(\%)\end{array}$ & $433(95)$ & $472(95)$ & 905 (95) \\
\hline & Rest, n (\%) & $266(61)$ & $260(56)$ & $526(58)$ \\
\hline & Cooling, n (\%) & $47(11)$ & $37(8)$ & $84(9)$ \\
\hline & Physiotherapy, n (\%) & $339(78)$ & 379 (81) & $718(79)$ \\
\hline & Inlays, n (\%) & $266(60)$ & $270(58)$ & $536(59)$ \\
\hline
\end{tabular}

CECS $=$ chronic exertional compartment syndrome, ICP = intracompartmental pressure measurement 


\section{Patient characteristics}

Table 2.1 depicts characteristics of individuals with CECS $(n=698)$ and without CECS ( $n=713)$. Earlier treatment modalities were comparable between the two groups. CECS patients were 8 years younger (median, $25 \mathrm{yr}$, range 12-81) than non-CECS patients (33 yr, range 14-90). The prevalence of CECS decreased with age (figure 2.3). Patients with unilateral symptoms more often had a history of previous lower leg trauma than patients with bilateral symptoms ( $14.4 \%$ vs $3.9 \%$, p<0.01). Moreover, vascular pathology was more often present in patients with unilateral complaints than in patients with bilateral complaints $(7.2 \%$ vs $3.6 \%, p<0.01)$.

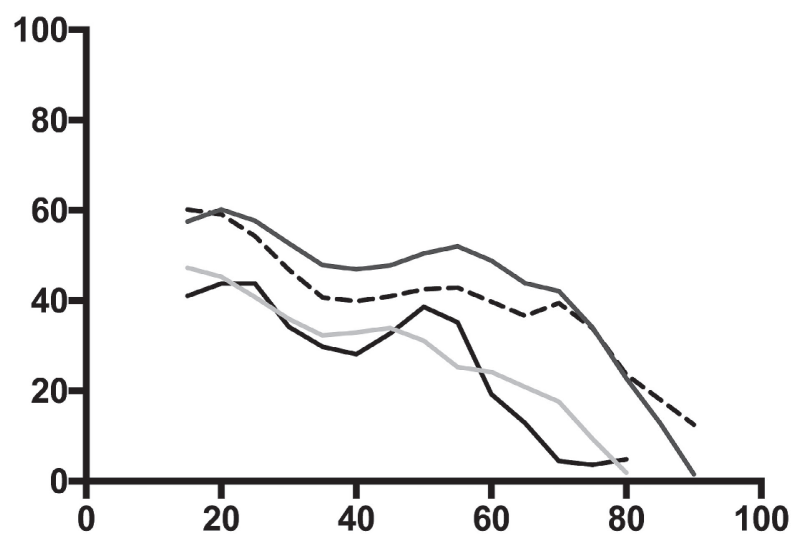

Figure 2.3: Ratio of $n$ patients diagnosed with CECS divided by total $n$ of evaluated patients ( $y$-axis) in relation to age $(x$-axis). Ant-CECS $=$ isolated anterior tibial compartment CECS, DP-CECS = isolated deep flexor compartment CECS, LatCECS $=$ isolated lateral compartment CECS.

Table 2.2 shows patient characteristics of the three subtypes of isolated lower leg CECS. Patients with dp-CECS were 4 and 2 years younger than patients with ant-CECS or lat-CECS, respectively $(p<0.01)$. Approximately three quarters of patients with ant-CECS (72\%) and dp-CECS (78\%) had bilateral symptoms compared to just a little over half of the lat-CECS patients $(53 \%, p=0.04)$. Patients with dp-CECS played soccer more often, whereas patients with ant-CECS were more of ten engaged in speed skating. Patients not engaged in sports were occasionally found to have ant-CECS but seldom suffered from other types of lower leg CECS (Table 2.2). 
Table 2.2: Characteristics of patients with isolated tibial anterior (Ant), deep flexor (DP), or lateral (Lat) chronic exertional compartment syndrome (CECS).

\begin{tabular}{|c|c|c|c|c|c|}
\hline & Ant & DP & Lat & $\begin{array}{r}\text { Chi } \\
\text { square }\end{array}$ & p-value \\
\hline$n(\%)$ & $300(43)$ & $239(34)$ & $19(3)$ & & \\
\hline \multicolumn{6}{|l|}{ Gender } \\
\hline Female n (\%) & $155(52)$ & $115(48)$ & $10(53)$ & 0.72 & 0.70 \\
\hline \multicolumn{6}{|l|}{ Age } \\
\hline Median (years) & 27 & 23 & 25 & $8.9 \#$ & $<0.01^{*}$ \\
\hline Range (years) & $14-81$ & $12-70$ & $17-77$ & & \\
\hline \multicolumn{6}{|l|}{ Duration symptoms } \\
\hline Median (months) & 18 & 21 & 18 & $0.2 \#$ & 0.75 \\
\hline Range (months) & $1-360$ & $3-284$ & $4-120$ & & \\
\hline \multicolumn{6}{|l|}{ Bilaterality } \\
\hline Bilateral symptoms, n (\%) & $214(72)$ & $184(78)$ & $10(53)$ & 6.68 & $0.04^{*}$ \\
\hline Type of sport n(\%) & 273 & 218 & 19 & & \\
\hline No & $26(10)$ & $5(2)$ & $1(5)$ & 10.81 & $<0.01^{*}$ \\
\hline Soccer & $35(13)$ & $69(32)$ & $4(21)$ & 25.75 & $<0.01^{*}$ \\
\hline Running & $54(20)$ & $45(21)$ & $3(16)$ & 0.28 & 0.87 \\
\hline Hiking & $28(10)$ & $12(6)$ & $1(5)$ & 3.91 & 0.14 \\
\hline Hockey & $22(8)$ & $12(6)$ & $1(5)$ & 1.32 & 0.52 \\
\hline Skating & $24(9)$ & $2(1)$ & $1(5)$ & 14.99 & $<0.01^{*}$ \\
\hline Handball & $11(4)$ & $6(3)$ & $\mathrm{O}(0)$ & 1.29 & 0.52 \\
\hline Military service & $14(5)$ & $4(2)$ & $O(0)$ & 4.58 & 0.10 \\
\hline Level of sport n(\%) & 189 & 164 & 10 & & \\
\hline No & $26(14)$ & $5(3)$ & $1(10)$ & 13.43 & $<0.01^{*}$ \\
\hline Social & $66(35)$ & $44(27)$ & $3(30)$ & 2.69 & 0.26 \\
\hline Local & $56(30)$ & $90(55)$ & $5(50)$ & 23.34 & $<0.01^{*}$ \\
\hline National & $17(9)$ & $13(8)$ & $1(10)$ & 0.16 & 0.93 \\
\hline International & $5(3)$ & $2(1)$ & $0(0)$ & 1.15 & 0.56 \\
\hline Professional & $18(10)$ & $10(6)$ & $0(0)$ & 2.31 & 0.32 \\
\hline Influence complaints & 173 & 158 & 9 & & \\
\hline Ceased sports & $45(26)$ & $36(23)$ & $1(11)$ & 1.32 & 0.52 \\
\hline Different sport & $2(1)$ & $4(3)$ & $O(0)$ & 1.07 & 0.59 \\
\hline Lower level & $62(36)$ & $67(42)$ & $6(67)$ & 4.29 & 0.12 \\
\hline Same level with complaints & $38(22)$ & $46(29)$ & $1(11)$ & 3.20 & 0.20 \\
\hline
\end{tabular}

Only isolated CECS are shown (77\% of total, 538/698), combinations are excluded from this table. Only sports with $>20$ patients are depicted, for categorical variables chi-square test was used, for continuous variables a one-way anova test was used (marked with \#). Statistically significant differences are marked with * 


\section{Predictors of CECS}

Univariable analysis of the whole population of 1411 individuals demonstrated that gender, age, clinical history, bilateral symptoms, type of sports, competitive level of sports and painful palpation during physical examination were associated with the diagnosis CECS (table 2.3).

Table 2.3: Univariable associations of potential predictors of CECS ( $n=1411)$

\begin{tabular}{|c|c|c|c|c|c|c|}
\hline \multirow{2}{*}{ Predictors } & & \multicolumn{5}{|c|}{$95 \% \mathrm{Cl}$} \\
\hline & & $\mathbf{n}$ & OR & LL & UL & p-value \\
\hline \multirow[t]{2}{*}{ Gender } & Female & 778 & ref & ref & ref & ref \\
\hline & Male & 633 & 1.46 & 1.18 & 1.80 & $<0.01^{*}$ \\
\hline \multicolumn{2}{|l|}{ Age (years) } & 1411 & 0.98 & 0.97 & 0.99 & $<0.01^{*}$ \\
\hline \multicolumn{2}{|c|}{ Duration symptoms (Months) } & 1131 & 1.00 & 1.00 & 1.00 & 0.46 \\
\hline \multirow[t]{2}{*}{ Clinical history } & Not relevant & 789 & ref & ref & ref & ref \\
\hline & Lower leg pathology & 416 & 0.57 & 0.45 & 0.72 & $<0,01^{*}$ \\
\hline \multirow[t]{2}{*}{ Bilaterality } & Bilateral & 941 & ref & ref & ref & ref \\
\hline & Unilateral & 449 & 0.54 & 0.45 & 0.72 & $<0,01^{*}$ \\
\hline \multirow[t]{12}{*}{ Type of sport } & None & 98 & ref & ref & ref & ref \\
\hline & Soccer & 218 & 2.16 & 1.33 & 3.51 & $<0.01^{*}$ \\
\hline & Running & 303 & 0.91 & 0.69 & 1.44 & 0.58 \\
\hline & Hiking & 105 & 1.00 & 0.57 & 1.74 & 0.99 \\
\hline & Hockey & 79 & 1.69 & 0.93 & 3.08 & 0.08 \\
\hline & Fitness & 52 & 1.49 & 2.93 & 0.76 & 0.25 \\
\hline & Cycling & 48 & 0.64 & 0.31 & 1.32 & 0.22 \\
\hline & Skating & 39 & 5.85 & 2.35 & 14.53 & $<0,01^{*}$ \\
\hline & Tennis & 37 & 0.61 & 0.28 & 1.36 & 0.23 \\
\hline & Handball & 36 & 1.79 & 0.83 & 3.88 & 0.14 \\
\hline & Military service & 31 & 3.13 & 1.31 & 7.48 & $0.01^{*}$ \\
\hline & Other & 207 & 1.32 & 0.81 & 2.14 & 0.26 \\
\hline \multirow[t]{6}{*}{ Level of sports } & None & 98 & ref & ref & ref & ref \\
\hline & Social & 328 & 0.98 & 0.62 & 1.54 & 0.92 \\
\hline & Local & 341 & 1.65 & 1.05 & 2.59 & $0.031 *$ \\
\hline & National & 56 & 2.30 & 1.17 & 4.53 & $0.016^{*}$ \\
\hline & International & 14 & 4.69 & 1.23 & 17.87 & $0.024^{*}$ \\
\hline & Professional & 56 & 1.98 & 1.01 & 3.86 & $0.046^{*}$ \\
\hline \multirow[t]{2}{*}{ Influence complaints } & Ceased sports & 231 & ref & ref & ref & ref \\
\hline & Different sport & 14 & 0.83 & 0.28 & 2.45 & 0.73 \\
\hline
\end{tabular}


Table 2.3: Continued

\begin{tabular}{llrrrrr}
\hline & & \multicolumn{7}{c}{$\mathbf{9 5 \%} \mathbf{C l}$} \\
\hline Predictors & & $\mathbf{n}$ & OR & LL & UL & p-value \\
\hline & Lower level & 325 & 1.13 & 0.81 & 1.59 & 0.46 \\
& $\begin{array}{l}\text { Same level with } \\
\text { complaints }\end{array}$ & & & & & \\
Painful anterior tibia & No & 645 & 1.13 & 0.78 & 1.65 & 0.52 \\
& Yes & 648 & ref & ref & ref & ref \\
Painful/tensed & No & 332 & 0.89 & 0.68 & 1.15 & 0.37 \\
Compartment & Yes & 483 & ref & ref & ref & ref \\
\hline
\end{tabular}

Odds ratio $(O R)>1.0$ indicates a positive predictive value of the variable for the diagnosis Chronic Exertional Compartment Syndrome (CECS). Odds ratio $<1.0$ indicates a negative predictive value for CECS. Lower limit (LL) and upper limit (UL) of the 95\%-confidence interval $(\mathrm{Cl})$ are shown. Statistically significant predictors are marked with *

Table 2.4: Multivariable associations of predictors of CECS

\begin{tabular}{|c|c|c|c|c|c|}
\hline \multirow[b]{2}{*}{ Predictors } & & \multicolumn{3}{|c|}{$95 \% \mathrm{Cl}$} & \multirow[b]{2}{*}{ p-value } \\
\hline & & OR & LL & UL & \\
\hline \multicolumn{6}{|l|}{ Full set } \\
\hline \multirow[t]{2}{*}{ Gender } & Female & ref & ref & ref & ref \\
\hline & Male & 1.69 & 1.32 & 2.16 & $<0.01^{*}$ \\
\hline Age (years) & & 0.99 & 0.98 & 1.00 & $0.02 *$ \\
\hline \multirow[t]{2}{*}{ Bilaterality } & Unilateral & ref & ref & ref & ref \\
\hline & Bilateral & 1.35 & 1.05 & 1.74 & $0.02^{*}$ \\
\hline \multirow[t]{2}{*}{ Clinical history } & Not relevant & ref & ref & ref & ref \\
\hline & Lower leg pathology & 0.63 & 0.49 & 0.81 & $<0.01^{*}$ \\
\hline \multirow[t]{12}{*}{ Type of sport } & None & ref & ref & ref & ref \\
\hline & Soccer & 1.19 & 0.57 & 2.48 & 0.65 \\
\hline & Running & 0.57 & 0.35 & 0.93 & $0.03^{*}$ \\
\hline & Hockey & 1.01 & 0.43 & 2.35 & 0.98 \\
\hline & Handball & 1.15 & 0.45 & 2.95 & 0.76 \\
\hline & Fitness & 1.30 & 0.65 & 2.60 & 0.46 \\
\hline & Hiking & 0.84 & 0.44 & 1.59 & 0.59 \\
\hline & Cycling & 0.54 & 0.25 & 1.15 & 0.11 \\
\hline & Skating & 3.22 & 1.01 & 10.26 & $0.05^{*}$ \\
\hline & Tennis & 0.47 & 0.17 & 1.25 & 0.13 \\
\hline & Military service & 1.55 & 0.36 & 6.58 & 0.55 \\
\hline & Other & 0.84 & 0.43 & 1.65 & 0.61 \\
\hline
\end{tabular}


Table 2.4: Continued

\begin{tabular}{|c|c|c|c|c|c|}
\hline \multirow[b]{2}{*}{ Predictors } & & \multicolumn{3}{|c|}{$95 \% \mathrm{Cl}$} & \multirow[b]{2}{*}{ p-value } \\
\hline & & OR & LL & UL & \\
\hline \multirow[t]{5}{*}{ Level of sports } & Social & ref & ref & ref & ref \\
\hline & Local & 0.95 & 0.61 & 1.47 & 0.80 \\
\hline & National & 1.16 & 0.57 & 2.36 & 0.68 \\
\hline & International & 3.02 & 0.77 & 11.83 & 0.11 \\
\hline & Professional & 0.90 & 0.30 & 2.70 & 0.85 \\
\hline Painful/tensed & No & ref & ref & ref & ref \\
\hline Compartment & Yes & 2.03 & 1.57 & 2.62 & $<0.01^{*}$ \\
\hline \multicolumn{6}{|c|}{ Final Selected model } \\
\hline \multirow[t]{2}{*}{ Gender } & Female & ref & ref & ref & ref \\
\hline & Male & 1.73 & 1.37 & 2.17 & $<0.01$ \\
\hline Age (years) & & 0.98 & 0.98 & 0.99 & $<0.01$ \\
\hline \multirow[t]{2}{*}{ Bilaterality } & Unilateral & ref & ref & ref & ref \\
\hline & Bilateral & 1.39 & 1.09 & 1.78 & 0.01 \\
\hline \multirow[t]{2}{*}{ Clinical history } & Not relevant & ref & ref & ref & ref \\
\hline & Lower leg pathology & 0.64 & 0.50 & 0.83 & 0.01 \\
\hline \multirow[t]{3}{*}{ Type of sport } & Other & ref & ref & ref & ref \\
\hline & Running & 0.61 & 0.46 & 0.80 & $<0.01$ \\
\hline & Skating & 4.03 & 1.70 & 9.59 & $<0.01$ \\
\hline Painful/tensed & No & ref & ref & ref & ref \\
\hline Compartment & Yes & 1.98 & 1.54 & 2.55 & $<0.01$ \\
\hline
\end{tabular}

Multivariate analysis performed on variables that were predictive during univariable analysis (full set). OR = Odds ratio, $\mathrm{Cl}=$ confidence interval, $\mathrm{LL}=$ lower limit, $\mathrm{UL}=$ upper limit. Statistically significant predictors $\left({ }^{*}\right)$ were included in the final model. 


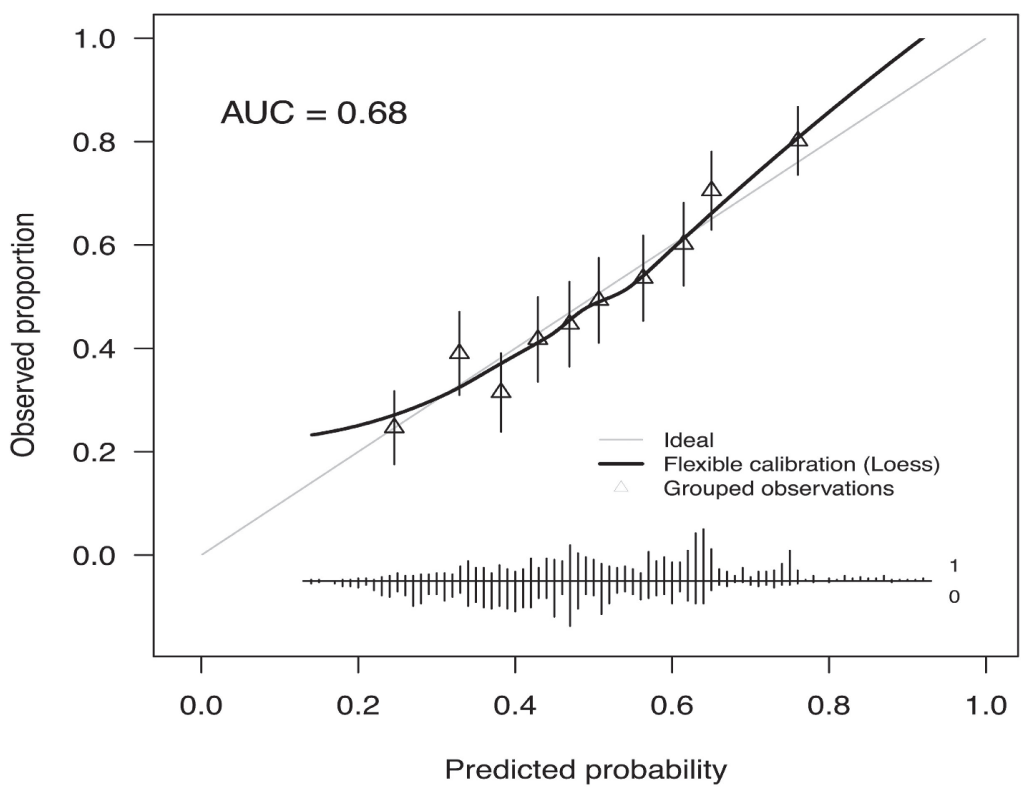

Figure 2.4: Calibration plot of the final model for predicting CECS. The distribution of predicted risks is displayed at the bottom of the graph. Triangles indicate the observed proportion by deciles ( $y$-axis) of predicted risks ( $x$-axis). AUC = area under the receiving operating characteristic curve.

After multiple imputation (5 times), we used the predictive variables that were identified with univariable analysis in a multivariable regression model. Age, gender, history of lower leg pathology, bilateral symptoms, type of sports (running and skating) and a painful/tensed compartment during palpation were identified as independent predictors of CECS (table 2.4). The AUC of the final model was 0.68. After bootstrapping to correct for optimism to improve the predictive capabilities in a different population, the AUC of the final model was 0.66 . The predicted probabilities were grouped into deciles and the mean probability for each decile was compared with the observed proportions of the diagnosis CECS (figure 2.4). Calibration was good for the complete range of predicted probabilities. The final model is displayed as a nomogram (figure 2.5). 
Points
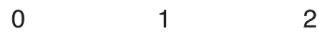

3

4

$4 \quad 5$

Gender

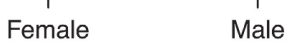

Age

$\begin{array}{llllll}65 & 55 & 45 & 35 & 25 & 15\end{array}$

Symptoms

Unilateral Bilateral

Clinical history

Lower leg pathology None

Sports

Other

Painful/tensed

compartment

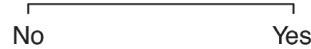

Total Points

\begin{tabular}{lllllllll}
\hline & 1 & & & 1 & 1 & 1 & 1 \\
0 & 2 & 4 & 6 & 8 & 10 & 12 & 14
\end{tabular}

CECS (\%)

\begin{tabular}{llllll}
\hline 19 & 35 & 56 & 75 & 87 & 94
\end{tabular}

Figure 2.5: Nomogram predicting CECS. To calculate an individual's probability of having CECS, first determine his or her risk factor values (e.g. male, 20 year old, speed skater, bilateral complaints, no previous medical history, painful compartment during palpation). Once determined, individual risk points associated with each risk factor are obtained by drawing a line straight up from each predictor value towards the "points axis" (1.4, 1.8, 5, 0.8, 1.2, and 1.8 respectively). Lastly, all points are totaled to obtain a sum risk score ( 12 points). The probability of having CECS is then calculated by drawing a line down from the "total points" axis to the probability "CECS" axis (approximately 91\%).

\section{DISCUSSION}

Most previous studies on CECS were performed in highly selected populations including elite athletes or military personnel. ${ }^{22,23}$ The present study describes a heterogeneous patient population with only one selection criterion: all individuals were suspected of having lower leg CECS by their referring physician. Half of these individuals were indeed diagnosed with lower leg CECS as determined by a suspect clinical history and elevated intracompartmental muscle pressures. Age, gender, history of lower leg 
pathology, bilateral symptoms and a painful/tensed compartment were identified as predictors of CECS.

Previous studies reporting on the relation between gender and CECS are conflicting. Early literature reported a higher male prevalence, ${ }^{5,9}$ whereas two recent large studies suggested a female predominance. ${ }^{4,23}$ It is likely that an earlier suggested male predominance is due to selection bias as mostly military personnel and athletes were studied. Moreover, previous cohorts only described patients who were diagnosed with a CECS whereas patients who tested negative for CECS were not studied. The present study included patients with and without CECS. Our analysis demonstrates an equal prevalence of females and males having CECS. However, the initial population of 1411 individuals contained more females (55\%). As a consequence, the portion of females with exercise induced lower leg symptoms that was diagnosed with CECS was smaller than their male counterparts. Indeed, multivariable analysis confirmed that male gender was associated with a higher likelihood for the diagnosis CECS.

The available literature suggests that CECS is associated with young age, $5,8,13,23,24$ although CECS was occasionally also identified in older individuals. ${ }^{25}$ The present study confirms that young patients are more prone to develop CECS. Median age at time of diagnosis was 25 years. However, our oldest CECS patient was 81 years. The prevalence of CECS decreases with age. Interestingly, the prevalence stabilized in patients aged around 50 years. Moreover, this plateau is consistently observed in all three types of lower leg CECS. We hypothesize that these older individuals increased their sportive activities as leisure time became more available around this age. Univariable and multivariable analysis confirm that age is an influential factor for the occurrence of CECS.

Lower leg CECS is a predominantly bilateral syndrome., ${ }^{4,25-29}$ Findings of the present study confirm this bilaterality as $74 \%$ of our total population had CECS in both legs. A novel finding is that bilaterality is CECS type dependent. $53 \%$ of the isolated lat-CECS patients had a bilateral syndrome compared to $72 \%$ of the ant-CECS and $78 \%$ of the dp-CECS patients. Furthermore, multivariable analysis demonstrated that patients with unilateral complaints were less likely to be diagnosed with CECS than patients with bilateral complaints. Higher prevalence of previous trauma or vascular pathology in 
patients with unilateral complaints may explain this finding. Thus, bilateral lower leg symptoms are predictive of CECS whereas unilateral symptoms may be associated with vascular or traumatic pathology.

Evidence indicates that CECS predominantly occurs in populations engaged in sports activities and military service. ${ }^{4,22,23}$ Nevertheless, less active individuals or diabetics can also suffer from CECS. ${ }^{25,30}$ Results of the present study are in line with previous literature. Although not significant, we found a trend that increasing sport intensity appeared to associate with a higher likelihood of the diagnosis CECS. However, we also found that patients who are not engaged in sports at all may also suffer from CECS, usually of the ant-CECS type. In our population, a wide variety of sports were practiced. Interestingly, only speed skating was associated with an increased likelihood of (ant-)CECS. We suspect that this type of CECS is related to posture during skating and this finding may also be applicable for inline skating, rollerblading and other types of skating. In contrast to previous studies, running was associated with a reduced likelihood of CECS. Furthermore, soccer conferred a higher risk on dp-CECS.

The present study has several limitations. Firstly, due to its retrospective nature and the 13-year study period we were not able to obtain complete datasets in all patients. Therefore, the number of variables that were analyzed was suboptimal and the power of the univariable analysis was reduced. Also, the potential of introducing bias is larger in retrospective studies. Secondly, the current study used ICP measurements (and the Pedowitz criteria) to confirm the diagnosis CECS. Recent literature debates the discriminative value and the role of proposed cut-off points. ${ }^{31-33}$ However, the methods and cutoff points used in the current manuscript are widely accepted and the best currently available. Moreover, it must be appreciated that CECS is not solely based on ICP measurements but also requires a suggestive history and physical examination. Thirdly, results of surgery were not available. A favorable outcome after invasive therapy is likely the most valid parameter supporting the diagnosis. Most patients underwent surgery in their referring hospitals and surgical results were, therefore, not available. Lastly, we corrected for optimism with bootstrapping. Although this is an accepted method to test external validity, validation of the current predictive model in a different population is desirable. Also, with an AUC of 0.66 , the predictive model is far from perfect (AUC 1.0). Clinicians should 
therefore use this model to support decision-making but should not fare blindly on its outcome. The predictive model should not be considered a substitute for dynamic ICP measurements. Strengths of the study are its volume and the heterogeneous population. Furthermore it is one of few studies to include individuals without CECS, thereby enabling us to provide independent predictors for lower leg CECS.

The differential diagnosis in lower leg pain is extensive. This often results in delay of diagnosis and treatment, with a consequential negative impact on the quality of life, especially in athletes and military personnel. ${ }^{23,34}$ Furthermore, the diagnosis CECS is largely based on a suggestive history and physical examination but additional invasive testing, such as an ICP measurement, is pivotal. ${ }^{4,7}$ The literature may suggest characteristics associated with CECS but predictors were hitherto not identified. A simple diagnostic bedside tool for CECS is currently lacking. The present study is the first to provide non-expert clinicians with a method to assist in predicting the likelihood of CECS in a patient with exercise-induced lower leg complaints. By inserting gender, age, bilaterality, previous lower leg pathology, sports (skating and running), and a tensed/painful compartment into the included nomogram, less experienced clinicians can approximate the risk for CECS in a patient with exercise-induced lower leg complaints. This bedside tool may reduce doctor's delay and may aid in selecting individuals that require invasive ICP measurements. In the near future we plan to validate the current predictive model in a different population. 


\section{REFERENCES}

1. Qvarfordt P, Christenson JT, Eklöf B, Ohlin P, Saltin B. Intramuscular pressure, muscle blood flow, and skeletal muscle metabolism in chronic anterior tibial compartment syndrome. Clin Orthop Relat Res. 1983;(179):284-290.

2. Styf J. Diagnosis of exercise-induced pain in the anterior aspect of the lower leg. American Journal of Sports Medicine. 1988;16(2):165-169.

3. Tzortziou V, Maffulli N, Padhiar N. Diagnosis and management of chronic exertional compartment syndrome (CECS) in the United Kingdom. Clin J Sport Med. 2006;16(3):209-213.

4. Davis DE, Raikin S, Garras DN, Vitanzo P, Labrador H, Espandar R. Characteristics of patients with chronic exertional compartment syndrome. Foot Ankle Int. 2013;34(10):1349-1354.

5. Detmer DE, Sharpe K, Sufit RL, Girdley FM. Chronic compartment syndrome: diagnosis, management, and outcomes. American Journal of Sports Medicine. 1985;13(3):162-170.

6. Winkes MB, Luiten EJT, van Zoest WJF, Sala HA, Hoogeveen AR, Scheltinga MR. Long-term results of surgical decompression of chronic exertional compartment syndrome of the forearm in motocross racers. Am J Sports Med. 2012;40(2):452458.

7. Blackman PG. A review of chronic exertional compartment syndrome in the lower leg. Medicine \& Science in Sports \& Exercise. 2000;32(3 Suppl):S4-S10.

8. Tucker AK. Chronic exertional compartment syndrome of the leg. Curr Rev Musculoskelet Med. 2010;3(1-4):32-37.

9. Pedowitz RA, Hargens AR, Mubarak SJ, Gershuni DH. Modified criteria for the objective diagnosis of chronic compartment syndrome of the leg. American Journal of Sports Medicine. 1990;18(1):35-40.

10. Fronek J, Mubarak SJ, Hargens AR, et al. Management of chronic exertional anterior compartment syndrome of the lower extremity. Clin Orthop Relat Res. 1987;(220):217-227.

11. Martens MA, Backaert M, Vermaut G, Mulier JC. Chronic leg pain in athletes due to a recurrent compartment syndrome. American Journal of Sports Medicine. 1984;12(2):148-151.

12. Winkes MB, van Zantvoort APM, de Bruijn JA, et al. Fasciotomy for Deep Posterior Compartment Syndrome in the Lower Leg: A Prospective Study. Am J Sports Med. 2016;44(5):1309-1316.

13. Micheli LJ, Solomon R, Solomon J, Plasschaert VF, Mitchell R. Surgical treatment for chronic lower-leg compartment syndrome in young female athletes. American Journal of Sports Medicine. 1999;27(2):197-201.

14. Dunn JC, Waterman BR. Chronic exertional compartment syndrome of the leg in the military. Clinics in Sports Medicine. 2014;33(4):693-705. 
15. Schep G, Bender MHM, van de Tempel G, Wijn PFF, de Vries WR, Eikelboom BC. Detection and treatment of claudication due to functional iliac obstruction in top endurance athletes: a prospective study. Lancet. 2002;359(9305):466-473.

16. van Zoest W, Hoogeveen A, Scheltinga M, Sala H, van Mourik J, Brink P. Chronic Deep Posterior Compartment Syndrome of the Leg in Athletes: Postoperative Results of Fasciotomy. Int J Sports Med. 2008;29(5):419-423. doi:10.1055/s-2007-965365.

17. Harriss DJ, Atkinson G. Ethical Standards in Sport and Exercise Science Research: 2016 Update. Int J Sports Med. 2015;36(14):1121-1124.

18. Winkes MB, Hoogeveen AR, Houterman S, Giesberts A, Wijn PF, Scheltinga MR. Compartment pressure curves predict surgical outcome in chronic deep posterior compartment syndrome. Am J Sports Med. 2012;40(8):1899-1905.

19. de Bruijn JA, van Zantvoort APM, Winkes MB, et al. Feasibility and Safety of an Operative Tool for Anterior Chronic Exertional Compartment Syndrome Treatment. Foot Ankle Int. 2015;36(12):1475-1482.

20. Rubin DB, Schenker N. Multiple imputation in health-are databases: An overview and some applications. Statistics in Medicine. 1991;10(4):585-598.

21. Harrell FE, Lee KL, Mark DB. Multivariable prognostic models: issues in developing models, evaluating assumptions and adequacy, and measuring and reducing errors. Statistics in Medicine. 1996;15(4):361-387.

22. Clanton TO, Solcher BW. Chronic leg pain in the athlete. In: Foot and Ankle Injuries. Vol 13. Clinics in Sports Medicine; 1994:743-759.

23. Waterman BR, Liu J, Newcomb R, Schoenfeld AJ, Orr JD, Belmont PJ. Risk factors for chronic exertional compartment syndrome in a physically active military population. Am J Sports Med. 2013;41(11):2545-2549.

24. Howard JL, Mohtadi NG, Wiley JP. Evaluation of outcomes in patients following surgical treatment of chronic exertional compartment syndrome in the leg. Clin J Sport Med. 2000;10(3):176-184.

25. Edmundsson D, Toolanen G, Sojka P. Chronic compartment syndrome also affects nonathletic subjects: a prospective study of 63 cases with exerciseinduced lower leg pain. SORT. 2007;78(1):136-142.

26. Packer JD, Day MS, Nguyen JT, Hobart SJ, Hannafin JA, Metzl JD. Functional outcomes and patient satisfaction after fasciotomy for chronic exertional compartment syndrome. Am J Sports Med. 2013;41(2):430-436.

27. Raikin SM, Rapuri VR, Vitanzo P. Bilateral simultaneous fasciotomy for chronic exertional compartment syndrome. Foot Ankle Int. 2005;26(12):1007-1011.

28. Turnipseed WD. Diagnosis and management of chronic compartment syndrome. Surgery. 2002;132(4):613-619. 


\section{Chapter 2}

29. Mouhsine E, Garofalo R, Moretti B, Gremion G, Akiki A. Two minimal incision fasciotomy for chronic exertional compartment syndrome of the lower leg. Knee Surg Sports Traumatol Arthrosc. 2006;14(2):193-197.

30.Edmundsson D, Toolanen G. Chronic exertional compartment syndrome in diabetes mellitus. Diabet Med. 2011;28(1):81-85.

31. Hislop M, Batt ME. Chronic exertional compartment syndrome testing: a minimalist approach. British Journal of Sports Medicine. 2011;45(12):954-955.

32. Roscoe D, Roberts AJ, Hulse D. Intramuscular Compartment Pressure Measurement in Chronic Exertional Compartment Syndrome: New and Improved Diagnostic Criteria. Am J Sports Med. 2014;43(2):392-398.

33. Roberts A, Franklyn-Miller A. The validity of the diagnostic criteria used in chronic exertional compartment syndrome: a systematic review. Scandinavian Journal of Medicine \& Science in Sports. 2012;22(5):585-595.

34.Paik RS, Pepple DA, Pepples D, Hutchinson MR. Chronic exertional compartment syndrome. BMJ. 2013;346(jan15 2):f33-f33. 
Predictors for chronic exertional compartment syndrome 


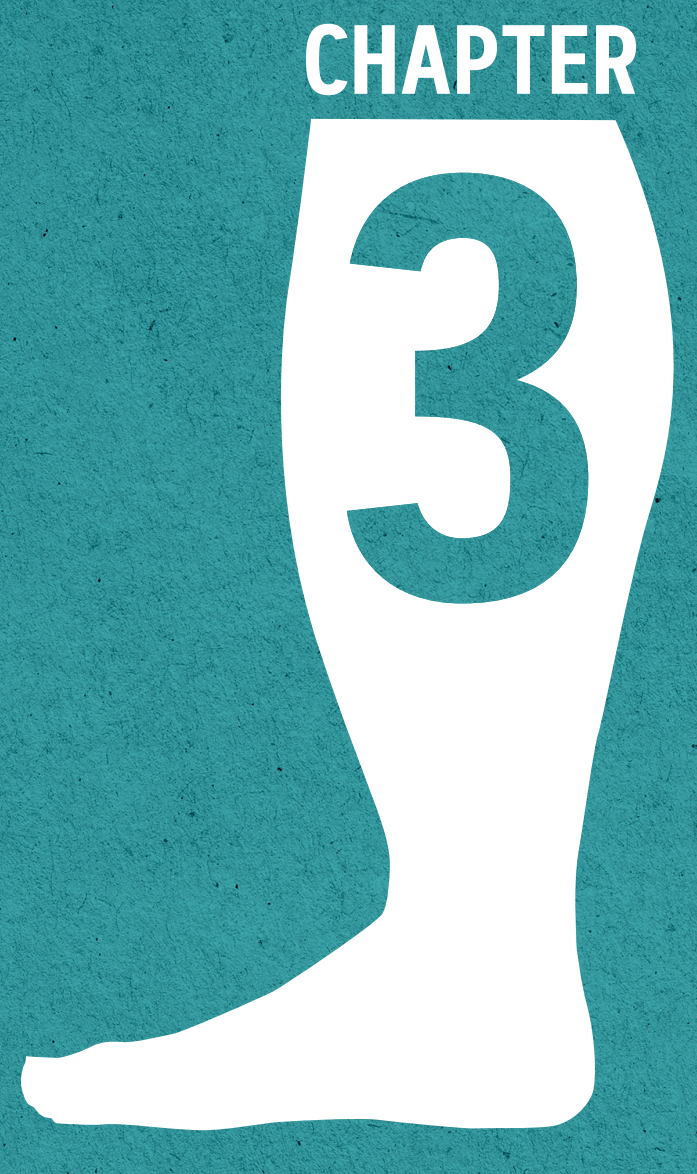




\section{CHAPTER 3}

\section{LOWER LEG CHRONIC}

\section{EXERTIONAL COMPARTMENT}

\section{SYNDROME IN PATIENTS 50}

\section{YEARS OF AGE AND OLDER}

\section{Published in}

Orthopaedic Journal of Sports Medicine, 2018 vol. 6, 2325967118757179

J.A. de Bruijn', A.P.M. van Zantvoort', M.B. Winkes'1, M. van der CruijsenRaaijmakers'², A.R. Hoogeveen², J.A.W. Teijink,4, M.R.M Scheltinga'

1 Department of Surgery, Maxima Medical Center, Veldhoven

2 Department of Sports Medicine, Maxima Medical Center, Veldhoven

3 Department of Surgery, Catharina Hospital, Eindhoven

4 CAPHRI research school, department of epidemiology, Maastricht University 


\section{ABSTRACT}

Background: Lower leg chronic exertional compartment syndrome (CECS) is usually diagnosed in young and athletic individuals. The presence of CECS in older patients has received little attention in the literature and patient characteristics are unknown.

Purpose: To determine the prevalence of CECS in older patients ( $\geq 50$ years) and to assess whether older patients with CECS differ clinically from younger patients with CECS.

Study design: Case-series

Methods: All individuals with exercise-induced lower leg pain who visited a referral center for CECS between January 2001 and December 2013 were eligible for analysis. Patients were included if history, physical examination and dynamic intracompartmental pressure measurement indicated CECS. Characteristics of CECS patients $\geq 50$ years were compared with patients $<50$ years.

Results: A total of 698 CECS patients were included: 98 were 50 years or older, 600 were younger than 50 years. Older individuals more often reported a history of lower leg events or comorbidities ( $\geq 50,45 \%$ vs $<50$, $25 \% ; p<0.01)$ and unilateral symptoms $(\geq 50,45 \%$ vs $<50,22 \% ; p<0.01)$. Most older patients $(62 \%, 51 / 98)$ did not participate in sport or only walked or hiked whereas the same was true of only $7 \%(38 / 600)$ of the younger population. Pain ( $\geq 50,94 \%$ vs $<50,96 \%)$ and tightness $(\geq 50,57 \%$ vs $<50,62 \%$ ) were the predominant symptoms in both groups. Type of CECS differed significantly $(p<0.01)$; the anterior muscle compartment was involved more frequently in older patients ( $\geq 50,82 \%$ vs $<50,58 \%$ ) and deep flexor muscle CECS was more often diagnosed in younger patients $(\geq 50$, $26 \%$ vs $<50,53 \%, p<0.01)$.

Conclusion: In the present population, 1 in 7 patients diagnosed with lower leg CECS was 50 years or older. These individuals were less active and had more comorbidities than CECS patients younger than 50 years. Older individuals predominantly have anterior CECS. Clinicians should consider CECS in older individuals with exercise-induced lower leg pain, particularly if it is unilateral. 


\section{BACKGROUND}

Lower leg chronic exertional compartment syndrome (CECS) is an exerciseinduced condition characterized by pain and tightness. ${ }^{1,2}$ Cramps, muscle weakness and even diminished skin sensation may also be reported. ${ }^{3,4}$ Symptoms usually disappear after 30 minutes of rest. ${ }^{5} \mathrm{~A}$ combination of a characteristic history and physical examination may suggest the diagnosis of CECS and additional diagnostic tests, such as dynamic intracompartmental pressure (ICP) measurements, are used to confirm the diagnosis. ${ }^{6}$

CECS is a condition mainly described in young and active individuals. ${ }^{7}$ Known patient characteristics of patients with CECS are largely based on cohorts of athletes and military personnel. ${ }^{8,9}$ Only two studies report on CECS in older individuals or in patients with comorbidities. ${ }^{10,11}$ Therefore, the occurrence of CECS in older patients with exercise-induced lower leg pain is unknown. Also, characteristics of these older patients with CECS may differ from those of the young and athletic populations with CECS described in the literature.

Our facility is a referral center for individuals with exercise-induced lower leg syndromes. We increasingly see older patients who are diagnosed with lower leg CECS. The aim of the present study is twofold: first, to determine the occurrence of CECS in individuals aged 50 years or older with exerciseinduced lower leg complaints who were evaluated for CECS; and second, to identify potential differences between older and younger individuals with CECS. Results of the study may increase awareness, among health care workers regarding CECS in older patients.

\section{MATERIALS AND METHODS \\ Background}

Máxima Medical Center serves as a referral center for exercise-induced extremity syndromes. ${ }^{12-14}$ Yearly, at a dedicated outpatient facility, our department of Sports Medicine evaluates approximately 225 individuals suspected of having CECS. Patients with exercise-induced symptoms of the extremities are referred by sports physicians, (orthopaedic) surgeons, neurologists, general practitioners or other health workers. All procedures in the current study are in agreement with the declaration of Helsinki and the hospital's medical ethical committee approved the study protocol. 


\section{Consultation and patient selection}

Each patient with exercise-induced lower leg complaints was evaluated by an experienced sports physician. Patients underwent a standardized physical examination including assessment of general health and posture, lower leg inspection, palpation of the muscle compartments and palpation of distal arterial pulses. If CECS was deemed possible based on a suggestive history (predictable lower leg pain and tightness during and/ or after exercise or physical activity) and other diseases were excluded during physical examination, a dynamic intracompartmental pressure (ICP) measurement was performed. Physical examination consisted of inspection and palpation of the legs and, if indicated, assessment of the vascular and nervous system. Pressure was measured only in lower leg compartments that were suspected of having CECS based on the location of the complaints and findings during physical examination. To further minimize the number of invasive measurements and potential complications, only the most symptomatic leg was measured.

ICP was measured initially with the patient in rest and then directly after, 1 minute after and 5 minutes after a standardized provocative treadmill test. If patients were unable to generate sufficient complaints, they were encouraged to hop and/or climb stairs. A more detailed description is given in previous reports. ${ }^{3,15}$ Intracompartmental muscle pressure was considered elevated if it met or exceeded one or more of the following cut-off points: $15 \mathrm{~mm} \mathrm{Hg}$ during rest, $30 \mathrm{~mm} \mathrm{Hg}$ at 1 minute after provocation, or $20 \mathrm{~mm}$ $\mathrm{Hg}$ at 5 minutes thereafter. ${ }^{6}$ Patients received the diagnosis CECS if their history, physical examination and the measured ICP values were consistent with CECS.

All patients evaluated for lower leg CECS between January 2001 and December 2013 were eligible for the present study. Only patients who were diagnosed with CECS based on a suggestive history, a matching physical examination and elevated intracompartmental pressure were included. Some patients were evaluated for CECS more than once during the study period. Only their first visit was included in this study whereas evaluations (including ICP measurement) that followed were excluded. 


\section{Data collection and statistics}

We extracted data from 2 sources and composed 1 comprehensive data file. Between January 2001 and March 2010, we retrieved data from a custom made Microsoft Access database that was supplemented by data from archived paper patient files. Between April 2010 and December 2013, data were retrieved from standard electronic patient hospital files. Only variables that were obtained in more than $50 \%$ of the patients were used in the present study. Peripheral artery disease, venous insufficiency, nerve conditions, major traumatic events or other significant lower leg events and comorbidities were tabulated. The following variables were excluded from this report: influence of complaints on level of sports, activities provoking symptoms and exercise duration before the symptoms began.

Analysis was performed using SPSS Statistics, Windows version 22.0.0.0. When normally distributed, data were expressed as mean \pm SD; nonparametric data were expressed as median (with range). Differences in categorical baseline characteristics were assessed with a chi-square test, and a Mann-whitney test was used to analyze continuous variables (i.e. duration of complaints). A p-value $<0.05$ was considered significant.

\section{RESULTS}

\section{Patient selection}

During the 13-year study period, 1765 patients with exercise-induced lower leg pain were referred to our hospital for evaluation. In 153 patients, history and physical examination suggested a condition other than CECS. After exclusion of 201 patients who were previously evaluated in our hospital for CECS, 1411 unique patients remained. Based on a combination of history, physical examination and elevated ICP, CECS was diagnosed in 698 patients (49\%) (figure 3.1). The prevalence of CECS in evaluated patients who were 50 or older was $38 \%(98 / 255)$, and in patients younger than 50 it was $52 \%$ $(600 / 1156)$. The current report is focused on the 698 patients diagnosed with CECS. 


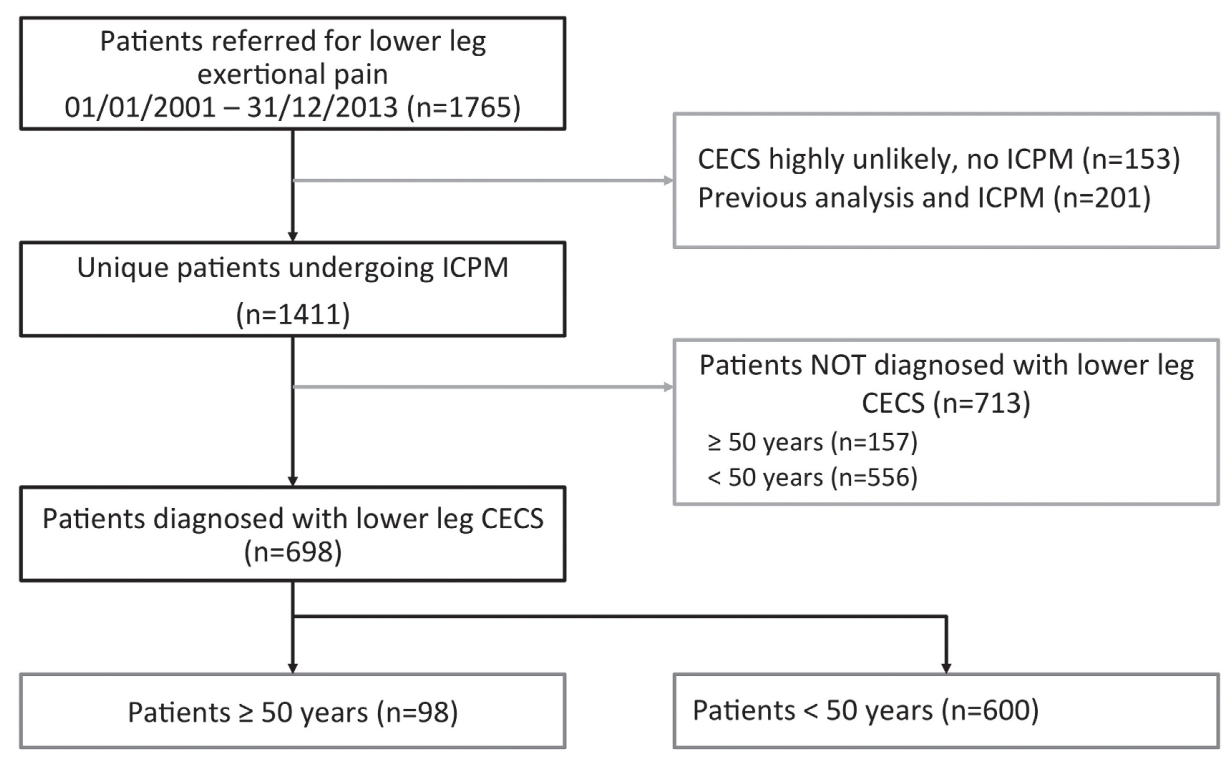

Figure 3.1: Study flow chart of patients evaluated for Chronic Exertional Compartment Syndrome (CECS) in a tertiary referral center, ICPM = intracompartmental pressure measurement

\section{Patient characteristics}

There were no differences in sex and duration of complaints between patients with CECS who were 50 or older $(n=98)$ and patients younger than $50(n=600)$ (Table 3.1). Older patient with CECS more often had relevant comorbidities (peripheral artery disease, venous disease, major nerve conditions, significant boney or soft tissue disorders) (table 3.1). Older patients also had received less physiotherapy ( $57 \%$ vs $80 \%$; $p<0.01$ ) and fewer orthotics ( $47 \%$ vs $62 \% ; p=0.05$ ) than younger patients. Bilateral complaints were seen less often in the older population ( $55 \%$ vs $78 \% ; p<0.01$ ).

\section{Sport activities}

Type and level of sports differed significantly between the older and younger patients with CECS (Table 3.2). Interestingly, 62\% (51/82) of the patients 50 years or older did not participate in sports or were only engaged in hiking or walking. In contrast, the same was true of only $7 \%$ (38/552) of patients younger than 50. Furthermore, patients 50 years or older were significantly less engaged in competitive sports as only $5 \%$ (3/66) practiced sports on a competitive level. Conversely, 69\% (270/392) of the younger patients sported on a competitive or professional level. 
Table 3.1: Characteristics of patients aged $\geq 50$ and $<50$ years diagnosed with lower leg Chronic Exertional Compartment Syndrome (CECS)

\begin{tabular}{lrrrr}
\hline & $\mathbf{2 5 0}$ y & $<\mathbf{5 0} \mathbf{y}$ & Total & p-value \\
\hline Total, $\mathrm{n}(\%)$ & $98(14)$ & $600(86)$ & $698(100)$ & \\
Female sex, n (\%) & $51(52)$ & $301(50)$ & $352(50)$ & 0.74
\end{tabular}

Duration symptoms (months)

Data available, $n$

Median (range)

$24(1-360)$

$18(1-200) \quad 18(1-360)$

0.22

\section{Clinical history}

Data available, $\mathrm{n}$

595

No relevant clinical history, $\mathrm{n}(\%)$

Leg surgery, n (\%)

$52(55)$

378 (75)

430 (72)

$<0.01$ *

Leg trauma, n (\%)

7 (7)

57 (11)

$64(10)$

0.26

$7(7)$

$26(5)$

$33(6)$

0.38

Peripheral artery disease, $\mathrm{n}(\%)$

8 (8)

$0(0)$

8 (1) $<0.01$ *

Peripheral venous disease, $\mathrm{n}(\%)$

$6(6)$

9 (2)

$15(3)<0.01$ *

Other, n (\%)

$14(15)$

$31(6)$

$45(8)<0.01$

Previous conservative treatment

Rest, n (\%)

Cooling, $n(\%)$

Physiotherapy, n (\%)

Orthotic insole (inlay), n (\%)

$28 / 47(60) \quad 238 / 388(61) \quad 266 / 435(61) \quad 0.82$

$4 / 46(9) \quad 43 / 386(11) \quad 47 / 432(11) \quad 0.25$

26/46 (57) 313/391(80) 339/437(78) < 0.01 *

$22 / 47$ (47) 244/395 (62) 266/442 (60) 0.05 *

Bilateral symptoms, n (\%)

$54 / 98(55) \quad 461 / 595(78) \quad 515 / 693(74)<0.01$ *

Physical examination

Tense/painful compartment, n (\%)

$51 / 77$ (66) 337/508 (66) 388/585 (66)

0.99

Painful medial tibia, n (\%)

7/62 (11) $\quad 151 / 424(36) \quad 158 / 486(33)$

$<0.01$ *

The number of patients in whom data were retrievable is either noted in a separate line ("Data available") or placed after a slash. * Statistically significant difference.

\section{Symptoms}

Symptoms were comparable in both groups (Table 3.3). Almost all patients reported pain as their main symptom $(\geq 50,94 \% ;<50,96 \% ; p=0.61)$. Tightness was also present in a majority of patients $(\geq 50,57 \% ;<50,62 \% ; p=0.38)$. Only a minority reported cramps, muscle weakness, and altered skin sensibility (Table 3.3). Physical examination revealed the same proportion of the 2 groups had a tense or painful compartment (both $66 \%, p=0.99$ ). A painful medial tibial rim during palpation was found more often in younger patients $(\geq 50,11 \%$; $<50,36 \%$; $p<0.01)$. 
Table 3.2: Sport activities of patients aged $\geq 50$ and $<50$ years diagnosed with lower leg Chronic Exertional Compartment Syndrome (CECS)

\begin{tabular}{|c|c|c|c|c|}
\hline & $\geq 50 y$ & $<50 y$ & Total & p-value \\
\hline Type of sports & & & & $<0.01$ * \\
\hline Data available, n & $82 / 98$ & $552 / 600$ & $634 / 698$ & \\
\hline None & $22(27)$ & $21(4)$ & $43(7)$ & \\
\hline Soccer & $1(1)$ & $135(24)$ & $136(21)$ & \\
\hline Running & $6(7)$ & $119(22)$ & $125(20)$ & \\
\hline Walking/Hiking & $29(35)$ & $17(3)$ & $46(7)$ & \\
\hline Hockey & $0(0)$ & $45(8)$ & $45(7)$ & \\
\hline Skating & $4(5)$ & $28(5)$ & $32(5)$ & \\
\hline Gym/fitness lessons & $7(9)$ & $20(4)$ & $27(4)$ & \\
\hline Military service & $O(0)$ & $22(4)$ & $22(3)$ & \\
\hline Handball & $O(0)$ & $21(4)$ & $21(3)$ & \\
\hline Athletics & $O(0)$ & $16(3)$ & $16(3)$ & \\
\hline Cycling & $7(9)$ & $9(2)$ & $16(3)$ & \\
\hline Volleyball & $1(1)$ & $13(2)$ & $14(2)$ & \\
\hline Tennis & $3(4)$ & $9(2)$ & $12(2)$ & \\
\hline Dancing & $1(1)$ & $11(2)$ & $12(2)$ & \\
\hline Professional trainers & $0(0)$ & $10(2)$ & $10(2)$ & \\
\hline Martial art & $0(0)$ & $9(2)$ & $9(1)$ & \\
\hline Korfball & $0(0)$ & $9(2)$ & $9(1)$ & \\
\hline Gymnastics & $0(0)$ & $8(1)$ & $8(1)$ & \\
\hline Swimming & $0(0)$ & $5(1)$ & $5(1)$ & \\
\hline Rugby & $0(0)$ & $4(1)$ & $4(1)$ & \\
\hline Badminton & $O(0)$ & $4(1)$ & $4(1)$ & \\
\hline Basketball & $0(0)$ & $4(1)$ & $4(1)$ & \\
\hline Baseball & $0(0)$ & $3(1)$ & $3(0)$ & \\
\hline Triathlon & $O(0)$ & $3(1)$ & $3(0)$ & \\
\hline Squash & $O(0)$ & $2(0)$ & $2(0)$ & \\
\hline Canoeing & $O(0)$ & $2(0)$ & $2(0)$ & \\
\hline Golf & $1(1)$ & $O(0)$ & $1(0)$ & \\
\hline Wakeboarding & $0(0)$ & $1(0)$ & $1(0)$ & \\
\hline Skiing & $0(0)$ & $1(0)$ & $1(0)$ & \\
\hline Yoga & $0(0)$ & $1(0)$ & $1(0)$ & \\
\hline
\end{tabular}

Level of sport participation 
Table 3.2: Continued

\begin{tabular}{|c|c|c|c|c|}
\hline & $\geq 50 y$ & $<50 y$ & Total & p-value \\
\hline Data available, $\mathrm{n}$ & $66 / 98$ & $392 / 600$ & $458 / 698$ & \\
\hline None & $22(33)$ & $21(5)$ & $43(9)$ & \\
\hline Social & $41(62)$ & $101(26)$ & $142(31)$ & \\
\hline Local competitive & $2(3)$ & $190(48)$ & $192(42)$ & \\
\hline National competitive & $1(2)$ & $35(9)$ & $36(8)$ & \\
\hline International competitive & $\mathrm{O}(0)$ & $11(3)$ & $11(2)$ & \\
\hline Professional, \# & $0(0)$ & $34(9)$ & $34(7)$ & \\
\hline
\end{tabular}

The number of patients for whom data were retrievable is noted in a separate line ("Data available"). Otherwise, data are reported as n(\%). * Statistically significant difference. \# Professional level consists of military service members, professional trainers, 1 police officer, and 1 waiter.

Table 3.3: Symptoms and physical examination in patients aged $\geq 50$ and $<50$ years diagnosed with lower leg Chronic Exertional Compartment Syndrome (CECS)

\begin{tabular}{lrrrr}
\hline & $\mathbf{2 0} \mathbf{y}$ & $<\mathbf{5 0} \mathbf{y}$ & Total & P-value \\
\hline Symptoms & & & & \\
Pain & $84 / 89(94)$ & $458 / 479(96)$ & $542 / 568(95)$ & 0.61 \\
Tightness & $38 / 67(57)$ & $221 / 352(62)$ & $259 / 421(62)$ & 0.38 \\
Cramps & $15 / 67(22)$ & $101 / 344(29)$ & $116 / 411(28)$ & 0.24 \\
Altered sensation & $15 / 67(22)$ & $59 / 347(17)$ & $74 / 414(18)$ & 0.29 \\
Muscle weakness & $11 / 67(16)$ & $42 / 345(12)$ & $53 / 412(13)$ & 0.34 \\
Physical examination & & & & \\
Tense/painful compartment & $51 / 77(66)$ & $337 / 508(66)$ & $388 / 585(66)$ & 0.99 \\
Painful medial tibia & $7 / 62(11)$ & $151 / 424(36)$ & $158 / 486(33)$ & $<0.01$ * \\
Affected lower leg muscle compartment & & & $<0.01$ * \\
Isolated anterior & $63(64)$ & $237(40)$ & $300(43)$ & \\
Isolated deep flexor & $17(17)$ & $222(37)$ & $239(34)$ & \\
Isolated lateral & $1(1)$ & $18(3)$ & $19(3)$ & \\
Anterior + deep flexor & $6(6)$ & $75(13)$ & $81(12)$ & \\
Anterior + lateral & $9(9)$ & $26(5)$ & $35(5)$ & \\
Deep flexor + lateral & $0(0)$ & $7(1)$ & $7(1)$ & \\
Anterior + deep flexor + lateral & $2(2)$ & $15(3)$ & $17(2)$ & \\
\hline A & & & &
\end{tabular}

All results are presented as $n(\%)$. The number of patients for whom data were retrievable is placed after a slash. * Statistically significant difference. 

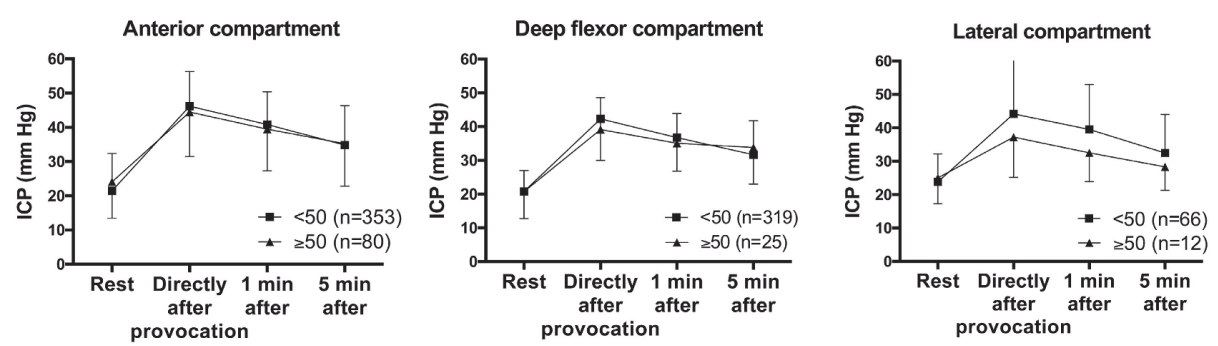

Figure 3.2: Lower leg muscle intracompartmental pressures (ICPs) before and after a standard provocative treadmill test in patients with Chronic Exertional Compartment Syndrome (CECS) who were aged $\geq 50$ and $<50$ years. For each separate compartment we included only patients diagnosed with CECS in that specific compartment.

\section{Affected compartments}

A statistically significant difference was found between older and younger patients with respect to the affected lower leg muscle compartment(s) (Table 3.3). Most older patients (82\%) were diagnosed with anterior CECS (either isolated or in combination with other compartments) whereas just $26 \%$ of the older patients were diagnosed with deep flexor CECS. In contrast, $59 \%$ of the younger patients were diagnosed with anterior CECS whereas $53 \%$ were diagnosed with deep flexor CECS. In both age groups, a similar proportion was diagnosed with lateral CECS ( $\geq 50,12 \%$; $<50,11 \%$ ). ICP data regarding the anterior, deep flexor and lateral compartment were comparable between the 2 groups of patients (Figure 3.2).

\section{DISCUSSION}

Current knowledge of CECS is almost exclusively based on cohorts of young and athletic individuals. ${ }^{8,9}$ However, the condition has occasionally been reported in slightly older patients or in patients with comorbidities. ${ }^{10,11}$ The prevalence of CECS in persons over 50 years is unknown. The present study demonstrates that CECS is not limited to young and active individuals as $14 \%(98 / 698)$ of all patients diagnosed with CECS at our facility were 50 years or older. Although these older patients with CECS mostly refrained from (competitive) sports, we suspect that increased physical activity due to increased available leisure time may induce complaints. Moreover, patients 50 years or older more often had unilateral complaints and the deep flexor compartment was seldom involved. 
CECS is often overlooked as the cause for exercise-induced lower leg pain. For instance, diagnostic delay in one study was up to seven years. ${ }^{16}$ The duration of exertional pain was 4 years in a second study of diabetic patients with CECS whose age ranged from 18 to 72 years. ${ }^{10}$ During this period, these patients with undiagnosed CECS may have undergone a host of diagnostic tests and treatments. In the absence of a diagnosis explaining their exertional leg pain, patients may curtail their physical activity. Diminished participation in sports and exercise may result in a decreased health status and quality of life. ${ }^{17}$ The present study also found an extended delay in some older patients (up to 360 months) prior to arriving at the diagnosis, although this difference with younger patients was not statistically significant (median 24 vs 18 months). Therefore, awareness among health care providers for the potential presence of CECS in any age group must be improved.

The majority of CECS studies report on cohorts of highly active individuals, most of whom participate in competitive sportive activities. ${ }^{8}$ The present report demonstrates that CECS may also occur in older patients who are not necessarily engaged in competitive sports. Most patients had complaints during everyday activities or during hiking or walking. Although these patients do not participate in competitive sports they are relatively active. We hypothesize that these older individuals increased their physical activities as leisure time became more available for them. Most studies found that patients with CECS do not have any relevant comorbidities or a history of lower leg abnormality. ${ }^{4,18}$ In contrast, the only 2 studies describing older patients with CECS found that a significant proportion of these patients reported relevant co-morbidities such as diabetes, cardiovascular disease or previous trauma. 10,11 As might be expected, the present study also found that rates of earlier lower leg surgery, trauma or relevant comorbidities were higher in the population 50 years or older than in the population younger than 50 years. Hence, we emphasize that comorbidities or previous lower leg events such as surgery do not exclude the presence of CECS in older patients.

At present, uniformity is lacking in regard to describing frequency and intensity of symptoms associated with CECS. However, exertional pain is universally accepted as the dominant symptom..$^{19-21}$ Two studies in older CECS patients found that all patients experienced pain, whereas only a 
minority experienced tightness, cramps, muscle weakness or altered skin sensation. ${ }^{10,11}$ The present study confirms these findings. Interestingly, these five symptoms were seen in similar rates in the older and younger population. In the present study population, pain (95\%) and tightness (62\%) characterized CECS both in older and younger patients.

Individuals with lower leg CECS have been reported to have predominantly bilateral anterior compartment involvement.7,22 The two studies in older patients with CECS also reported predominantly involvement of the anterior compartment. ${ }^{10,11}$ However, deep-flexor CECS is common, as recognized in recent reports. ${ }^{5}$ In the present population, $82 \%$ of all older patients had involvement of the anterior compartment, whereas this percentage was limited to little over half of the younger patients. Conversely, only 1 in 4 older patients had involvement of the deep flexor compartment, compared with more than half of the younger patients. We found a higher prevalence of unilateral complaints in older CECS patients (45\%) than in younger patients (22\%). The rate of unilateral complaints in our older population is remarkably higher than in other studies. ${ }^{23-25}$ We suspect that this high rate of unilateral CECS may be related to a higher rate of mainly unilateral comorbidities in our older patients with CECS. Unfortunately, the current dataset is too limited to explore this potential relation.

Our study has some limitations. Its retrospective design limited the number of variables we were able to include in the analysis, and missing data may have introduced information bias. Furthermore, the retrospective design obstructs us from thoroughly exploring relations between several variables. Operative results and outcome data were not available as most patients were treated in other hospitals. In the absence of operative results, ICP measurements were used to confirm the diagnosis CECS. The absolute role of elevated ICP measurements is currently under debate. ${ }^{26-28}$ However, we believe that a combination of a suggestive history, physical examination and elevated ICP values is sufficient to diagnose patients with CECS. Last, because we are a referral center, our population is highly selected and the incidence of CECS in other populations of patients with exercise-induced lower leg pain may be lower.

In conclusion, CECS may occur in individuals 50 years or older with exerciseinduced lower leg pain. These patients are less active and more often have 
sustained previous lower leg events or comorbidities than younger patients with CECS. In older individuals, CECS is more often localized in the anterior compartment rather than the deep flexor compartment. Clinicians should be aware that lower leg exertional pain in older patients may be caused by CECS. These patients may present differently than younger patients with CECS. 


\section{REFERENCES}

1. Blackman PG. A review of chronic exertional compartment syndrome in the lower leg. Medicine \& Science in Sports \& Exercise. 2000;32(3 Suppl):S4-S10.

2. Brennan FH, Kane SF. Diagnosis, treatment options, and rehabilitation of chronic lower leg exertional compartment syndrome. Curr Sports Med Rep. 2003;2(5):247-250.

3. Winkes MB, Hoogeveen AR, Houterman S, Giesberts A, Wijn PF, Scheltinga MR. Compartment pressure curves predict surgical outcome in chronic deep posterior compartment syndrome. Am J Sports Med. 2012;40(8):1899-1905.

4. Dunn JC, Waterman BR. Chronic exertional compartment syndrome of the leg in the military. Clinics in Sports Medicine. 2014;33(4):693-705.

5. Winkes MB, van Zantvoort APM, de Bruijn JA, et al. Fasciotomy for Deep Posterior Compartment Syndrome in the Lower Leg: A Prospective Study. Am J Sports Med. 2016;44(5):1309-1316.

6. Pedowitz RA, Hargens AR, Mubarak SJ, Gershuni DH. Modified criteria for the objective diagnosis of chronic compartment syndrome of the leg. American Journal of Sports Medicine. 1990;18(1):35-40.

7. Davis DE, Raikin S, Garras DN, Vitanzo P, Labrador H, Espandar R. Characteristics of patients with chronic exertional compartment syndrome. Foot Ankle Int. 2013;34(10):1349-1354.

8. Clanton TO, Solcher BW. Chronic leg pain in the athlete. In: Foot and Ankle Injuries. Vol 13. Clinics in Sports Medicine; 1994:743-759.

9. Waterman BR, Liu J, Newcomb R, Schoenfeld AJ, Orr JD, Belmont PJ. Risk factors for chronic exertional compartment syndrome in a physically active military population. Am J Sports Med. 2013;41(11):2545-2549.

10. Edmundsson D, Toolanen G. Chronic exertional compartment syndrome in diabetes mellitus. Diabet Med. 2011;28(1):81-85.

11. Edmundsson D, Toolanen G, Sojka P. Chronic compartment syndrome also affects nonathletic subjects: a prospective study of 63 cases with exerciseinduced lower leg pain. SORT. 2007;78(1):136-142.

12. Schep G, Bender MHM, van de Tempel G, Wijn PFF, de Vries WR, Eikelboom BC. Detection and treatment of claudication due to functional iliac obstruction in top endurance athletes: a prospective study. Lancet. 2002;359(9305):466-473.

13. Winkes MB, Luiten EJT, van Zoest WJF, Sala HA, Hoogeveen AR, Scheltinga MR. Long-term results of surgical decompression of chronic exertional compartment syndrome of the forearm in motocross racers. Am J Sports Med. 2012;40(2):452458.

14. van Zoest W, Hoogeveen A, Scheltinga M, Sala H, van Mourik J, Brink P. Chronic Deep Posterior Compartment Syndrome of the Leg in Athletes: Postoperative Results of Fasciotomy. Int J Sports Med. 2008;29(5):419-423. 
15. de Bruijn JA, van Zantvoort APM, Winkes MB, et al. Feasibility and Safety of an Operative Tool for Anterior Chronic Exertional Compartment Syndrome Treatment. Foot Ankle Int. 2015;36(12):1475-1482.

16. Rorabeck CH, Fowler PJ, Nott L. The results of fasciotomy in the management of chronic exertional compartment syndrome. American Journal of Sports Medicine. 1988;16(3):224-227.

17. Paik RS, Pepple DA, Pepples D, Hutchinson MR. Chronic exertional compartment syndrome. BMJ. 2013;346(jan15 2):f33-f33.

18. Tucker AK. Chronic exertional compartment syndrome of the leg. Curr Rev Musculoskelet Med. 2010;3(1-4):32-37.

19. Slimmon D, Bennell K, Brukner P, Crossley K, Bell SN. Long-term outcome of fasciotomy with partial fasciectomy for chronic exertional compartment syndrome of the lower leg. American Journal of Sports Medicine. 2002;30(4):581588.

20. Rorabeck $\mathrm{CH}$, Bourne RB, Fowler PJ. The surgical treatment of exertional compartment syndrome in athletes. J Bone Joint Surg Am. 1983;65(9):1245-1251.

21. Micheli LJ, Solomon R, Solomon J, Plasschaert VF, Mitchell R. Surgical treatment for chronic lower-leg compartment syndrome in young female athletes. American Journal of Sports Medicine. 1999;27(2):197-201.

22. Turnipseed WD. Diagnosis and management of chronic compartment syndrome. Surgery. 2002;132(4):613-619.

23. Detmer DE, Sharpe K, Sufit RL, Girdley FM. Chronic compartment syndrome: diagnosis, management, and outcomes. American Journal of Sports Medicine. 1985;13(3):162-170.

24. Howard JL, Mohtadi NG, Wiley JP. Evaluation of outcomes in patients following surgical treatment of chronic exertional compartment syndrome in the leg. Clin J Sport Med. 2000;10(3):176-184.

25. Campano D, Robaina JA, Kusnezov N, Dunn JC, Waterman BR. Surgical Management for Chronic Exertional Compartment Syndrome of the Leg: A Systematic Review of the Literature. Arthroscopy. 2016;32(7):1478-1486.

26. Hislop M, Batt ME. Chronic exertional compartment syndrome testing: a minimalist approach. British Journal of Sports Medicine. 2011;45(12):954-955.

27. Roscoe D, Roberts AJ, Hulse D. Intramuscular Compartment Pressure Measurement in Chronic Exertional Compartment Syndrome: New and Improved Diagnostic Criteria. Am J Sports Med. 2014;43(2):392-398.

28. Roberts A, Franklyn-Miller A. The validity of the diagnostic criteria used in chronic exertional compartment syndrome: a systematic review. Scandinavian Journal of Medicine \& Science in Sports. 2012;22(5):585-595. 


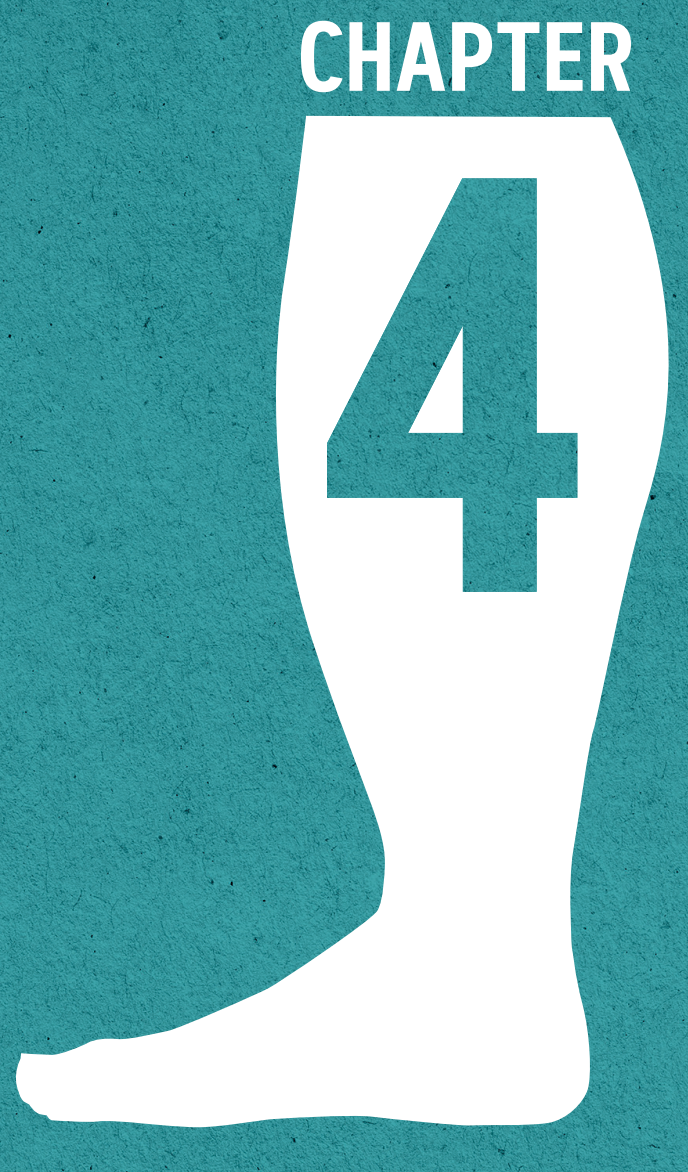




\section{CHAPTER 4}

\section{EXERCISE INDUCED}

\section{LEG PAIN IN PATIENTS}

\section{OLDER THAN 50 YEARS:}

\section{PERIPHERAL ARTERIAL DISEASE OR CHRONIC EXERTIONAL COMPARTMENT SYNDROME?}

\section{Under review}

J.A. de Bruijn', K.C.A. Wijns', S.M.J. van Kuijk², A.R. Hoogeveen³, J.A.W.

Teijink $^{4,5}$, M.R.M Scheltinga'

1 Department of Surgery, Maxima Medical Center, Veldhoven, Veldhoven, The Netherlands

2 Department of Clinical Epidemiology and Medical Technology Assessment, MUMC+, Maastricht;

3 Department of Sports Medicine, Maxima Medical Center, Veldhoven, The Netherlands

4 Department of Surgery, Catharina Hospital, Eindhoven

5 Department of Epidemiology and Caphri Research School, Maastricht University, Maastricht, The Netherlands 


\section{ABSTRACT}

Background: Peripheral arterial disease (PAD) and chronic exertional compartment syndrome (CECS) both cause exercise-induced pain. CECS is mostly described in young individuals and may therefore not be considered in older patients with intermittent claudication (IC).

Objectives: To identify differences in characteristics and symptomatology between patients with CECS and PAD that may help in recognizing CECS in patients $\geq 50$ years with exercise induced lower leg pain.

Design: case-control study

Materials and methods: Since January 2013, patients diagnosed with CECS are asked to complete a questionnaire assessing frequency and severity of lower leg pain, tightness, cramps, muscle weakness and altered sensation during rest and exercise. CECS patients $\geq 50$ years were selected and compared with a sample of newly diagnosed PAD patients $\geq 50$ years who completed a similar questionnaire.

Results: During rest, CECS patients ( $n=43,42 \%$ female, 57 years, range 50-76) reported significantly more pain, tightness, muscle weakness and altered lower leg skin sensation (all $p<0.01)$ than PAD patients $(n=41$, $39 \%$ female, 72 years, range 51-93). Having CECS was associated with a significantly higher combined symptom score in rest $(p=0.02)$. During exercise, CECS patients experienced more tightness, muscle weakness and altered sensation $(p<0.01)$ but not pain and cramps $(p=0.36, p=0.70)$. Exercise induced complaints occurred much later in CECS patients than in PAD (15 vs 4 minutes, $\mathrm{p}<0.01$ ). Persistence of pain over 4.5 minutes proved most discriminative for the presence of CECS (sensitivity $95 \%$, specificity 54\%, PPV 65\%). Cessation completely alleviated complaints in all PAD patients $(n=41)$ but not in $73 \%(n=29)$ of the CECS patients. Ongoing discomfort strongly predicted the presence of CECS (sensitivity $73 \%$, specificity $100 \%$, PPV 100\%).

Conclusions: CECS patients $\geq 50$ years report a symptom pattern that is different from patients with PAD. These differences may aid vascular surgeons in identifying older patients with CECS. 


\section{INTRODUCTION}

The differential diagnosis of exercise-induced lower leg pain is primarily determined by age. In older patients, pain and discomfort following mild exertion are often referred to as intermittent claudication (IC). If orthopedic or neurological disorders are excluded, IC is mostly caused by lower extremity peripheral arterial disease (PAD). ${ }^{1}$ PAD is extremely rare in patients younger than 50 years but its prevalence increases to $14,5 \%$ in individuals over 70 years. $^{2}$

In individuals younger than 50 years however, exercise induced leg pain is rarely due to PAD. In these individuals, a variety of other vascular (popliteal artery entrapment syndrome (PAES), iliac endofibrosis, polycystic adventitial disease) and nonvascular entities (medial tibial stress syndrome (MTSS), nerve entrapments) may cause symptoms during exercise. ${ }^{3-7}$ Exerciseinduced leg pain may also be due to a chronic exertional compartment syndrome (CECS). In CECS patients, pain arises shortly after initiation of exercise and declines again after cessation. ${ }^{8,9}$ Additional complaints such as tightness, cramps, muscle weakness or altered leg/foot skin sensation are also reported..$^{10}$ Findings during physical examination are usually not sensitive and distal arterial pulsations are normal.11

Although both PAD and CECS are associated with exercise induced pain, PAD patients are usually older and often report risk factors such as smoking, hypercholesterolemia and inactivity. ${ }^{12}$ Conversely, CECS is described mostly in young and active individuals, particularly athletes and military personnel..$^{13,14}$ Reports describing CECS in older non-athletic individuals and diabetics are scarce. ${ }^{15,16}$ Due to these contrasting patient populations, CECS may be overlooked as a cause of exercise induced lower leg pain in older patients.

Our hospital serves as a national referral center for exercise induced lower leg pain and is exposed to large volumes of individuals with lower leg CECS. Our vascular surgeons actively participate in the management of these CECS patients. As a consequence, CECS is regularly diagnosed in older patients who were previously suspected of having lower extremity PAD. In addition, we found that older CECS patient often have less specific characteristics than their younger counterparts. ${ }^{17}$ The present study aimed to compare these older CECS patients with PAD patients. By identifying 
similarities and differences in patient characteristics and symptoms, we hope to improve recognition of CECS in older patients and aid vascular surgeons in determining which patients require consultation of a sports physician.

\section{MATERIALS AND METHODS}

Maxima Medical Center (MMC), Veldhoven/Eindhoven, the Netherlands is a hospital that provides general care in a mixed rural and urban area in the southeastern part of the Netherlands. The department of sport medicine serves as a tertiary referral center for exercise-induced leg syndromes. ${ }^{4,18}$ As such, a wide variety of patients with conditions such as CECS, MTSS, nerve entrapments, and iliac endofibrosis both from within and outside our catchment area are evaluated at an outpatient clinic. Our research group has a special focus on CECS and includes sports physicians and (vascular) surgeons.

\section{Patient selection}

The current study consists of two samples. The first is composed of patients aged 50 years or older who were diagnosed with CECS between January 2013 and March 2018. Starting January 2013, each patient who was evaluated for CECS was asked to complete a standardized questionnaire. For the current study, only individuals aged 50 years or older who completed this questionnaire were selected. Individuals who at the time of evaluation had pathology potentially interfering with the clinical picture ( $P A D$, venous insufficiency, neurological conditions, or significant previous leg trauma or surgery) were excluded.

The second sample is composed of patients with IC who were diagnosed with PAD between November 2017 and December 2018. All patients were seen by a single nurse practitioner who evaluated patients with IC complaints under the direct supervision of a vascular surgeon. Patients with advanced PAD (rest pain and wounds) were evaluated elsewhere. Patients were eligible if they had leg PAD and completed the same questionnaire as mentioned above. Individuals were excluded when complaints included the upper legs, were limited to just the upper leg or gluteal muscle, if they were unable to complete the questionnaire, if they had interfering leg comorbidity (such as orthopedic or neurological disorders), if time between questionnaire and vascular testing was over 4 months, if they were younger 
than 50 years, or if additional tests were inconclusive. All consecutively evaluated PAD patients who fulfilled inclusion criteria and were willing to participate were asked to participate until group size approximated the number of CECS patients.

\section{Diagnostic steps in both patient groups}

Patients suspected of having CECS were assessed by two experienced sports physicians. History and symptoms were evaluated and a physical examination was aimed at finding signs traditionally associated with CECS such as a tender muscle compartment upon palpation. Legs were examined to rule out chronic arterial (or venous) insufficiency. On indication, a pedal pulse test and a brief neurological examination were performed. When history and physical examination were suggestive of CECS, a dynamic intracompartmental pressure measurement (ICP) was performed using a previously described slit-catheter technique. ${ }^{19}$ For this test, symptoms were provoked with a standardized treadmill test during which patients were instructed to walk or run until the characteristic symptoms emerged. If this provocation was inconclusive or insufficient, they were instructed to hop, walk on their toes, climb stairs or walk on their heels until painful sensations occurred. We considered intramuscular pressure pathologically elevated if it exceeded one or more of the following cut-off points: $\geq 15 \mathrm{~mm}$ $\mathrm{Hg}$ in rest, $\geq 30 \mathrm{~mm} \mathrm{Hg} 1$ minute after provocation, or $\geq 20 \mathrm{~mm} \mathrm{Hg} 5$ minutes thereafter. ${ }^{20}$ Patients were diagnosed with a leg CECS when their history and physical examination were suggestive and intramuscular pressure surpassed one or more of the cut-off points.

Patients with IC complaints potentially having PAD underwent physical examination aimed at finding primary (reduced femoral artery, popliteal artery, posterior tibial artery and/or dorsal pedal artery pulsations) or secondary signs of arterial insufficiency (skin and nail abnormalities). Also, symptoms, characteristics and potential comorbidities were tabulated. When history and physical examination were consistent with the diagnosis $P A D$, ankle brachial systolic pressure index ( $A B I)$ was performed during a standardized treadmill test. A rest $A B I$ below 0.90 or a drop larger than $15 \mathrm{~mm} \mathrm{Hg}$ following walking were required for the diagnosis PAD. If the $A B I$ was inconclusive, ultrasonography, magnetic resonance angiography (MRA) or computed tomography angiography (CTA) were performed to detect peripheral arterial stenoses. Patients were diagnosed with PAD when 
history and physical examination were consistent with arterial insufficiency and $\mathrm{ABI}$ (or ultrasonography, MRA or CTA) confirmed the diagnosis.

\section{Questionnaire}

All patients included in the current study completed a similar questionnaire. It was initially designed to assess symptoms associated with CECS and was handed over to all patients who were evaluated for CECS at the department of sports medicine since January 2013. Pain, tightness, cramps, muscle weakness and altered sensation are rated in rest and during exercise on a 5 -point verbal rating scale (VRS) in terms of intensity (no, mild, moderate, severe, extremely severe) and frequency (never, sometimes, half of the time, most of the time, always). Intensity (score 0-4) and frequency (score 0-4) of each symptom were combined in a symptom score (intensity*frequency, range $0-16$ ). In addition, we calculated a combined symptom score as a measure of total complaint burden in rest and during exercise (pain score + tightness score + cramp score + muscle weakness score + altered sensation score, range $0-80$ ). Patients were also asked to estimate time from initiation of exercise until onset of complaints, and whether and how long symptoms continued after cessation of the provocative activity. Furthermore, the time between starting of complaints and diagnosis was assessed. A similar questionnaire was presented to patients with exercise-induced complaints due to PAD. These patient-reported outcome measurements were supplemented with data extracted from the digital hospital patient file.

\section{Statistical methods and ethical aspects}

All analyses were performed with IBM SPSS statistics, version 22.0.0.0. Data are expressed as mean ( \pm SD and range) when normally distributed, or as median (with range) if skewed. Potential differences in patient characteristics were assessed with a chi square test (nominal variables) or a T-test (continuous variables). Time from initiation of the provocative activity until onset of complaints and symptom scores were compared using a Mann-Whitney $U$ test. We used the receiver operating characteristic (ROC) curve to determine the most discriminative (highest sensitivity and specificity) time from initiation of the activity until onset of complaints. Once determined, the positive predictive value (PPV) of the diagnosis CECS was calculated. Differences regarding the continuation of complaints following cessation of the provocative activity were assessed with a Fisher's exact test. The PPV of persistent complaints after cessation of the provocative 
activity for the diagnosis CECS was also calculated. Associations between either CECS or PAD and the height of the combined symptom score in rest and during exercise were assessed using multivariate linear regression. Prior to analyses, we identified gender, age, duration of complaints and bilaterality as potential confounders and corrected for these variables. We did not correct for comorbidities known to play an important role in the pathogenesis of PAD (i.e. hypertension, hypercholesterolemia, diabetes mellitus) or for previous treatment of venous and/or arterial insufficiency.

All procedures performed in this study are in accordance with the ethical standards of our institutional research committee and with the declaration of Helsinki. The local medical ethical committee judged that the rules laid down in the Medical Research Involving Human Subjects Act (WMO) did not apply to the study protocol.

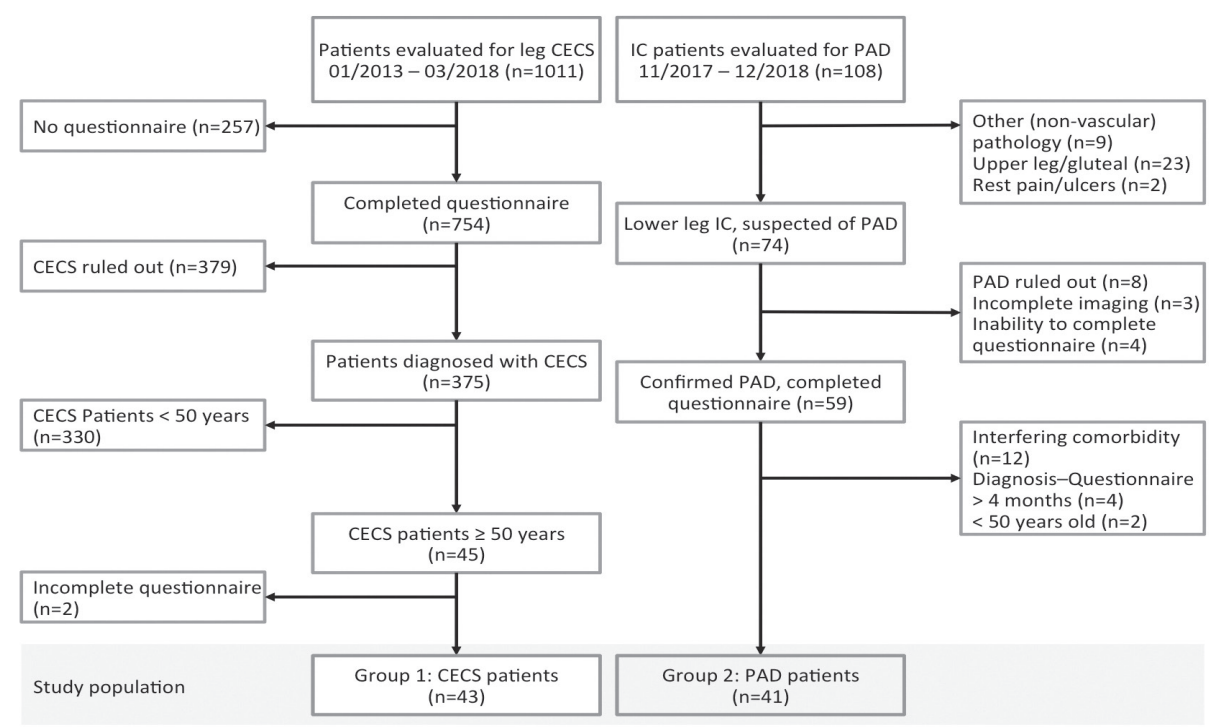

Figure 4.1: Patient selection. Chronic Exertional Compartment syndrome (CECS), Intermittent claudication (IC), Peripheral arterial disease (PAD). Interfering comorbidities were neurological $(n=9)$, polymyalgia rheumatica $(n=2)$ or gonartrosis $(n=1)$.

\section{RESULTS}

Between January 2013 and March 2018, we evaluated 1011 patients for CECS at our department of sports medicine. Of the 754 patients who completed a questionnaire, 375 were diagnosed with CECS (figure 4.1). A total of 45 
(12\%) were 50 years or older. As some items of the questionnaire were missing in two patients, 43 CECS patients were included in the current study.

A total of 108 subsequent patients during a 14 month-period were evaluated by the nurse practitioner under the guidance of the vascular surgeon. Lower leg PAD was confirmed in 63 patients, of whom 59 completed the questionnaire. As 18 patients were excluded due to interfering leg comorbidities ( $n=12)$, a prolonged period ( $>4$ months) between completion of the questionnaire and diagnosis (as confirmed by $A B I$ or vascular imaging, $n=4)$ or age below 50 years $(n=2)$, the PAD group consists of 41 patients. Mean rest $A B I$ of the most symptomatic leg was $0.62 \pm 0.17 \quad(n=40$, range 0.18-0.90) and mean $A B I$ after exercise was $0.33 \pm 0.17(n=34$, range 0.090.77). Based on the criteria mentioned above (rest $A B I<0.9$ or $>15 \mathrm{~mm} \mathrm{Hg}$ drop after exercise) 39 patients were diagnosed with PAD. Two additional patients did not fulfill these criteria but had significant reduced arterial flow (ultrasound, $\mathrm{n}=1$ ) or significant stenoses (MRA, $\mathrm{n}=1$ ) and were also included. As such, the PAD group included 41 patients.

Table 4.1: Characteristics of patients with exercise induced lower leg pain due to Chronic Exertional Compartment Syndrome (CECS) or Peripheral Artery Disease (PAD)

\begin{tabular}{llrrr}
\hline & & CECS & PAD & \\
& & $(\mathrm{n}=43)$ & $(\mathrm{n}=41)$ & $\mathrm{p}$-value \\
\hline Age & years, median (range) & $57(50-76)$ & $72(51-93)$ & $<0.001$ * \\
Gender & female, $\mathrm{n}(\%)$ & $18(42)$ & $16(39)$ & 0.79 \\
Duration of complaints & months, median (range) & $36(1-360)$ & $6(1-96)$ & $<0.001$ * \\
Bilateral complaints & $\mathrm{n}(\%)$ & $22(51)$ & $16(39)$ & 0.26 \\
Hypertension & $\mathrm{n}(\%)$ & $12(29)$ & $30(73)$ & $<0.001$ * \\
Hypercholesterolemia & $\mathrm{n}(\%)$ & $13(31)$ & $23(56)$ & 0.02 \\
Diabetes Mellitus & $\mathrm{n}(\%)$ & $3(7)$ & $7(17)$ & 0.17 \\
Cardiovascular disease & $\mathrm{n}(\%)$ & $10(24)$ & $16(39)$ & 0.14 \\
Previous treatment VI & $\mathrm{n}(\%)$ & $5(12)$ & $1(2)$ & 0.10 \\
Previous treatment PAD & $\mathrm{n}(\%)$ & $4(9)$ & $14(34)$ & 0.01 * \\
\hline
\end{tabular}

Venous insufficiency $(\mathrm{VI})$. Statistically significant differences are marked with *

\section{Patient characteristics}

Patient characteristics are provided in table 4.1. Even though only individuals $\geq 50$ years were selected, CECS patients were still 15 years younger on average (57 years, range 50-76) than PAD patients (72 years, range 51- 
93). Gender distribution and number of patients with bilateral complaints were not different between groups. Strikingly, diagnostic delay was six times longer in patients with CECS (CECS 36 months vs PAD 6 months). As expected, comorbidities such as hypertension and hypercholesterolemia were more prevalent abundant in the PAD group.

Rest

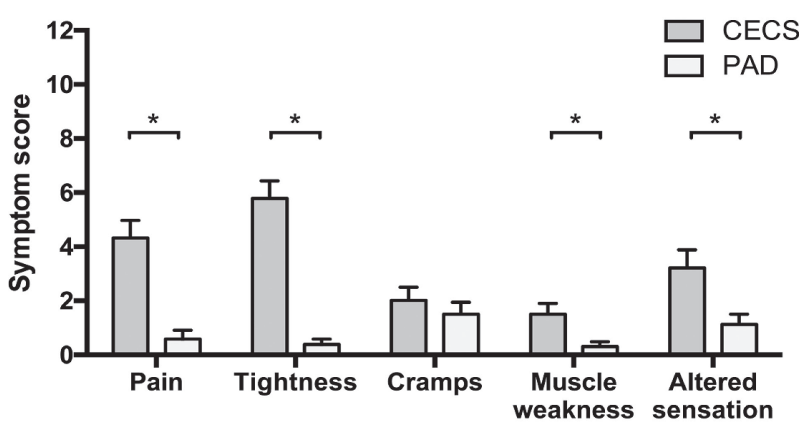

\section{Exercise}

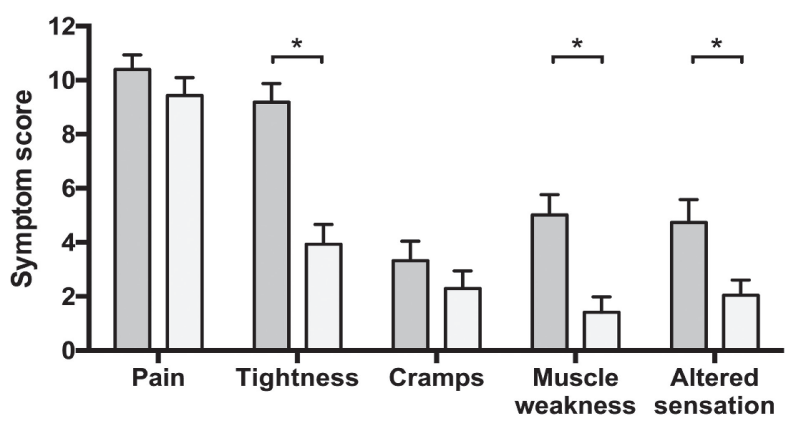

Figure 4.2: Symptom scores in rest (upper panel) and during exercise (lower panel) of patients with chronic exertional compartment syndrome (CECS) or peripheral arterial disease (PAD). Scores range from 0 to 16 and are comprised of intensity and frequency. Bars represent mean scores and error bars represent standard error of the mean (SEM). Statistically significant differences between both groups are depicted with *.

\section{Symptoms during rest and exercise}

Symptom scores in rest and during exercise are depicted in figure 4.2. In rest, CECS patients reported more pain ( 4.33 vs. $0.59 ; p<0.01$ ), tightness ( 5.79 vs. $0.39 ; p<0.01$ ), muscle weakness (1.51 vs. $0.30 ; p<0.01$ ) and altered sensation ( 3.21 vs. $1.12 ; p<0.01$ ) than PAD patients. Cramps were comparable 
in both groups (2.02 vs. 1.50; $p=0.44$ ). After correction for age, gender, bilaterality and duration of complaints, having CECS was associated with a higher combined symptom score in rest (difference 9.9, 95\% Cl 1.8-18.0, $\mathrm{p}=0.02$ ).

Exercise increased symptom scores from a median of 14 (range 0-65) to 29 (11-80) in CECS patients and from a median of 1 (range 0-29) to 21 (0-52) in PAD patients. During exercise, pain (CECS 10.40 vs. PAD 9.44; $p=0.36)$ and cramps (3.33 vs. $2.30 ; p=0.70$ ) were comparable. However, patients with CECS experienced more tightness ( 9.19 vs. $3.93 ; p<0.01$ ), muscle weakness ( 5.02 vs. $1.42 ; p<0.01$ ) and altered sensation ( 4.74 vs. 2.05; $\mathrm{p}<0.01)$ than patients with PAD. After correction for age, gender, bilaterality and duration of complaints, having CECS was not associated with a higher combined symptoms score (difference 6.2, 95\% Cl -2.5-15, $\mathrm{p}=0.16$ ).

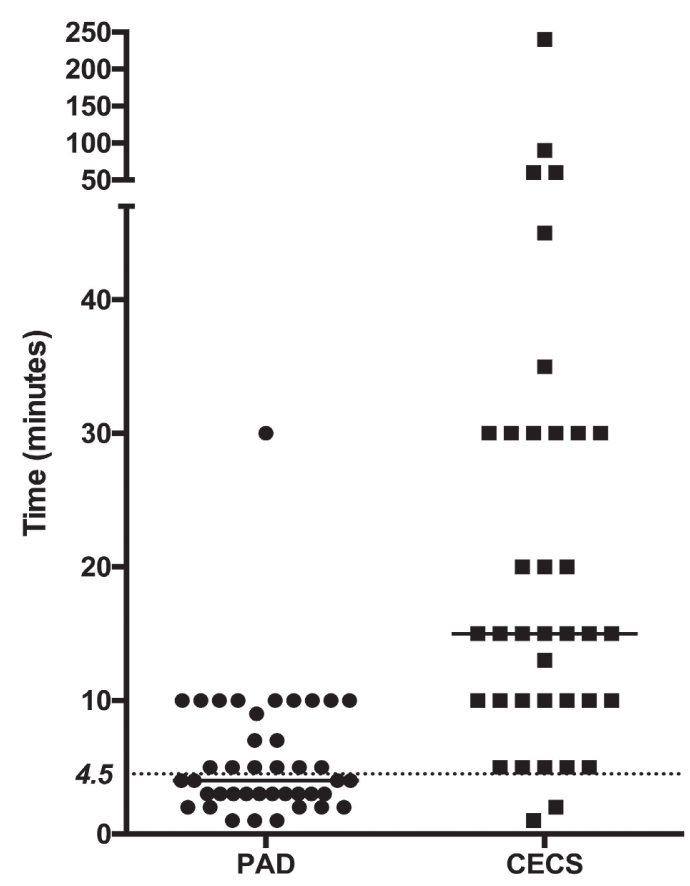

Figure 4.3: Time between initiation of the provocative activity and start of symptoms. The horizontal line represents the median. A time of 4.5 minutes has the highest discriminative capability (sensitivity $95 \%$, specificity $54 \%$, PPV 65\%) for detecting CECS. 


\section{Onset of symptoms after starting exercise}

After initiation of exercise, symptoms started 11 minutes earlier in PAD patients (median 4 minutes, range 1-30) than in CECS patients (median 15 minutes, range 1-240, $p<0.001$, figure 4.3). A time over 4.5 minutes between initiation of the provocative activity and the start of complaints proved most discriminative the presence of CECS based on a ROC curve (sensitivity $95 \%$, specificity $54 \%$, PPV $68 \%$, NPV 92\%). In the present sample, $95 \%$ of the CECS patients did not experience complaints within the first 4.5 minutes of exercise. Conversely, if symptoms started within the first 4.5 minutes, the probability of having CECS was low ( $8 \%$ in this sample).

All PAD patients $(n=41)$ reported that cessation of the provocative activity completely alleviated leg complaints. In contrast, almost three quarters of CECS patients ( $n=29,73 \%, p<0.001)$ experienced persisting complaints after cessation of the provocative activity. Ongoing discomfort following discontinuation of the provocative exercise is associated with the diagnosis CECS (sensitivity $73 \%$, specificity $100 \%$, PPV $100 \%$ )

\section{DISCUSSION}

Diagnostic delay in CECS patients, irrespective of age, is substantial. It is our experience that some older CECS patients have previously consulted (vascular) surgeons to exclude PAD but CECS was not considered during these analyses. Some of the symptoms and patient characteristics associated with both entities may overlap. Therefore, the current study aimed to compare characteristics and symptoms of CECS patients with those of PAD patients. The results indicate that patients with PAD hardly experience discomfort during rest while most patients with CECS do report discomfort albeit minor. In addition, PAD mostly caused leg pain while CECS often also caused tightness, muscle weakness and altered sensation. Moreover, symptoms appear and disappear much faster after respectively initiation and discontinuation of a provocative activity in PAD patients than in CECS patients.

Patients of advanced age with atherosclerotic risk factors who report walking induced lower leg pain are most likely to have lower extremity PAD. Plaque formation in PAD is due to aging and the ongoing presence of these risk factors. ${ }^{2,12}$ In contrast, CECS is associated with younger age as confirmed in numerous studies. Only two reports describe the possibility of 
CECS in older patients with exercise induced leg pain. $.{ }^{15},{ }^{16}$ However, a recent study demonstrated that one in seven patients diagnosed with CECS was 50 years or older. ${ }^{17}$ The difference in age is also confirmed by the present study as CECS patients were 15 years younger than patients with PAD. However, advanced age does not rule out CECS as the oldest patient was 76 years old.

A number of aspects in the patient history differ between PAD patients and CECS patients. Hypertension and hypercholesterolemia play an important role in the pathophysiology of PAD, but have no known correlation with CECS. ${ }^{2}$ Diabetes mellitus, on the other hand, is a risk factor of PAD but is also seen in patients with CECS. ${ }^{16}$ Our results confirm these beliefs as hypertension and hypercholesterolemia are clearly associated with PAD and rates of diabetes were comparable in both groups. While PAD is often unilateral, CECS predominantly (up to $80 \%$ ) affects both legs. ${ }^{21,22}$ In older CECS patients however, rates of bilaterality are remarkably lower. ${ }^{17}$ The current study confirms that bilaterality is not associated with CECS in patients aged 50 or older as only half of the patients has bilateral complaints. Hypertension and hypercholesterolemia may be indicative of PAD while diabetes and bilaterality do not help in discriminating between CECS and PAD in patients with exercise induced leg pain.

Although CECS and PAD both cause exertional pain, a number of distinct differences may help discriminating between the two. IC is a well-known symptom for early stage PAD and is recognized as a valuable determinant for its detection. ${ }^{1}$ Typically, only advanced PAD will cause pain in rest. CECS is also characterized by exercise induced leg pain and tightness. ${ }^{8}$ Additionally, some patients also experience cramps, muscle weakness and/ or altered lower leg skin sensations. ${ }^{10}$ Some studies however suggested that these complaints may be less typical in older CECS patients. ${ }^{15,17}$ In line with literature, our PAD patients hardly experienced complaints in rest but walking quickly induced pain. In contrast, the majority of our older CECS patients reported some discomfort in rest that worsened significantly during exercise. Furthermore, CECS patients also experience more tightness, muscle weakness and altered sensation than patients with PAD. In fact, logistic regression revealed that the presence of CECS was the main contributor to the total level of complaints in rest. 
It is a generally accepted belief that symptoms caused by CECS and PAD are provoked by physical activity and disappear with rest. In patients with PAD, IC is typically described as progressive calf pain that starts shortly after initiation of exercise and limits walking capacity. ${ }^{23}$ It usually resides within 10 minutes after cessation of the provocative activity. In contrast, symptoms characterizing CECS are less well defined. Typically its onset is thought to occur at a relatively predictable time point after initiation of the provocative activity. ${ }^{8}$ However, this point can vary substantially among individual patients. Pain and tightness in CECS progressively increase during exertion and are reported to reduce dramatically within minutes after cessation. ${ }^{9}$ However, a number of studies found prolonged duration of complaints that may even last until the next day. ${ }^{24}$ Our results indicate that complaints arise almost 4 times faster in patients with PAD than in patients with CECS. Furthermore, whereas complaints quickly disappeared after cessation of the provocative activity in all PAD patients, almost three quarters of CECS patients reported ongoing complaints, albeit at a lower intensity. Therefore, a longer time from initiation of exercise until the start of complaints as well as ongoing complaints after cessation are indicative of CECS.

The current study has limitations. The main limitation is the questionnaire that was developed for CECS and is not (yet) validated. It was not designed for PAD and may therefore miss certain characteristics of the symptom complex of these patients. However, as is shown by the differences in patients reported outcomes in rest and during exercise in the current study, the questionnaire was responsive to changes in the experienced intensity and frequency of symptoms. Furthermore, CECS patients were analyzed at the department of sports medicine and did not routinely undergo a vascular workup. Conversely, PAD patients, who were selected at the department of vascular surgery, did not undergo an ICP measurement. Although clinicians routinely checked for physical signs of both entities, we are not entirely sure that some patients may have suffered from both CECS and PAD. As both groups were selected from different outpatient departments, the introduced selection bias may have resulted in overestimation of the differences found in this study. 
In conclusion, this study is the first to directly compare symptoms and characteristics of patients $\geq 50$ years with IC due to PAD and patients with exercise induced lower leg pain due to CECS. Complaints in rest, the presence of symptoms other than pain or lingering symptoms after discontinuation of the provocative activity may suggest presence of CECS in patients with leg complaints. These findings may help a vascular surgeon in deciding whether referral of an older patient with exercise induced leg pain and an absent risk pattern for PAD to a sports physician is indicated.

\section{ACKNOWLEDGEMENTS}

We would like to thank M. van der Cruijsen-Raaijmakers for performing analyses in individuals suspected of having CECS and for collecting questionnaires in these patients. 


\section{REFERENCES}

1. McDermott MM, Greenland P, Liu K, et al. Leg symptoms in peripheral arterial disease: associated clinical characteristics and functional impairment. JAMA. 2001;286(13):1599-1606.

2. Selvin E. Prevalence of and Risk Factors for Peripheral Arterial Disease in the United States: Results From the National Health and Nutrition Examination Survey, 1999-2000. Circulation. 2004;110(6):738-743.

3. Lane R, Nguyen T, Cuzzilla M, Oomens D, Mohabbat W, Hazelton S. Functional popliteal entrapment syndrome in the sportsperson. Eur J Vasc Endovasc Surg. 2012;43(1):81-87.

4. Schep G, Bender MHM, van de Tempel G, Wijn PFF, de Vries WR, Eikelboom BC. Detection and treatment of claudication due to functional iliac obstruction in top endurance athletes: a prospective study. Lancet. 2002;359(9305):466-473.

5. Celecova Z, Krahulec B, Lizicarova D, Gaspar L. Vasculitides as a rare cause of intermittent claudication. Bratislava Medical Journal. 2013;114(6):353-356.

6. Apigian AK, Landry GJ. Basic data underlying decision making in nonatherosclerotic causes of intermittent claudication. Annals of Vascular Surgery. 2015;29(1):138-153.

7. Ehsan O, Darwish A, Edmundson C, Mills V, Al-Khaffaf H. Non-traumatic lower limb vascular complications in endurance athletes. Review of literature. Eur $J$ Vasc Endovasc Surg. 2004;28(1):1-8.

8. Blackman PG. A review of chronic exertional compartment syndrome in the lower leg. Medicine \& Science in Sports \& Exercise. 2000;32(3 Suppl):S4-S10.

9. Brennan FH, Kane SF. Diagnosis, treatment options, and rehabilitation of chronic lower leg exertional compartment syndrome. Curr Sports Med Rep. 2003;2(5):247-250.

10. Fraipont MJ, Adamson GJ. Chronic exertional compartment syndrome. J Am Acad Orthop Surg. 2003;11(4):268-276.

11. Tucker AK. Chronic exertional compartment syndrome of the leg. Curr Rev Musculoskelet Med. 2010;3(1-4):32-37.

12. Criqui MH, Aboyans V. Epidemiology of peripheral artery disease. Circ Res. 2015;116(9):1509-1526.

13. Clanton TO, Solcher BW. Chronic leg pain in the athlete. In: Foot and Ankle Injuries. Vol 13. Clinics in Sports Medicine; 1994:743-759.

14. Waterman BR, Liu J, Newcomb R, Schoenfeld AJ, Orr JD, Belmont PJ. Risk factors for chronic exertional compartment syndrome in a physically active military population. Am J Sports Med. 2013;41(11):2545-2549.

15. Edmundsson D, Toolanen G, Sojka P. Chronic compartment syndrome also affects nonathletic subjects: a prospective study of 63 cases with exerciseinduced lower leg pain. SORT. 2007;78(1):136-142. 
16. Edmundsson D, Toolanen G. Chronic exertional compartment syndrome in diabetes mellitus. Diabet Med. 2011;28(1):81-85.

17. de Bruijn JA, van Zantvoort APM, Winkes MB, et al. Lower Leg Chronic Exertional Compartment Syndrome in Patients 50 Years of Age and Older. Orthop J Sports Med. 2018;6(3):2325967118757179.

18. Winkes MB, Hoogeveen AR, Houterman S, Giesberts A, Wijn PF, Scheltinga MR. Compartment pressure curves predict surgical outcome in chronic deep posterior compartment syndrome. Am J Sports Med. 2012;40(8):1899-1905.

19. de Bruijn JA, van Zantvoort APM, van Klaveren D, et al. Factors Predicting Lower Leg Chronic Exertional Compartment Syndrome in a Large Population. Int J Sports Med. 2018;39(1):58-66.

20.Pedowitz RA, Hargens AR, Mubarak SJ, Gershuni DH. Modified criteria for the objective diagnosis of chronic compartment syndrome of the leg. American Journal of Sports Medicine. 1990;18(1):35-40.

21. Davis DE, Raikin S, Garras DN, Vitanzo P, Labrador H, Espandar R. Characteristics of patients with chronic exertional compartment syndrome. Foot Ankle Int. 2013;34(10):1349-1354.

22. Howard JL, Mohtadi NG, Wiley JP. Evaluation of outcomes in patients following surgical treatment of chronic exertional compartment syndrome in the leg. Clin J Sport Med. 2000;10(3):176-184.

23. Le Faucheur A, Noury-Desvaux B, Mahé G, et al. Variability and short-term determinants of walking capacity in patients with intermittent claudication. Journal of Vascular Surgery. 2010;51(4):886-892.

24. Martens MA, Backaert M, Vermaut G, Mulier JC. Chronic leg pain in athletes due to a recurrent compartment syndrome. American Journal of Sports Medicine. 1984;12(2):148-151. 
Exertional leg pain in older patients: CECS or PAD? 


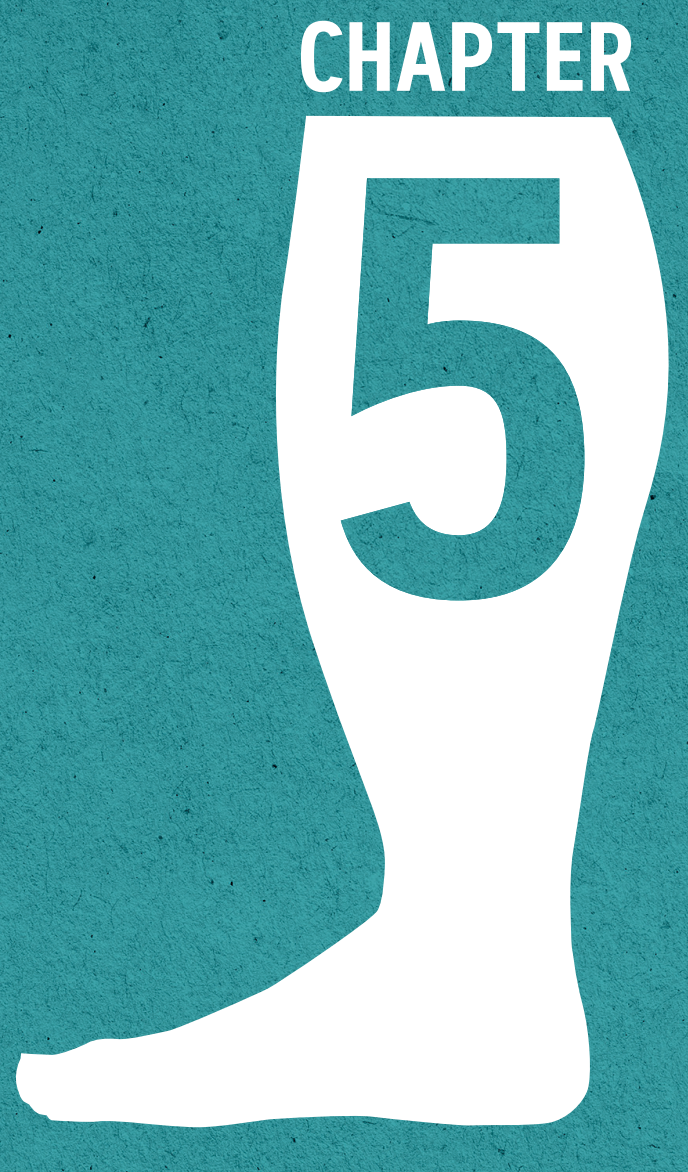




\section{CHAPTER 5}

\section{FEASIBILITY AND SAFETY}

\section{OF AN OPERATIVE TOOL}

\section{FOR ANTERIOR CHRONIC}

\section{EXERTIONAL COMPARTMENT}

\section{SYNDROME TREATMENT}

\section{Published in}

Published in Foot \& Ankle International, 2015, vol. 36, page:1475-82.

J.A. de Bruijn', A.P.M. van Zantvoort', M.B. Winkes', L. Raaymakers, M. van der Cruijsen-Raaijmakers², A.R. Hoogeveen², M.R.M Scheltinga'

* Both authors equally contributed

1 Department of Surgery, Máxima Medical Center, Veldhoven

2 Department of Sports Medicine, Máxima Medical Center, Veldhoven 


\section{ABSTRACT}

Background: Operative management of chronic exertional compartment syndrome of the tibialis anterior muscle compartment (ant-CECS) usually involves the use of a fasciotome. Collateral tissue damage such as hematoma and nerve damage may occur during the procedure. The current report assessed the feasibility and safety of an alternative tool for the operative management of ant-CECS.

Methods: The system had a speculum-like hollow tube that is inserted via a $2-\mathrm{cm}$ skin incision and allowed for the protected advancement of a fasciotome. The device was tested in patients with bilateral ant-CECS. Symptoms were prospectively scored before and after surgery using a 5 -category verbal rating scale (VRS). Fourteen patients (age $26 \pm 10$ years) were analyzed. Complications and operative efficacy were determined using physical examination and questionnaires after 21 (range 16-25) months.

Results: Technical operative success rate was 100\% (28/28 legs). Operation time was $10 \pm 2$ minutes per leg (range 6-14). Perioperative complications were not observed. One superficial wound infection was treated nonoperatively. Significant reductions in pain $(-2.2 \pm 1.1$ on 5 -point VRS, $p<0.001)$, tightness $(-1.9 \pm 1.6, p=0.01)$, cramps $(-1.4 \pm 1.6, p=0.009)$, muscle weakness $(-1.6 \pm 1.2, p<0.001)$ and altered sensibility $(-1.3 \pm 1.4, p=0.005)$ were registered 21 months postoperatively.

Conclusion: This fasciotome was simple to use and allows for a safe fasciotomy in patients with leg ant-CECS. A randomized controlled trial comparing the present device with a widely used fasciotome ('Due') was underway at the time of writing of this study.

Level of evidence: level IV, case series 


\section{INTRODUCTION}

In 1 in 8 young individuals with exercise induced leg pain, symptoms are due to a chronic exertional compartment syndrome (CECS). ${ }^{1}$ In athletes, this portion may even be higher. ${ }^{2}$ Leg CECS is usually found in the anterior (antCECS, 40-60\%) or deep flexor (dp-flex-CECS, 30-50\%) compartments. ${ }^{3,4}$ Typically, patients experience exercise-induced pain that is alleviated by a period of rest. ${ }^{5,6}$ Other symptoms are tightness, cramps, muscle weakness, and diminished sensibility. 7,8 Diagnosis is confirmed with a dynamic intracompartmental pressure measurement (ICP). A pressure $\geq 30 \mathrm{~mm} \mathrm{Hg}$ 1 minute after a standardized provocative treadmill test or $\geq 20 \mathrm{~mm} \mathrm{Hg} 5$ minutes thereafter, are widely used cut-off points for the diagnosis. ${ }^{9-11}$

Once diagnosed, patients with CECS will initially undergo nonoperative treatments but often to no avail.12,13 Most recalcitrant patients will opt for an operative intervention. During surgery the covering fascia is ether split (fasciotomy) or a strip is removed (fasciectomy). ${ }^{14-16}$ Several operative techniques and devices have been proposed. ${ }^{3,17}$ In previous times, the operative management of ant-CECS involved a $10-$ to $15 \mathrm{~cm}$ longitudinal incision. ${ }^{18}$ With the introduction of a specialized tool, Due and Nordstrand reduced the size of the skin incision to $2-3 \mathrm{~cm} \cdot{ }^{19} \mathrm{~A}$ fasciotome is essentially a metal rod that is mounted with a vertically placed small knife that splits the fascia subcutaneously. This technique is termed 'semi-blind' as advancement of the tip of the fasciotome does not occur under direct vision.

Complications such as superficial peroneal nerve damage have prompted physicians to explore alternative approaches such as an endoscopically assisted technique allowing visualization of anatomical structures at risk. ${ }^{20}$ Feasibility was demonstrated in cadaveric legs as well as in patients. ${ }^{21-23}$ However, cosmesis may not be improved as total incision size was larger whereas operation time was possibly longer. ${ }^{24}$ Clinical data on these endoscopic techniques are scarce and more research is necessary to determine whether endoscopic assisted techniques are superior compared to non-endoscopic approaches in patients with ant-CECS. ${ }^{25,26}$

Literature concerning efficacy and complication rates after operative treatment of ant-CECS is heterogeneous in terms of outcome. Success ranged from $63-100 \% .13,14,27-37$ Complication rates including muscle and nerve damage varied from 5 to $17 \%$. However, only $6 / 13$ retrospective studies 
indeed reported on the incidence of complications. $13,14,27-37$ Prospectively obtained complication rates range from 0 to $11 \% .^{38-42}$ The options for operative treatment of ant-CECS may leave room for improvement. The present study aimed to answer whether an alternative fasciotome was simple to use, safe, and effective in the treatment of ant-CECS. If so, it would be worthwhile to test this tool in a randomized control trail.

\section{METHODS}

The Department of Sports Medicine of Máxima Medical Center, Veldhoven, The Netherlands, serves as a national referral center for sports related injuries. In recent years, considerable expertise has been gained in exerciserelated pain syndromes including vascular syndromes in cyclists and CECS. ${ }^{43-46}$ In the year 2013, a total of 221 patients suspected of having CECS were referred for an ICP measurement.

\section{Patient selection}

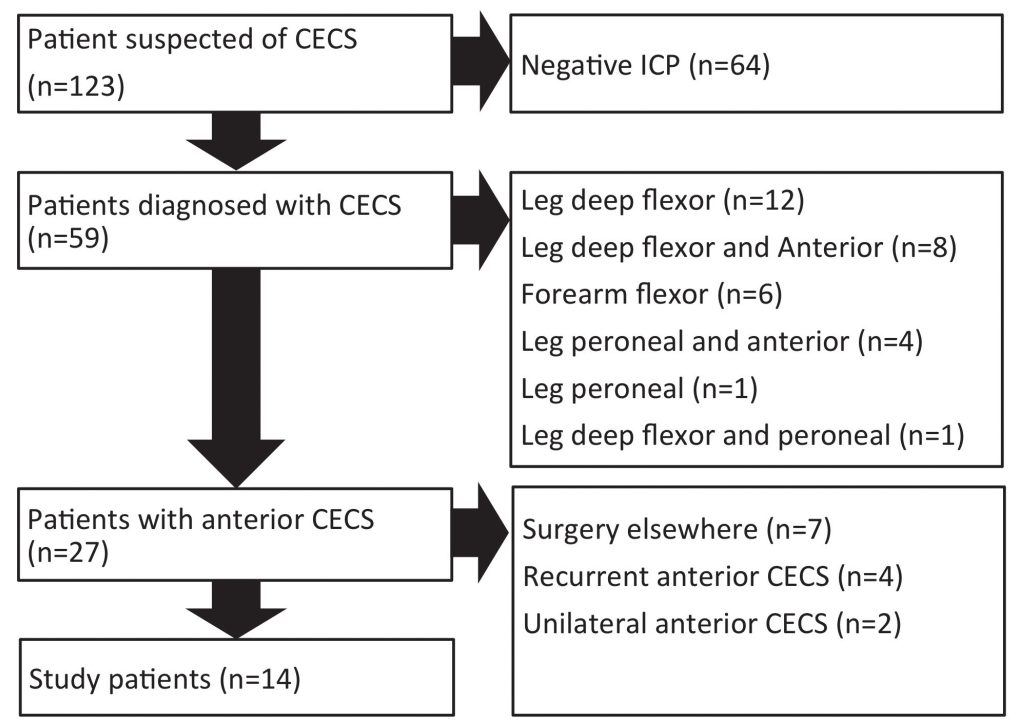

Figure 5.1: Patient selection. All patients were evaluated for possible CECS during a 6-months time period in a high volume institution. CECS=chronic exertional compartment syndrome, ICP=intracompartmental pressure measurement. 
The present study entailed a portion of all patients $(n=123)$ who were evaluated by the department of sports medicine between January $1^{\text {st }}$ and June $30^{\text {th }} 2013$ with leg complaints that were suggestive for a CECS.

Study inclusion criteria were bilateral leg symptoms associated with antCECS and a positive ICP measurement (ICP $\geq 30 \mathrm{~mm} \mathrm{Hg} 1$ minute after a standardized provocative test, or ICP $\geq 20 \mathrm{~mm} \mathrm{Hg}$ after 5 minutes). Patients with combined CECS syndromes (ant and dp-flex $n=8$, ant and peroneal $n=4$, peroneal and dp-flex $n=1)$ were excluded, as were dp-flex $(n=12), C E C S$ of forearms $(n=6)$, peroneal $(n=1)$, recurrent ant-CECS $(n=4)$ and unilateral ant-CECS $(n=2)$. Patients that were operated in a different hospital $(n=7)$ were also excluded (Figure 5.1).

During the 6 months study period, 14 patients with bilateral ant-CECS fulfilled study criteria. Provocative sports are depicted in Table 5.1. Median duration of symptoms prior to operation was almost 3 years. Two patients had previously received surgery for dp-flex CECS.

Table 5.1: Characteristics of patients undergoing surgery for tibialis anterior muscle chronic exertional compartment syndrome $(n=14)$

\begin{tabular}{|c|c|c|}
\hline Gender & Female n (\%) & $9(64)$ \\
\hline \multirow[t]{2}{*}{ Age } & Mean \pm SD (years) & $26 \pm 10$ \\
\hline & Range (years) & $18-48$ \\
\hline Height & Mean \pm SD $(\mathrm{cm})$ & $173 \pm 8$ \\
\hline Weight & Mean \pm SD (kg) & $72 \pm 10$ \\
\hline BMI & Mean \pm SD $(\mathrm{kg} / \mathrm{m} 2)$ & $24 \pm 3$ \\
\hline \multirow[t]{7}{*}{ Type of sports } & Soccer $\mathrm{n}(\%)$ & $5(36)$ \\
\hline & Running n (\%) & $3(21)$ \\
\hline & Hockey n (\%) & $2(14)$ \\
\hline & Handball n (\%) & $1(7)$ \\
\hline & Volleyball n (\%) & $1(7)$ \\
\hline & Basketball n (\%) & $1(7)$ \\
\hline & Fitness n (\%) & $1(7)$ \\
\hline \multirow[t]{2}{*}{ Duration complaints } & Median (months) & 33 \\
\hline & Range (months) & $6-240$ \\
\hline
\end{tabular}

$\mathrm{BMI}=$ body mass index, $\mathrm{SD}=$ standard deviation 


\section{Diagnosis and intracompartmental pressure measurement}

Two investigators ( $\mathrm{MC}$ and $\mathrm{AH}$ ) with ample experience (over 1500 procedures) performed the ICP measurements using a slit catheter (Stryker ${ }^{\oplus}$ Instruments, Kalamazoo, Michigan, USA). Patients were lying supine with the ankle joint in $20^{\circ}$ of plantarflexion and the knee in $10^{\circ}$ to $30^{\circ}$ of flexion. The leg was positioned horizontally with the anterior tibial margin in neutral position. Before needle introduction, a $1-\mathrm{cm}^{2}$ portion of overlying skin was infiltrated using $2 \mathrm{~mL}$ of $1 \%$ lidocaiine. ${ }^{45}$ The needle containing the catheter was inserted horizontally at the junction of the proximal and middle thirds of the anterior aspect of the leg. A perceptible 'pop' is usually experienced upon piercing of the fascia.

After the needle was removed while leaving the tip of the flexible catheter in the compartment, patients were instructed to evert and dorsiflex the foot against resistance as a test for correct catheter placement. After the catheter was flushed once with saline, resting pressures were measured. The arterial line manometer was subsequently disconnected and the catheter end was taped to the skin. The exercise protocol depended on the patients' physical ability and on the activity subjectively provoking the symptoms. In most patients, symptoms were elicited during treadmill running starting with an $8 \mathrm{~km} / \mathrm{h}$ speed and an $8 \%$ inclination during 5 minutes. If symptoms remained absent, heel walking or uphill walking tests were used as an additional provocation. Patients were encouraged to continue until symptoms were maximal. After ensuring the catheter was still functional and in the correct position, pressures were again recorded in a supine position immediately after cessation, and after 1 and 5 minutes.

The sports physician communicated to the patient whether history and levels of ICP were consistent with the diagnosis of ant-CECS. If patients opted for surgery, they received an appointment for an operative outpatient visit. All patients were counseled by the senior author, a surgeon with extensive experience in the operative treatment of CECS (>250 operations). Complications and the department's historical success rates of ant-CECS surgery using the technique proposed by Due and Nordstrand were discussed with the patients. They were also informed on the characteristics of the alternative operative tool and its method of action was demonstrated. All patients consented either verbally or in writing to undergo the procedure using the alternative tool. None of the patients 
opted for a Due and Nordstrand procedure when given the alternative for the current treatment.

\section{Description of technique}

The fasciotome (FascioMax) consisted of two components. The first part was a speculum-type stainless steel instrument (Figure 5.2). By manipulating the handle, the 2 semi-circular blades either open or close, thus forming a $30-\mathrm{cm}$ long, 5- $\mathrm{mm}$ wide (inner diameter) hollow tube. The second part was a stainless steel fasciotome consisting of a thin metal rod holding a small vertically placed knife (Figure 5.2). In essence, it is a thinner version of the fasciotome as proposed by Due and Nordstrand. ${ }^{19}$ When closed, the tube acts as a sheath in which the fasciotome is advanced towards the end (Figure 5.2).

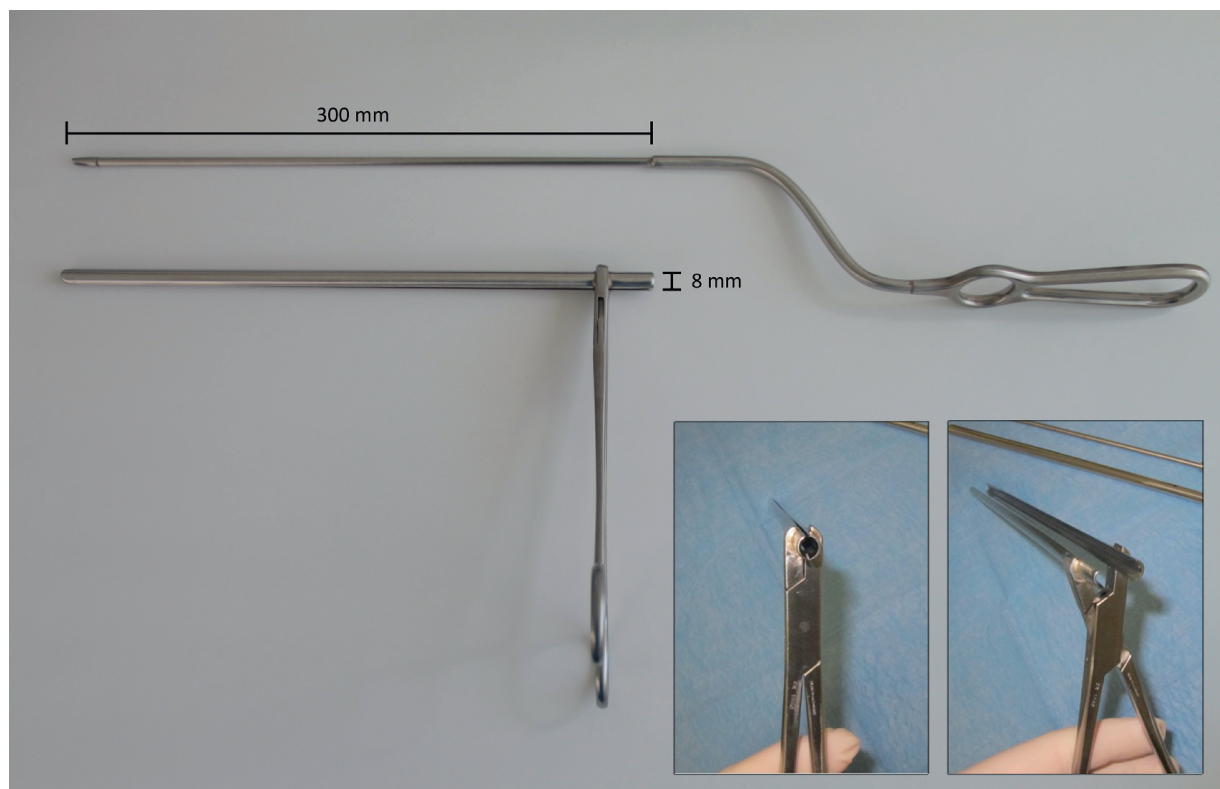

Figure 5.2: The fasciotome consists of 2 separate parts. The first part is a speculum-type instrument with a handle, lock and two long blades. Tips of the blades are blunt so tissue damage is minimized during advancement. By manipulating the handle, the two semi-circular blades either open or close, thus forming a $30 \mathrm{~cm}$ long hollow tube in which the second part, a small vertical knife mounted on a thin metal rod, can be advanced.

The contour of the tibialis anterior muscle was marked onto the skin using a surgical marker. A tourniquet was not used. After sterile exposure, a 2- 
to $2.5 \mathrm{~cm}$ longitudinal skin incision was made approximately $3 \mathrm{~cm}$ lateral to the medial margin of the tibia at the transition zone between middle and distal thirds of the tibialis anterior muscle. The incision was made approximately halfway along the line from the fibular head to the lateral malleolus (3A). The superficial crural fascia was bluntly freed of overlying fatty tissue. A 2-cm-wide subcutaneous tunnel immediately superficial to the crural fascia was created bluntly towards the knee joint and the ankle joint using scissors (Figure 5.3B). The exit site of the superficial peroneal nerve penetrating the crural fascia was located lateroinferior from this tunnel, so nerve identification was not performed.

Following a 1.5- to 2-cm longitudinal fascial incision (5.3C), the upper blade of the speculum was carefully advanced in the subcutaneous tunnel towards the knee superficially to the muscle's fascia (Figure 5.3D). By doing so, the sturdy second blade will automatically follow just underneath the fascia. By closing the handle, the fascia is firmly grasped between the two blades. The tips of the instrument were positioned at least $5 \mathrm{~cm}$ away from the fibular head so the common peroneal nerve was not damaged (Figure 5.3D). Once the correct position of the instrument was confirmed by transcutaneous palpation (Figure 5.3D), the fasciotome was introduced (Figure 5.3F) and advanced into the hollow tube that is formed by the two blades (Figure 5.3G). The fascia is thus cut in a controlled fashion. The distal portion of the crural fascia (approximately $4-$ to $5-\mathrm{cm}$ towards the ankle joint) was cut under direct visual inspection using a small retractor and scissors (Figure $5.3 \mathrm{H}$ ). Completeness of the fasciotomy was confirmed by palpating medial and lateral fascial edges (Figure 5.31). Once confirmed, the skin was closed in one layer. (This procedure and a fasciotomy according to Due and Nordstrand are shown in more detail in a short video, available as an online electronic supplement.) Patients received compressive stockings day and night for 14 days. They were instructed to refrain from sports during this time period but normal ambulation was recommended. 

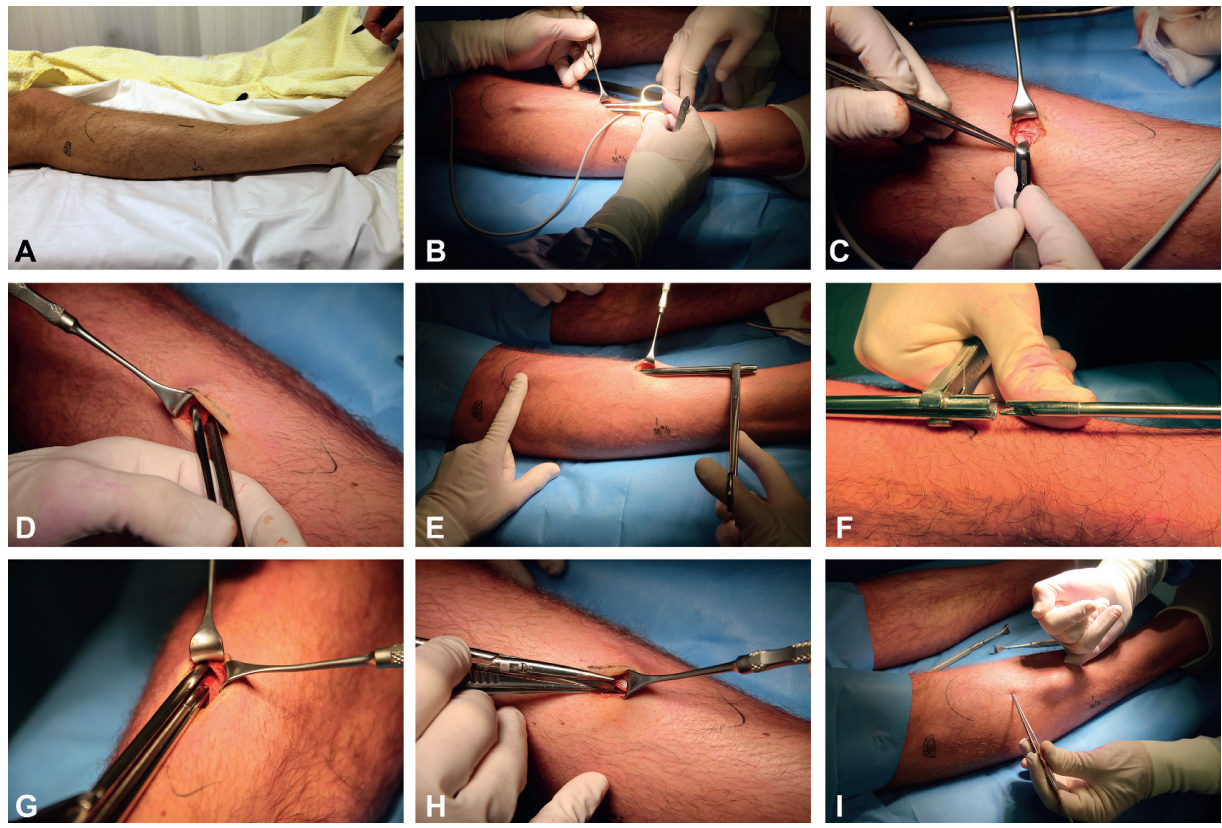

Figure 5.3: Intraoperative view of the procedure. In all images, the knee is located on the left. (A) A 2-cm incision is made halfway along the line from the fibular head to lateral malleolus, approximately $3 \mathrm{~cm}$ lateral to the tibia. (B) A subcutaneous tunnel is created via the skin incision. (C) A 1.5- to 2-cm incision in the crural fascia. (D) The 2-bladed instrument is inserted. The deepest blade is located just underneath the fascia covering the muscle compartment while the superficial blade is positioned in the subcutaneous tunnel between fascia and skin. (E) The fascia is grasped between the 2 blades by closing of the handle; the position of tip of the instrument is checked via transcutaneous palpation. (F) The fasciotome is introduced into the tube. (G) The protective tube may be opened slightly to visualize the position of the fasciotome in relation to the crural fascia. $(\mathrm{H})$ Toward the ankle, the crural fascia is opened under direct visual inspection using scissors. (I) Completeness of the fasciotomy is confirmed by palpating medial and lateral fascial edges using the fifth finger that is inserted via the skin incision.

\section{Postoperative outpatient visit}

Two weeks postoperatively, patients were interviewed and physically examined by the senior author at the outpatient department. Complications due to tissue damage such as hematoma, tunnel infection, loss of sensibility, or infection were tabulated. Instructions on rehabilitation were then provided. A last telephone contact occurred once thereafter, usually 6 to 8 weeks postoperatively. 


\section{Questionnaire}

Each patient completed a questionnaire just prior to the ICP measurement. Pain, tightness, cramps, muscle weakness, and diminished sensibility were scored using a verbal rating scale (VRS). Patients judged each symptom as extremely severe (4 points), severe ( 3 points), moderate ( 2 points), mild (1 point), or absent (0 points). This scale is known to have the best equidistance, allowing for statistical analysis. ${ }^{47}$ Postoperatively, current functional status and symptoms were determined using similar symptom questionnaires.

\section{Statistical analysis}

Data are expressed as mean \pm standard deviation when normally distributed, or as median and range if not normally distributed. Mean preand postoperative symptoms were compared using a paired-samples test. For all tests, $\mathrm{p}<0.05$ was considered significant. This study was conducted in accordance with the World Medical Association Declaration of Helsinki (Brazil, October 2013). Study design and protocol were reviewed and approved by the Medical Ethics Committee of Máxima Medical Center.

\section{RESULTS}

Mean ICP at rest was $20 \pm 8 \mathrm{~mm} \mathrm{Hg}$. Immediately after the standardized provocative test, it increased to $46 \pm 12 \mathrm{~mm} \mathrm{Hg}$. One and 5 minutes after cessation, pressures again declined to $41 \pm 12 \mathrm{~mm} \mathrm{Hg}$ and $34 \pm 7 \mathrm{~mm} \mathrm{Hg}$, respectively (Figure 5.4).

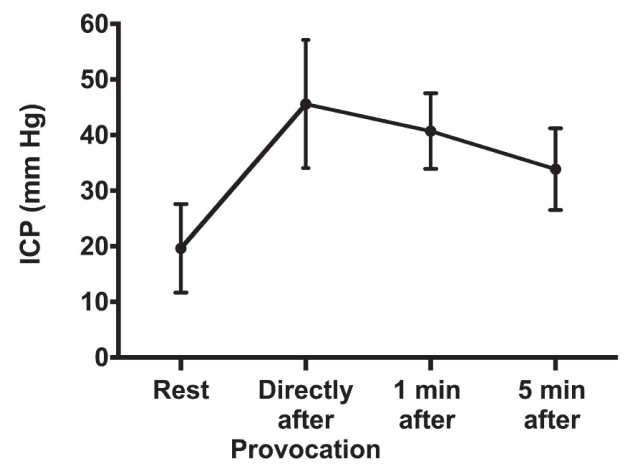

Figure 5.4: Tibialis anterior muscle Intracompartmental pressure (ICP) in patients $(n=14)$ with chronic exertional compartment syndrome. Readings were obtained during rest, and directly, 1 minute, and 5 minutes after a standardized provocative treadmill test. Dots represent mean pressure values $(n=14)$, error-bars represent standard deviations. 
The fasciotome was easily introduced and advanced with mild resistance. Correct positioning of the tips relative to the fibular head (approximately 5 $\mathrm{cm}$ distal to) was easily confirmed by transcutaneous palpation. Splitting of the fascia occurred at first intention. The technical success rate as judged by intraoperative palpation of both edges of the split fascia via the $2-\mathrm{cm}$ incision was $100 \%$. Operation time ('skin to skin') was $10 \pm 2$ minutes per leg (range 6-14).

Two weeks postoperatively, there were no cases of disturbed wound healing, hematoma, subcutaneous tunnel complications or nerve injuries $(n=0 / 28$ legs). One patient had used a 7-day course of antibiotics for superficial infection of the incision as advised by his general practitioner. Thus, overall complication rate was $3.6 \%$ (1/28 legs).

Symptoms were assessed preoperatively $(n=14)$ and postoperatively $(n=13$, loss to follow up=1). Before the operation, the 2 principal symptoms during exercise were pain and tightness. Less prominent symptoms were cramps, muscle weakness and diminished sensibility. Self reported recovery was 4 weeks (mean; range 1-8). All symptoms were greatly attenuated during follow up evaluation, both at short term (median 4 months, range 3-9; n=13, response rate 93\%) and after a longer period (median 21 months, range $16-25 ; n=13$, response rate $93 \%$ ). Twenty-one months postoperatively, mean levels of pain had decreased by $2.2 \pm 1.1$ ( 5 -point VRS, $p<0.001$ ) and levels of tightness had dropped by 1.9 $\pm 1.6(p=0.001)$. Cramps $(-1.4 \pm 1.6, p=0.009)$, muscle weakness $(-1.6 \pm 1.2, p<0.001)$, and diminished sensibility $(-1.3 \pm 1.4$, $\mathrm{p}=0.005$ ) were also significantly attenuated (Figure 5.5).

Almost two years postoperatively (median, 21 months), 31\% of the patients $(n=4)$ judged their clinical outcome as excellent, $31 \%(n=4)$ as good, $23 \%$ $(n=3)$ as fair, $8 \%(n=1)$ as poor and $8 \%(n=1)$ as bad. All patients had resumed a type of sports activity although two patients had abandoned their original sport (soccer). The one patient who judged her postoperative result as 'poor' was able to continue her sport at a reasonable level although with complaints. She was later diagnosed with medial tibial stress syndrome during follow-up. The patient who judged his postoperative result as 'bad' was treated for achillotendinopathy. However, pain in the decompressed anterior compartment was absent in these patients who rated the result as 'poor' and 'bad'. 

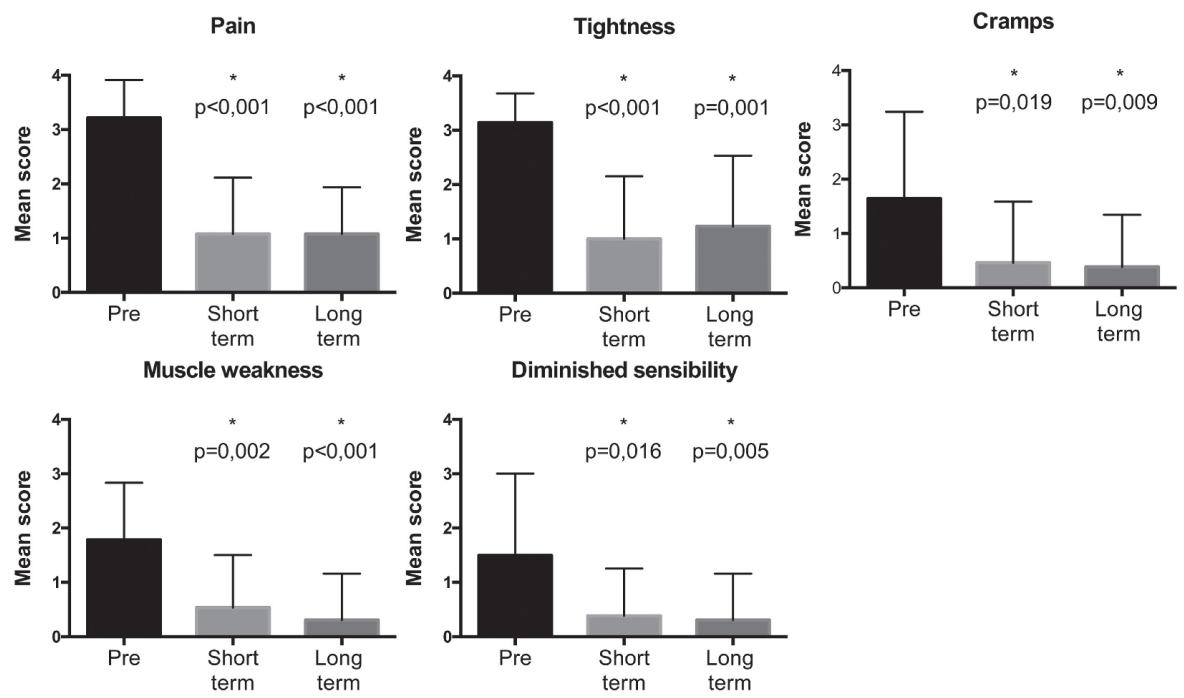

Figure 5.5: Symptoms in patients before (pre, $n=14$ ), 5 months (Short term, n=13) and 21 months (Long term, $n=13$ ) after a fasciotomy. Symptoms associated with CECS were scored as extremely severe (4 points), severe (3 points), moderate ( 2 points), mild (1 point), or no symptoms (0 points). Bars represent mean values, and error bars depict standard deviation. * Significant reduction compared to mean preoperative score.

\section{DISCUSSION}

The aim of the present study was to test an alternative technique for the operative treatment of patients with ant-CECS. The technique is minimally invasive but allows for optimal tissue protection. The results indicate that this tool (FascioMax) was simple, safe and effective for the treatment of ant-CECS. Performance and handling of the current instrument were thoroughly assessed during the trial. The fasciotome performed as expected during each of the 28 operative procedures. Introduction into the tissue tunnel and advancement along the fascial plane were not difficult. Splitting of the fascia was successful in all patients. A second introduction of the device or additional skin incisions was not required. Removal of the instrument was smooth in all patients. Clinically relevant bleeding was not encountered. These findings indicate that the tool is simple to use.

All patients had a 2-week postoperative follow-up ensuring that all potential complications were identified. One wound infection that was treated successfully with antibiotics resulted in a $3.6 \%$ minor complication rate (1/28 legs). Signs of an absorbed hematoma were occasionally observed. Major 
complications such as major hematoma, deep tissue infection or superficial peroneal nerve damage did not occur. In the literature, complication rates up to $17 \%$ are reported. These include major complications that required surgical intervention. ${ }^{13,14,27-37}$

Cardinal symptoms were significantly reduced at 5 and 21 months postoperatively. Furthermore, all patients were able to engage in sports. Literature concerning the clinical results of operative treatment for antCECS is very heterogeneous in terms of clinical outcome. Therefore, it is impossible to compare present efficacy rates with previous studies. Only a randomized controlled trial would allow for a comparison of efficacy. Nevertheless, the results of the present trial indicate that this technique effectively reduced symptoms associated with the presence of ant-CECS.

The present study has limitations. Firstly, the absolute diagnostic value of ICP measurements is debated in recent literature. ${ }^{48,49}$ However, the role of ICP measurements in our hospital is to confirm a diagnosis that is predominantly based on a characteristic medical history and physical examination as judged by exceedingly experienced sports physicians (evaluated $>1500$ patients suspected with CECS). Moreover, a recent systematic review emphasized that an ICP $\geq 30 \mathrm{~mm} \mathrm{Hg} 1$ minute after provocation along with a convincing history is highly suggestive of CECS. ${ }^{50}$ In the present study, all patients demonstrated both a highly suggestive medical history and an ICP $\geq 30 \mathrm{~mm} \mathrm{Hg} 1$ minute after provocation.

Second, patients were counseled before the operative procedure by the surgeon (MS) who participated in the development of the alternative fasciotome and performed all surgical procedures. Although counseling was performed on the basis of current knowledge, his behavior may have prompted patients to opt for the new tool. Furthermore, the senior author was the only person to register potential complications. Although patients were instructed to report complications in the postoperative questionnaire, this may potentially have influenced study results. Finally, the present study is purely observational and has no control intervention. However, a randomized controlled trial is only worthwhile if the alternative tool was found to be safe in the present pilot study. 


\section{Chapter 5}

In conclusion, the described fasciotome was a simple, safe, and effective tool for the operative management of patients with chronic exertional compartment syndrome of the tibialis anterior muscle compartment of the leg. Data of the present safety and feasibility study were so encouraging that a randomized controlled trial comparing the new technique (FascioMax) and the technique according to Due and Nordstrand was initiated (Dutch Clinical Trial Register no 4274).

\section{CONFLICT OF INTEREST}

None of the authors declared any potential conflicts of interest with respect to the research, authorship, or publication of this article. Furthermore, the author(s) received no financial support for the research, authorship, and/ or publication of this article. 


\section{REFERENCES}

1. Qvarfordt P, Christenson JT, Eklöf B, Ohlin P, Saltin B. Intramuscular pressure, muscle blood flow, and skeletal muscle metabolism in chronic anterior tibial compartment syndrome. Clin Orthop Relat Res. 1983;(179):284-290.

2. Clanton TO, Solcher BW. Chronic leg pain in the athlete. In: Foot and Ankle Injuries. Vol 13. Clinics in Sports Medicine; 1994:743-759.

3. Detmer DE, Sharpe K, Sufit RL, Girdley FM. Chronic compartment syndrome: diagnosis, management, and outcomes. American Journal of Sports Medicine. 1985;13(3):162-170.

4. Reinking MF. Exercise Related Leg Pain (ERLP): a Review of The Literature. $N$ Am J Sports Phys Ther. 2007;2(3):170-180.

5. Blackman PG. A review of chronic exertional compartment syndrome in the lower leg. Medicine \& Science in Sports \& Exercise. 2000;32(3 Suppl):S4-S10.

6. Touliopolous S, Hershman EB. Lower leg pain. Diagnosis and treatment of compartment syndromes and other pain syndromes of the leg. Sports Med. 1999;27(3):193-204.

7. Paik RS, Pepple DA, Pepples D, Hutchinson MR. Chronic exertional compartment syndrome. BMJ. 2013;346(jan15 2):f33-f33.

8. Fraipont MJ, Adamson GJ. Chronic exertional compartment syndrome. J Am Acad Orthop Surg. 2003;11(4):268-276.

9. Pedowitz RA, Hargens AR, Mubarak SJ, Gershuni DH. Modified criteria for the objective diagnosis of chronic compartment syndrome of the leg. American Journal of Sports Medicine. 1990;18(1):35-40.

10. Slimmon D, Bennell K, Brukner P, Crossley K, Bell SN. Long-term outcome of fasciotomy with partial fasciectomy for chronic exertional compartment syndrome of the lower leg. American Journal of Sports Medicine. 2002;30(4):581-588.

11. Tucker AK. Chronic exertional compartment syndrome of the leg. Curr Rev Musculoskelet Med. 2010;3(1-4):32-37.

12. Brennan FH, Kane SF. Diagnosis, treatment options, and rehabilitation of chronic lower leg exertional compartment syndrome. Curr Sports Med Rep. 2003;2(5):247-250.

13. Verleisdonk EJ, van den Helder CJ, Hoogendoorn HA, van der Werken C. [Good results of fasciotomy in chronic compartment syndrome of the lower leg]. Ned Tijdschr Geneeskd. 1996;140(50):2513-2517.

14. Almdahl SM, Samdal F. Fasciotomy for chronic compartment syndrome. Acta Orthop Scand. 1989;60(2):210-211.

15. Bell S. Repeat compartment decompression with partial fasciectomy. J Bone Joint Surg Br. 1986;68(5):815-817. 
16. Bong MR, Polatsch DB, Jazrawi LM, Rokito AS. Chronic exertional compartment syndrome: diagnosis and management. Bull Hosp Jt Dis. 2005;62(3-4):77-84.

17. Wood ML, Almekinders LC. Minimally invasive subcutaneous fasciotomy for chronic exertional compartment syndrome of the lower extremity. Am J Orthop. 2004;33(1):42-44.

18. Mubarak SJ, Owen CA. Double-incision fasciotomy of the leg for decompression in compartment syndromes. J Bone Joint Surg Am. 1977;59(2):184-187.

19. Due J, Nordstrand K. A simple technique for subcutaneous fasciotomy. Acta Chir Scand. 1987;153(9):521-522.

20. Ota Y, Senda M, Hashizume H, Inoue H. Chronic compartment syndrome of the lower leg: a new diagnostic method using near-infrared spectroscopy and a new technique of endoscopic fasciotomy. Arthroscopy. 1999;15(4):439-443.

21. Hutchinson MR, Bederka B, Kopplin M. Anatomic structures at risk during minimal-incision endoscopically assisted fascial compartment releases in the leg. American Journal of Sports Medicine. 2003;31(5):764-769.

22. Stein DA, Sennett BJ. One-portal endoscopically assisted fasciotomy for exertional compartment syndrome. Arthroscopy. 2005;21(1):108-112.

23. Leversedge FJ, Casey PJ, Seiler JG, Xerogeanes JW. Endoscopically assisted fasciotomy: description of technique and in vitro assessment of lowerleg compartment decompression. American Journal of Sports Medicine. 2002;30(2):272-278.

24. Knight JR, Daniels M, Robertson W. Endoscopic compartment release for chronic exertional compartment syndrome. Arthrosc Tech. 2013;2(2):e187-e190.

25. Wittstein J, Moorman CT, Levin LS. Endoscopic compartment release for chronic exertional compartment syndrome. J Surg Orthop Adv. 2008;17(2):119-121.

26. Lohrer H, Nauck T. Endoscopically assisted release for exertional compartment syndromes of the lower leg. Arch Orthop Trauma Surg. 2007;127(9):827-834.

27. Rorabeck CH, Bourne RB, Fowler PJ. The surgical treatment of exertional compartment syndrome in athletes. J Bone Joint Surg Am. 1983;65(9):1245-1251.

28. Wallensten R. Results of fasciotomy in patients with medial tibial syndrome or chronic anterior-compartment syndrome. J Bone Joint Surg Am. 1983;65(9):1252-1255.

29. Styf JR, Körner LM. Chronic anterior-compartment syndrome of the leg. Results of treatment by fasciotomy. J Bone Joint Surg Am. 1986;68(9):1338-1347.

30.Fronek J, Mubarak SJ, Hargens AR, et al. Management of chronic exertional anterior compartment syndrome of the lower extremity. Clin Orthop Relat Res. 1987;(220):217-227.

31. Rorabeck CH, Fowler PJ, Nott L. The results of fasciotomy in the management of chronic exertional compartment syndrome. American Journal of Sports Medicine. 1988;16(3):224-227. 
32. Turnipseed W, Detmer DE, Girdley F. Chronic compartment syndrome. An unusual cause for claudication. Ann Surg. 1989;210(4):557-62-discussion562-3.

33. Schepsis AA, Martini D, Corbett M. Surgical management of exertional compartment syndrome of the lower leg. Long-term followup. American Journal of Sports Medicine. 1993;21(6):811-7-discussion817.

34. Micheli LJ, Solomon R, Solomon J, Plasschaert VF, Mitchell R. Surgical treatment for chronic lower-leg compartment syndrome in young female athletes. American Journal of Sports Medicine. 1999;27(2):197-201.

35. Howard JL, Mohtadi NG, Wiley JP. Evaluation of outcomes in patients following surgical treatment of chronic exertional compartment syndrome in the leg. Clin J Sport Med. 2000;10(3):176-184.

36. de Fijter WM, Scheltinga MR, Luiting MG. Minimally invasive fasciotomy in chronic exertional compartment syndrome and fascial hernias of the anterior lower leg: short- and long-term results. Mil Med. 2006;171(5):399-403.

37. Edmundsson D, Toolanen G. Chronic exertional compartment syndrome in diabetes mellitus. Diabet Med. 2011;28(1):81-85.

38. Sudmann E. The painful chronic anterior lower leg syndrome. A prospective clinical and experimental study. Acta Orthop Scand. 1979;50(5):573-581.

39. Schepsis AA, Gill SS, Foster TA. Fasciotomy for exertional anterior compartment syndrome: is lateral compartment release necessary? American Journal of Sports Medicine. 1999;27(4):430-435.

40.Verleisdonk EJMM, Schmitz RF, van der Werken C. Long-term results of fasciotomy of the anterior compartment in patients with exercise-induced pain in the lower leg. Int J Sports Med. 2004;25(3):224-229.

41. van den Brand JGH, van der Werken C, Verleisdonk EJMM, T N. The Diagnostic Value of Intracompartmental Pressure Measurement, Magnetic Resonance Imaging, and Near-Infrared Spectroscopy in Chronic Exertional Compartment Syndrome: A Prospective Study in 50 Patients. American Journal of Sports Medicine. 2005;33(5):699-704.

42. Edmundsson D, Toolanen G, Sojka P. Chronic compartment syndrome also affects nonathletic subjects: A prospective study of 63 cases with exerciseinduced lower leg pain. SORT. 2007;78(1):136-142.

43. Schep G, Bender MHM, van de Tempel G, Wijn PFF, de Vries WR, Eikelboom BC. Detection and treatment of claudication due to functional iliac obstruction in top endurance athletes: a prospective study. Lancet. 2002;359(9305):466-473.

44.van Zoest W, Hoogeveen A, Scheltinga M, Sala H, van Mourik J, Brink P. Chronic Deep Posterior Compartment Syndrome of the Leg in Athletes: Postoperative Results of Fasciotomy. Int J Sports Med. 2008;29(5):419-423.

45. Winkes MB, Hoogeveen AR, Houterman S, Giesberts A, Wijn PF, Scheltinga MR. Compartment pressure curves predict surgical outcome in chronic deep posterior compartment syndrome. Am J Sports Med. 2012;40(8):1899-1905. 


\section{Chapter 5}

46. Winkes MB, Luiten EJT, van Zoest WJF, Sala HA, Hoogeveen AR, Scheltinga MR. Long-term results of surgical decompression of chronic exertional compartment syndrome of the forearm in motocross racers. Am J Sports Med. 2012;40(2):452458.

47. Bocklisch F, Bocklisch SF, Krems JF. Sometimes, often, and always: exploring the vague meanings of frequency expressions. Behav Res Methods. 2012;44(1):144157.

48. Hislop M, Batt ME. Chronic exertional compartment syndrome testing: a minimalist approach. British Journal of Sports Medicine. 2011;45(12):954-955.

49. Roscoe D, Roberts AJ, Hulse D. Intramuscular Compartment Pressure Measurement in Chronic Exertional Compartment Syndrome: New and Improved Diagnostic Criteria. Am J Sports Med. 2014;43(2):392-398.

50. Aweid O, Del Buono A, Malliaras P, et al. Systematic review and recommendations for intracompartmental pressure monitoring in diagnosing chronic exertional compartment syndrome of the leg. Clin J Sport Med. 2012;22(4):356-370. 
Novel operative tool for CECS 


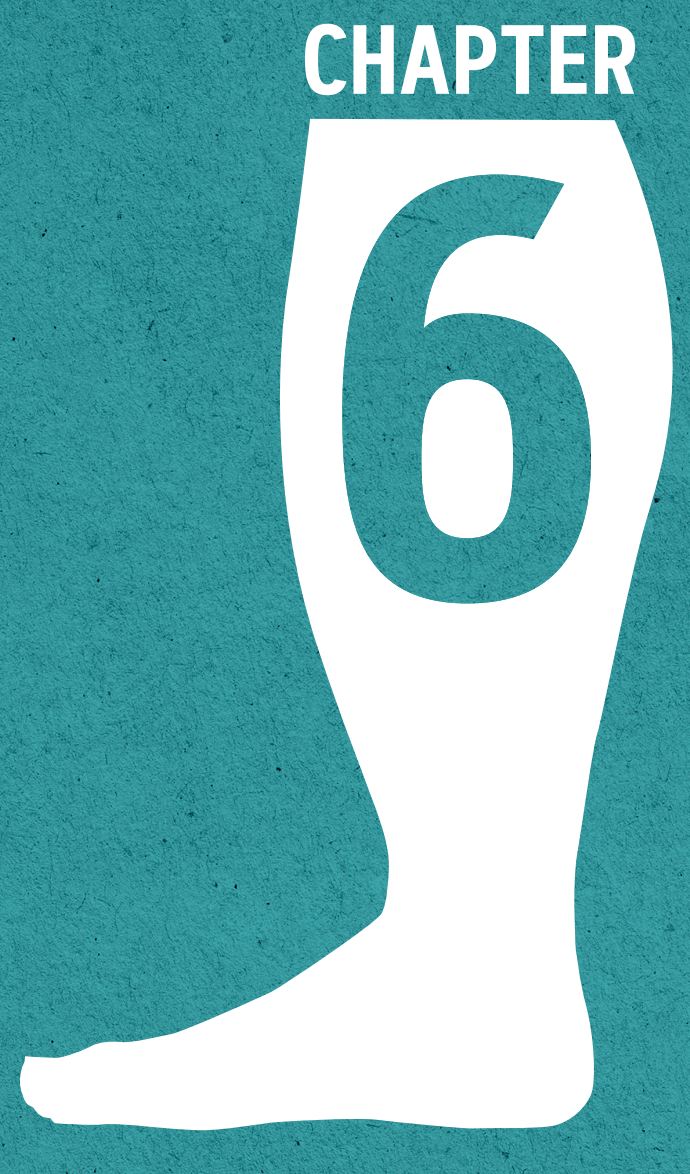




\section{CHAPTER 6}

\section{SUPERFICIAL PERONEAL NERVE}

INJURY RISK DURING

\section{A SEMIBLIND FASCIOTOMY}

FOR ANTERIOR CHRONIC

EXERTIONAL COMPARTMENT

SYNDROME OF THE LEG:

AN ANATOMICAL AND CLINICAL STUDY

Published in

Foot \& Ankle international, 2019, vol. 40(3), p343-351

J.A. de Bruijn ${ }^{\star 1}$, A.P.M. van Zantvoort", ${ }^{* 1}$, H.P.H. Hundscheid',

A.R. Hoogeveen ${ }^{3}$, J.A.W. Teijink ${ }^{4,5}$, M.R. Scheltinga ${ }^{1}$

1 Department of Surgery, Maxima Medical Center, Veldhoven

2 Department of Sports Medicine, Maxima Medical Center, Veldhoven

3 Department of Surgery, Catherina Hospital, Eindhoven, the Netherlands

4 Department of Epidemiology, CAPHRI research school, Maastricht 


\section{ABSTRACT}

Background: Up to $8 \%$ of patients who underwent a fasciotomy for leg anterior chronic exertional compartment syndrome (ant-CECS) report sensory deficits suggestive of iatrogenic superficial peroneal nerve (SPN) injury. In the current study we aimed to thoroughly assess the risk of SPN injury during a semiblind fasciotomy of the anterior compartment using 2 separate approaches.

Methods: A modified semiblind fasciotomy of the anterior compartment was performed via a longitudinal $2-\mathrm{cm}$ skin incision $2 \mathrm{~cm}$ lateral of the anterior tibial crest halfway along the line fibular head-lateral malleolus both in cadaver legs and in patients with ant-CECS. In the cadaver legs, the skin was removed after the procedure and possible SPN injuries and spatial relationships between the SPN and the opened fascia were studied. Between January 2013 and December 2016, 64 ant-CECS patients who underwent a fasciotomy of the anterior compartment were prospectively followed. latrogenic SPN injuries were assessed using questionnaires and physical examinations.

Results: Macroscopic SPN nerve injury was not observed in any of the 9 cadaver legs. In 8 specimens, the SPN was located at least $5 \mathrm{~mm}$ posterolateral to the opened fascia. In one specimen, an undamaged SPN branch crossed the operative field in a ventral plane. De novo sensory deficits suggestive for iatrogenic SPN injury were not observed in any of the 64 patients (120 legs; 36 females; median age 22 years) who underwent a fasciotomy of the anterior compartment.

Conclusion: The proposed semiblind fasciotomy for treatment of ant-CECS is not associated with SPN injury in either the cadaveric study or our clinical series.

Level of evidence: IV, case series 


\section{INTRODUCTION}

Chronic exertional compartment syndrome (CECS) is an exerciseinduced condition that is predominantly found in the leg tibialis anterior compartment (ant-CECS). ${ }^{1-3}$ Conservative treatments may offer relief but a substantial portion of patients are ultimately operated. ${ }^{4}$ Results of a fasciotomy for ant-CECS are generally satisfactory with success rates between $52 \%$ and $100 \% .{ }^{5-8}$ However, complications associated with surgery, ranging from simple hematomas to long-lasting disabilities, are not unusual. ${ }^{9,10}$ Injury of the superficial peroneal nerve (SPN) is a troublesome complication incidentally seen after a fasciotomy of the anterior (and lateral) compartment.9.11 Persistent pain, tingling and/or reduced skin sensation of the dorsum of the foot and the anterolateral ankle suggesting iatrogenic SPN injury are found in up to $8 \%$ of the patients who underwent a fasciotomy of the anterior compartment. ${ }^{12-18}$

Several operative techniques are currently available for the treatment of ant-CECS. A popular approach is a 'semiblind fasciotomy' that was introduced in the late 1980s. ${ }^{19}$ This technique is fast and requires a skin incision of only 2- to $3-\mathrm{cm}$ through which a small fascial cut is made that is extended subcutaneously towards the ankle and the fibular head using a fasciotome. As direct visual contact with the fasciotome's tip is largely absent during this procedure, SPN injury may occur. To overcome this complication, others have used larger skin incisions ${ }^{20,21}$ or even multiple incisions. ${ }^{13,22}$ More recently, the assistance of an endoscope was advocated. ${ }^{23}$ True comparative studies are absent; hence the optimal operative technique that is associated with a minimal risk of SPN injury has yet to be determined.

As a referral center we perform a substantial number of semiblind anterior releases. In January 2013 we adopted a technique using a modified fasciotome in our hospital. ${ }^{24}$ If this technique is safe, it may provide a costeffective and simple alternative for an endoscope-assisted fasciotomy of the leg anterior compartment. The aim of the present study was to accurately determine the risk of iatrogenic SPN injury using this modified semiblind technique. Therefore, we used two separate approaches. We performed a fasciotomy of the anterior compartment in human cadavers to objectively assess the risk for SPN injury. We also searched for SPN injuries in a prospectively followed cohort of ant-CECS patients who underwent an anterior fasciotomy in our center. 


\section{MATERIALS AND METHODS \\ Cadaver study}

We used 9 fresh frozen legs of 5 individuals. None of these were previously used for research purposes or operative training and visible external scars suggesting previous major trauma or surgery were absent. One leg had a small skin defect over the anterolateral aspect, probably the result of postmortem freezing and storage (specimen 9, Figure 6.1A).

A fasciotomy of the leg anterior compartment was performed with the FascioMax system (van Straten Medical, Nieuwegein, the Netherlands). This re-usable device was designed and constructed in our hospital. In short, the novel instrument consists of 2 parts: a thin fasciotome with a vertical knife and a speculum-type steel device with handle, lock and two sturdy semi-circular blades. These sturdy blades can be opened or closed thus forming a $30-\mathrm{cm}$ long, $5-\mathrm{mm}$ wide hollow tube that allows for insertion of the fasciotome. The device itself, including its mode of action, were previously described in detail. ${ }^{24}$ The fibular head and lateral malleolus were marked and a 2-cm longitudinal skin incision was made 2-3 $\mathrm{cm}$ lateral to the lateral margin of the tibial crest, exactly halfway along the line between these landmarks (Figure 6.1A). From this location the anterior compartment was easily accessible. However, as the intramuscular septum is located more laterally, this location is not suitable for a fasciotomy of the lateral compartment. Next, the crural fascia was bluntly freed of overlying fatty tissue and a 1.5- to $2-\mathrm{cm}$ fascial incision was made (Figure 6.1B). A $2-\mathrm{cm}$ wide subcutaneous tunnel immediately superficial to the crural fascia was created towards the knee joint and the ankle joint (Figure 6.1C/6.1D). The lower blade of the speculum was inserted immediately underneath the tibialis anterior muscle fascia and carefully advanced towards the knee (Figure 6.1E). By doing so, the sturdy second blade automatically followed through the subcutaneous tunnel superficial to the fascia. By closing the handle, the crural fascia was firmly grasped between the 2 blades. Once a correct position was confirmed by transcutaneous palpation, the thin rod with the vertical knife is advanced into the tube towards the end, thus cutting the fascia in a very controlled fashion (Figure 6.1F). A 4- to $5-\mathrm{cm}$ portion of distal crural fascia towards the ankle joint was cut under direct visual inspection using a small retractor and scissors. The lateral compartment was not opened. 

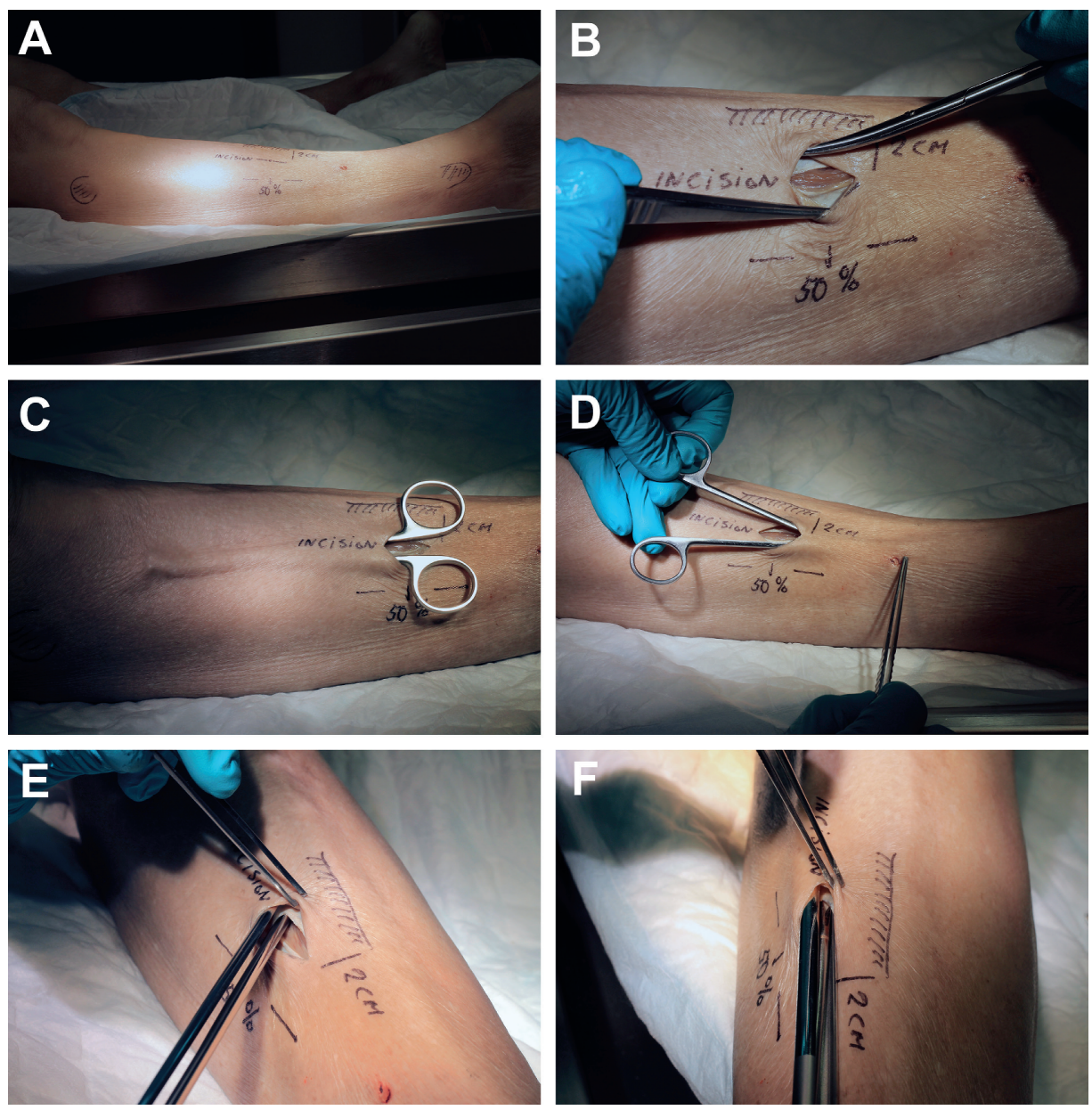

Figure 6.1: Consecutive steps of a semiblind fasciotomy of the anterior compartment in cadavers. (A) Anatomical landmarks (fibular head and lateral malleolus) and location of the incision are marked. Note the small skin defect just distal of the incisional site. (B) The crural fascia was bluntly freed of overlying fatty tissue and a 1.5- to $2-\mathrm{cm}$ fascial incision was made. ( $C$ and $D$ ) A subcutaneous tunnel immediately superficial to the fascia is bluntly created towards knee and ankle joint using spreading movements of scissors. (E) The lower blade of the speculum is inserted into the tibialis anterior muscle compartment and carefully advanced towards the knee just underneath the crural fascia. (F) After confirmation of the correct position by transcutaneous palpation, closing the handle fixates the fascia and the thin rod with the vertical knife is advanced into the tube towards the end.

Once the fasciotomy was performed, skin and subcutaneous tissue were removed, and the SPN was carefully inspected for macroscopic damage and distances between SPN and cleaved fascia were measured. These 
measurements were only performed at the distal portion of the SPN, where the nerve is thought to surface through the fascia and is at risk. Additional measured parameters were completeness and length of the fasciotomy and the SPN course. The latter was to clarify the relation between the SPN and the opened fascia. By studying only 9 legs, the intention of the study was to describe a proof of concept but not to ascertain all possible anatomical SPN variants.

\section{Patient study}

The Department of sports medicine of Máxima Medical Center, Veldhoven, the Netherlands is a referral center for exercise-induced leg entities. Patients were diagnosed with an ant-CECS if history and physical examination were suggestive of a CECS and intracompartmental pressure (ICP) was elevated in the anterior compartment. ICP was termed elevated if it exceeded one or more of the following cutoff values: $15 \mathrm{~mm} \mathrm{Hg}$ at rest, $30 \mathrm{~mm} \mathrm{Hg} 1$ minute after provocation, or $20 \mathrm{~mm} \mathrm{Hg} 5$ minutes after provocation..$^{25} \mathrm{~A}$ detailed description of the diagnostic process was previously published. ${ }^{24}$

Starting January 2013, each patient who was evaluated for CECS in our institution was asked to complete a questionnaire. They scored intensity and frequency of leg pain, tightness, cramps, muscle weakness and altered sensibility/tingling at rest and during exercise using a verbal rating scale (VRS). A similar questionnaire was completed 3-6 months postoperative (short term) and at least 12 months postoperative (long-term). Some antCECS patients were referred only for diagnostics and underwent treatment in their referring hospital. Patients who opted for an operative treatment in our center were counseled and treated by the senior author (M.S.). The operative procedure for the anterior fasciotomy was similar to the method described above (cadaver study). Additional fasciotomies of the lateral and/ or deep flexor compartment were only performed if a multicompartmental CECS was found during ICP measurements. These were performed via additional skin incisions, either during the initial procedure or in an additional operation. The lateral compartment was not opened in patients with isolated ant-CECS, as this possibly adds risk and morbidity while clinical results may not be improved. ${ }^{14,26}$ 


\section{Postoperative outpatient evaluation}

Each patient was invited to our outpatient clinic 2-4 weeks after the fasciotomy. They were asked whether they experienced new alterations in skin sensation or a tingling feeling in the leg. Anterolateral leg skin sensation was tested using light touch with gauzes drained in alcohol or swabs. We defined iatrogenic SPN injury as reduced skin sensitivity and/or tingling in the lower lateral portions of the leg and/or dorsum of the foot that was not present during the preoperative outpatient visit. In addition, we termed patient-reported newly acquired continuous altered skin sensibility or tingling as suggestive of SPN injury. When patients reported findings suggestive of SPN that were not noticed during the postoperative outpatient visit, they were invited for a second outpatient visit.

\section{Patient selection}

Between January 2013 and December 2016, 719 individuals were evaluated for CECS at our department of sports medicine (Figure 6.2). A total of 137 patients were eligible for the present study as they were diagnosed with ant-CECS and treated in our hospital. Patients were excluded if they did not undergo a fasciotomy of the anterior compartment using the FascioMax technique $(n=18)$; were included in a randomized controlled trial $(n=29$, all patients aged 18 years or older with isolated bilateral antCECS, Dutch trial registry number NTR4274); or declined further followup $(n=8)$. As 18 patients were lost to follow up, the study population consisted of 64 patients. These patients all underwent a fasciotomy of the anterior compartment, had completed preoperative and postoperative questionnaires and had visited the outpatient clinic after surgery at least once.

\section{Statistics and ethics}

SPSS Statistics, Windows version 22.0.0.0 (IBM Corp, Armonk, NY) was used for all analyses. Data are shown as mean ( \pm SD) when normally distributed, or as median (range) when not normally distributed. The Radboud University, Department of Anatomy provided us with the cadaveric specimens. All deceased patients had given consent for scientific usage of their bodies after their death. All procedures performed in this study are in accordance with the ethical standards of our institutional research committee and with the declaration of Helsinki. The local medical ethical committee judged that 
the rules laid down in the Medical Research Involving Human Subjects Act (WMO) did not apply to the study protocol. No outside funding was used.

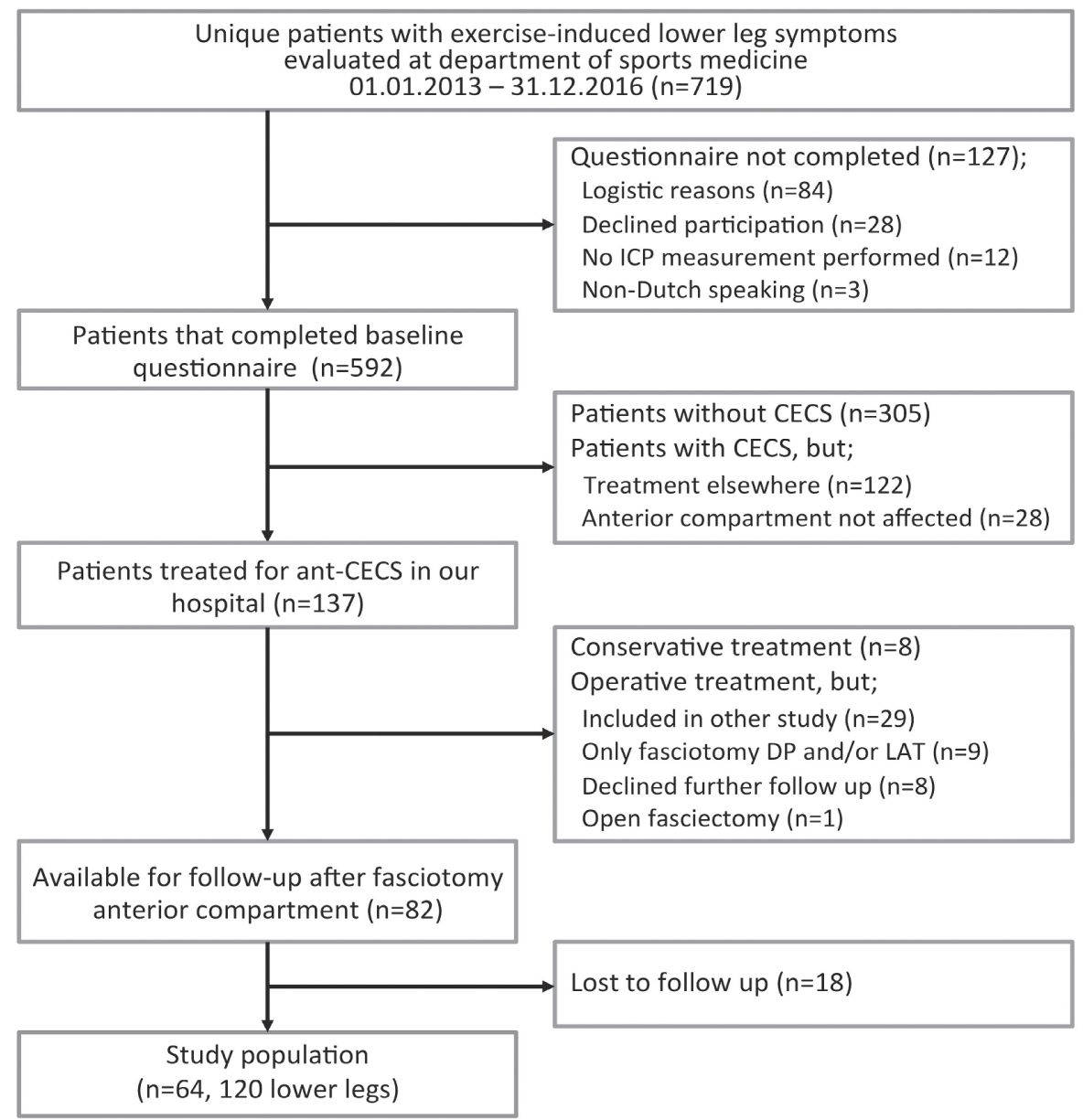

Figure 6.2: Patient selection. CECS, Chronic Exertional Compartment Syndrome; DP, deep flexor compartment; ICP, intracompartmental pressure measurement; LAT, lateral compartment

\section{RESULTS}

\section{Cadaver study}

Characteristics of the deceased patients and measured distances are depicted in Table 6.1. The SPN was not visible via the $2-\mathrm{cm}$ skin incision in any of the 9 legs. The introduction of the fasciotome occurred smoothly and always at the first intend. The median length of the released fascia was 
$212 \mathrm{~mm}$ (range 175-235). Median distance between fibular head and the released fascia was $48 \mathrm{~mm}$ (range 25-110) and median distance between lateral malleolus and the released fascia was $105 \mathrm{~mm}$ (range 60-125). One fasciotomy was incomplete as a proximal portion of the fascia was still intact (specimen 1). This failure may have been due to a suboptimal quality of the cadaver's crural fascia as multiple fascial defects were seen after removal of the skin.

Macroscopic SPN injury was not observed. In all 9 legs, the SPN originated from the common peroneal nerve proximal in the lateral compartment. In $6 / 9$ legs, the SPN exited the lateral compartment through the crural fascia and continued subcutaneously towards the ankle joint. In these 6 specimens, the nerve remained lateral of the released fascia by at least $7 \mathrm{~mm}$ (Figure 6.3A, Table 6.1). In the remaining 3 legs, the SPN branched in the lateral compartment; one branch remained in the lateral compartment whereas the other branch exited the lateral compartment through the crural fascia. In two of these legs (specimen 4 and 7), this medial subcutaneous branch coursed at least $5 \mathrm{~mm}$ lateral to the released fascia. However, in one leg (specimen 3 ) the SPN was potentially at risk as its subcutaneous branch crossed the opened fascia in a ventral plane (Figure 6.3B). Even though the nerve crossed the released fascia, it was macroscopically intact.

\section{Patient study}

Of the 64 included patients, 36 were female (56\%) and the median age was 22 years (range 15-65). A total of 62 patients participated in sports ( social $n=25$, local competitive $n=23$, national competitive $n=13$, international competitive $n=1)$. Most patients were engaged in running $(n=17)$ or ball sports $(n=35)$. Symptoms had started 29 months prior to analysis (median, range $3-360)$ and resulted in practicing sports with complaints $(n=7)$, lowering the level/intensity $(n=19)$, choosing a different sport $(n=4)$ or quitting sports altogether $(n=32)$. A bilateral fasciotomy was performed in 56 patients amounting to a total of 120 operated legs. In $55 \%$ of the patients (35/64), only the anterior compartment was decompressed. The remaining 29 patients (45\%) also underwent a fasciotomy of the deep flexor compartment $(n=18)$, lateral compartment $(n=9)$, or both the deep flexor and the lateral compartment $(n=2)$. One ant-CECS patient was also diagnosed with a concurrent distal SPN entrapment and also underwent a release of the SPN via a separate incision just above the ankle joint. The 
SPN was not seen in any of the patients during the procedure. Perioperative complications such as bleeding or the necessity to extend the $2-\mathrm{cm}$ incision were not encountered.

During the postoperative visit, we identified 5 patients with postoperative sensory complaints and/or abnormalities during neurological examination of the operated leg(s) (Table 6.2). Four of these five patients also reported continuous sensory leg complaints in the operated leg(s). In 3 of these 5 patients, sensory deficits were already documented during the preoperative outpatient clinic visit. Surgery had not altered these preexisting sensory complaints. New onset sensory deficits were diagnosed in the two remaining patients. One patient, who had undergone combined anterior and deep flexor muscle decompression, reported skin numbness of a medial portion of the distal leg that was ascribed to an injured side branch of the saphenous nerve. The second patient had reduced skin sensibility of a $9 \times 4 \mathrm{~cm}$ area of a proximal portion of the left lateral leg. This hyposensitivity may have been caused by injury of a proximal side branch of the sural nerve. However, skin sensibility of his distal leg and foot was unaltered indicating an intact SPN. Therefore, none of the 120 legs displayed new onset sensory deficits suggestive of iatrogenic SPN injury.
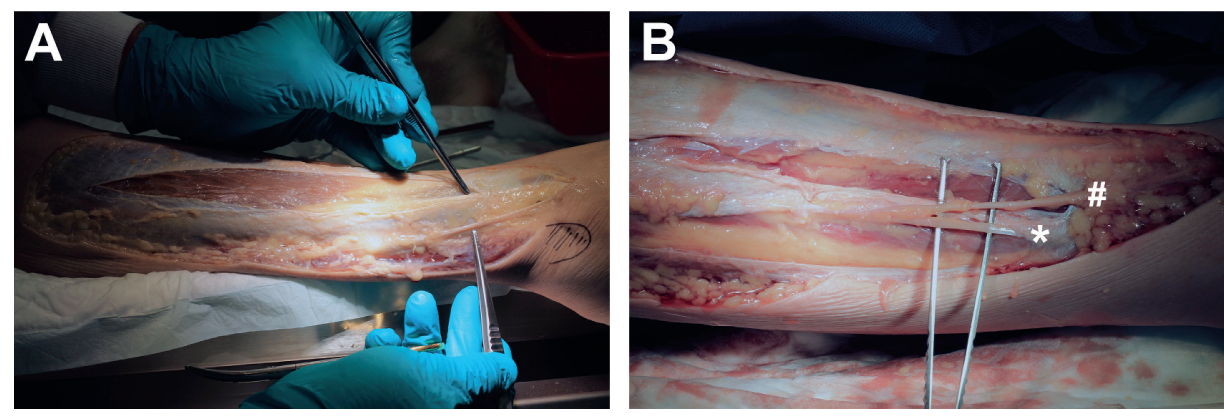

Figure 6.3: Superficial peroneal nerve (SPN) after skin removal following an anterior compartment fasciotomy in a cadaver leg. (A) The distance between the opened fascia (left hand forceps) and the SPN (right hand forceps) was measured. (B) The SPN branched in the lateral compartment in specimen 3. One branch continued in the lateral compartment $\left(^{*}\right)$ while the other exited the lateral compartment and crossed the released crural fascia in a ventral plane (\#). Although at risk, this branch was not damaged. 


\section{DISCUSSION}

The aim of the current study was to assess the risk of iatrogenic SPN injury during a modified semiblind fasciotomy of the anterior compartment of the leg. We did not find macroscopic damage of the SPN in any of the 9 cadaveric legs, although a branch of the SPN was potentially at risk in 1 specimen as it crossed the operative field. Furthermore, signs of iatrogenic SPN injury were not identified in a prospective cohort of 64 patients who had undergone a fasciotomy of the anterior compartment in 120 legs. Therefore, this modified semiblind technique carries a low risk on SPN injury during a fasciotomy of the anterior compartment.

Table 6.2: Patients with sensory deficits after surgery, either self-reported or diagnosed during outpatient visit

\begin{tabular}{|c|c|c|}
\hline ID & Source & Findings \\
\hline \multirow[t]{6}{*}{62} & Patient questionnaire & $\begin{array}{l}\text { Reported newly acquired continuous sensory } \\
\text { deficits after surgery }\end{array}$ \\
\hline & Outpatient clinic, preoperative & $\begin{array}{l}\text { Tingling and reduced sensibility dorsal side foot } \\
\text { during palpation of anterior compartment }\end{array}$ \\
\hline & Procedure & Left tibialis anterior fasciotomy \\
\hline & Outpatient clinic, postoperative & Unchanged tingling and reduced sensibility \\
\hline & Additional examinations & Electromyography: reduced conductivity SPN \\
\hline & Conclusion & $\begin{array}{l}\text { Peroneal entrapment syndrome, successfully } \\
\text { treated with surgical release }\end{array}$ \\
\hline \multirow[t]{6}{*}{203} & Patient questionnaire & $\begin{array}{l}\text { Reported newly acquired continuous sensory } \\
\text { deficits after surgery }\end{array}$ \\
\hline & Outpatient clinic, preoperative & No sensory deficits \\
\hline & Procedure & Bilateral tibialis anterior fasciotomy \\
\hline & Outpatient clinic, postoperative & $\begin{array}{l}\text { Reduced sensibility strip }(9 * 4 \mathrm{~cm}) \text { proximal left } \\
\text { lower leg, normal sensibility distal portion }\end{array}$ \\
\hline & Additional examinations & None \\
\hline & Conclusion & Injury proximal side branch of the sural nerve \\
\hline \multirow[t]{6}{*}{266} & Patient questionnaire & $\begin{array}{l}\text { Reported no newly acquired continuous sensory } \\
\text { deficits after surgery }\end{array}$ \\
\hline & Outpatient clinic, preoperative & Tingling lateral left lower leg and toes \\
\hline & Procedure & Bilateral anterior + deep flexor fasciotomy \\
\hline & Outpatient clinic, postoperative & Unchanged tingling lateral left lower leg and toes \\
\hline & Additional examinations & $\begin{array}{l}\text { Intracompartmental pressure maesurement: } \\
\text { elevated pressure lateral compartment }\end{array}$ \\
\hline & Conclusion & $\begin{array}{l}\text { Sensory deficits due to CECS of the lateral } \\
\text { compartment }\end{array}$ \\
\hline
\end{tabular}


Table 6.2: Continued

\begin{tabular}{|c|c|c|}
\hline ID & Source & Findings \\
\hline \multirow[t]{6}{*}{268} & Patient questionnaire & $\begin{array}{l}\text { Reported newly acquired continuous sensory } \\
\text { deficits after surgery }\end{array}$ \\
\hline & Outpatient clinic, preoperative & $\begin{array}{l}\text { Reduced sensibility sole and lateral side right } \\
\text { foot }\end{array}$ \\
\hline & Procedure & Right tibialis anterior + deep flexor fasciotomy \\
\hline & Outpatient clinic, postoperative & $\begin{array}{l}\text { Reduced sensibility sole and lateral side right } \\
\text { foot }\end{array}$ \\
\hline & Additional examinations & None \\
\hline & Conclusion & $\begin{array}{l}\text { Pre-existing sensory deficits not suspect for } \\
\text { operative SPN injury }\end{array}$ \\
\hline \multirow[t]{6}{*}{422} & Patient questionnaire & $\begin{array}{l}\text { Reported newly acquired continuous sensory } \\
\text { deficits after surgery }\end{array}$ \\
\hline & Outpatient clinic, preoperative & No sensory deficits \\
\hline & Procedure & Bilateral anterior + deep flexor fasciotomy \\
\hline & Outpatient clinic, postoperative & Reduced sensibility medial distal right lower leg \\
\hline & Additional examinations & None \\
\hline & Conclusion & Injury of the saphenous nerve \\
\hline
\end{tabular}

Abbreviations: CECS, chronic exertional compartment syndrome; SPN, superficial peroneal nerve

Due to its location, the SPN is at risk during a fasciotomy of the anterior compartment. Its course and anatomical variations were previously studied in cadavers. ${ }^{27,28}$ The SPN consistently originates in the proximal lateral compartment of the leg as a branch of the common peroneal nerve. ${ }^{27}$ Towards the ankle joint its course is highly variable and the nerve may be at risk if it approaches the operative field. In our current small series, the SPN was located safely posterolateral to the released fascia in $8 / 9$ legs. In 1 , however, a SPN side branch crossed the released fascia in a ventral plane. Although this branch was not damaged, a SPN is clearly at risk in patients with this SPN variant during a fasciotomy of the anterior compartment.

Several operative techniques have been advocated for treating antCECS. Approaches vary in terms of invasiveness, efficacy and risk of complications including SPN injury. A completely open technique offers direct visual contact but at the expense of a rather large skin incision. ${ }^{29}$ Invasiveness can be reduced by using 2 or 3 smaller incisions ${ }^{1,11}$ or by using a fasciotome through a single 2 -cm skin incision. ${ }^{19}$ SPN injury has been reported both after open and semiblind techniques. 8,15,18,20,30 More recently, the use of endoscopic assistance to enhance visibility without increasing 
incisional length has been reported. ${ }^{31}$ Early reports of endoscope-assisted fasciotomies suggest that the risk of SPN injury is reduced compared with conventional semiblind techniques. ${ }^{32,33}$ However, clinical results were not superior to non-endoscopic assisted techniques and endoscope-assisted fasciotomies are likely to be more expensive and time-consuming. . $^{31,34-36}$ Therefore, it is still questionable whether the increased visibility outweighs its disadvantages.

In the present cadaver and human study, the SPN was not injured once during a fasciotomy of the anterior compartment. These optimal results may be explained in several ways. First, the proposed point of introduction of the fasciotome was safe. The $2-\mathrm{cm}$ skin incision, located $2-3 \mathrm{~cm}$ lateral to the tibial crest and exactly halfway between the fibular head and lateral malleolus, offered optimal visibility of the area where the SPN is most likely to surface through the crural fascia. ${ }^{28}$ Moreover, by using this location, the fasciotomy towards the ankle joint can be executed under direct visual contact, preventing injury to an SPN variant that crosses the operative area. Second, this location allows for a safe and reliable release of much larger proximal portions of the crural fascia. The FascioMax system likely separates the fascia from its overlying subcutaneous tissue and may thus minimalize the risk of nerve injury during the fasciotomy toward the knee when direct visual contact was lacking. However, it may not be possible to avoid injury of all small, clinically less-relevant proximal sensory branches as illustrated by one patient (no 203, Table 6.2).

The current study has limitations. The cadaver study entailed a limited number of specimens and alternative anatomical SPN variants are likely to exist. However, we feel confident that the proposed technique minimizes the risk of SPN injury during a fasciotomy of the anterior compartment, as was illustrated by the absence of SPN injuries. Also, the clinical study entailed a limited number (64 patients, 120 legs) of selected cases. However, we believe that the volume of this case series was sufficient for the current goal, which was to evaluate the number of SPN injuries after a fasciotomy of the anterior compartment. The presented modified approach will be compared with a standard-of-care operative treatment in a currently ongoing randomized controlled trial. The strengths are the use of both anatomical and clinical data. Moreover, by using data from outpatient clinic 
visits and patient-reported outcomes, the risk of missed SPN injuries was minimized.

The present study demonstrated that the proposed modified semiblind fasciotomy for the treatment of ant-CECS was not associated with iatrogenic SPN injury. This method appears to be a simple and safe alternative for open or endoscope-assisted techniques.

\section{ACKNOWLEDGEMENTS}

The Department of Anatomy, Radboud University, Nijmegen, the Netherlands is acknowledged for facilitating the cadaver study. 


\section{REFERENCES}

1. Detmer DE, Sharpe K, Sufit RL, Girdley FM. Chronic compartment syndrome: diagnosis, management, and outcomes. American Journal of Sports Medicine. 1985;13(3):162-170.

2. Qvarfordt P, Christenson JT, Eklöf B, Ohlin P, Saltin B. Intramuscular pressure, muscle blood flow, and skeletal muscle metabolism in chronic anterior tibial compartment syndrome. Clin Orthop Relat Res. 1983;(179):284-290.

3. Reinking MF. Exercise Related Leg Pain (ERLP): a Review of The Literature. $N$ Am J Sports Phys Ther. 2007;2(3):170-180.

4. Brennan FH, Kane SF. Diagnosis, treatment options, and rehabilitation of chronic lower leg exertional compartment syndrome. Curr Sports Med Rep. 2003;2(5):247-250.

5. Wallensten R. Results of fasciotomy in patients with medial tibial syndrome or chronic anterior-compartment syndrome. J Bone Joint Surg Am. 1983;65(9):1252-1255.

6. García-Mata S, Hidalgo-Ovejero A, Martinez-Grande M. Chronic exertional compartment syndrome of the legs in adolescents. J Pediatr Orthop. 2001;21(3):328-334.

7. Roberts AJ, Krishnasamy P, Quayle JM, Houghton JM. Outcomes of surgery for chronic exertional compartment syndrome in a military population. J R Army Med Corps. March 2014:jramc-2013-000191.

8. Drexler M, Rutenberg TF, Rozen N, et al. Single minimal incision fasciotomy for the treatment of chronic exertional compartment syndrome: outcomes and complications. Arch Orthop Trauma Surg. 2017;137(1):73-79.

9. Schepsis AA, Martini D, Corbett M. Surgical management of exertional compartment syndrome of the lower leg. Long-term followup. American Journal of Sports Medicine. 1993;21(6):811-7-discussion817.

10. Fronek J, Mubarak SJ, Hargens AR, et al. Management of chronic exertional anterior compartment syndrome of the lower extremity. Clin Orthop Relat Res. 1987;(220):217-227.

11. Rorabeck $\mathrm{CH}$, Bourne RB, Fowler PJ. The surgical treatment of exertional compartment syndrome in athletes. J Bone Joint Surg Am. 1983;65(9):1245-1251.

12. de Fijter WM, Scheltinga MR, Luiting MG. Minimally Invasive Fasciotomy in Chronic Exertional Compartment Syndrome and Fascial Hernias of the Anterior Lower Leg: Short- and Long-Term Results. Mil Med. 2006;171(5):399-403.

13. Rorabeck $\mathrm{CH}$, Fowler PJ, Nott L. The results of fasciotomy in the management of chronic exertional compartment syndrome. American Journal of Sports Medicine. 1988;16(3):224-227. 
14. Schepsis AA, Gill SS, Foster TA. Fasciotomy for exertional anterior compartment syndrome: is lateral compartment release necessary? American Journal of Sports Medicine. 1999;27(4):430-435.

15. Verleisdonk EJMM, Schmitz RF, van der Werken C. Long-term results of fasciotomy of the anterior compartment in patients with exercise-induced pain in the lower leg. Int J Sports Med. 2004;25(3):224-229.

16. Raikin SM, Rapuri VR, Vitanzo P. Bilateral simultaneous fasciotomy for chronic exertional compartment syndrome. Foot Ankle Int. 2005;26(12):1007-1011.

17. Turnipseed W, Detmer DE, Girdley F. Chronic compartment syndrome. An unusual cause for claudication. Ann Surg. 1989;210(4):557-62-discussion562-3.

18. Styf JR, Körner LM. Chronic anterior-compartment syndrome of the leg. Results of treatment by fasciotomy. J Bone Joint Surg Am. 1986;68(9):1338-1347.

19. Due J, Nordstrand K. A simple technique for subcutaneous fasciotomy. Acta Chir Scand. 1987;153(9):521-522.

20. Cook S, Bruce G. Fasciotomy for chronic compartment syndrome in the lower limb. ANZ J Surg. 2002;72(10):720-723.

21. Finestone AS, Noff M, Nassar Y, Moshe S, Agar G, Tamir E. Management of chronic exertional compartment syndrome and fascial hernias in the anterior lower leg with the forefoot rise test and limited fasciotomy. Foot Ankle Int. 2014;35(3):285-292.

22. Micheli LJ, Solomon R, Solomon J, Plasschaert VF, Mitchell R. Surgical treatment for chronic lower-leg compartment syndrome in young female athletes. American Journal of Sports Medicine. 1999;27(2):197-201.

23. Ota Y, Senda M, Hashizume H, Inoue H. Chronic compartment syndrome of the lower leg: a new diagnostic method using near-infrared spectroscopy and a new technique of endoscopic fasciotomy. Arthroscopy. 1999;15(4):439-443.

24. de Bruijn JA, van Zantvoort APM, Winkes MB, et al. Feasibility and Safety of an Operative Tool for Anterior Chronic Exertional Compartment Syndrome Treatment. Foot Ankle Int. 2015;36(12):1475-1482.

25. Pedowitz RA, Hargens AR, Mubarak SJ, Gershuni DH. Modified criteria for the objective diagnosis of chronic compartment syndrome of the leg. American Journal of Sports Medicine. 1990;18(1):35-40.

26. Tjeerdsma J. Outcome of a Specific Compartment Fasciotomy Versus a Complete Compartment Fasciotomy of the Leg in One Patient With Bilateral Anterior Chronic Exertional Compartment Syndrome-A Case Report. J Foot Ankle Surg. 2015;O(0).

27. Adkison DP, Bosse MJ, Gaccione DR, Gabriel KR. Anatomical variations in the course of the superficial peroneal nerve. J Bone Joint Surg Am. 1991;73(1):112-114.

28. Blair JM, Botte MJ. Surgical anatomy of the superficial peroneal nerve in the ankle and foot. Clin Orthop Relat Res. 1994;(305):229-238. 
29. Mubarak SJ, Owen CA. Double-incision fasciotomy of the leg for decompression in compartment syndromes. J Bone Joint Surg Am. 1977;59(2):184-187.

30.Edmundsson D, Toolanen G. Chronic exertional compartment syndrome in diabetes mellitus. Diabet Med. 2011;28(1):81-85.

31. Lohrer H, Nauck T. Endoscopically assisted release for exertional compartment syndromes of the lower leg. Arch Orthop Trauma Surg. 2007;127(9):827-834.

32. Hutchinson MR, Bederka B, Kopplin M. Anatomic structures at risk during minimal-incision endoscopically assisted fascial compartment releases in the leg. American Journal of Sports Medicine. 2003;31(5):764-769.

33. Leversedge FJ, Casey PJ, Seiler JG, Xerogeanes JW. Endoscopically assisted fasciotomy: description of technique and in vitro assessment of lowerleg compartment decompression. American Journal of Sports Medicine. 2002;30(2):272-278.

34. Stein DA, Sennett BJ. One-portal endoscopically assisted fasciotomy for exertional compartment syndrome. Arthroscopy. 2005;21(1):108-112.

35. Wittstein J, Moorman CT, Levin LS. Endoscopic compartment release for chronic exertional compartment syndrome: surgical technique and results. Am J Sports Med. 2010;38(8):1661-1666.

36. Lohrer H, Nauck T, Lohrer L. Endoscopic-assisted Release of Lower Leg Chronic Exertional Compartment Syndromes: Results of a Systematic Literature Review. Sports Med Arthrosc. 2016;24(1):19-23. 


\section{Letter Regarding: Superficial Peroneal Nerve Injury Risk During a Semiblind Fas- ciotomy for Anterior Chronic Exertional Compartment Syndrome of the Leg: An Anatomical and Clinical Study}

N. Maffulli, A. D'Addona, G.D. Maffulli, Foot \& Ankle International, 2019;40:486-6

\section{Dear Editor:}

We are pleased to see that minimally invasive techniques are becoming a reality, and progressively accepted by the foot and ankle surgeons' community. Minimal incision fasciotomy for chronic exertional compartment syndrome (CECS) can be technically demanding, but in the right hands and for the correct indications, it provides remarkably reliable outcomes with minimal morbidity and a relatively fast return to activity, including sport.

The technique described by de Bruijn et al is elegant, ${ }^{1}$ and very similar to the one we published in 2016,3 though we started using it at least two decades earlier. Using the simple technical tips described in that article, ${ }^{2}$ which de Bruijn et al reproduced in their own cadaveric study, ${ }^{1}$ we demonstrated that the neural structures at risk were not injured, and that excellent results can be obtained using routinely available surgical instruments. Other previous studies demonstrated that diagnosis obtained by measurement of intracompartmental pressure (ICP) was necessary to decide the best treatment options and the more indicated surgical technique. ${ }^{3}$ In particular, one single minimally invasive incision of the anterior compartment was demonstrated to be able to achieve decompression and relief of symptoms among these patients, with low risk of complications such as injuries of neural structures. ${ }^{3,4}$

No doubt cost analysis studies and randomized controlled trials will be necessary to ascertain whether we are on the right path, but their results, still to be regarded as preliminary, are encouraging to prompt us to continue to explore and use these minimally invasive techniques. 


\section{REFERENCES}

1. de Bruijn JA, van Zantvoort APM, Hundscheid HPH, Hoogeveen AR, Teijink JAW, Scheltinga MR. Superficial Peroneal Nerve Injury Risk During a Semiblind Fasciotomy for Anterior Chronic Exertional Compartment Syndrome of the Leg: An Anatomical and Clinical Study. Foot Ankle Int. 2018;40(3):343-351.

2. Maffulli N, Loppini M, Spiezia F, D’Addona A, Maffulli GD. Single minimal incision fasciotomy for chronic exertional compartment syndrome of the lower leg. $J$ Orthop Surg Res. 2016;11(1):61.

3. Aweid O, Del Buono A, Malliaras P, et al. Systematic review and recommendations for intracompartmental pressure monitoring in diagnosing chronic exertional compartment syndrome of the leg. Clin J Sport Med. 2012;22(4):356-370.

4. Tzortziou V, Maffulli N, Padhiar N. Diagnosis and management of chronic exertional compartment syndrome (CECS) in the United Kingdom. Clin J Sport Med. 2006;16(3):209-213. 


\section{Response to "Letter Regarding: Superficial Peroneal Nerve Injury Risk During a Semiblind Fasciotomy for Anterior Chronic Exertional Compartment Syndrome of the Leg: An Anatomical and Clinical Study"}

J.A. de Bruijn, M.R. Scheltinga

Foot \& Ankle International, 2019;40:487-7.

\section{Dear Editor:}

We are delighted with the interest that is expressed by Professor Maffulli et al regarding our recent work on the safety of neural structures (and in particular the superficial peroneal nerve) during a minimally invasive fasciotomy of the leg anterior tibialis muscle (ant-CECS). ${ }^{1}$ We agree that a "one-incision fasciotomy" for ant-CECS is (initially) technically demanding, but the learning curve is steep. We reported that the integrity of the superficial peroneal nerve (SPN) and its unpredictable branches was maintained, both in cadaveric specimens and in 120 operated legs of patients with ant-CECS. The most important factor of the procedure is the location of the incision. We used a $2-\mathrm{cm}$ vertical incision halfway from the fibular headline to the lateral malleolar bone some $2-3 \mathrm{~cm}$ lateral to the anterior tibial crest. We earlier reported on this approach in a feasibility study encompassing 28 legs with ant-CECS in a 2015 issue of this journal. ${ }^{3}$ As a high-volume center, we now surgically treat more than 150 CECS patients yearly, approximately half with a bilateral type ant-CECS. In over 750 legs to date, we have not observed SPN damage once confirming its safety.

A difference from Maffulli's approach that was published in 2016 is related to the instrument. ${ }^{2}$ Professor Maffulli's technique may be considered a variant on the fasciotomy according to Due and Nordstrand. ${ }^{4}$ These Scandinavian surgeons introduced a "semiblind" technique with a fasciotome (rather than a pair of scissors) in 1987, possibly a minimally invasive technique "avant la lettre." Whereas Maffulli et al prefer scissors for their fasciotomy, we use a specially designed speculum coined FascioMax. This instrument has 2 blades that tightly fixate the fascia during the fasciotomy and protect the surrounding anatomical structures. ${ }^{13}$ We strongly feel that the risk of collateral tissue damage is minimized using this approach. Although we completely agree with Professor Maffulli that regular scissors may suffice in highly experienced hands, we believe our technique may have advantages 
for (orthopedic) surgeons who do not routinely perform minimally invasive fasciotomies.

We support Maffulli et al on their closing remarks that randomized controlled trials are required prior to fully embracing this minimally invasive technique for ant-CECS. To that extent, we have recently completed patient inclusion of a randomized trial determining whether the FascioMax technique performs at least as well as the Due gold standard fasciotome in experienced hands.

\section{REFERENCES}

1. de Bruijn JA, van Zantvoort APM, Hundscheid HPH, Hoogeveen AR, Teijink JAW, Scheltinga MR. Superficial Peroneal Nerve Injury Risk During a Semiblind Fasciotomy for Anterior Chronic Exertional Compartment Syndrome of the Leg: An Anatomical and Clinical Study. Foot Ankle Int. 2018;40(3):343-351.

2. Maffulli N, Loppini M, Spiezia F, D’Addona A, Maffulli GD. Single minimal incision fasciotomy for chronic exertional compartment syndrome of the lower leg. $J$ Orthop Surg Res. 2016;11(1):61.

3. de Bruijn JA, van Zantvoort APM, Winkes MB, et al. Feasibility and Safety of an Operative Tool for Anterior Chronic Exertional Compartment Syndrome Treatment. Foot Ankle Int. 2015;36(12):1475-1482.

4. Due J, Nordstrand K. A simple technique for subcutaneous fasciotomy. Acta Chir Scand. 1987;153(9):521-522. 


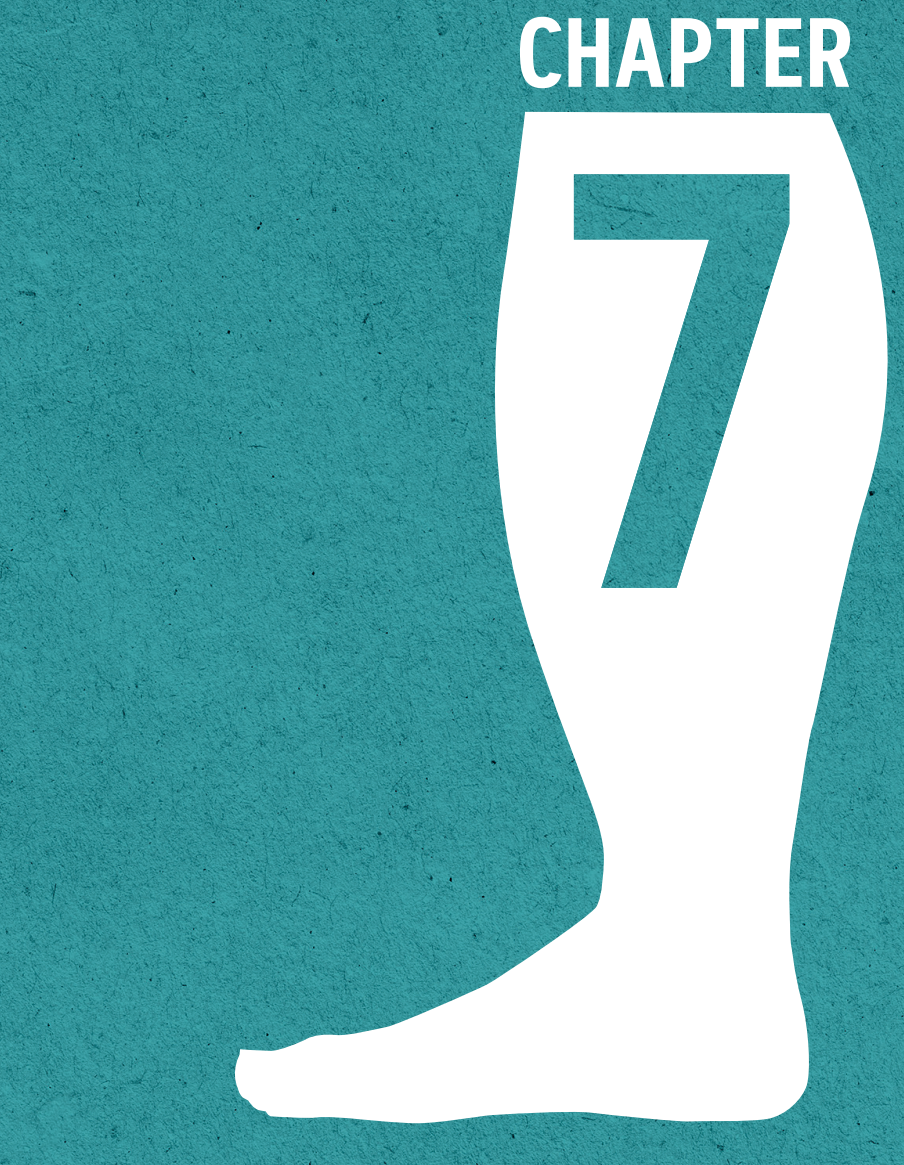




\section{CHAPTER 7}

\section{FASCIOTOMY FOR LEG}

\section{ANTERIOR CHRONIC EXERTIONAL}

\section{COMPARTMENT SYNDROME:}

\section{A COMPARISON OF TWO OPERATIVE DEVICES}

\section{Under review}

J.A. de Bruijn*,1, A.P.M. van Zantvoort*,, H.P.H. Hundscheid",

A.R. Hoogeveen ${ }^{3}$, P. van Eerten', J.A.W. Teijink ${ }^{4,5}$, M.R. Scheltinga'

1 Department of Surgery, Maxima Medical Center, Veldhoven

2 Department of Sports Medicine, Maxima Medical Center, Veldhoven

3 Department of Surgery, Catherina Hospital, Eindhoven, the Netherlands

4 Department of Epidemiology, CAPHRI research school, Maastricht 


\section{ABSTRACT}

Background: A minimally invasive semiblind fasciotomy is an operative technique for treatment of chronic exertional compartment syndrome of the anterior leg compartment (ant-CECS). Several operative techniques and devices exist but none were studied in a systematical and randomized manner.

Purpose: To compare efficacy, safety and postoperative pain of a novel operative device with a widely used device (Due fasciotome) during a semiblind fasciotomy for ant-CECS.

Study design: Randomized self-controlled clinical trial.

Methods: 50 patients with bilateral isolated ant-CECS were assigned to undergo a fasciotomy with one fasciotome (FascioMax) in one leg and another fasciotome (Due) in the other leg in one operative session. Allocation was randomized and concealed from patients at all time. Postoperative pain, peri- and postoperative complications, symptom reduction and ability to regain sports were assessed using diaries, physical examination and timed questionnaires.

Results: Enrollment occurred between October 2013 and April 2018. 50 patients (66\% female, median age 22 years, range 18-65) were studied. Complaints had forced more than half of the patients (56\%) to terminate sports. Median operative time was 15 minutes for both legs (range 1137). Perioperative complications were absent and minor postoperative complications (hematoma and superficial wound infection) were comparable in both groups. Two weeks postoperatively, most patients hardly experienced pain or required analgesics. Both devices significantly reduced cardinal symptoms in rest and during exercise in a similar manner. One year follow-up rate was $96 \%$. By then, $82 \%$ of the patients were able to regain their desired type of sports.

Discussion: The current study is the first to compare two operative devices for a semiblind fasciotomy for ant-CECS. Both performed similar in terms of efficacy, safety and levels of postoperative pain. 


\section{INTRODUCTION}

Chronic exertional compartment syndrome of the anterior leg compartment (ant-CECS) may cause invalidating complaints such as pain and tightness. Ant-CECS is found in up to a quarter of individuals who visit a sports physician with exercise induced leg complaints. ${ }^{1-3}$ This portion is even higher in specialized centers. ${ }^{4}$ Although the exact incidence in the general population is unknown, the fact that 1 in 2000 active military service members are diagnosed with CECS each year suggests that the condition is rather common. ${ }^{5}$ Patients with undiagnosed or inadequately treated ant-CECS may lose interest in sports resulting in reduced quality of life, decreased level of fitness and reduced overall health. ${ }^{6}$

Treatment of ant-CECS is initially non-operative, including rest, avoiding provocative activities, non-steroid anti-inflammatory drugs, stretching, inlays and massage. ${ }^{7,8}$ A more elaborate non-operative program including gait retraining and extensive physiotherapeutic treatment may be successful in subgroups of patients. ${ }^{9-11}$ Although these treatments are beneficial in some, most patients ultimately choose to undergo an operative treatment, which is generally more successful. ${ }^{12,13}$

A variety of techniques and tools are available for the operative treatment of ant-CECS patients. The fascia of the anterior compartment is either cut (fasciotomy) or a strip thereof is removed (fasciectomy). A fasciotomy is less invasive and is generally preferred as an initial surgical treatment. Approaches range from entirely open to minimally invasive with the aid of a fasciotome and/or an endoscope. ${ }^{14-17}$ At present, the more invasive fasciectomy is reserved for patients with recurrent or persistent antCECS after an initial fasciotomy. ${ }^{18} \mathrm{~A}$ semiblind technique uses a fasciotome that subcutaneously opens the fascia through a single $2 \mathrm{~cm}$ skin incision. ${ }^{16}$ Although results of this technique are reasonably good, we believe that the lack of direct visual contact with the fasciotome's tip and the inability to control the movements of the fascia during the procedure may increase the likelihood of damage to adjacent structures or an incomplete fasciotomy.

As a national referral center, we treat approximately 100-150 patients with ant-CECS, yearly. Up to 2012, a minimally invasive semiblind technique introduced by Due \& Nordstrand was used. ${ }^{16,19}$ With the goal of reducing the risk of complications associated with the use of this traditional fasciotome, 
we developed a novel fasciotome. ${ }^{20,21}$ Aim of the current study was to compare this instrument with a proven and widely used fasciotome in terms of efficacy, safety and postoperative pain.

\section{MATERIALS AND METHODS}

\section{Patient selection}

Maxima Medical Center in Veldhoven, the Netherlands is a referral center for diagnosis and treatment of exercise induced extremity syndromes. ${ }^{22-24}$ Starting October 2013, all patients $\geq 18$ years who were planned for operative treatment of bilateral ant-CECS were eligible for the current study. Patients were diagnosed with ant-CECS if history and physical examination were suggestive of ant-CECS and intracompartmental pressure (ICP) was elevated in the anterior compartment. All patients underwent a dynamic ICP measurement of suspected compartments before and after a standardized treadmill test to elicit complaints. ICP was considered elevated when it exceeded $15 \mathrm{~mm} \mathrm{Hg}$ in rest, $30 \mathrm{~mm} \mathrm{Hg} 1$ minute after the test or $20 \mathrm{~mm} \mathrm{Hg}$ after 5 minutes. We refrained from standardly measuring all four leg compartments to limit morbidity associated with this invasive test. Details of this diagnostic procedure were previously described. ${ }^{4}$ Patients were excluded if they had clear clinical signs of CECS in other leg compartments, had elevated ICP values in the deep flexor (dp-CECS) and/ or lateral compartment (lat-CECS), had leg conditions that may interfere with subjective pain sensations (previous leg trauma or leg surgery, neuropathy, peripheral arterial disease), or if there was a language barrier. They were informed by both the treating surgeon and the first author and received a study information brochure. All participants signed an informed consent after minimally 7 days of consideration. Enrollment continued until the calculated sample size was reached. The study protocol was approved by the local medical ethics committee and uploaded in the national trial registry (Dutch trial registry number NTR4274). All procedures adhered to the 1984 Declaration of Helsinki and its later amendments. ${ }^{25}$

\section{Study design and sample size}

The trial was designed as a randomized self-controlled clinical trial. Patients underwent the experimental operative treatment in one leg and a control operative treatment in the contralateral leg during one operative session. This design eliminates patient-related confounders and minimizes intergroup variability. Potential introduction of bias was minimized by 
randomized allocation and blinding of patients for the device allocation. The treating physicians were not blinded. Sample size calculation was based on non-inferiority (10\% margin), a power of $80 \%$, an $\alpha$ of 0.05 , a success rate of $90 \%$ for the experimental treatment and a success rate of $83 \%$ for the control treatment. Success rate of the control treatment was based on past experience whereas the success rate of the experimental treatment was estimated.

\section{Randomization, allocation and blinding}

Allocation of the devices to either the left or right leg was randomized in blocks of 4 participants. A non-involved individual performed randomization and blinded the allocation using consecutively numbered closed envelopes. Allocation was concealed for the investigators and treating physicians until the operative procedure. Allocation was kept at all times from the patients until they completed the long-term follow up questionnaire.

\section{Intervention}

On the day of surgery, all patients received $2.500 \mathrm{IU}$ of a low molecular weight heparin subcutaneously 1-2 hours prior to surgery. In all patients, both legs were operated in a single procedure under general anesthesia or a spinal block, depending on patient preferences. A tourniquet was not used. The anterior compartment was released through a $2 \mathrm{~cm}$ incision located $2-3 \mathrm{~cm}$ lateral of the tibial crest halfway between fibular head and lateral malleolus. No additional compartments were released. After bluntly removing the fatty tissue overlying the fascia, a small longitudinal fascial cut was made. The fascia towards the knee joint was further opened using the allocated fasciotome. In one leg the FascioMax fasciotome (experimental treatment; van Straten Medical, de Meern, The Netherlands) was used, in the other leg a Due fasciotome (control treatment). Characteristics of both devices were previously described in detail. ${ }^{16,20} \mathrm{~A}$ video of both procedures was supplemented to a previous publication. ${ }^{20}$ The fundamental difference between both surgical instruments is the use of a speculum in the FascioMax fasciotome (Figure 7.1). The speculum is inserted through the skin incision and stabilizes the fascia between both blades while cutting it in the direction of the knee joint. In theory, this approach has the potential to reduce the risk of injury of the surrounding tissue including blood vessels and nerves. The fascial cut was extended distally under direct visual contact with scissors some $4-6 \mathrm{~cm}$ towards the ankle. After digital 
palpation confirmed completeness of the fasciotomy, the skin was closed in one layer. All patients continuously wore compressive leg stockings for 14 days. They were permitted to walk but were asked to refrain from sports until the first outpatient visit after 2 weeks. Patients were then instructed to slowly increase their activity level until they reached maximal intensity in week 5-8. Patients were asked to contact the department of surgery after this period in case of insufficient improvement during sportive activities.
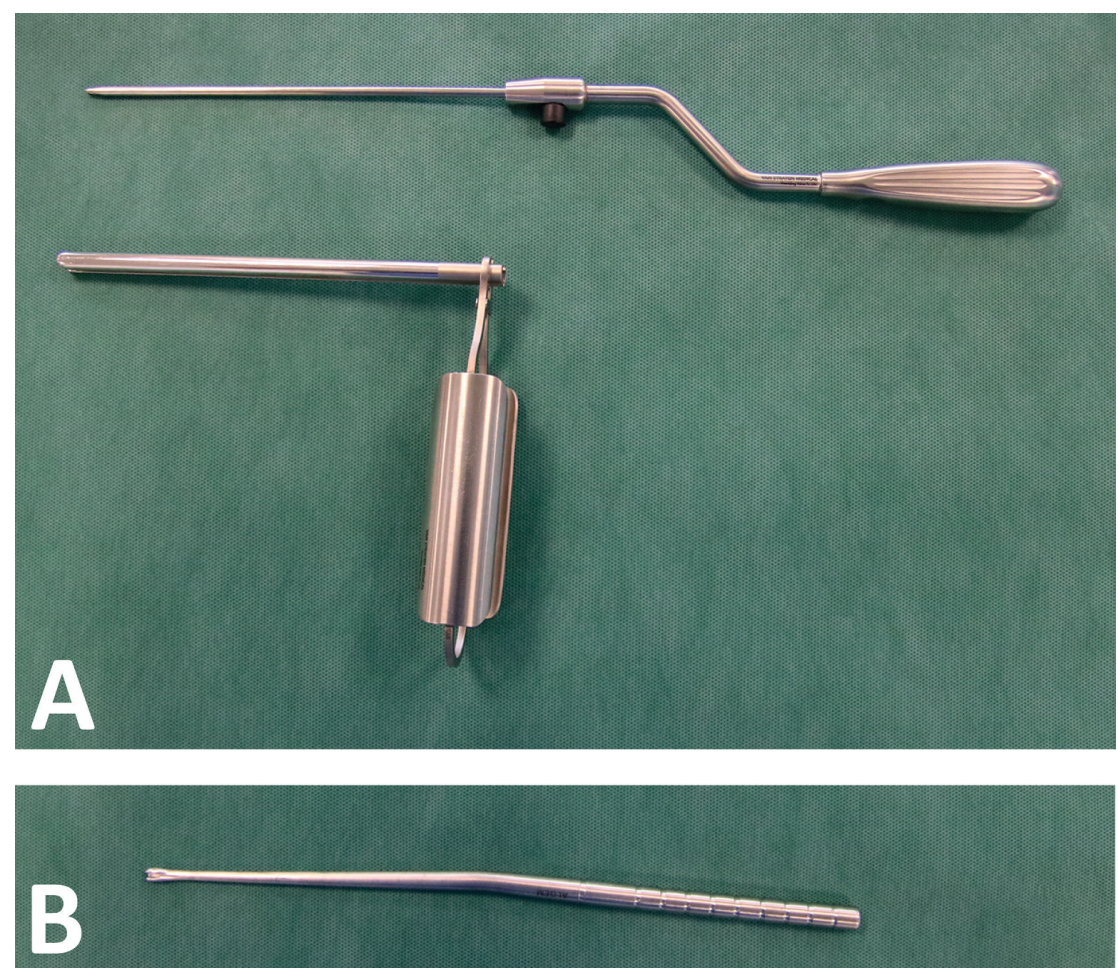

Figure 7.1: FascioMax and Due fasciotome. Panel A: FascioMax system consisting of two parts: a thin regular fasciotome and a speculum that can be opened and closed to fixate the fascia during the fasciotomy. Panel B: Due fasciotome, essentially a metal rod with a vertical knife.

\section{Outcome}

Both devices were compared in terms of postoperative pain, peri- and postoperative complications, and symptom reduction. Also the ability to regain sports was assessed. Primary outcome was reduction of the five cardinal symptoms associated with CECS, namely pain, tightness, muscle weakness, cramps and altered sensibility. Both intensity and frequency of 
each symptom were assessed after 3-6 months (short term) and $>12$ months postoperatively (long term). Participants scored pain intensity using an 11-point Numerical Rating Scale (NRS; 0 absent pain - 10 unbearable pain). Evidence suggests that this NRS is most suitable for detecting differences in pain, has a high compliance and allows for statistical analysis ${ }^{26,27}$. A 5-point Verbal Rating Scale (no, mild, moderate, severe, extremely severe) was deemed more suitable for assessing intensity of the other 4 symptoms (tightness, cramps, muscle weakness and altered sensation). This scale is patient-friendly although statistical analyses are more complicated. Frequency was assessed with a 5-point VRS (never, sometimes, half of the time, most of the time, always). An individual symptom score was calculated (Intensity*frequency) for all 5 cardinal symptoms. To compare overall improvement, individual symptom scores were added to a combined CECS-symptom score (minimal 0, maximal 104). The exact composition of both scores is shown in Table 7.1.

Table 7.1: CECS symptom score

\begin{tabular}{llllll}
\hline Symptom & Intensity & Frequency & Formula & Min & Max \\
\hline Pain & $0-10$ & $0-4$ & Intensity*Frequency & 0 & 40 \\
Tightness & $0-4$ & $0-4$ & Intensity*Frequency & 0 & 16 \\
Muscle weakness & $0-4$ & $0-4$ & Intensity*Frequency & 0 & 16 \\
Cramps & $0-4$ & $0-4$ & Intensity*Frequency & 0 & 16 \\
Altered sensation & $0-4$ & $0-4$ & Intensity*Frequency & 0 & 16 \\
\hline Total & & SUM(pain, tightness, muscle & 0 & 104 \\
& & & weakness, cramps, altered & & \\
& & & sensation) & \\
\end{tabular}

Immediately following the operative procedure, the surgeon tabulated potential untoward events including substantial bleeding, technical failures, and operative time (skin-to-skin). Postoperative pain was regarded as a measure for surgical trauma. During the first 14 postoperative days patients scored deep anterolateral leg pain as well as wound pain on an 11-point NRS (0-10). Total postoperative pain was defined as the sum of daily pain scores during the first 14 postoperative days (area under the curve, AUC). Patients were also asked to tabulate the use of analgesics. Potential postoperative complications (hematoma, wound infection and nerve injury) were reported by patients and registered at the postoperative outpatient clinic visit by the attending surgeon. Only wound infections that required antibiotics or operative treatment were tabulated. All visible hematomas were registered 
during the postoperative outpatient visit. In each patient, sensory function was assessed to identify potential nerve injuries. The ability to regain sports was determined in the postoperative questionnaires.

\section{Statistical methods}

Data analysis was performed with SPSS Statistics version 22.0.0.0 (IBM Corp, Armonk, NY, USA). When distributed normally, data are expressed as mean $\pm S D$, while non-parametric data are expressed as median with range. Postoperative pain, individual symptom scores and the combined CECS symptom score were seen as 'continuous' variables and the intervention by either device as 'paired'. Therefore, we used a Wilcoxon signed rank test (non-parametric) to assess differences in postoperative pain, individual symptom reduction and combined symptom score reduction. Differences in complication rate were assessed with a McNemar test. A p-value $<0.05$ was considered statistically significant. 


\section{RESULTS}

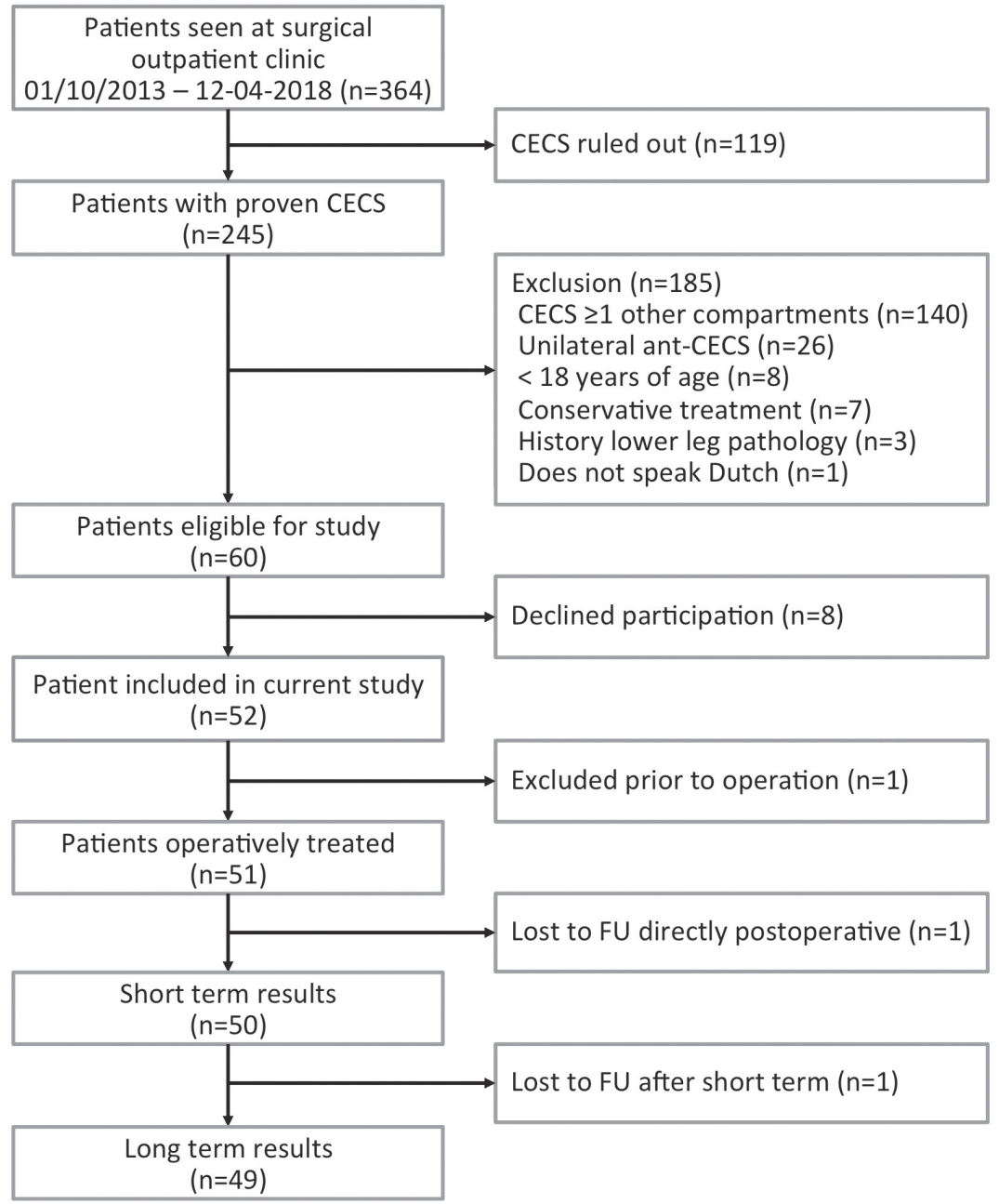

Figure 7.2: patient selection and follow-up. CECS: Chronic Exertional Compartment Syndrome, FU: Follow-up.

\section{Patient selection and follow up}

Enrollment occurred between October first 2013 and April 12 ${ }^{\text {th }} 2018$. During that period, 364 patients with exercise related leg complaints visited our surgical outpatient clinic. The vast majority ( $>90 \%$ ) was evaluated by the senior author who also performed all operations. A total of 245 patients were diagnosed with CECS. Of these, 185 met exclusion criteria (Figure 7.2). Eight suitable patients declined participation resulting in 52 included 
participants. One participant was excluded prior to the operative procedure as the preoperative questionnaire revealed that complaints were mostly unilateral. Thus, the legs of 51 ant-CECS patients were randomized. As one patient was lost to follow up immediately after surgery, the analysis of postoperative pain diaries and short-term evaluations was performed in 50 patients ( $98 \%$ short term follow up rate). Long-term data (at least 12 months postoperative) were obtained in 49 patients ( $96 \%$ long term follow up rate).

\section{Patient characteristics}

Patient characteristics are tabulated in Table 7.2. All 50 participants had participated in sportive activities but more than half (56\%) had ceased sports altogether due to pain and discomfort. As dictated by the study criteria, none of the patients had a history of peripheral artery disease, peripheral neuropathy, previous major leg trauma or earlier leg surgery. However, 2 patients had received sclerotherapy for cutaneous varicose veins.

\section{Operative procedure, peri- and postoperative complications}

Median operative time was 15 minutes (range: 11-37) for both legs together. Perioperative digital palpation revealed an incomplete fasciotomy after a first intend in two legs ( $2 \%$; FascioMax $n=1$, Due $n=1$ ). Reintroduction of the device resulted in a successful fasciotomy in both. Perioperative complications such as excessive bleeding or trauma were not observed. Additional skin incisions were not required. At the two-week outpatient evaluation, 5 superficial hematomas were seen and treated conservatively (FascioMax n=3, Due $n=2$ ). Two superficial wound infections required oral antibiotics (FascioMax $\mathrm{n}=1$, Due $\mathrm{n}=1$ ). Major complications requiring reoperation or creating lasting complaints were not encountered. Overall complication rate was $7 \%$ and similar in both groups (FascioMax $8 \%$, Due $6 \%, p=1.0$ ).

Table 7.2: Characteristics of participants $(n=50)$

\begin{tabular}{lr}
\hline Female gender, $\mathrm{n}(\%)$ & $33(66)$ \\
Median age, years (range) & $22(18-65)$ \\
Median duration complaints, months (range) & $24(5-300)$ \\
Sports type & $12(24)$ \\
$\quad$ Soccer, $\mathrm{n}(\%)$ & $10(20)$ \\
$\quad$ Running, $\mathrm{n}(\%)$ &
\end{tabular}


Table 7.2: Continued

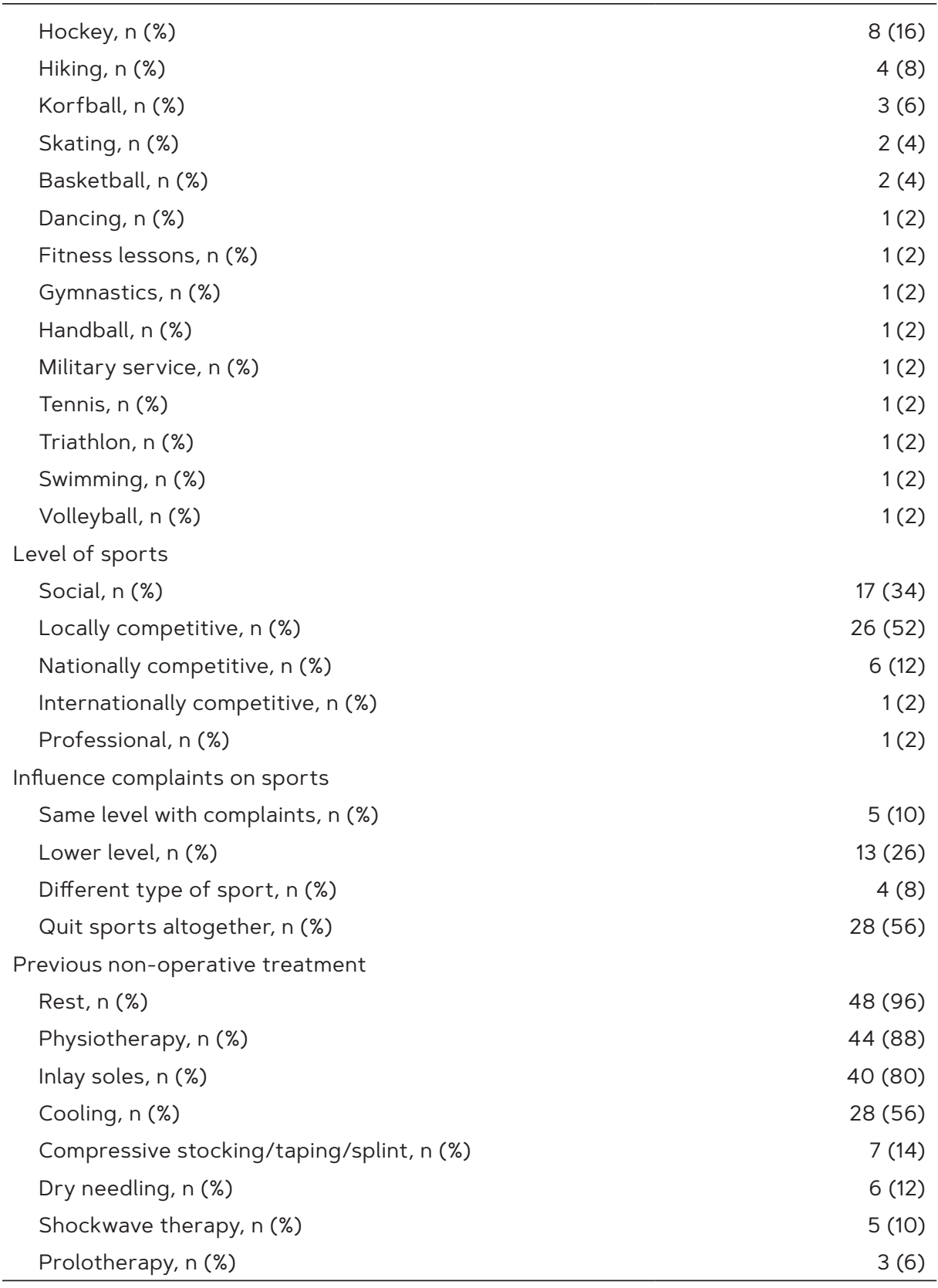

\section{Postoperative pain}

Postoperative pain levels were similar in both groups during the first 14 days after the procedure (Figure 7.3). All patients $(n=50)$ used the prescribed 
oral analgesics during the postoperative period. At day 14 , only $4 \%(2 / 50)$ still used analgesics. Anterolateral leg pain and wound pain were virtually absent (score $\leq 1)$ in 78\% (39/50) and 74\% (37/50) of the legs operated with the FascioMax, respectively. In legs operated with the Due, these numbers were comparable (leg pain 70\%, 35/50; wound pain 72\%, 36/50). Total postoperative wound pain $(p=0.41)$ and leg pain $(p=0.65)$ were also similar in both groups (Figure 7.3).

Postoperative wound pain

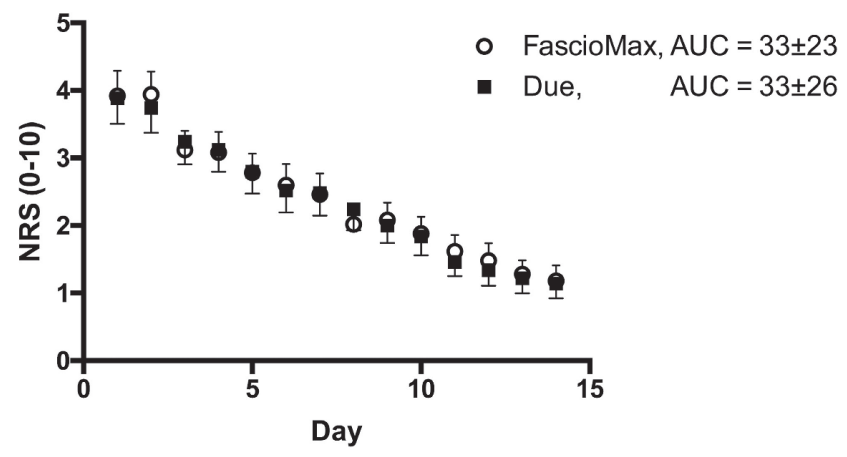

Figure 7.3: Postoperative pain on day 1-14 after a fasciotomy for ant-CECS. Patients daily scored wound pain and anterlateral leg pain using a numerical rating scale (NRS, 0-10). Areas under curve (AUC) were calculated for patients individually, mean AUC ( \pm standard error of the mean) is given

\section{Events during follow up period}

After the operation, 54\% of the participants (27/50) were just seen during routine outpatient appointments as the intervention had the desired result. The remaining $46 \%(23 / 50)$ had residual or recurrent complaints in both legs that prompted them to schedule at least one additional outpatient visit during the follow up period of at least 12 months (Supplemental Table 7.1). None of the patients returned for unilateral complaints. During the followup period, 4 patients were diagnosed with medial tibial stress syndrome (MTSS) and treated with prolotherapy $(n=1)$ or a fasciotomy of the posterior compartment(s) $(n=2)$. When complaints were suggestive of persistent ant-CECS or CECS in another leg compartment, ICP measurements were repeated $(n=16)$. Two patients were diagnosed with recurrent ant-CECS as ICP was still elevated in the anterior compartments of both legs. They were offered a fasciectomy but both declined, as symptoms were not debilitating. Patients with elevated ICP in the deep flexor compartment 
$(n=5)$ or in both the deep flexor and lateral compartment $(n=2)$ underwent a fasciotomy of the affected compartments in both legs. Other causes for persistent leg complaints were bilateral non-iatrogenic neuropathic pain $(n=1)$, bilateral hypomagnesic cramps $(n=1)$, bilateral fascial herniation $(n=1)$ or an insufficient gait pattern $(n=1)$. In 6 patients, it remained unclear what the cause for the recurrent/persistent complaints was. On the long term, patients rated the results in both legs as excellent $(n=8), \operatorname{good}(n=16)$, reasonable $(n=10)$, poor $(n=11)$ or bad $(n=4)$.
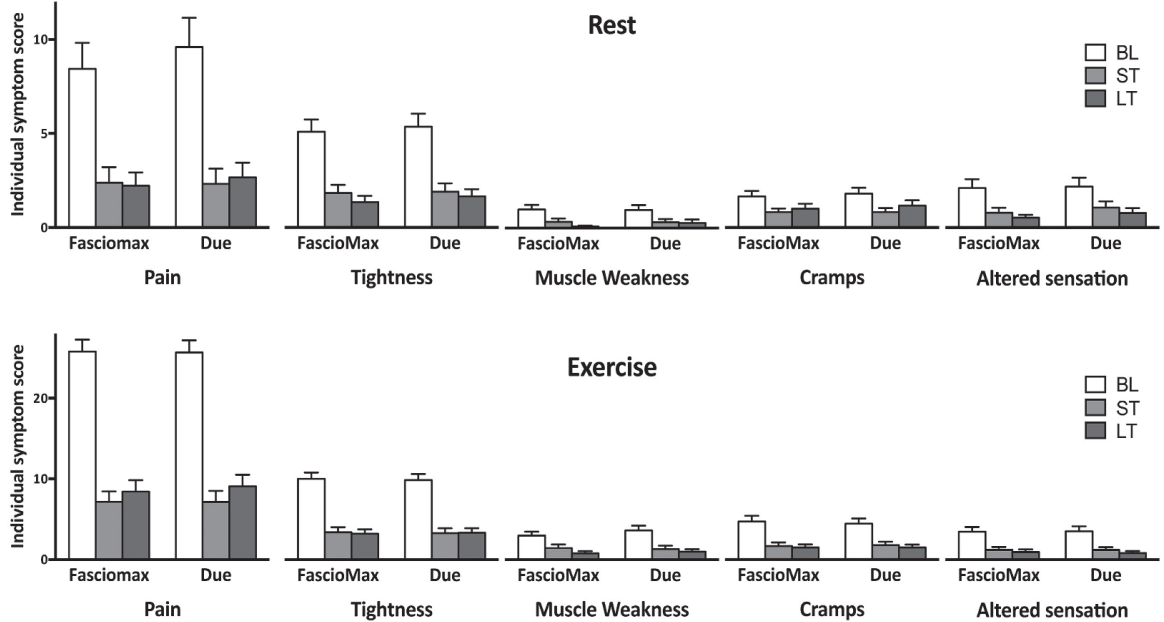

Figure 7.4: Individual symptom scores (intensity*frequency) at baseline (BL), 3-6 months postoperative (ST) and $>12$ months postoperatively (LT). The individual symptom scores range from 0-40 (pain), or from 0 to 16 (tightness, muscle weakness, cramps, altered sensation). Bars depict the mean score; error bars represent the standard error of the mean.

\section{Symptom reduction}

Figure 7.4 depicts the individual symptom scores before and after the operation. After 3-6 months, reductions of individual symptom scores were similar in both groups in rest ( $p$ ain $p=0.06$; tightness $p=0.57$; muscle weakness $p=0.89$; cramps $p=0.39$; altered sensation $p=0.59$ ) or during exercise (pain $p=0.60$; tightness $p=0.64$; muscle weakness $p=0.05$; cramps $p=0.74$; altered sensation $p=0.91$ ). In the long-term, both devises also accomplished comparable reductions of symptoms in rest (pain $p=0.23$; tightness $p=0.88$; muscle weakness $p=0.52$; cramps $p=0.92$; altered sensation $p=0.45$ ) and during exercise (pain $p=0.87$; tightness $p=0.82$; muscle weakness $p=0.24$; $\operatorname{cramps} p=0.62$; altered sensation $p=0.67$ ). All 
5 individual symptom scores were added to create a combined CECS symptom score (Table 7.1, Figure 7.5). Intervention with both devices significantly reduced the combined CECS symptom score after 3-6 months (rest: FascioMax $p<0.01$, Due $p<0.01$; exercise: FascioMax $p<0.01$, Due $p$ $<0.01$ ) and after $>12$ months (rest: FascioMax $p<0.01$, Due $p<0.01$; exercise: FascioMax $p<0.01$, Due $p<0.01$ ). No differences were found between the reductions induced by either device in rest (short term $p=0.23$, long term $p=0.63$ ) and during exercise (short term $p=0.78$, long term $p=0.85$, Figure 7.5 , lower panel).

\section{Return to sports}

Some 3-6 months postoperatively, $82 \%$ of the patients (41/50) were able to resume their desired type of sports. Moreover, $62 \%$ of the patients (31/50) were able to increase sports intensity to a level comparable or higher than before the complaints started. A total of 20\% (10/50) practiced their sport of choice at a lower-than-desired intensity, 8\% (4/50) changed the type of sport, and $10 \%$ (5/50) quitted sports altogether. At the long term follow up, $82 \%$ of the patients $(40 / 49)$ were able to participate in their favorite sport whereas $8 \%$ (4/49) was forced to start a new sport and 10\% (5/49) was not able to regain sportive activities. Two thirds of the patients $(67 \%, 33 / 49)$ were able exercise at a pre-injury (or higher) level of sports.

\section{DISCUSSION}

The current study is the first to compare a proven and widely used operative device with a novel fasciotome during a semiblind fasciotomy in patients treated for ant-CECS. Both devices significantly reduced symptoms during rest and exercise, and the overall minor complication rate was $7 \%$. No differences were found between both devices in terms of efficacy, complication rate and postoperative pain. After $>12$ months, two thirds of the patients $(67 \%)$ reported that their level of exercise had improved to a pre-injury level, and $82 \%$ was able to regain the type of sport they desired. 
Rest
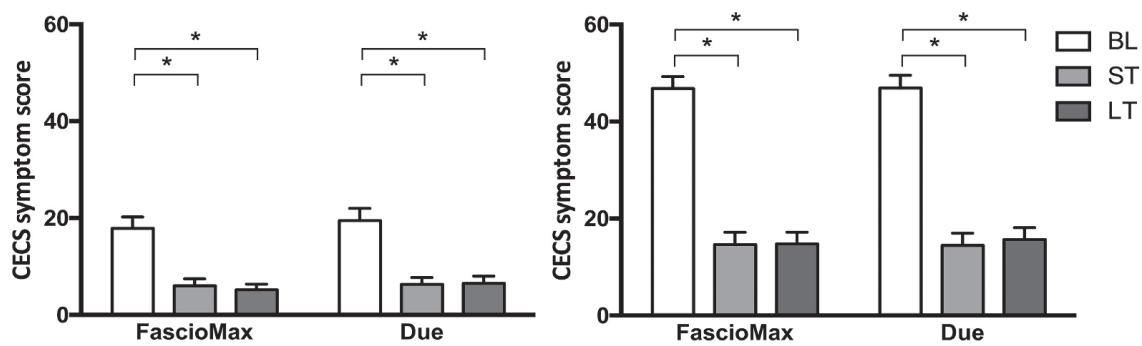

CECS symptom score reduction ratio

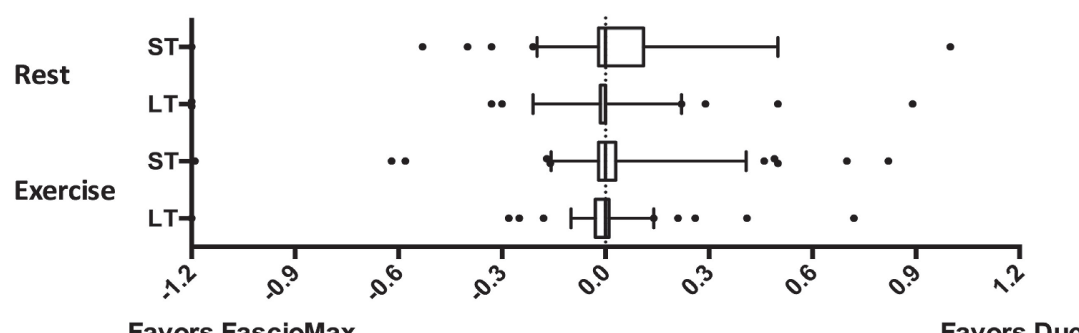

Figure 7.5: CECS symptom scores in rest (upper left panel) and during exercise (upper right panel) preoperative (BL), 3-6 months postoperative (ST) and $>12$ months postoperative (LT). Significant differences are marked with *. For each individual patient we compared the proportional reduction of the CECS symptom score in the leg operated with the FascioMax fasciotome and the leg operated with the Due fasciotome. These differences were pooled and are shown in the lower panel. The box represents the $25^{\text {th }}$ to $75^{\text {th }}$ percentile; the whiskers represent the $10^{\text {th }}$ to $90^{\text {th }}$ percentile

A variety of operative techniques for the treatment of ant-CECS are currently available. Each has its advantages and limitations. An entirely open approach offers good visibility of muscle, crossing blood vessels and nerves but at the expense of a rather large and cosmetic unattractive skin incision. 14,15,28 A technique proposed by Due in the late 1980's using a fasciotome that was introduced via a small $2-3 \mathrm{~cm}$ longitudinal skin incision greatly reduced invasiveness but the lack of continuous visual contact during the fasciotomy ('semiblind') could increase the risk on collateral damage or an incomplete fasciotomy. ${ }^{16,19,29,30}$ More recently, the aid of an endoscope was advocated. ${ }^{31,32}$ Such an approach optimizes visibility without requiring a larger incision but is time consuming and more expensive. ${ }^{17,33-35}$ The present study was undertaken to test a novel fasciotome that may help to gain more control of the fascia during a semiblind fasciotomy, 
thereby increasing ease-of-use and potentially reducing complications. We compared this alternative device with the well-proven Due fasciotome to test this hypothesis.

In the current study, major intraoperative complications such as uncontrollable bleeding, superficial peroneal nerve (SPN) damage, muscle tissue necrosis or reoperations were not encountered. Multiple retrospective and prospective cohorts describe the effects of operative treatment for ant-CECS but these are very heterogeneous in terms of size, patient selection and goals. As such, complication rates are often not reported. ${ }^{36-38}$ In studies that do mention untoward events, complication rates up to $25 \%$ were found. .9,34,39-43 These include minor complications such as hematomas or superficial wound infections but also major ones requiring reintervention (deep wound infection, major bleeding) or SPN injury. One report suggested that a semiblind fasciotomy is commonly associated with SPN damage as it was injured in 4 of 6 cadaveric legs during fasciotomy. ${ }^{33}$ The current report, as well as two earlier publications, contradicts this suggestion as a semiblind fasciotomy of the anterior compartment using the FascioMax or Due not once resulted in SPN injury in over 250 operated legs. ${ }^{4,21}$

Little is known regarding levels of pain in the weeks immediately after ant-CECS surgery. The introduction of less invasive techniques has likely reduced postoperative scarring and the total amount of surgical trauma. This approach may have resulted in less postoperative pain, a parameter reflecting iatrogenic damage. However, there are no reports focusing on postoperative pain after a fasciotomy for ant-CECS, although it may be one of the few markers of early surgical trauma. Both devices resulted in limited levels of leg and wound pain in the immediate postoperative days. In addition, just $4 \%$ of the patients still required analgesics at the 14th day postoperatively. Interestingly, the speculum that was inserted during the FascioMax approach did not cause additional incisional trauma whilst it did also not reduce collateral trauma surrounding the cleaved fascia.

Reported rates of success following surgery for ant-CECS vary substantially. Some claim that residual or recurrent complaints following a fasciotomy were virtually absent ${ }^{15,28,44}$ while others are considerable less successful. ${ }^{39}$ A recent study in military personnel, for whom physical requirements are 
considerable higher, found rates of recurrence as high as $45 \% .{ }^{45}$ However, a comparison is difficult as most publications fail to distinguish between recurrent/persistent ant-CECS, the onset of other types of leg CECS (dp-CECS, lat-CECS) or additional exercise-induced syndromes such as MTSS. The number of participants that experienced residual or recurrent complaints after the fasciotomy is higher in the current study than in the literature. ${ }^{46}$ This is likely not caused by an incomplete fasciotomy as only 2 participants with persistent complaints had persistently elevated ICP in the anterior compartment. In contrast, most patients with ongoing complaints were diagnosed with a different type of CECS. Deep-flexor and lateral compartments were only measured preoperatively when history and physical examination suggested CECS in these compartments as a means to limit ICP related complications. Symptoms in these other compartments may have been masked earlier by the dominant discomfort in the anterior compartment and by subsequent lower intensity of exertion in the months prior to operative intervention. Following successful treatment of antCECS, most patients were again able to increase sportive activities possibly promoting pressure increases in other compartments. This may also explain our high re-intervention rate $(18 \%, 9 / 50)$.

The discomfort associated with the presence of a CECS is essentially caused by a combination of five cardinal symptoms, namely pain, tightness, cramps, muscle weakness and altered skin sensation. ${ }^{47,48}$ Traditionally, these symptoms are thought to arise during exercise and to subside during prolonged rest. Although these exercise-related phenomena are pivotal in establishing the diagnosis, fate of these symptoms was never evaluated separately when considering outcome after treatment. Most reports are restricted to patient satisfaction or return to sports. $15,28,37,49,50$ When studies report on symptoms, the focus is often on pain only. ${ }^{51}$ The current study assesses changes of intensity and frequency of all 5 symptoms associated with CECS. This approach enables us to compose an individual symptom score and a combined symptom score that allow for comparison of the effect of both devices. Interestingly, both the Due and the FasioMax approach reduced CECS-associated symptoms in a similar way indicating that none of the studied techniques is superior in our hands.

Being able to improve the level of exercise is important for virtually all patients. Although this is a very broad indicator, most studies mention 
return to sportive activities (or return to full activity in army-based studies). It appears that most patients are able to regain sports following surgery, ${ }^{36,37,41,52}$ although the number of patients that experienced full recovery without any residual complaints may be limited. ${ }^{38,53}$ In active military personnel, these numbers are even lower. ${ }^{45,54}$ Our results are in line with the literature. Most patients were able to regain sports shortly after the operation, and the majority experienced complete or partial remission. However, a third of our patients were forced to exercise at a lower than desired level or decided to shift to another type of sports. This is also likely due to the ongoing presence of untreated additional exercise-induced syndromes such as MTSS or CECS of other compartments. Although most patients are able to regain sports, no less than $30 \%$ rated their outcome as 'poor' or 'bad'. We believe that this low rating in part is explained by high expectations these sportive patients had. Improved preoperative counseling may help to manage their expectations.

The present study is the first to compare two devices for a semiblind fasciotomy for ant-CECS in a randomized and highly controlled environment. The main limitation is related to the study power. Although the calculated required sample size was reached, differences between the two devices were substantially smaller than anticipated. In order to reach the predetermined power, the number of included participants would need to increase fivefold, a number that is unrealistic for a condition such as ant-CECS. As we decided to terminate the study at the current number of participants, small differences in untoward events or symptom reduction may not have been detected. Secondly, we only performed ICP measurements of suspected compartments in order to minimize ICP related morbidity. Thereby, we may have missed other types of leg CECS that became symptomatic once patients increased their sportive level after successful ant-CECS surgery. This has likely affected the re-intervention rate and has resulted in additional interventions during the follow-up period. We have tried to minimize bias by postponing the long-term questionnaire until reintervention was performed in both legs. Thirdly, a single surgeon with ample experience in both techniques performed all fasciotomies. It is possible that complication rate and symptom reduction may have been different if operative results of two (or more) surgeons with various levels of expertise had been compared. 
In conclusion, a semiblind fasciotomy of the anterior compartment with the aid of the FascioMax fasciotome is comparable to the generally accepted Due fasciotome in terms of efficacy, complication rate and postoperative pain. Both may serve as safe and effective techniques for the treatment of isolated ant-CECS. However, adequate diagnosis of concurrent dp-and/ or lat-CECS during initial diagnosis is imperative for successful treatment. 


\section{REFERENCES}

1. Qvarfordt P, Christenson JT, Eklöf B, Ohlin P, Saltin B. Intramuscular pressure, muscle blood flow, and skeletal muscle metabolism in chronic anterior tibial compartment syndrome. Clin Orthop Relat Res. 1983;(179):284-290.

2. Styf J. Diagnosis of exercise-induced pain in the anterior aspect of the lower leg. American Journal of Sports Medicine. 1988;16(2):165-169.

3. Clanton TO, Solcher BW. Chronic leg pain in the athlete. In: Foot and Ankle Injuries. Vol 13. Clinics in Sports Medicine; 1994:743-759.

4. de Bruijn JA, van Zantvoort APM, van Klaveren D, et al. Factors Predicting Lower Leg Chronic Exertional Compartment Syndrome in a Large Population. Int J Sports Med. 2018;39(1):58-66.

5. Waterman BR, Liu J, Newcomb R, Schoenfeld AJ, Orr JD, Belmont PJ. Risk factors for chronic exertional compartment syndrome in a physically active military population. Am J Sports Med. 2013;41(11):2545-2549.

6. Paik RS, Pepple DA, Pepples D, Hutchinson MR. Chronic exertional compartment syndrome. BMJ. 2013;346(jan15 2):f33-f33.

7. Rajasekaran S, Hall MM. Nonoperative Management of Chronic Exertional Compartment Syndrome: A Systematic Review. Curr Sports Med Rep. 2016;15(3):191-198.

8. Barnes M. Diagnosis and management of chronic compartment syndromes: a review of the literature. British Journal of Sports Medicine. 1997;31(1):21-27.

9. Helmhout PH, Diebal AR, van der Kaaden L, Harts CC, Beutler A, Zimmermann WO. The Effectiveness of a 6-Week Intervention Program Aimed at Modifying Running Style in Patients With Chronic Exertional Compartment Syndrome: Results From a Series of Case Studies. Orthop J Sports Med. 2015;3(3):2325967115575691.

10. Zimmermann WO, Helmhout PH, Beutler A. Prevention and treatment of exercise related leg pain in young soldiers; a review of the literature and current practice in the Dutch Armed Forces. J R Army Med Corps. 2017;163(2):94-103.

11. Diebal AR, Gregory R, Alitz C, Gerber JP. Forefoot running improves pain and disability associated with chronic exertional compartment syndrome. Am J Sports Med. 2012;40(5):1060-1067.

12. Packer JD, Day MS, Nguyen JT, Hobart SJ, Hannafin JA, MetzI JD. Functional outcomes and patient satisfaction after fasciotomy for chronic exertional compartment syndrome. Am J Sports Med. 2013;41(2):430-436.

13. Van der Wal WA, Heesterbeek PJC, van den Brand JGH, Verleisdonk EJMM. The natural course of chronic exertional compartment syndrome of the lower leg. Knee Surg Sports Traumatol Arthrosc. January 2014:1-6.

14. Mubarak SJ, Owen CA. Double-incision fasciotomy of the leg for decompression in compartment syndromes. J Bone Joint Surg Am. 1977;59(2):184-187. 
15. Rorabeck $\mathrm{CH}$, Bourne RB, Fowler PJ. The surgical treatment of exertional compartment syndrome in athletes. J Bone Joint Surg Am. 1983;65(9):1245-1251.

16. Due J, Nordstrand K. A simple technique for subcutaneous fasciotomy. Acta Chir Scand. 1987;153(9):521-522.

17. Wittstein J, Moorman CT, Levin LS. Endoscopic compartment release for chronic exertional compartment syndrome: surgical technique and results. Am J Sports Med. 2010;38(8):1661-1666.

18. Bell S. Repeat compartment decompression with partial fasciectomy. J Bone Joint Surg Br. 1986;68(5):815-817.

19. de Fijter WM, Scheltinga MR, Luiting MG. Minimally Invasive Fasciotomy in Chronic Exertional Compartment Syndrome and Fascial Hernias of the Anterior Lower Leg: Short- and Long-Term Results. Mil Med. 2006;171(5):399-403.

20. de Bruijn JA, van Zantvoort APM, Winkes MB, et al. Feasibility and Safety of an Operative Tool for Anterior Chronic Exertional Compartment Syndrome Treatment. Foot Ankle Int. 2015;36(12):1475-1482.

21. de Bruijn JA, van Zantvoort APM, Hundscheid HPH, Hoogeveen AR, Teijink JAW, Scheltinga MR. Superficial Peroneal Nerve Injury Risk During a Semiblind Fasciotomy for Anterior Chronic Exertional Compartment Syndrome of the Leg: An Anatomical and Clinical Study. Foot Ankle Int. 2018;40(3):343-351.

22. Schep G, Bender MHM, van de Tempel G, Wijn PFF, de Vries WR, Eikelboom BC. Detection and treatment of claudication due to functional iliac obstruction in top endurance athletes: a prospective study. Lancet. 2002;359(9305):466-473.

23. van Zoest W, Hoogeveen A, Scheltinga M, Sala H, van Mourik J, Brink P. Chronic Deep Posterior Compartment Syndrome of the Leg in Athletes: Postoperative Results of Fasciotomy. Int J Sports Med. 2008;29(5):419-423. doi:10.1055/s-2007-965365.

24. Winkes MB, van Zantvoort APM, de Bruijn JA, et al. Fasciotomy for Deep Posterior Compartment Syndrome in the Lower Leg: A Prospective Study. Am J Sports Med. 2016;44(5):1309-1316.

25. World Medical Association. World Medical Association Declaration of Helsinki: ethical principles for medical research involving human subjects. JAMA. 2013;310(20):2191-2194.

26. Hjermstad MJ, Fayers PM, Haugen DF, et al. Studies comparing Numerical Rating Scales, Verbal Rating Scales, and Visual Analogue Scales for assessment of pain intensity in adults: a systematic literature review. J Pain Symptom Manage. 2011;41(6):1073-1093.

27. Ferreira-Valente MA, Pais-Ribeiro JL, Jensen MP. Validity of four pain intensity rating scales. Pain. 2011;152(10):2399-2404.

28. Detmer DE, Sharpe K, Sufit RL, Girdley FM. Chronic compartment syndrome: diagnosis, management, and outcomes. American Journal of Sports Medicine. 1985;13(3):162-170. 
29. Verleisdonk EJMM, Schmitz RF, van der Werken C. Long-term results of fasciotomy of the anterior compartment in patients with exercise-induced pain in the lower leg. Int J Sports Med. 2004;25(3):224-229.

30.Edmundsson D, Toolanen G, Sojka P. Chronic compartment syndrome also affects nonathletic subjects: a prospective study of 63 cases with exerciseinduced lower leg pain. SORT. 2007;78(1):136-142.

31. Leversedge FJ, Casey PJ, Seiler JG, Xerogeanes JW. Endoscopically assisted fasciotomy: description of technique and in vitro assessment of lowerleg compartment decompression. American Journal of Sports Medicine. 2002;30(2):272-278.

32. Stein DA, Sennett BJ. One-portal endoscopically assisted fasciotomy for exertional compartment syndrome. Arthroscopy. 2005;21(1):108-112.

33. Hutchinson MR, Bederka B, Kopplin M. Anatomic structures at risk during minimal-incision endoscopically assisted fascial compartment releases in the leg. American Journal of Sports Medicine. 2003;31(5):764-769.

34. Lohrer H, Nauck T. Endoscopically assisted release for exertional compartment syndromes of the lower leg. Arch Orthop Trauma Surg. 2007;127(9):827-834.

35. Lohrer H, Nauck T, Lohrer L. Endoscopic-assisted Release of Lower Leg Chronic Exertional Compartment Syndromes: Results of a Systematic Literature Review. Sports Med Arthrosc. 2016;24(1):19-23.

36. Tam JPH, Gibson AGF, Murray JRD, Hassaballa M. Fasciotomy for chronic exertional compartment syndrome of the leg: clinical outcome in a large retrospective cohort. Eur J Orthop Surg Traumatol. 2018;27(6):23-27.

37. Pasic N, Bryant D, Willits K, Whitehead D. Assessing Outcomes in Individuals Undergoing Fasciotomy for Chronic Exertional Compartment Syndrome of the Leg. Arthroscopy. 2014;0(0).

38. van den Brand JGH, van der Werken C, Verleisdonk EJMM, T N. The Diagnostic Value of Intracompartmental Pressure Measurement, Magnetic Resonance Imaging, and Near-Infrared Spectroscopy in Chronic Exertional Compartment Syndrome: A Prospective Study in 50 Patients. American Journal of Sports Medicine. 2005;33(5):699-704

39. Howard JL, Mohtadi NG, Wiley JP. Evaluation of outcomes in patients following surgical treatment of chronic exertional compartment syndrome in the leg. Clin J Sport Med. 2000;10(3):176-184.

40.Drexler M, Rutenberg TF, Rozen N, et al. Single minimal incision fasciotomy for the treatment of chronic exertional compartment syndrome: outcomes and complications. Arch Orthop Trauma Surg. 2017;137(1):73-79.

41. Maffulli N, Loppini M, Spiezia F, D’Addona A, Maffulli GD. Single minimal incision fasciotomy for chronic exertional compartment syndrome of the lower leg. $J$ Orthop Surg Res. 2016;11(1):61. 
42. Sudmann E. The painful chronic anterior lower leg syndrome. A prospective clinical and experimental study. Acta Orthop Scand. 1979;50(5):573-581.

43. Schepsis AA, Gill SS, Foster TA. Fasciotomy for exertional anterior compartment syndrome: is lateral compartment release necessary? American Journal of Sports Medicine. 1999;27(4):430-435.

44.Rorabeck CH, Fowler PJ, Nott L. The results of fasciotomy in the management of chronic exertional compartment syndrome. American Journal of Sports Medicine. 1988;16(3):224-227.

45. Waterman BR, Laughlin M, Kilcoyne K, Cameron KL, Owens BD. Surgical treatment of chronic exertional compartment syndrome of the leg: failure rates and postoperative disability in an active patient population. J Bone Joint Surg Am. 2013;95(7):592-596.

46. Campano D, Robaina JA, Kusnezov N, Dunn JC, Waterman BR. Surgical Management for Chronic Exertional Compartment Syndrome of the Leg: A Systematic Review of the Literature. Arthroscopy. 2016;32(7):1478-1486.

47. Dunn JC, Waterman BR. Chronic exertional compartment syndrome of the leg in the military. Clinics in Sports Medicine. 2014;33(4):693-705.

48. Blackman PG. A review of chronic exertional compartment syndrome in the lower leg. Medicine \& Science in Sports \& Exercise. 2000;32(3 Suppl):S4-S10.

49. Schepsis AA, Martini D, Corbett M. Surgical management of exertional compartment syndrome of the lower leg. Long-term followup. American Journal of Sports Medicine. 1993;21(6):811-7-discussion817.

50.Schepsis AA. Revision Surgery for Exertional Anterior Compartment Syndrome of the Lower Leg: Technique, Findings, and Results. American Journal of Sports Medicine. 2005;33(7):1040-1047.

51. Finestone AS, Noff M, Nassar Y, Moshe S, Agar G, Tamir E. Management of chronic exertional compartment syndrome and fascial hernias in the anterior lower leg with the forefoot rise test and limited fasciotomy. Foot Ankle Int. 2014;35(3):285-292.

52. Gatenby G, Haysom S, Twaddle B, Walsh S. Functional Outcomes After the Surgical Management of Isolated Anterolateral Leg Chronic Exertional Compartment Syndrome. Orthop J Sports Med. 2017;5(11): 2325967117737020.

53. Styf JR, Körner LM. Chronic anterior-compartment syndrome of the leg. Results of treatment by fasciotomy. J Bone Joint Surg Am. 1986;68(9):1338-1347.

54. Roberts AJ, Krishnasamy P, Quayle JM, Houghton JM. Outcomes of surgery for chronic exertional compartment syndrome in a military population. J R Army Med Corps. March 2014:jramc-2013-000191. 


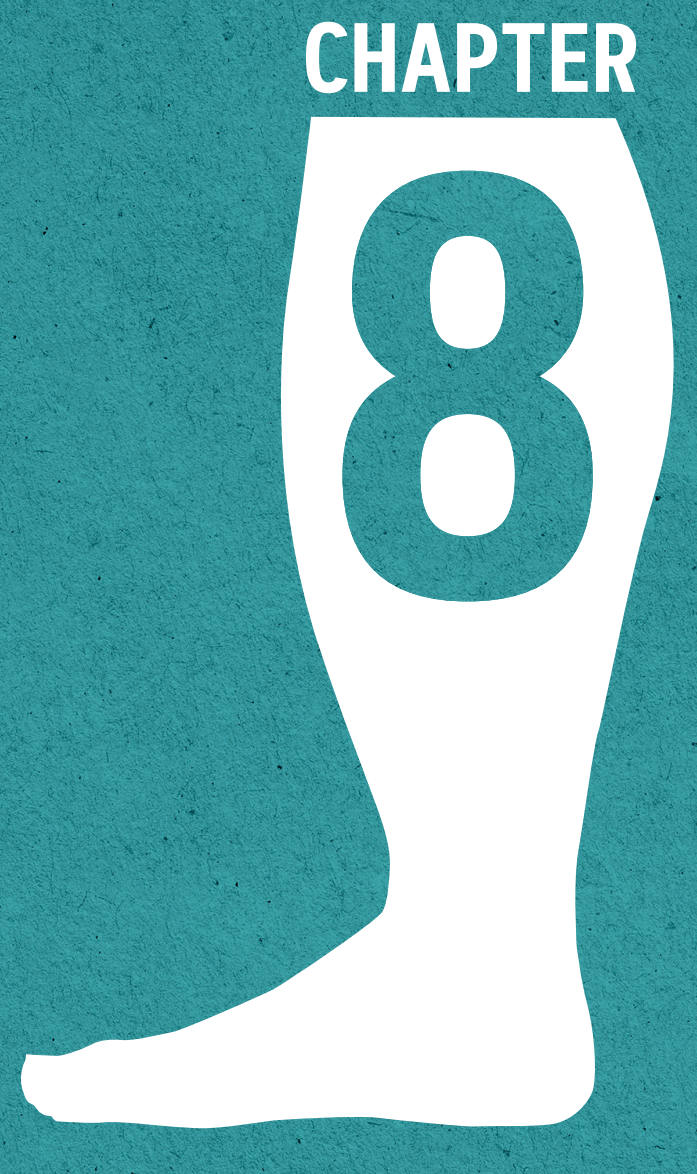




\section{CHAPTER 8}

\section{SUMMARY,}

DISCUSSION AND

FUTURE PERSPECTIVES 


\section{SUMMARY}

In this thesis, several studies are presented that may aid in improving recognition, diagnosis and treatment of chronic exertional compartment syndrome (CECS) in patients with exercise induced leg complaints. In the first half, emphasis is on identifying characteristics that may predict leg CECS in a general population and in particular in older patients. With these contributions, we strive to aid clinicians who are exposed to patients with exercise induced leg complaints and increase awareness regarding CECS. In the second half of this thesis, the focus is on the evaluation of a novel surgical tool for the treatment of CECS in the anterior leg compartment (ant-CECS). Aim was to assess whether this tool may prove a valuable alternative for currently available semiblind techniques.

Approximately one in 7 patients with exercise induced leg complaints is thought to suffer from a CECS. 'This syndrome can arise in three of the four leg muscle compartments, namely the anterior compartment (ant-CECS), the deep posterior compartment (dp-CECS), or the lateral compartment (lat-CECS). Combinations of multiple compartments are described. ${ }^{2}$ Several contradictory theories were proposed to explain the underlying mechanism explaining leg CECS. At this moment however, consensus is lacking regarding its exact pathophysiology. Although the first reports emerged more than 60 years ago and numerous reports followed, details of the clinical picture are still vague. This diagnostic confusion is mostly the result of heterogeneity in patient selection and small group sizes. One aspect however that is generally accepted by most is the finding that CECS is a condition of young and fit individuals; it is hardly described in older or unhealthy patients. Therefore, clinicians with exposure to older individuals with exercise induced leg complaints such as vascular surgeons who evaluate patients with intermittent claudication (IC) may not recognize CECS. Several conservative treatments exist but most recalcitrant CECS patients will at some point opt for an operative treatment that is aimed at opening the tight layer that is enveloping the suffocating leg muscle. Several techniques are used ranging from an entirely open to a minimally invasive approach with the use of a fasciotome..$^{3-5}$

In chapter 2 we described a large heterogeneous population of 1411 individuals who were analyzed for leg CECS in Máxima MC between 2001 and 2013. In all patients clinical history was assessed and they all 
underwent physical examination and a dynamic intracompartmental pressure measurement (ICP). Of those, 698 were diagnosed with CECS in one or more of three lower leg muscle compartments. Prevalence of CECS peaked around the age of 20-25 years and decreased thereafter, although a plateau around 50 years was found. Age, gender, bilateral symptoms, previous lower leg pathology, type of sports (running and skating) and tender muscle compartments were identified as independent predictors of leg CECS. Based on these variables, a predictive model was constructed. Its discriminative ability is moderate (AUC 0.66) and it has a good calibration over the complete range of predicted probabilities. The predictive model, presented as a nomogram, may aid in selecting individuals with exercise induced leg complaints for referral to a specialized center.

A typical CECS patient is a young and active individual as demonstrated by the vast majority of studies generally focusing on athletes and military service members. Although there are some reports describing CECS in older or less healthy individuals, little is known of similarities and differences between older CECS patients and their younger counterparts. In chapter $\mathbf{3}$ we used retrospectively gathered data of individuals who were diagnosed with CECS between January 2001 and December 2013. The 698 patients with CECS were split in two groups, patients aged 50 years or older $(n=98)$ and patients younger than 50 years $(n=600)$. A comparison of the two groups demonstrated that older individuals more often reported a history of lower leg events or comorbidities ( $\geq 50$ years, $45 \%$ vs $<50$ years, $25 \%$; $\mathrm{P}<0.01)$ and unilateral symptoms $(\geq 50$ years, $45 \%$ vs $<50$ years, $22 \%$; $\mathrm{P}<0.01)$. Most older patients (62\%) did not participate in sports or were only engaged in walking or hiking, whereas the same was true of just $7 \%$ of the younger population. Pain ( $\geq 50$ years, $94 \% ;<50$ years, $96 \%$ ) and tightness ( $\geq 50$ years, $57 \% ;<50$ years, $62 \%$ ) were the dominant symptoms of CECS in both groups. Type of CECS differed significantly as the anterior muscle compartment was more frequently affected in older patients ( $\geq 50$ years, $82 \%$ vs $<50$ years, $59 \%$ ) and $\mathrm{dp}$-CECS was more often diagnosed in younger patients ( $\geq 50$ years, $26 \%$ vs $<50$ years, $53 \%$ ). We concluded that older CECS patients were less active and had more comorbidities than their younger counterparts. In addition, older individuals more often suffered from anterior CECS. Clinicians should consider CECS in active older individuals with exercise-induced lower leg pain, particularly if it is unilaterally located. 
Peripheral arterial disease (PAD) and CECS both cause exercise-induced pain. CECS is usually present in young individuals but occasionally develops with advanced age. If so, the differentiation with intermittent claudication (IC) due to PAD may be difficult. In chapter 4, 43 CECS patients were compared to 41 PAD patients. Self reported severity and frequency of pain, tightness, muscle weakness and altered lower leg skin sensation were used to calculate individual symptom scores as well as a total symptom score. CECS patients reported significantly more symptoms in rest. After correction for age, gender, bilaterality and duration of complaints, CECS was associated with a higher combined symptom score (difference 9.9, $95 \% \mathrm{Cl} 1.8-18.0, \mathrm{p}=0.02$ ) than PAD. During exercise, group differences in pain and cramps were attenuated but CECS patients again experienced more tightness, muscle weakness and altered sensation. In addition, CECS patients reported discomfort during walking almost 4 times later than PAD patients. A time of 4.5 minutes from initiation of the activity to the start of complaints proved most discriminative for the presence of CECS (ROC curve, sensitivity 95\%, specificity 54\%, PPV 65\%). Cessation of the provocative activity alleviated complaints in all PAD patients $(n=41,100 \%)$. In contrast, the majority $(n=29,73 \%)$ of the CECS patients experienced ongoing discomfort (sensitivity $73 \%$, specificity $100 \%$, PPV 100\%). We therefore concluded that the presence of symptoms in rest such as tightness, altered sensation or muscle weakness, or ongoing complaints after cessation of the provocative activity may be indicative of CECS. If these phenomena are present in an older patient lacking risk factors of $P A D$, a vascular surgeon should consider the diagnosis CECS.

If conservative treatments are not successful, most ant-CECS patients will undergo operative treatment. A popular approach uses a surgical instrument termed a fasciotome to subcutaneously cut the fascia via a $2 \mathrm{~cm}$ skin incision, it thereby reduces invasiveness. During this 'semiblind' fasciotomy, direct visual contact with the tip of the sharp instrument is lacking. As a consequence, collateral tissue damage of muscle and nerve may occur. In chapter $\mathbf{5}$ we evaluated a novel fasciotome that was developed in our hospital that may optimize tissue protection during the fasciotomy. This FascioMax system has a speculum-like hollow tube that is inserted via a 2 -cm skin incision and allows for the protected advancement of a fasciotome. This technique was tested in 14 patients with bilateral antCECS. Technical operative success rate was 100\% (28/28 legs). Operation 
time was 10 minutes per leg (range=6-14). Perioperative complications were not observed. One superficial wound infection was treated non-operatively. Significant reduction in pain $(-2.2 \pm 1.1$ on 5 -point $V R S, P<0.001)$, tightness $(-1.9 \pm 1.6, P=0.01)$, cramps $(-1.4 \pm 1.6, P=0.009)$, muscle weakness $(-1.6 \pm$ $1.2, P<0.001)$, and altered sensibility $(-1.3 \pm 1.4, P=0.005)$ were registered 21 months postoperatively. As such, this pilot study demonstrated that the FascioMax system was safe and effective for the operative treatment of ant-CECS.

latrogenic superficial peroneal nerve (SPN) injury is a major complication that is reported in up to $8 \%$ of patients who underwent a fasciotomy for antCECS. In chapter 6 we assessed the risk of SPN injury during a semiblind fasciotomy of the anterior compartment using the FascioMax system. We performed a semiblind fasciotomy in 9 cadaver legs and did not observe any macroscopic SPN injuries. After dissecting these legs, the undamaged SPN proved safely situated at least $5 \mathrm{~mm}$ posterolateral to the opened fascia in 8/9 specimens. In 1 specimen, an undamaged intact SPN branch crossed the operative field in a ventral plane. In addition, 64 patients (120 legs) who underwent a fasciotomy of the anterior compartment between January 2013 and December 2016 in our hospital were prospectively followed. De novo sensory deficits suggestive of iatrogenic SPN injury were neither reported by the patients nor found during physical examination in any of the 120 operated legs, indicating this new technique is not associated with collateral SPN damage.

In chapter $\mathbf{7}$ we compared efficacy, safety and postoperative pain of the FascioMax fasciotome with a widely accepted device (Due fasciotome) during a semiblind fasciotomy for ant-CECS. In a randomized self-controlled clinical trial, 50 patients with bilateral isolated ant-CECS were assigned to undergo a fasciotomy using one fasciotome (FascioMax) in one leg, and another fasciotome (Due) in the other leg, in one operative session. Between October 2013 and April 2018, 50 patients were enrolled in our hospital. Complaints had forced more than half of them (56\%) to terminate sports. Median operative time was 15 minutes for both legs (range 1137). Perioperative complications were absent, and minor postoperative complications (hematoma and superficial wound infection) were comparable in both groups. Two weeks postoperatively, most patients hardly experienced pain or required analgesics. Both devices significantly reduced 
cardinal symptoms in rest and during exercise in a similar manner. One year follow-up rate was $96 \%$. By then, $82 \%$ of the patients were able to regain their original type of sports. It was concluded that both devices performed similar in terms of efficacy, safety and levels of postoperative pain.

\section{CONCLUSIONS}

1. Young age, male gender, bilateral complaints, absence of previous leg pathology and type of sport (skating) are predictive of CECS in patients with exercise induced leg complaints.

2. One in seven patients diagnosed with CECS in our hospital is 50 years or older. These patients are less active, have more comorbidities and tend to have unilateral ant-CECS more often than CECS patients younger than 50 years.

3. Compared to PAD patients, CECS patients have more symptoms in rest and experience more abundant complaints during exercise. In addition, symptoms arise later on during the provocative exercise, and persist more often after cessation of the provocative activity.

4. The FascioMax fasciotome is safe and it is feasible to use it as an alternative operative device in the treatment of ant-CECS.

5. A minimally invasive semiblind fasciotomy of the anterior leg compartment with the aid of the FascioMax fasciotome is not associated with SPN injury.

6. The FascioMax fasciotome performs similar in terms of efficacy, complication rate and postoperative pain as the commonly used Due fasciotome for a semiblind fasciotomy for ant-CECS.

\section{GENERAL DISCUSSION}

In some individuals, exercise induced leg symptoms are due to the presence of CECS. Reported history and findings during physical examination are often not specific leading to an exceedingly long diagnostic delay. The lack of a definite diagnosis may result in cessation of sportive activities and reduced overall quality of life. ${ }^{6}$ When diagnosed with CECS, most patients will opt for operative treatment, as surgery has proven to be superior over a conservative treatment regimen. ${ }^{7-9}$ This thesis focuses on improving recognition and diagnosis of CECS as well as on the evaluation of a novel operative device. The forthcoming discussion is aimed to place our study results in the context of the available literature. 


\section{History and physical examinations in CECS patients}

Most reports that describe patients with leg CECS are based on relatively small and highly selected cohorts. Due to this variation in selection criteria, characteristics reportedly associated with CECS vary and are often conflicting. ${ }^{10-12}$ For instance, early literature identified a male predominance, ${ }^{13,14}$ whereas later studies claimed that females are more prone to develop CECS.11,15 As a consequence, it is difficult for non-expert clinicians to recognize CECS in patients with leg complaints, a fact that is also reflected by an often very long diagnostic delay. ${ }^{16}$

In chapter 2 we describe a large civil cohort of patients who were analyzed for CECS. CECS was diagnosed when history and physical examination were suggestive and ICP was elevated in at least one leg compartment. In this population, young age, male gender, absence of previous lower leg pathology, sports (skating), bilateral symptoms and a painful/tensed compartment proved predictive of the presence of leg CECS. Young age and good health were already known to be associated with CECS as most reports agree that a 'typical' CECS patient is young and otherwise healthy. ${ }^{13,17,18}$ The association of male gender with leg CECS is in line with some, ${ }^{8}$ but contradictory to most recent studies. ${ }^{11,15}$ Bilateral complaints have long been associated with CECS. ${ }^{2,9,19,20}$ Findings during physical examination of CECS patients are often vague..$^{21} \mathrm{~A}$ tensed or painful compartment while palpating is frequently reported as suggestive of CECS, particularly if performed immediately following a provocative exercise. ${ }^{22,23}$ This thesis confirms that a painful and tensed compartment is indeed predictive of CECS. We have combined these factors in a predictive model. It is the first of its kind and may help clinicians in recognizing CECS based on patient specific variables.

\section{CECS in older patients}

The diagnosis CECS is mostly based on a number of items in the patient's history and often vague signs during physical examination. ${ }^{22,24}$ As leg CECS is almost always reported in young and active individuals, associated patient-related characteristics are also based on this group of patients. ${ }^{25,26}$ In fact, just two reports exist that describe CECS in older and less-sportive individuals.12,27 Therefore, CECS may not be considered or recognized in older patients having leg pain. In chapter $\mathbf{3}$ we report that CECS is not exclusively found in young and healthy patients as one in 7 patients with CECS was 50 years or older. 
It has long been recognized that CECS is a primarily bilateral entity. ${ }^{9,13}$ In one population of older patients, complaints were also mostly bilateral. ${ }^{12}$ Our results differ substantially, as almost half of the CECS patients of $\geq 50$ years had unilateral complaints. This discrepancy may be the result of a higher rate of (unilateral) comorbidities in these patients as was previously described in literature. ${ }^{27}$ Most CECS patients are actively participating in sportive activities. In fact, most reports describe populations of elite athletes and military personnel. 10,13,28 Chapter $\mathbf{3}$ demonstrates that most patients $\geq 50$ years do not participate in sports at all, but already experience complaints during walking or hiking. This finding is in line with the limited body of literature describing older individuals with CECS. ${ }^{12}$ Exertional pain and tightness are considered as the main symptoms related to CECS. $18,29,30$ Our results confirm that this is also true for older patients; both in older patients as well as their younger counterparts pain and tightness were indeed the dominant symptoms. We conclude that characteristics of older patients with CECS differ from young patients with CECS. They are usually less active, have more comorbidities and more often report unilateral complaints.

In older individuals, exercise induced leg pain, which is often referred to as IC, is mostly caused by PAD. ${ }^{34}$ However, it may also be caused by CECS (chapter 3). The incidence of PAD increases with age and is mostly seen in individuals with several comorbidities. In contrast, CECS is mostly described in young and healthy individuals. Therefore, clinicians exposed to IC patients may not think of CECS. ${ }^{10,15,31,32}$ Both CECS and IC due to PAD are characterized by exercise-induced pain. ${ }^{22,33}$ In both, complaints usually arise at a predictable moment after initiation of the provocative activity and fade shortly after cessation. ${ }^{34-36}$ In PAD patients, pain is the predominant symptom whereas in CECS patients tightness, cramps, muscle weakness and altered sensation are also reported. ${ }^{37}$

In chapter 4, we confirm that both PAD and CECS are associated with exercise-induced complaints. However, patients with CECS experience significantly more complaints in rest. As also suggested by the available literature, PAD was mostly associated with pain (and to a lesser extend, cramps) while CECS patients also experienced additional complaints namely tightness, muscle weakness and altered sensation. A clear difference between the two groups of patients is the time of onset of complaints. 
Complaints arose significantly later in CECS patients than in PAD patients. Furthermore, symptoms faded shortly after cessation of the provocative activity in all PAD patients whereas the vast majority of the CECS patients experienced ongoing complaints. We conclude that the presence of symptoms in rest, additional symptoms besides pain, a prolonged period from initiation of the provocative activity to the start of complaints, and persisting symptoms after cessation are suggestive of having CECS in older individuals with exercise induced leg complaints.

\section{Surgical treatment of (ant-)CECS}

Several operative techniques exist for the treatment of ant-CECS. These range from an entirely open approach via a rather large skin incision to a minimally invasive approach using a skin incision of only $2 \mathrm{~cm} .{ }^{4,18,38-40} \mathrm{~A}$ popular technique uses a fasciotome. ${ }^{3}$ This semiblind technique reduces invasiveness, but the lack of direct visual contact with the cutting tip during the fasciotomy limits its ease of use and may increase the likelihood of untoward events or an incomplete fasciotomy. ${ }^{41,42}$ To overcome potential disadvantages associated with this semiblind technique we developed a novel operative instrument. To test if it was worthwhile to consider a comparative study, we initially used this modified fasciotome ('FascioMax') in a small cohort of ant-CECS patients (Chapter 5). A (minor) complication rate of $3.6 \%$ is low compared to the rates found in literature. ${ }^{41,43,44}$ Furthermore, major complications needing reintervention or causing long term adverse effects (nerve damage) were not encountered. All 5 cardinal symptoms were significantly reduced postoperatively. The results of this pilot study were encouraging allowing for the initiation of two additional studies investigating safety and efficacy in depth.

A variety of complications are reported after a fasciotomy of the anterior compartment. These untoward events range from minor complications such as a small hematoma and superficial wound infections to major ones requiring reintervention. Some believe that the use of a semiblind approach increases the likelihood of these complications as visualization of collateral structures such as vessels or nerves is hampered. ${ }^{25,42}$ Reported complication rates after operative treatment for ant-CECS range from $3 \%$ up to $17 \%,{ }^{27,43,44}$ Following the successful pilot study reported in chapter $\mathbf{5}$, a randomized clinical trial was undertaken to compare complication rates and efficacy of the FascioMax device with another widely used fasciotome 
termed the Due fasciotome. In chapter $\mathbf{7}$ an overall $7 \%$ minor complication rate was seen after surgery for ant-CECS. Reintervention was never necessary. These numbers were similar in both interventional groups and somewhat lower than those found in literature. We therefore concluded that a semiblind fasciotomy with the aid of both devices is safe in our hands and is associated with a low risk of complications.

latrogenic SPN injury is a troublesome complication after a fasciotomy of the anterior compartment that may result in sensory dysfunction of the ankle and foot and may even result in foot drop. ${ }^{45}$ Symptoms suggestive for SPN injury are described in up to $8 \%$ of the patients who underwent a fasciotomy for ant-CECS. 20,39,41,46,47 Some suggest that these high numbers may be explained by the highly variable course of the nerve and suboptimal visual contact during a semiblind fasciotomy. ${ }^{42,48,49}$ In chapter 6, none of the SPNs of 9 cadaveric legs was macroscopically damaged during a semiblind fasciotomy with aid of the FascioMax fasciotome. Furthermore, no clinical signs suggestive of iatrogenic SPN injury were seen in a cohort of 120 legs operated for ant-CECS. Moreover, signs of SPN injury were also not observed in any of the 100 legs of 50 patients undergoing a fasciotomy of the anterior compartment in the randomized clinical trial described in chapter $\mathbf{7}$. We therefore conclude that the proposed modified semiblind technique with aid of the FascioMax fasciotome poses a negligible risk of SPN injury.

Rates of success following surgery for ant-CECS vary substantially. A true comparison between different techniques is difficult since studies greatly vary in size, patient selection and, most importantly, in the used definition of outcome. Some use complete remission of complaints ${ }^{13,46,50}$ while others use return to sports, ${ }^{20,51}$ return to full military service ${ }^{28}$ or patient satisfaction. ${ }^{9,16,52}$ If these heterogeneous outcome parameters are considered, surgical treatment is reportedly successful in $52-100 \%$ of the patients. ${ }^{39,44,46,53}$

In chapter $\mathbf{7}$ we compared efficacy of two operative devices during a semiblind fasciotomy of the anterior compartment using a comprehensive and structured unprecedented approach. Reduction of all cardinal symptoms, namely pain, tightness, cramps, muscle weakness and altered sensation was compared separately and as a whole using a combined 
symptom score. During rest as well as during exercise, both interventions significantly reduced all of these symptoms in a comparable manner. In addition, $82 \%$ of the patients were able to regain their preferential sports and two thirds reported that surgery improved their level of exercise to a pre-injury level. This is comparable with numbers described in civilians. ${ }^{16,51,54}$ In conclusion, we found that a semiblind fasciotomy, irrespective of the used fasciotome, was safe and effective in reducing CECS-associated symptoms. Considering these findings we believe that the FascioMax is a suitable alternative fasciotome, especially for centers with a large exposure to CECS patients that aim to perform minimally invasive fasciotomies without compromising safety.

\section{FUTURE PERSPECTIVES}

The exact incidence of leg chronic exertional compartment syndrome (CECS) in a general population is unknown. Approximations are based on small and highly selected cohorts and derived numbers are largely dependent on selection criteria. As such, the percentage of patients diagnosed with CECS ranges from one in seven patients in a sample of civilian patients who visited a sports physician with exercise induced leg complaints ${ }^{1}$ to up to half of the patients in dedicated and specialized outpatient clinics, such as described in chapter 2. In contrast to civilians, the CECS incidence is extensively studied in military populations. In the US army, yearly one in 2000 active military service members was diagnosed with CECS. ${ }^{15}$ These numbers can not be extrapolated to a general population as their characteristics and requirements are quite different. Future studies should focus on determining the incidence of CECS in civilian populations.

Due to regular exposure, most sports physicians, some orthopedic surgeons, and the occasional vascular surgeon are knowledgeable of CECS and probable able to recognize the entity in a patient with leg discomfort. However, many general practitioners, vascular surgeons, physiotherapists, or other clinicians with exposure to patients with exercise-induced complaints may not recognize the syndrome. ${ }^{55}$ This lack of awareness is reflected by a diagnostic delay of over 2 years in most publications. ${ }^{11,51}$ During this period of uncertainty, many individuals will reduce or give up their sportive activities resulting in reduced quality of life and general health. ${ }^{2}$ Therefore, increasing knowledge of CECS is of the utmost importance for these individuals. We believe this can be achieved by the use 
of tools such as the predictive nomogram presented in chapter 2 and by providing information to specific target groups such as vascular surgeons in chapter 4. More importantly however, is providing unambiguous and easy accessible information to health care professionals who are regularly exposed to CECS patients. Increasing awareness is one of the goals of the Dutch workgroup 'Netwerk inspanningsafhankelijke pijnsyndromen' (NIAPS, 'network exercise-related pain syndromes') that was established in 2017. In the near future, we expect that this multidisciplinary network of sports physicians, physiotherapists, neurologists, radiologists and (orthopedic) surgeons will provide clear and uniform information for primary care and guidelines regarding diagnostics and therapy.

The current understanding of the mechanisms responsible for leg CECS is incomplete. It is generally accepted that repetitive muscular contractions such as during exercise increase intracompartmental volume and pressure. ${ }^{56,57}$ However, why these events are asymptomatic in healthy individuals but cause complaints in CECS patients is largely unknown. Most experts believe a prolonged elevated intracompartmental pressure (ICP) is pivotal in the pathophysiology. ${ }^{58,59}$ The mechanism by which this elevated pressure causes symptoms is also still a matter of debate. The finding that symptom patterns in elderly CECS patients are entirely different from vascular patients with intermittent claudication suggests that ischemia is not crucial. Future research including fascial biopsies, fascial electrophysiology or ultrasound elastography will hopefully provide new insights in these mechanisms.

Diagnosing CECS is difficult in most patients and requires expert clinicians and adequate diagnostic tools. For an appropriate referral of a suspected patient, clinicians should be able to recognize CECS in a heterogeneous population of patients with leg complaints. In chapter $\mathbf{2}$ we have introduced a predictive nomogram that could aid in deciding whether patients require (invasive) diagnostics. This nomogram was constructed based on a retrospective cohort. In the near future it will need to be validated in a different population that is preferentially followed in a prospective manner.

At present, the gold standard for diagnosis of leg CECS is an invasive ICP measurement. ${ }^{14}$ However, this method is severely criticized in recent years as validity of the test itself and the used cut-off values were questioned. ${ }^{60,61}$ 
In addition, the accuracy of freehand placed catheters in the deep flexor compartment requires improvement. ${ }^{62}$ The need for improved diagnostic tools is reflected by a relatively high number of patients with persistent complaints in chapter 7 . Only a minority of these patients had recurrent or persisting ant-CECS after surgical treatment suggesting that diagnosis could be improved. Magnetic resonance imaging (MRI) and/or near infrared spectrometry (NIRS) have shown potential in an experimental setting but are, to our knowledge, currently not used on a larger scale. ${ }^{63}$ Future research should focus on improving current diagnostics and implementing alternatives.

Several techniques are used for the surgical treatment of ant-CECS. Most reports describing these techniques are heterogeneous in terms of goals, patient population and, most importantly, outcome measurements. This variety greatly hinders an adequate comparison of efficacy of techniques. A recent systematic review confirms that comparison between techniques is difficult, and described benefits or risks of certain techniques are largely anecdotal. ${ }^{5}$ Randomized comparative studies that could potentially establish definite and good quality evidence are difficult to execute due to strong researcher prevalence and a relatively limited number of patients. Therefore, we advocate the use of universal outcome parameters. The method described in chapter 7 may contribute to this goal. This questionnaire systematically addresses all 5 cardinal symptoms both in rest and during exercise before and after treatment and addresses subjective variables such as 'return to sports' and 'satisfaction'. 


\section{REFERENCES}

1. Qvarfordt P, Christenson JT, Eklöf B, Ohlin P, Saltin B. Intramuscular pressure, muscle blood flow, and skeletal muscle metabolism in chronic anterior tibial compartment syndrome. Clin Orthop Relat Res. 1983;(179):284-290.

2. Tucker AK. Chronic exertional compartment syndrome of the leg. Curr Rev Musculoskelet Med. 2010;3(1-4):32-37.

3. Due J, Nordstrand K. A simple technique for subcutaneous fasciotomy. Acta Chir Scand. 1987;153(9):521-522.

4. Mubarak SJ, Owen CA. Double-incision fasciotomy of the leg for decompression in compartment syndromes. J Bone Joint Surg Am. 1977;59(2):184-187.

5. Campano D, Robaina JA, Kusnezov N, Dunn JC, Waterman BR. Surgical Management for Chronic Exertional Compartment Syndrome of the Leg: A Systematic Review of the Literature. Arthroscopy. 2016;32(7):1478-1486.

6. Paik RS, Pepple DA, Pepples D, Hutchinson MR. Chronic exertional compartment syndrome. BMJ. 2013;346(jan15 2):f33-f33.

7. Van der Wal WA, Heesterbeek PJC, van den Brand JGH, Verleisdonk EJMM. The natural course of chronic exertional compartment syndrome of the lower leg. Knee Surg Sports Traumatol Arthrosc. January 2014:1-6.

8. Thein R, Tilbor I, Rom E, et al. Return to sports after chronic anterior exertional compartment syndrome of the leg: Conservative treatment versus surgery. $J$ Orthop Surg (Hong Kong). 2019;27(2):2309499019835651.

9. Packer JD, Day MS, Nguyen JT, Hobart SJ, Hannafin JA, Metzl JD. Functional outcomes and patient satisfaction after fasciotomy for chronic exertional compartment syndrome. Am J Sports Med. 2013;41(2):430-436.

10. Clanton TO, Solcher BW. Chronic leg pain in the athlete. In: Foot and Ankle Injuries. Vol 13. Clinics in Sports Medicine; 1994:743-759.

11. Davis DE, Raikin S, Garras DN, Vitanzo P, Labrador H, Espandar R. Characteristics of patients with chronic exertional compartment syndrome. Foot Ankle Int. 2013;34(10):1349-1354.

12. Edmundsson D, Toolanen G, Sojka P. Chronic compartment syndrome also affects nonathletic subjects: a prospective study of 63 cases with exerciseinduced lower leg pain. SORT. 2007;78(1):136-142.

13. Detmer DE, Sharpe K, Sufit RL, Girdley FM. Chronic compartment syndrome: diagnosis, management, and outcomes. American Journal of Sports Medicine. 1985;13(3):162-170.

14. Pedowitz RA, Hargens AR, Mubarak SJ, Gershuni DH. Modified criteria for the objective diagnosis of chronic compartment syndrome of the leg. American Journal of Sports Medicine. 1990;18(1):35-40. 
15. Waterman BR, Liu J, Newcomb R, Schoenfeld AJ, Orr JD, Belmont PJ. Risk factors for chronic exertional compartment syndrome in a physically active military population. Am J Sports Med. 2013;41(11):2545-2549.

16. Pasic N, Bryant D, Willits K, Whitehead D. Assessing Outcomes in Individuals Undergoing Fasciotomy for Chronic Exertional Compartment Syndrome of the Leg. Arthroscopy. 2014;0(0).

17. Howard JL, Mohtadi NG, Wiley JP. Evaluation of outcomes in patients following surgical treatment of chronic exertional compartment syndrome in the leg. Clin J Sport Med. 2000;10(3):176-184.

18. Micheli LJ, Solomon R, Solomon J, Plasschaert VF, Mitchell R. Surgical treatment for chronic lower-leg compartment syndrome in young female athletes. American Journal of Sports Medicine. 1999;27(2):197-201.

19. Mouhsine E, Garofalo R, Moretti B, Gremion G, Akiki A. Two minimal incision fasciotomy for chronic exertional compartment syndrome of the lower leg. Knee Surg Sports Traumatol Arthrosc. 2006;14(2):193-197.

20. Raikin SM, Rapuri VR, Vitanzo P. Bilateral simultaneous fasciotomy for chronic exertional compartment syndrome. Foot Ankle Int. 2005;26(12):1007-1011.

21. Lohrer H, Malliaropoulos N, Korakakis V, Padhiar N. Exercise-induced leg pain in athletes: diagnostic, assessment, and management strategies. Phys Sportsmed. 2019;47(1):47-59.

22. Blackman PG. A review of chronic exertional compartment syndrome in the lower leg. Medicine \& Science in Sports \& Exercise. 2000;32(3 Suppl):S4-S10.

23. Burrus MT, Werner BC, Starman JS, et al. Chronic Leg Pain in Athletes. Am J Sports Med. August 2014:0363546514545859.

24. Reinking MF. Exercise Related Leg Pain (ERLP): a Review of The Literature. $N$ Am J Sports Phys Ther. 2007;2(3):170-180.

25. Turnipseed W, Detmer DE, Girdley F. Chronic compartment syndrome. An unusual cause for claudication. Ann Surg. 1989;210(4):557-62-discussion562-3.

26. Styf J. Diagnosis of exercise-induced pain in the anterior aspect of the lower leg. American Journal of Sports Medicine. 1988;16(2):165-169.

27. Edmundsson D, Toolanen G. Chronic exertional compartment syndrome in diabetes mellitus. Diabet Med. 2011;28(1):81-85.

28. Waterman BR, Laughlin M, Kilcoyne K, Cameron KL, Owens BD. Surgical treatment of chronic exertional compartment syndrome of the leg: failure rates and postoperative disability in an active patient population. $J$ Bone Joint Surg Am. 2013;95(7):592-596.

29. Rorabeck CH, Bourne RB, Fowler PJ. The surgical treatment of exertional compartment syndrome in athletes. J Bone Joint Surg Am. 1983;65(9):1245-1251. 
30.Slimmon D, Bennell K, Brukner P, Crossley K, Bell SN. Long-term outcome of fasciotomy with partial fasciectomy for chronic exertional compartment syndrome of the lower leg. American Journal of Sports Medicine. 2002;30(4):581588.

31. Selvin E. Prevalence of and Risk Factors for Peripheral Arterial Disease in the United States: Results From the National Health and Nutrition Examination Survey, 1999-2000. Circulation. 2004;110(6):738-743.

32. Criqui MH, Aboyans V. Epidemiology of peripheral artery disease. Circ Res. 2015;116(9):1509-1526.

33. Apigian AK, Landry GJ. Basic data underlying decision making in nonatherosclerotic causes of intermittent claudication. Annals of Vascular Surgery. 2015;29(1):138-153.

34. McDermott MM, Greenland P, Liu K, et al. Leg symptoms in peripheral arterial disease: associated clinical characteristics and functional impairment. JAMA. 2001;286(13):1599-1606.

35. Winkes MB, van Zantvoort APM, de Bruijn JA, et al. Fasciotomy for Deep Posterior Compartment Syndrome in the Lower Leg: A Prospective Study. Am J Sports Med. 2016;44(5):1309-1316.

36.Brennan FH, Kane SF. Diagnosis, treatment options, and rehabilitation of chronic lower leg exertional compartment syndrome. Curr Sports Med Rep. 2003;2(5):247-250.

37. Fraipont MJ, Adamson GJ. Chronic exertional compartment syndrome. J Am Acad Orthop Surg. 2003;11(4):268-276.

38. Wallensten R. Results of fasciotomy in patients with medial tibial syndrome or chronic anterior-compartment syndrome. J Bone Joint Surg Am. 1983;65(9):1252-1255.

39. Verleisdonk EJMM, Schmitz RF, van der Werken C. Long-term results of fasciotomy of the anterior compartment in patients with exercise-induced pain in the lower leg. Int J Sports Med. 2004;25(3):224-229.

40.Lohrer H, Nauck T. Endoscopically assisted release for exertional compartment syndromes of the lower leg. Arch Orthop Trauma Surg. 2007;127(9):827-834.

41. de Fijter WM, Scheltinga MR, Luiting MG. Minimally Invasive Fasciotomy in Chronic Exertional Compartment Syndrome and Fascial Hernias of the Anterior Lower Leg: Short- and Long-Term Results. Mil Med. 2006;171(5):399-403.

42. Hutchinson MR, Bederka B, Kopplin M. Anatomic structures at risk during minimal-incision endoscopically assisted fascial compartment releases in the leg. American Journal of Sports Medicine. 2003;31(5):764-769.

43. Fronek J, Mubarak SJ, Hargens AR, et al. Management of chronic exertional anterior compartment syndrome of the lower extremity. Clin Orthop Relat Res. 1987;(220):217-227. 
44.Roberts AJ, Krishnasamy P, Quayle JM, Houghton JM. Outcomes of surgery for chronic exertional compartment syndrome in a military population. J R Army Med Corps. March 2014:jramc-2013-000191.

45. Asp AR, Marsland D, Elliot RR. The superficial peroneal nerve: A review of its anatomy and surgical relevance. OA anatomy. 2014;15;2(1):1-6.

46. Rorabeck $\mathrm{CH}$, Fowler PJ, Nott L. The results of fasciotomy in the management of chronic exertional compartment syndrome. American Journal of Sports Medicine. 1988;16(3):224-227.

47. Schepsis AA, Martini D, Corbett M. Surgical management of exertional compartment syndrome of the lower leg. Long-term followup. American Journal of Sports Medicine. 1993;21(6):811-7-discussion817.

48. Adkison DP, Bosse MJ, Gaccione DR, Gabriel KR. Anatomical variations in the course of the superficial peroneal nerve. J Bone Joint Surg Am. 1991;73(1):112-114.

49. Blair JM, Botte MJ. Surgical anatomy of the superficial peroneal nerve in the ankle and foot. Clin Orthop Relat Res. 1994;(305):229-238.

50. Cook S, Bruce G. Fasciotomy for chronic compartment syndrome in the lower limb. ANZ J Surg. 2002;72(10):720-723.

51. Gatenby G, Haysom S, Twaddle B, Walsh S. Functional Outcomes After the Surgical Management of Isolated Anterolateral Leg Chronic Exertional Compartment Syndrome. Orthop J Sports Med. 2017;5(11):2325967117737020.

52. Drexler M, Rutenberg TF, Rozen N, et al. Single minimal incision fasciotomy for the treatment of chronic exertional compartment syndrome: outcomes and complications. Arch Orthop Trauma Surg. 2017;137(1):73-79.

53. Almdahl SM, Samdal F. Fasciotomy for chronic compartment syndrome. Acta Orthop Scand. 1989;60(2):210-211.

54.Tam JPH, Gibson AGF, Murray JRD, Hassaballa M. Fasciotomy for chronic exertional compartment syndrome of the leg: clinical outcome in a large retrospective cohort. Eur J Orthop Surg Traumatol. 2018;27(6):23-27.

55. Turnipseed WD. Diagnosis and management of chronic compartment syndrome. Surgery. 2002;132(4):613-619.

56. Arai $\mathrm{M}$, Endoh $\mathrm{H}$. Blood flow through human skeletal muscle during and after contraction. Tohoku J Exp Med. 1974;114(4):379-384.

57. Veith RG, Matsen FA, Newell SG. Recurrent Anterior Compartmental Syndromes. Phys Sportsmed. 1980;8(11):80-88.

58.Puranen J, Alavaikko A. Intracompartmental pressure increase on exertion in patients with chronic compartment syndrome in the leg. J Bone Joint Surg Am. 1981;63(8):1304-1309.

59. Styf J. Chronic exercise-induced pain in the anterior aspect of the lower leg. An overview of diagnosis. Sports Med. 1989;7(5):331-339. 


\section{Chapter 8}

60. Aweid O, Del Buono A, Malliaras P, et al. Systematic review and recommendations for intracompartmental pressure monitoring in diagnosing chronic exertional compartment syndrome of the leg. Clin J Sport Med. 2012;22(4):356-370.

61. Roberts A, Franklyn-Miller A. The validity of the diagnostic criteria used in chronic exertional compartment syndrome: a systematic review. Scandinavian Journal of Medicine \& Science in Sports. 2012;22(5):585-595.

62. Winkes MB, Tseng CM, Pasmans HL, van der Cruijsen-Raaijmakers M, Hoogeveen AR, Scheltinga MR. Accuracy of Palpation-Guided Catheter Placement for Muscle Pressure Measurements in Suspected Deep Posterior Chronic Exertional Compartment Syndrome of the Lower Leg: A Magnetic Resonance Imaging Study. American Journal of Sports Medicine. 2016;44(10).

63. van den Brand JGH, van der Werken C, Verleisdonk EJMM, T N. The Diagnostic Value of Intracompartmental Pressure Measurement, Magnetic Resonance Imaging, and Near-Infrared Spectroscopy in Chronic Exertional Compartment Syndrome: A Prospective Study in 50 Patients. American Journal of Sports Medicine. 2005;33(5):699-704. 
Summary, general discussion, and future perspectives 


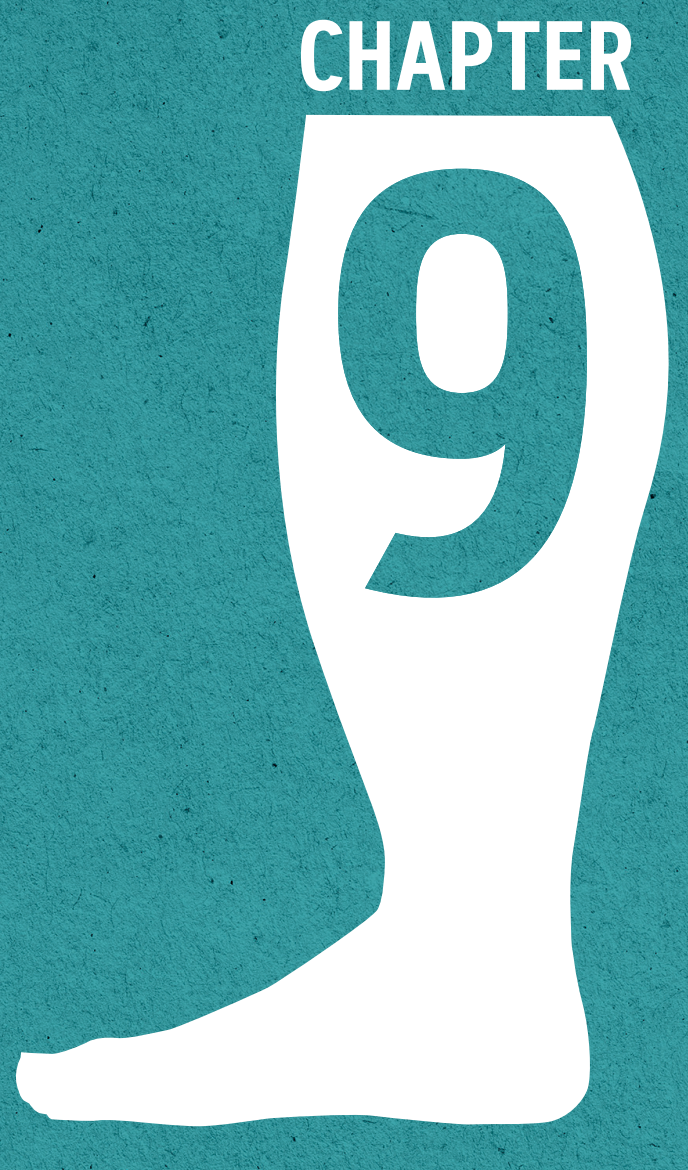




\section{CHAPTER 9}

\section{VALORIZATION}




\section{INTRODUCTION}

Chronic exertional compartment syndrome (CECS) of the leg is a condition seen mostly in young and otherwise healthy individuals. However, as is demonstrated in this thesis, elderly may also suffer from CECS during sportive activities or walking. Although the exact incidence in the general population is unknown, CECS is believed to be the underlying cause in a considerable portion of patients with exercise related leg complaints. ' In specialized outpatient clinics evaluating a highly selected population, up to half of the patients with exercise-induced leg complaints is diagnosed with CECS (chapter 2). Moreover, the fact that yearly one out of every 2000 active military service members is diagnosed with CECS may be indicative that CECS is also not uncommon in the general population. ${ }^{2}$

We are convinced that CECS is greatly underdiagnosed and, thus, undertreated. Many affected individuals reduce their sportive activities on their own initiative, thereby lowering complaints to an acceptable level and deterring them from consulting a clinician. Those who do seek medical help, risk to be confronted with unawareness as most physicians and physiotherapists are unfamiliar with specifics of the condition. As a consequence, many individuals with CECS experience prolonged leg complaints or may never be diagnosed as such.

\section{SOCIAL AND ECONOMICAL RELEVANCE}

Recent years have seen an increasing interest in preventative medicine. ${ }^{3}$ A growing body of evidence suggests that it is better to prevent chronic diseases rather than treat once symptoms emerge. Prevention of certain diseases such as lung cancer and chronic obstructive pulmonary disease by reducing known risk factors such as smoking is well accepted by the community. Numerous other chronic illnesses are related to a sedentary lifestyle, and promoting a healthy and sportive lifestyle may serve as highly effective primary prevention. In fact, it has been shown that individuals who adhere to a healthy and active lifestyle at mid-life have a longer life expectancy free of major chronic diseases. ${ }^{4}$ In addition, evidence suggests that engaging in exercise has a positive influence in patients with cardiovascular disease, pulmonary disease, metabolic diseases and some psychiatric diseases. ${ }^{5}$ 
Patients with CECS experience complaints during sports and even during regular everyday activities. This thesis reports that a substantial portion of patients is hindered also during rest, in contrast to generally accepted beliefs. Due to these invalidating complaints, most patients with unrecognized and/or untreated CECS will adapt their lifestyle or abandon sports. Many CECS patients already experience complaints in everyday life and some are not able to continue their current job and may withdraw from the labor market. On the other hand, undiagnosed patients may undergo a host of non-specific therapies that are often costly and timeconsuming. Being unable to participate in sports and/or everyday activities will negatively affect quality of life. Furthermore, lowering physical activity will increase the likelihood of chronic diseases later on in life including obesity, cardiovascular disease, pulmonary disease, and diabetes. ${ }^{4}$ As such, early recognition and proper treatment of CECS may prevent individuals from quitting sports and reducing physical activity. Moreover, invalidating or incapacitating and costly chronic diseases that may occur later on in life may be prevented.

\section{RELEVANCE IN THE MEDICAL FIELD}

CECS is a condition that most physicians do not diagnose on a daily basis. As such, it may be difficult to recognize as is illustrated by the average doctor's delay of several years. The first chapters in this thesis were aimed at increasing knowledge on CECS and helping clinicians in its recognition. In chapter 2, we have constructed a predictive nomogram that may aid in identifying CECS in patients with exercise-induced leg complaints. With this tool, clinicians may select patients requiring invasive intracompartmental pressure measurements. In chapter $\mathbf{3}$ we demonstrate that characteristics and symptomatology of older CECS patients ( $\geq 50$ years) differ from their younger counterparts. As current knowledge on CECS is based on young and healthy patients, these findings may aid in recognizing CECS in older patients with exercise-induced leg complaints. In chapter 4 we compared a cohort of CECS patients with a cohort of peripheral artery disease (PAD) patients who experienced intermittent claudication (IC). The differences in characteristics and symptomatology between both populations were substantial and may be used to recognize CECS in individuals who visit a vascular surgeon with IC. 


\section{Chapter 9}

The second main goal of this thesis was to introduce and test a novel tool for the surgical treatment of CECS in the anterior compartment of the leg (ant-CECS). Several techniques exist but none were compared in a randomized manner. Moreover, continuously varying outcome parameters make comparison of efficacy and safety of the different techniques difficult. In chapter $\mathbf{5}$ we demonstrated that our newly introduced FascioMax system was safe and feasible. In chapter $\mathbf{6}$ we investigated the potential risk on one of the most invalidating complications after a fasciotomy of the anterior compartment, namely injury of the superficial peroneal nerve (SPN). Using this novel system, the SPN was never injured in 9 cadaveric legs nor in 64 patients. Lastly, chapter 7 compared efficacy, postoperative pain and complications of the Fasciomax system with a well-known alternative fasciotome during a semiblind fasciotomy of the anterior compartment. In addition, a questionnaire was introduced that allows for quantifying the effect of surgery on all 5 cardinal symptoms associated with CECS. Introduction of these methods may facilitate future comparison of efficacy of treatment modalities for CECS. 


\section{REFERENCES}

1. Qvarfordt P, Christenson JT, Eklöf B, Ohlin P, Saltin B. Intramuscular pressure, muscle blood flow, and skeletal muscle metabolism in chronic anterior tibial compartment syndrome. Clin Orthop Relat Res. 1983;(179):284-290.

2. Waterman BR, Liu J, Newcomb R, Schoenfeld AJ, Orr JD, Belmont PJ. Risk factors for chronic exertional compartment syndrome in a physically active military population. Am J Sports Med. 2013;41(11):2545-2549.

3. Burgering E, Drewes Y. Preventie en Gezondheidsbevordering. KNMG. May 2015.

4. Li Y, Schoufour J, Wang DD, et al. Healthy lifestyle and life expectancy free of cancer, cardiovascular disease, and type 2 diabetes: prospective cohort study. BMJ. 2020;368:16669.

5. Pedersen BK, Saltin B. Exercise as medicine - evidence for prescribing exercise as therapy in 26 different chronic diseases. Scandinavian Journal of Medicine \& Science in Sports. 2015;25 Suppl 3(39):1-72. 


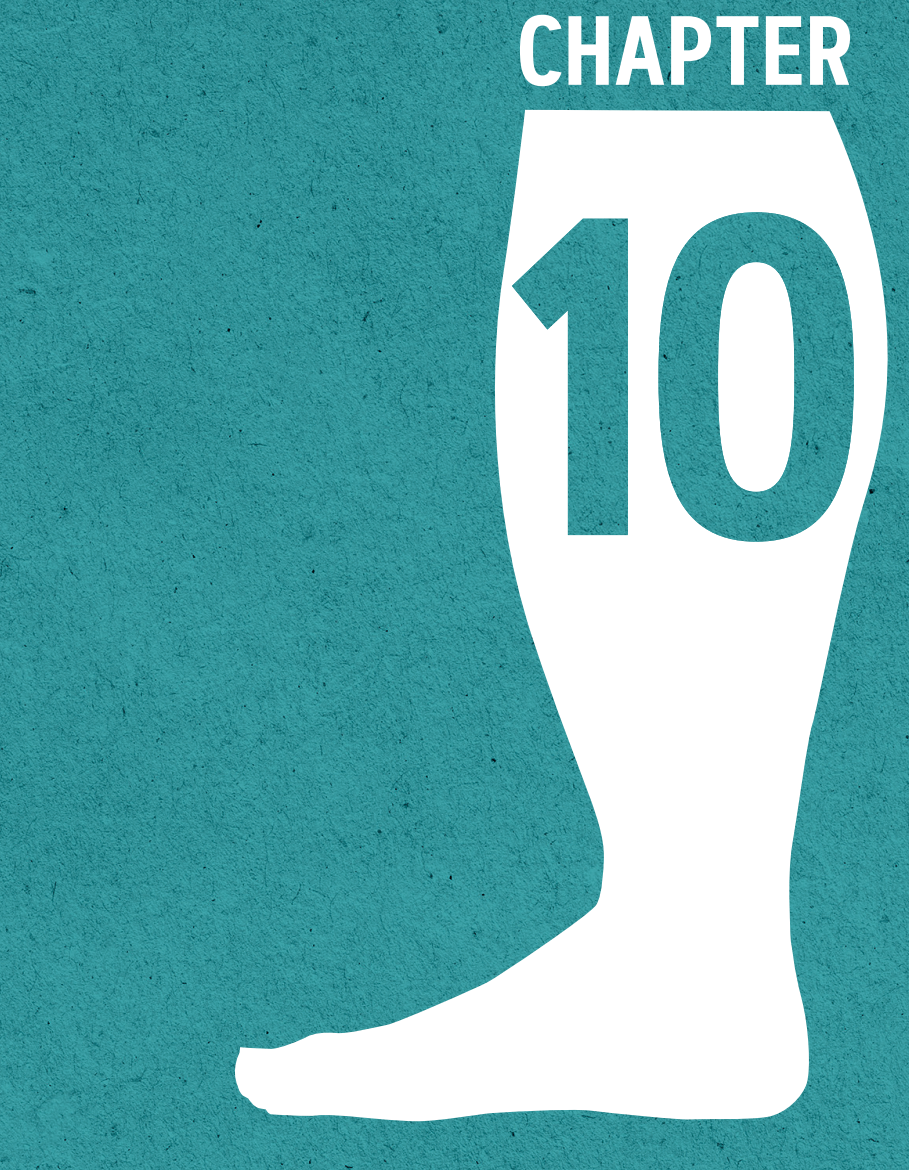




\section{CHAPTER 10}

\section{DUTCH SUMMARY}


Dit proefschrift is een collectie van diverse studies met het doel om herkennen, diagnosticeren en behandelen van een chronisch inspanningsgebonden compartiment syndroom ('chronic exertional compartment syndrome', CECS) te bevorderen in patiënten met inspanningsgebonden onderbeenklachten.

In de eerste helft ligt de focus op het identificeren van patiëntgebonden karakteristieken die kunnen helpen bij het herkennen van CECS in een algemene populatie. Bijzondere aandacht is er voor CECS bij oudere patiënten; bij deze groep wordt in geval van inspanningsgebonden onderbeenklachten zelden aan CECS gedacht, waardoor vaak een lange 'diagnostic delay' bestaat, waarbinnen het 'doctor's delay' een aanzienlijk aandeel inneemt. Hiermee hopen we de herkenning van dit vaak gemiste ziektebeeld te bevorderen bij artsen en andere zorgprofessionals die met potentiele CECS-patiënten worden geconfronteerd. In de tweede helft van dit proefschrift wordt de toepassing van een nieuw instrument bij de behandeling van CECS van het anterieure onderbeencompartiment (antCECS) onderzocht. Wanneer dit instrument veilig is en (op zijn minst) zo goed werkt als bestaande methoden, kan de chirurgische behandeling van ant-CECS worden verbeterd.

Eerder onderzoek heeft laten zien dat ongeveer één op de 7 patiënten met inspanningsgebonden onderbeenklachten CECS heeft. Deze aandoening kan optreden in 3 van de 4 onderbeen compartimenten, namelijk het anterieure compartiment (ant-CECS), het diepe posterieure compartiment (dp-CECS), of het laterale compartiment (lat-CECS). Combinaties van meerdere compartimenten zijn mogelijk. Alhoewel diverse theorieën bestaan die het ontstaan van CECS kunnen verklaren, ontbreekt consensus over de exacte pathofysiologie. Wel lijkt een abnormaal verhoogde druk in het aangedane spiercompartiment centraal te staan in het optreden van klachten zoals pijn, strak gevoel, kramp, spierzwakte en/of veranderde sensibiliteit. Echter, waarom dit bij de een wel en de ander niet optreedt en wat het exacte mechanisme is waardoor de klachten ontstaan, is vooralsnog onbekend.

Hoewel het ziektebeeld CECS reeds 60 jaar geleden voor het eerst is beschreven, bestaat nog steeds verwarring over het exacte klinische beeld. Deze onduidelijkheid wordt met name veroorzaakt doordat de beschreven patiëntengroepen verschillend zijn. Eén aspect wat vrijwel alle studies 
gemeen hebben, is het feit dat CECS meestal wordt gezien in jonge en fitte individuen. Het ziektebeeld werd tot voor kort nauwelijks beschreven in ouderen. Hierdoor zullen clinici zoals vaatchirurgen, die veel ouderen met inspanningsgebonden onderbeenklachten zien, CECS mogelijk niet herkennen.

Er bestaan verschillende niet-operatieve behandelingen voor CECS maar uiteindelijk worden de meeste patiënten geopereerd. Tijdens deze operatie wordt het strakke vlies (de 'fascie') rondom de spieren van het aangedane compartiment gekliefd (fasciotomie) of wordt er een strook fascie verwijderd ('fasciectomie'). Een fasciotomie, de voorkeursbehandeling bij niet-recidiverende CECS, kan op verschillende manieren worden uitgevoerd. Wanneer een fasciotoom wordt gebruikt om via een kleine huidincisie onderhuids de fascie over een grote afstand te klieven, noemen we deze techniek een 'semiblinde' fasciotomie.

In hoofdstuk 2 beschrijven we een grote heterogene populatie van 1411 personen die tussen 2001 en 2013 in Máxima MC werden geanalyseerd voor onderbeen CECS. Op basis van het klinische beeld en een dynamische intracompartimentale drukmeting (ICP) werd bij 698 personen CECS aangetoond in 1 (of meerdere) onderbeencompartimenten. De prevalentie piekte tussen de 20-25 jaar en nam af met het ouder worden tot een plateau rond 50 jaar. Leeftijd, geslacht, bilaterale symptomen, afwezigheid van eerdere onderbeen pathologie, type sport (hardlopen en schaatsen), en pijnlijke gespannen compartiment(en) waren onafhankelijke voorspellers voor de diagnose CECS. Een voorspellend model, gebaseerd op deze variabelen, had een redelijk onderscheidend vermogen (AUC 0.66) en een goede kalibratie over het gehele bereik van voorspelde waarden. Het nomogram wat aan de hand van dit model werd gemaakt kan artsen helpen bij het herkennen van CECS in patiënten met inspanningsgebonden onderbeenklachten. Hierdoor kunnen deze patiënten gericht worden verwezen naar een gespecialiseerd centrum.

Doordat in de bestaande literatuur vooral militairen en atleten worden beschreven, is (onterecht) het beeld ontstaan dat CECS alleen voorkomt bij fitte en gezonde jonge personen. Slechts twee eerdere studies beschrijven CECS bij oudere patiënten waardoor het onbekend is of patiëntkarakteristieken tussen ouderen en jongeren met CECS 
overeenkomen. In hoofdstuk 3 hebben we een retrospectieve database bestudeerd om oudere CECS patiënten ( $\geq 50$ jaar) te vergelijken met jongere CECS patiënten ( $<50$ jaar). De 698 patiënten die tussen 2001 en 2013 werden gediagnosticeerd met onderbeen CECS werden verdeeld in patiënten van 50 jaar of ouder $(n=68)$ en patiënten jonger dan 50 jaar $(n=600)$. Ouderen rapporteerden vaker andere aandoeningen van de onderbenen ( $\geq 50$ jaar, $45 \%,<50$ jaar $25 \%, p<0.01$ ) en unilaterale (versus bilaterale) klachten ( $\geq 50$ jaar, $45 \%,<50$ jaar $22 \%, p<0.01)$. De meeste oudere patiënten (62\%) beoefenden geen sport en wandelden alleen, terwijl van de jongeren slechts $7 \%$ geen sport beoefende. Pijn ( $\geq 50$ jaar, 94\%, $<50$ jaar $96 \%$ ) en strak gevoel ( $\geq 50$ jaar, $57 \%,<50$ jaar $62 \%$ ) waren in beide groepen de dominante symptomen. Het type CECS verschilde significant tussen de leeftijdsgroepen. Het anterieure compartiment was vaker aangedaan bij de oudere CECS patiënten ( $\geq 50$ jaar, $82 \%,<50$ jaar $59 \%$ ) terwijl dp-CECS vaker werd gediagnosticeerd bij de jongere CECS patiënten ( $\geq 50$ jaar, $26 \%$, $<50$ jaar $53 \%$ ). Derhalve kan gezegd worden dat oudere CECS patiënten minder actief zijn en meer comorbiditeiten hebben dan hun jongere tegenhangers. Clinici moeten de diagnose CECS overwegen bij ouderen met inspanningsgebonden onderbeen klachten, in het bijzonder wanneer pijn en strak gevoel slechts in een been optreden.

Perifeer arterieel vaatlijden (PAV) en CECS veroorzaken beiden inspanningsgebonden onderbeenpijn. Zoals eerder gezegd, wordt CECS vooral gediagnosticeerd in jongeren, maar kan het incidenteel op latere leeftijd optreden (een op 7 CECS patiënten in een tertiair centrum is > 50 jaar). Wanneer een patiënt zich meldt met intermitterend hinken ('claudicatio intermittens, $\mathrm{Cl}^{\prime}$ ), kan differentiatie tussen CECS en PAV lastig zijn. In hoofdstuk 4 worden 43 oudere CECS patiënten vergeleken met 41 PAV patiënten. Beide groepen rapporteerden intensiteit en frequentie van pijn, strak gevoel, kramp, spierzwakte en veranderde sensibiliteit in rust en tijdens inspanning. Na correctie voor leeftijd, geslacht, bilateraliteit en duur van de klachten blijkt dat CECS patiënten meer klachten ervaren in rust $(p=0.02)$. Tijdens inspanning rapporteren CECS patiënten vaker een strak gevoel, spierzwakte en veranderde sensibiliteit dan de PAV patiënten. $\mathrm{Na}$ het starten van een provocerende activiteit zoals lopen of rennen duurde het bij CECS patiënten bijna 4 keer zo lang voordat klachten optraden. Een tijdsduur $>4.5$ minuten bleek het meest voorspellend voor de aanwezigheid van CECS (ROC-curve, sensitiviteit 95\%, specificiteit 54\%, PPV 65\%). Na 
het staken van de provocerende activiteit verdwenen de klachten bij alle PAV patiënten binnen enkele minuten, terwijl bij driekwart van de CECS patiënten ( $n=29,73 \%$ ) de klachten aanhielden (sensitiviteit 73\%, specificiteit $100 \%$, PPV 100\%). Wij concludeerden dan ook dat de aanwezigheid van symptomen in rust, zoals een strak gevoel, veranderde sensibiliteit of spierzwakte en blijvende klachten na staken van de provocerende activiteit mogelijk duiden op CECS. Wanneer een vaatchirurg dit patroon ziet in een oudere patiënt zonder risicofactoren voor atherosclerose, moet er gedacht worden aan een CECS, en valt het te overwegen de patiënt te verwijzen naar een gespecialiseerd centrum.

Wanneer reguliere niet-operatieve behandelingen onvoldoende werken, zullen de meeste ant-CECS patiënten kiezen voor een chirurgische oplossing. Vaak wordt bij een operatie een gespecialiseerd instrument ('fasciotoom'), gebruikt om via een kleine huidincisie (ongeveer $2 \mathrm{~cm}$ ) de fascie te klieven. Tijdens deze 'semiblinde' fasciotomie ontbreekt het zicht op de punt van dit mes waardoor er kans op schade aan omringende structuren is. In hoofdstuk $\mathbf{5}$ introduceren we een nieuw type fasciotoom, de FascioMax, die dit risico mogelijk verkleind. Dit instrument is in samenwerking met de instrumentele dienst van Máxima MC ontworpen. Het systeem bestaan uit 2 delen. Een speculum-achtig deel met 2 bladen die na sluiten een holle buis vormen, en de daadwerkelijke fasciotoom. $\mathrm{Na}$ het inbrengen kan het beweegbare speculum worden gesloten waardoor de fascie stevig wordt gefixeerd tussen de 2 bladen. Als via deze holle buis de fasciotoom wordt opgevoerd om de fascie te klieven, zijn de omliggende structuren beschermd. In een pilot van 14 patiënten met bilaterale ant-CECS bleek dat deze techniek in alle 28 onderbenen de fascie succesvol kliefde. De gemiddelde operatieduur was 10 minuten per been (spreiding 6-14), Perioperatieve complicaties werden niet gezien. Een postoperatieve oppervlakkige wondinfectie werd behandeld met antibiotica. Na een gemiddelde follow-up van 21 maanden bleken mate van inspanningsgebonden pijn (-2.2 \pm 1.1 op een 5 -punts VRS, $p<0.001)$, strak gevoel $(-1.9 \pm 1.6, p=0.01), \operatorname{kramp}(-1.4 \pm 1.6, p=0.009)$, spierzwakte $(-1.6 \pm 1.2, p<0.001)$ en veranderde sensibiliteit $(-1.3 \pm 1.4, p=0.005)$ allen significant verminderd. We concludeerden dat dit nieuwe FascioMax systeem voldoende werkzaam en veilig was om in een uitgebreidere studie nader te onderzoeken. 
latrogeen letsel van de nervus peroneus superficialis (NPS) is een vervelende complicatie die soms (tot bij $8 \%$ van de patiënten) ontstaat na een fasciotomie voor ant-CECS. Bij deze complicatie kan huiddoofheid of een hinderlijke chronische pijn ontstaan in het onderbeen. Het risico op NPS letsel tijdens een semiblinde fasciotomie van het anterieure compartiment met de FascioMax fasciotoom wordt uitgebreid onderzocht in hoofdstuk 6. In 9 humane anatomische preparaten werd een fasciotomie uitgevoerd op exact dezelfde manier als bij de CECS patiënten. Na de fasciotomie werden de onderbenen minutieus ontleed maar bij geen van allen bleek de NPS macroscopisch beschadigd. In 8 onderbenen was de NPS minimaal $5 \mathrm{~mm}$ van de gekliefde fascie verwijderd. In 1 onderbeen liep de NPS risico omdat deze het operatieve veld dwars kruiste. Hiernaast hebben we een cohort van 64 patiënten (120 onderbenen) gevolgd welke tussen januari 2013 en december 2016 in ons ziekenhuis een fasciotomie ondergingen van het anterieure compartiment. In geen van de 120 onderbenen vond de behandelend chirurg neurologische afwijkingen verdacht voor NPS letsel bij het postoperatieve lichamelijk onderzoek. Daarnaast rapporteerde niemand van de 64 patiënten nieuwe neurologische klachten na de operatie welke verdacht waren voor een NPS letsel. We concludeerden dat een fasciotomie van het anterieure compartiment met de FascioMax een verwaarloosbaar risico vormt voor iatrogeen NPS letsel.

Effectiviteit, veiligheid en postoperatieve pijn bij de behandeling van antCECS werden in hoofdstuk 7 vergeleken tussen de FascioMax fasciotoom en een ander veelgebruikt instrument (Due fasciotoom). Vijftig patiënten met bilaterale ant-CECS ondergingen in een gerandomiseerde zelfgecontroleerde klinische trial in het ene been een fasciotomie met de FascioMax, en in het andere been een fasciotomie met de Due. Tussen oktober 2013 en april 2018 werden 50 proefpersonen geïncludeerd. Meer dan de helft (56\%) was door de klachten geheel gestopt met sporten. De gemiddelde operatietijd was 15 minuten voor beide benen samen (bereik, 11-37). Er traden geen perioperatieve complicaties op. Het aantal postoperatieve complicaties (alleen hematoom en oppervlakkige wondinfectie) waren in beide groepen vergelijkbaar (FascioMax $8 \%$, Due $6 \%, p=1.0$ ). Hiervoor was nooit een chirurgische reinterventie nodig. De postoperatieve pijn in de eerste 2 weken was vergelijkbaar in beide groepen, en na 2 weken had slechts een enkele patiënt nog pijnstilling nodig. De kardinale symptomen (pijn, strak gevoel, kramp, spierzwakte en veranderde 
sensibiliteit), werden door beide instrumenten in vergelijkbare mate verminderd. $\mathrm{Na} 1$ jaar was $82 \%$ van de patiënten in staat om de gewenste sport te hervatten.

\section{CONCLUSIES}

1. Jonge leeftijd, mannelijk geslacht, bilaterale klachten, afwezigheid van eerdere onderbeen pathologie, type sport (schaatsen) en een pijnlijk compartiment bij palpatie zijn voorspellend voor de aanwezigheid van CECS bij patiënten met inspanningsgebonden onderbeenklachten.

2. Eén op de 7 patiënten die in ons ziekenhuis werd gediagnosticeerd met CECS bleek 50 jaar of ouder. Deze patiënten zijn minder actief, hebben meer comorbiditeiten, en hebben vaker unilaterale klachten dan jongere CECS patiënten.

3. Vergeleken met PAV patiënten, hebben CECS patiënten in rust meer klachten, en ervaren ze meer soorten klachten bij inspanning. Daarnaast treden de symptomen na inspanning later op, en blijven ze langer aanwezig na het staken van de provocatieve activiteit.

4. De FascioMax fasciotoom bleek in een pilotstudie veilig en effectief bij de behandeling van patiënten met ant-CECS.

5. Het gebruik van de FascioMax fasciotoom tijdens een minimaal invasieve semiblinde fasciotomie van het anterieure compartiment is niet geassocieerd met NPS letsel.

6. Tijdens de operatieve behandeling van ant-CECS is de FascioMax fasciotoom even veilig, effectief en pijnlijk als de veelgebruikte Due fasciotoom. 


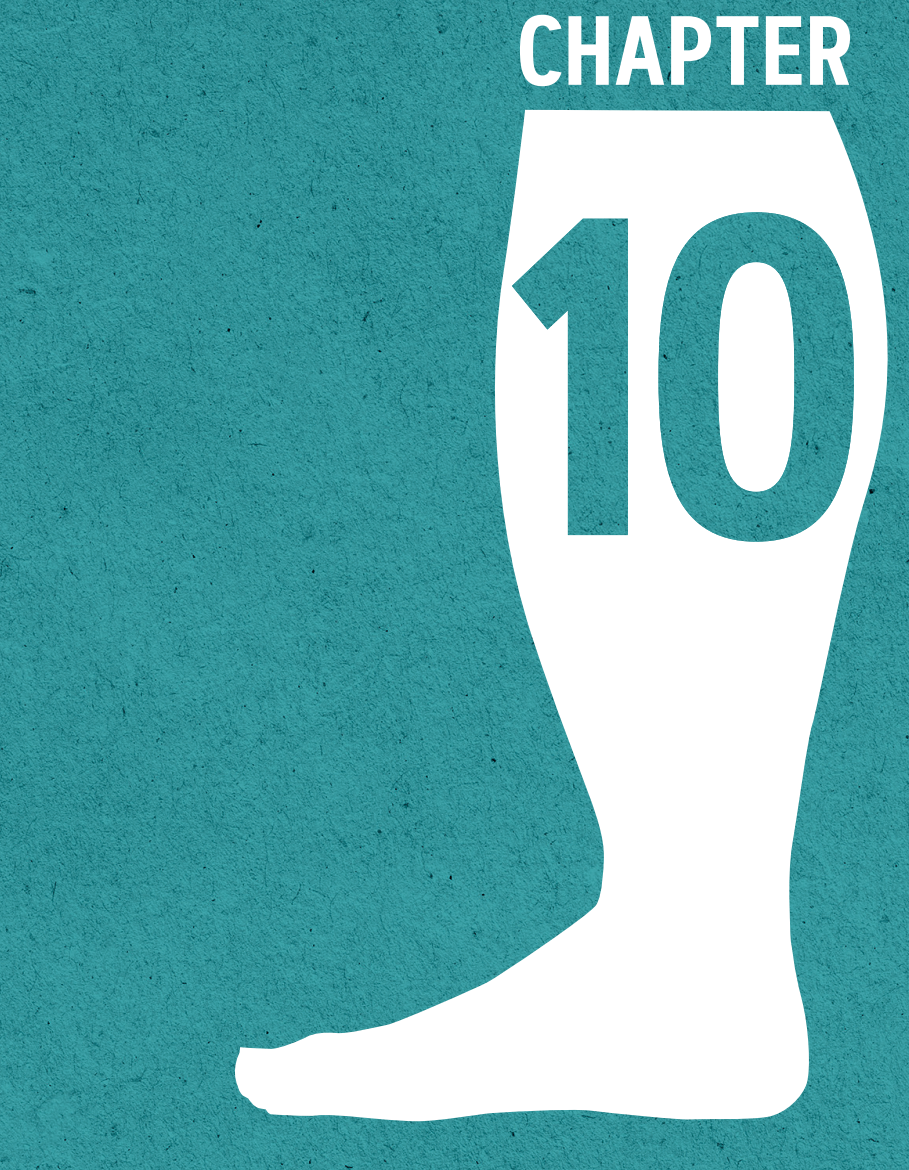




\section{CHAPTER 10}

ACKNOWLEDGEMENTS 
Geachte prof. dr. Teijink, beste Joep,

Pas enige tijd na de start van mijn promotietraject werd duidelijk dat jij mijn promotor zou worden en ik had me geen betere kunnen wensen. Dankzij je razendsnelle en scherpe commentaren en vaak frisse invalshoek zijn alle volgende projecten en artikelen beter geworden. Bedankt voor je bijdrage!

Geachte dr. Scheltinga, beste Marc,

Waar kan ik beginnen om je te bedanken? Zoals bij vele promovendi voor mij, was jij de motor achter mijn promotietraject en dit proefschrift. Dankzij jouw aanstekelijke enthousiasme was ik al tijdens mijn coschappen druk aan het schrijven aan een METC-aanvraag en al voor het afronden van mijn studie geneeskunde lag er een heel promotieplan klaar. Na elke meeting kwam ik je kamer uit met hernieuwde energie en weer 100 nieuwe onderzoeksvragen. Zelfs wanneer deze bijeenkomsten niet doorgingen wist je me te vinden. Het maakte niet uit of je op je eigen kamer in Veldhoven, de Mont Ventoux of een marine fregat rond de evenaar zat: wekelijks kon ik mailtjes verwachten met nieuwe artikelen, nieuwe ideeën of nieuwe correcties en revisies. Wanneer je even niets van me hoorde, stuurde je berichten met titels als "ik verveel me" en "stuur me iets op, maakt niet hoe ver je ermee bent". Dank je voor de ongeëvenaard snelle correcties (geklokte record was binnen 51 minuten na ontvangen van een manuscript), je tomeloze energie, mooie gesprekken over het wielrennen en bovenal voor je bevlogenheid voor de wetenschap!

Geachte leden van de beoordelingscommissie; prof. dr. M. Poeze, prof. dr. F.J.G. Backx, prof. dr. I.C. Heyligers en dr. W.O. Zimmermann, bedankt voor het beoordelen van mijn manuscript.

Leden van de onderzoeksgroep CECS, jullie hulp was onmisbaar bij het tot stand komen van dit proefschrift. Aniek, een eeuwigheid geleden, in 2014, mocht ik tegelijk met je starten aan het grote CECS avontuur. Samen analyseren, publiceren en hopelijk ook binnenkort beiden promoveren! Michiel, onze voorganger, fijn dat de paden al enigszins bewandeld waren en bedankt voor al je hulp bij het opzetten, uitvoeren en afronden van de verschillende projecten. Adwin en Marike, jullie sportgeneeskundige kennis over het ziektebeeld CECS en jullie hulp bij het rekruteren van patiënten is van onschatbare waarden geweest voor dit proefschrift. Beste Rick en Kim, dank voor jullie inzet bij de verschillende onderdelen van dit proefschrift, hopelijk heb ik jullie ook iets kunnen leren tijdens jullie stage/opleiding! 
Coauteurs; David van Klaveren, Sander van Kuijk en Percy van Eerten: dank voor de bijdragen aan de artikelen.

Chirurgen, SEH artsen en arts-assistenten MMC, heel erg bedankt voor de fijne jaren in Veldhoven! Ik heb me er vanaf het eerste tot het laatste moment thuis gevoeld en de jaren in het MMC hebben me als arts en persoon gevormd. Dank voor de opgedane klinische vaardigheden, het stimuleren van mijn wetenschappelijke ambities en bovenal voor de interesse in mij als persoon!

Arts-onderzoekers chirurgie MMC, afgelopen jaren zaten we in het zelfde promotie-schuitje. Het was fijn om met jullie de successen maar ook de frustraties verbonden aan een promotietraject te kunnen delen. Daarnaast kijk ik met veel plezier terug op het 'hazen', de bar-dancings en de 3 Liter glazen Belgisch bier tijdens de verschillende weekendjes.

Lieve vriendjes en vriendinnetjes, dank jullie wel voor alle borrels, feesten en gala's, fietsvakanties (avec montagnes et piscines), skrogweekendjes, jungle-party's, concerten, verjaardagen, spelletjesavonden, vriendenweekenden, kroegavonden, kitesurf-sessies, park-hang-middagen, whisky-risk avonden, borrels, lustrumvakanties, white Russians, mannendagen, Berlijn-weekendjes, biercantussen, kerstdiners, kroegentochten, tentfeesten, museum bezoekjes, stedentrips, smulpaapdiners, festivals en nog veel meer leuks. Zonder jullie was het proefschrift waarschijnlijk al een tijdje klaar maar was mijn leven een heel stuk saaier geweest!

Beste Philip, Hetty, Thomas en Dirk ook wel bekend als de 'schoonfamilie', dank jullie wel voor het opnemen in jullie gezin en de oprechte interesse in mij en het werk wat samenhangt met dit proefschrift. In bijzonder wil ik opa Gerard bedanken. Zelfs toen hij al over de 100 jaar was heeft hij meerdere manuscripten gelezen en kwam hij na afloop steevast met een lijstje inhoudelijke vragen.

Lieve papa en mama, jullie hebben het fundament voor dit proefschrift gelegd. Dankzij jullie opvoeding ben ik geworden wie ik nu ben. Jullie hebben me geleerd om nieuwsgierig te zijn, anderen te respecteren en bovenal om hard te werken. Al vroeg leerde ik dat dingen niet vanzelf gebeuren maar dat je hiervoor zelf de handen uit de mouwen moet steken. Het is tenslotte 
zo zaterdagavond! Mark en Tim, broertjes. Hoewel we alle 3 een compleet ander pad zijn opgegaan, ben ik blij jullie nog geregeld te zien! Bedankt dat jullie het al die jaren met me hebben uit gehouden!

Lieve Eva, wie had er 12 jaar geleden gedacht dat jij hier als belangrijkste persoon in mijn leven toegesproken zou worden? Ik in ieder geval niet. Maar ik ben zo blij dat je in mijn leven gekomen en gebleven bent! Jouw steun is zonder twijfel één van de belangrijkste redenen dat dit boekje er nu eindelijk is. Maar veel belangrijker nog; je hebt ook voor gezorgd dat ik oog hield voor de wereld buiten het ziekenhuis en mijn laptop. Ik zou me geen leven zonder jouw spontaniteit, zorgzaamheid en liefde kunnen voorstellen en kijk intens uit naar onze toekomst samen met Lena! 
Acknowledgements 


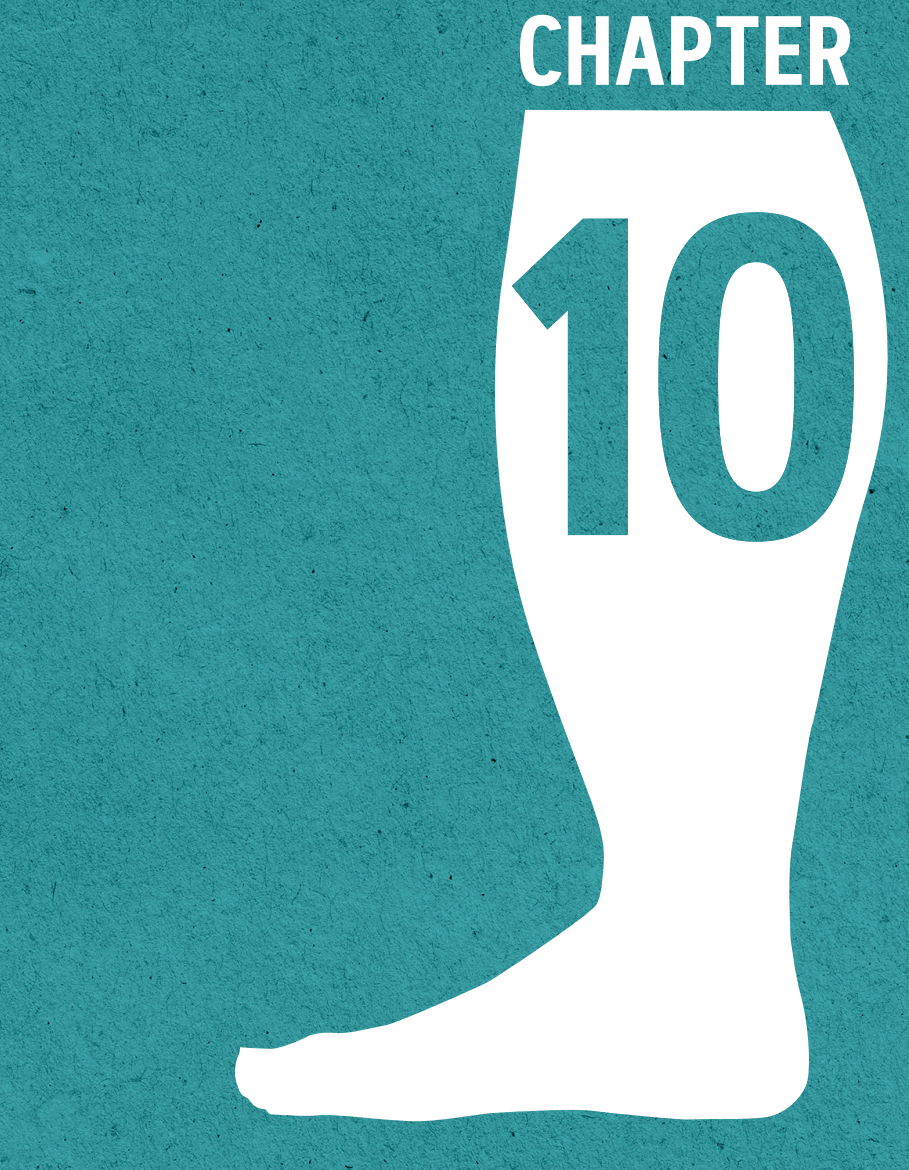




\section{CHAPTER 10}

\section{LIST OF PUBLICATIONS}


1. van Zantvoort APM, Hundscheid HPH, de Bruijn JA, Hoogeveen AR, Teijink JAW, Scheltinga MRM. Isolated Lateral Chronic Exertional Compartment Syndrome of the leg: A new entity? Orthop J Sports Med. 2019 Dec 24;7(12):2325967119890105.

2. de Bruijn JA, Winkes MB, van Eerten P, Scheltinga MRM. Chronic exertional compartment syndrome as a cause of anterolateral leg pain. Unfallchirurg. 2020 Jan;123(Suppl 1):8-14.

3. de Bruijn JA, van Zantvoort APM, Hundscheid HPH, Hoogeveen AR, Teijink JAW, Scheltinga MRM. Superficial Peroneal Nerve Injury Risk During a Semiblind Fasciotomy for Anterior Chronic Exertional Compartment Syndrome of the Leg: An Anatomical and Clinical Study. Foot Ankle Int. 2019 Mar;40(3):343-351.

4. van Zantvoort APM, de Bruijn JA, Hundscheid HPH, van der CruijsenRaaijmakers M, Teijink JAW, Scheltinga MRM. Fasciotomy for Lateral Lower-leg Chronic Exertional Compartment Syndrome. Int J Sports Med. 2018 Dec;39(14):1081-1087.

5. de Bruijn JA, van Zantvoort APM, Winkes MB, van der CruijsenRaaijmakers M, Hoogeveen AR, Teijink JAW, Scheltinga MRM. Lower Leg Chronic Exertional Compartment Syndrome in Patients 50 Years of Age and Older. Orthop J Sports Med. 2018 Mar 2;6(3):2325967118757179.

6. de Bruijn JA, van Zantvoort APM, van Klaveren D, Winkes MB, van der Cruijsen-Raaijmakers M, Hoogeveen AR, Teijink JAW, Scheltinga MRM. Factors Predicting Lower Leg Chronic Exertional Compartment Syndrome in a Large Population. Int J Sports Med. 2018 Jan;39(1):58-66.

7. van Zantvoort APM, de Bruijn JA, Winkes MB, Hoogeveen AR, Teijink JAW, Scheltinga MRM. Role of Repeat Muscle Compartment Pressure Measurements in Chronic Exertional Compartment Syndrome of the Lower Leg. Orthop J Sports Med. 2017 Jun 9;5(6):2325967117711121.

8. Winkes MB, van Zantvoort APM, de Bruijn JA, Smeets SJ, van der Cruijsen-Raaijmakers M, Hoogeveen AR, Scheltinga MRM. Fasciotomy for Deep Posterior Compartment Syndrome in the Lower Leg: A Prospective Study. Am J Sports Med. 2016 May;44(5):1309-16.

9. van Zantvoort APM, de Bruijn JA, Winkes MB, Dielemans JP, van der Cruijsen-Raaijmakers M, Hoogeveen AR, Scheltinga MRM. Isolated Chronic Exertional Compartment Syndrome of the Lateral Lower Leg: A Case Series. Orthop J Sports Med. 2015 Nov 23;3(11):2325967115617728. 
10. de Bruijn JA, van Zantvoort APM, Winkes MB, Raaymakers $L$, van der Cruijsen-Raaijmakers M, Hoogeveen AR, Scheltinga MRM. Feasibility and Safety of an operative Tool for anterior chronic exertional compartment syndrome treatment. Foot Ankle Int. 2015 Dec;36(12):1475-82.

11. Pingen M, Nijhuis M, de Bruijn JA, Boucher CA, Wensing AM. Evolutionary pathways of transmitted drug-resistant HIV-1. J Antimicrob Chemother. 2011 Jul;66(7):1467-80. 


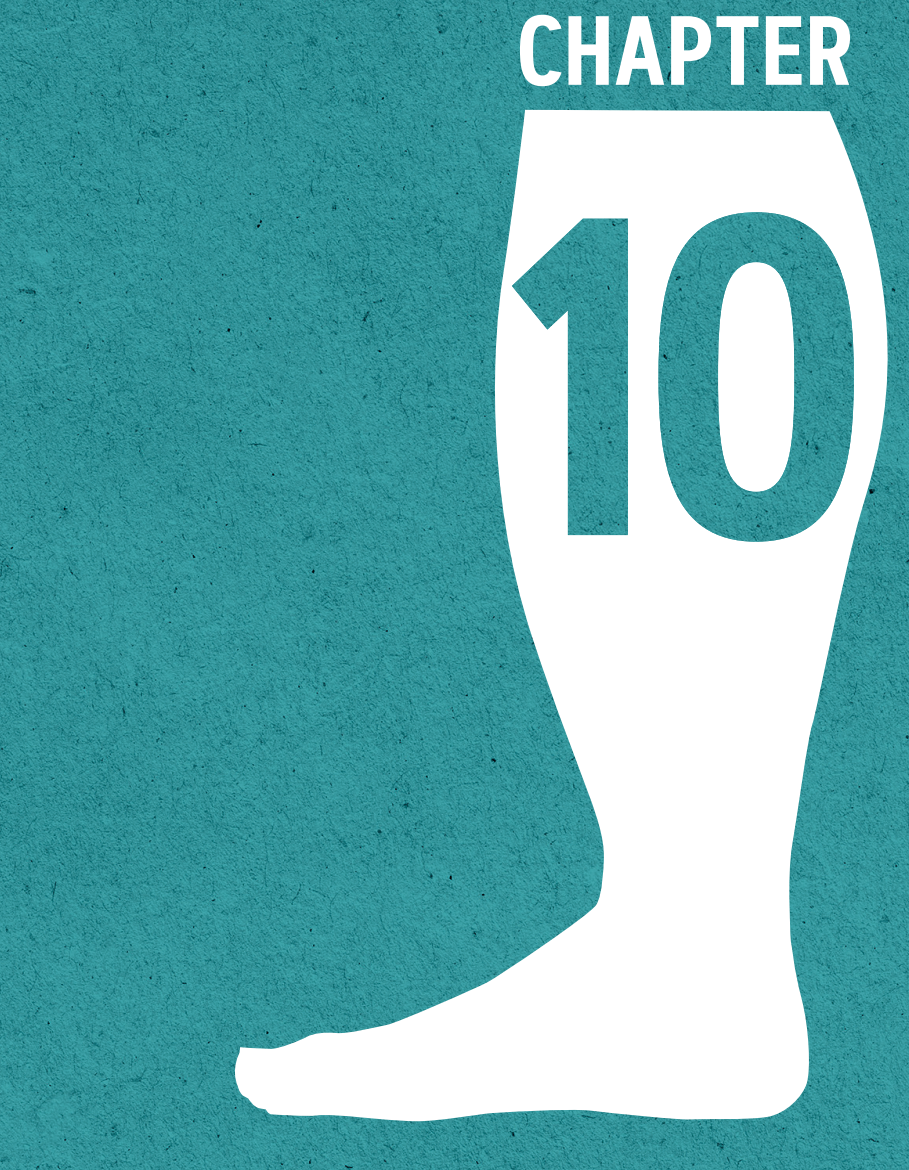




\section{CHAPTER 10}

CURRICULUM VITAE 


\section{CURRICULUM VITAE}

Johannes Anthonius de Bruijn was born on November 11th 1985 in Maurik, the Netherlands. In 2004, he graduated from high school (Revius lyceum, Doorn) and started his bachelor Biomedical Sciences at Utrecht University. During his bachelor he was treasurer of the study association M.B.V. Mebiose (2006-2007) and was a member of the educational board (2007-2008). After obtaining his BSc, Johan attended the master Biology of disease (Biomedical Sciences) at Utrecht University. He obtained his master

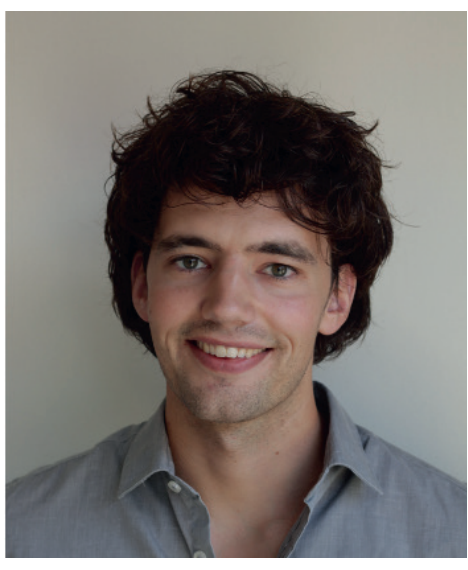
degree in 2010, and was subsequently selected for the master Medicine and Clinical Research at Maastricht University. During this master he was closely involved in the evaluation and adjustment of the curriculum and worked as a research assistant at the department of physiology of Maastricht University.

After graduating with distinction in 2014, Johan started as a resident in the departments Surgery and Emergency Medicine in Máxima Medical Center, Veldhoven/Eindhoven, the Netherlands. During the following three years he initiated, executed and completed several clinical studies that would result in this thesis. Johan had a leading role in the initiation and execution of the first randomized clinical trial ever focusing on the surgical treatment of chronic exertional compartment syndrome of the leg anterior compartment. In 2017, he started training as a general practitioner at the University Medical Center Groningen, which he completed in September 2020.

Johan lives together with Eva van der Want in Utrecht. Their daughter, Lena, was born in September 2019. 
Johannes Anthonius de Bruijn werd op 11 november 1985 in Maurik geboren. In 2004 rondde hij zijn middelbare school (Revius Lyceum, Doorn) af en startte hij met de bachelor opleiding Biomedische Wetenschappen aan de Universiteit Utrecht. Tijdens zijn opleiding was hij onder andere Fiscus van de studievereniging M.B.V. Mebiose en was hij lid van het opleidingsbestuur. $\mathrm{Na}$ het afronden van zijn bachelor in 2008, startte hij met de master Biology of Disease (biomedische wetenschappen). Na het afronden van deze master in 2010, werd hij geselecteerd voor de Master Arts-klinisch onderzoeker aan de Universiteit Maastricht. Tijdens deze opleiding was hij als jaarvertegenwoordiger nauw betrokken bij het curriculum en werkte hij als onderzoeksassistent bij de afdeling fysiologie van de Universiteit Maastricht.

In 2014 ronde hij deze opleiding cum laude af en begon hij als arts-assistent op de afdelingen chirurgie en spoedeisende hulp van het Máxima Medisch Centrum te Veldhoven/Eindhoven. De wetenschappelijke projecten die hij de 3 volgende jaren naast zijn klinische werkzaamheden heeft geïnitieerd, uitgevoerd en afgerond waren de basis voor dit proefschrift. Zo had hij onder andere een leidende rol bij het opzetten en uitvoeren van 's werelds eerste gerandomiseerde klinische studie naar de chirurgische behandeling van chronisch inspanningsgebonden compartiment syndromen. In 2017 startte hij met de opleiding tot huisarts bij het Universitair Medisch Centrum Groningen, welke in september 2020 werd voltooid.

Johan woont samen met Eva van der Want en hun dochter Lena in Utrecht. 
